UNIVERSIDADE DE SÃO PAULO

FACULDADE DE ODONTOLOGIA DE RIBEIRÃO PRETO

FABIANO MISAEL CAVENAGHI

EFEITOS DE INIBIDOR DE PROTEASE SOBRE OS EPITÉLIOS DE REVESTIMENTO E GLANDULAR DO RATO

RIBEIRÃo PRETO 


\section{UNIVERSIDADE DE SÃO PAULO \\ FACULDADE DE ODONTOLOGIA DE RIBEIRÃO PRETO}

\section{EFEITOS DE INIBIDOR DE PROTEASE SOBRE OS EPITÉLIOS DE REVESTIMENTO E GLANDULAR DO RATO}

Dissertação apresentada à Faculdade de Odontologia de Ribeirão Preto - USP para obtenção do título de Mestre em Biologia Oral

Orientadora: Profa. Dra. Marilena Chinali Komesu

\section{RIBEIRÃO PRETO}


Autorizo a reprodução e divulgação total ou parcial do teor deste trabalho, por qualquer meio convencional ou eletrônico, para fins de estudo e pesquisa, desde que citada a fonte.

\section{FICHA CATALOGRÁFICA}

\section{Cavenaghi, Fabiano M.}

Efeitos de inibidor de protease sobre os epitélios de revestimento e glandular do rato. Ribeirão Preto, 2009.

158p.: il; $30 \mathrm{~cm}$

Dissertação de Mestrado, apresentada à Faculdade de Odontologia de Ribeirão Preto/ USP - Área de concentração: Biologia Oral.

Orientador: Komesu, Marilena Chinali 
FOLHA DE APROVAÇÃO

FABIANO MISAEL CAVENAGHI

\title{
EFEITOS DE INIBIDOR DE PROTEASE SOBRE OS EPITÉLIOS DE REVESTIMENTO E GLANDULAR DO RATO
}

\author{
Dissertação apresentada à Faculdade de Odontologia \\ de Ribeirão Preto - USP para obtenção do título de \\ Mestre em Biologia Oral
}

Aprovado em: 12009 .

Banca Examinadora

Prof. Dr.

Instituição Assinatura

Prof. Dr.

Instituição Assinatura

Prof. Dr. 


\section{DEDICATÓRIA}

A Deus,

Por me presentear diariamente com a vida, por iluminar meu caminho, me dar saúde e paciência para alcançar meus objetivos.

Ao meu filho Murilo,

Razão da minha vida. 


\section{AGRADECIMENTOS}

À Faculdade de Odontologia de Ribeirão Preto, da Universidade de São Paulo, à qual considero a minha segunda casa e da qual tenho um imenso orgulho, por todo o conhecimento adquirido durante todos esses anos que incluem o curso de graduação e de mestrado

À Comissão Coordenadora da Área de Biologia Oral da FORP-USP, na pessoa dos docentes e secretária;

À Comissão de Pós-Graduação da Área de Biologia Oral da FORP-USP, na pessoa dos docentes e secretária;

Aos meus pais, pelo exemplo, incentivo e amor incondicional em todos os momentos da minha vida.

À Luiza, pela compreensão, paciência e amor;

Aos colegas, Ana Luiza e Gilberto pela enorme contribuição dada a este trabalho, pela dedicação nos inúmeros e complexos passos deste trabalho e por serem grandes referências de alunos de PósGraduação e de pessoas.

Aos funcionários/amigos Edna, Antonio, Ana Carolina, Adriana e Filomena que tornaram minhas atividades mais simples e prazerosas;

Aos amigos André Luiz dos Santos e Mateus Malvezzi pela enorme contribuição dada a este trabalho nas inúmeras tabelas estatísticas;

A todos os meus amigos, em especial ao Fernando Kurita Varoli, Francisco Marcelo Paranhos Pinto, Marcelo Vinícius de Oliveira Vespúcio e Márcio Belotti pelos inesquecíveis momentos vividos; 


\title{
AGRADECIMENTOS ESPECIAIS
}

\author{
A Prof. Dra. Marilena Chinale Komesu,
}

Minha caríssima mestre, mãe e amiga, fonte de imensa sabedoria e referência profissional e pessoal, meus sinceros agradecimentos por todo o conhecimento transferido a mim durante a graduação e mestrado; por me orientar na pós-graduação e na vida, durante esses ótimos anos de convivência.

Sou grato por ter apostado em mim, mesmo nos momentos em que eu não merecia e acreditava; por ter me incentivado quando o desânimo parecia mais forte e por ter paciência quando eu não correspondia à altura.

Agradeço pela imensa contribuição neste trabalho, que sem seu conhecimento e esforço, seria inviável a sua a realização.

Muito obrigado! 


\section{RESUMO}

CAVENAGHI, F.M. Efeitos de inibidor de protease sobre os epitélios de revestimento e glandular do rato. 2009. 158p. Dissertação Mestrado - Faculdade de Odontologia de Ribeirão Preto, Universidade de São Paulo, Ribeirão Preto.

O tratamento anti-HIV conhecido como HAART (Highly Active Antiretroviral Therapy) se tornou comum por volta de 1996, e utiliza 3 ou 4 diferentes medicamentos em combinação - geralmente dois inibidores de transcriptase reversa + 1 ou 2 inibidores de protease. A introdução desse tipo de tratamento trouxe um grande impacto na morbidade e mortalidade de indivíduos infectados pelo HIV. Os inibidores de protease (PIs) são uma boa alternativa às falhas terapêuticas observadas com o uso dos inibidores de transcriptase reversa, no entanto também são associados a vários efeitos tóxicos, como desconforto abdominal, vômito, diarréia, dor de cabeça, tontura, lipodistrofia, hipercolesterolemia, hipertrigliceridemia e hiperglicemia. Em função da existência de efeitos adversos e da condição do ritonavir como protótipo desse tipo de medicação, nosso objetivo é avaliar o efeito desse medicamento sobre os epitélios de revestimento e glandular relacionados à cavidade bucal, de forma a identificar a possibilidade da existência de complicações bucais relacionadas ao uso de inibidores de protease. Ratos albinos (Wistar) foram tratados com Ritonavir $(10 \mathrm{mg} / \mathrm{Kg})$ por períodos de 4 e 8 semanas. Foram avaliadas as taxas séricas de triglicérides e colesterol (total, HDL, LDL, VLDL). Ao final dos períodos de tratamentos propostos, os animais foram sacrificados, e as peças utilizadas no estudo foram colhidas, (sangue, pele, língua, palatos e glândulas salivares). O sangue coletado foi imediatamente centrifugado sendo o plasma foi utilizado para avaliação das lipoproteínas. Os tecidos colhidos foram fixados, descalcificados quando necessário, processados para inclusão em parafina, cortados com $6 \mu \mathrm{m}$ de espessura, montados em slides e corados com hematoxilina e eosina, para avaliação histopatológica, morfométrica e estereológica. Os dados colhidos foram apresentados em valores médios, e as diferenças analisadas por testes estatísticos adequados para a comparação entre as amostras. Nossos resultados mostram pequenas variações nas características morfológicas de epitélios de revestimento e glandulares, variações essas que poderiam deixar esses tecidos mais propensos a sofrer alterações significativas com traumas ou injúrias, comuns nos tecidos bucais. Embora observadas com pequeno grau de expressão, essas variações, parecem ser progressivas, ou seja, mais expressivas com o uso continuado do medicamento. Mais estudos devem ser realizados, principalmente voltados para avaliações histoquímicas, bioquímicas e moleculares, no entanto nosso estudo é um alerta inicial para a avaliação dos tecidos bucais de pacientes que utilizam inibidores de protease.

Palavras-chaves: Inibidores de protease, epitélio de revestimento, mucosa bucal, glandula salivar submandibular, ratos wistar. 


\begin{abstract}
CAVENAGHI, F.M. Effects of protease inhibitors on epithelial tissues and salivar glands of rats. 2009 158p. Dissertation (Master - Oral Biology) - Faculdade de Odontologia de Ribeirão Preto, Universidade de São Paulo, Ribeirão Preto.

HAART had a dramatic impact on the HIV infection, however, protease inhibitor exhibit significant drug-drug interactions, and side effects. There are only few data on effects of protease inhibitors on oral tissues. We propose to observe experimental effects of ritonavir on oral epithelial tissues, covering and glandular. Wistar rats received Ritonavir twice a week for 4-8 weeks. Controls received no treatment. At the time for sacrifice, plasma were collected for evaluation of triglycerides, total cholesterol, HDL, LDL and VLDL. Were also collected skin, tongue, palate and glandular tissues Lipoproteins were evaluated and histological examination of skin, mucosal epithelium on tongue, palate and salivar submandibular glandula were made under light microscope. Morphometric methods (cariometry and stereology) were used. Data were statistically analysed by Kruskal Wallis test for multiple samples, since our data were considered not-normal. P[U] $\square 0.05$ were considered statistically significant. Our results show that protease inhibitor may be associated with small alterations in epithelial tissues, significant mostly when on longer times using the medication. The complete significance of this data has to be better understood, and other studies has to be done to define these points.
\end{abstract}

Keywords: Protease inhibitor; epithelial tissues; salivar submandibular gland; Experimental study; Wistar rats 


\section{SUMÁRIO}

RESUMO

ABSTRACT

1 INTRODUÇÃO E REVISÃO DE LITERATURA

5 RESULTADOS.

5.1 Avaliação de triglicérides e colesterol. 17

5.2 Avaliação do epitélio da pele. 21

5.2.1 Cariometria do epitélio da pele. 22

5.2.2 Estereologia do epitélio da pele..... 29

5.3 Avaliação do epitélio da língua........................................ 35

5.3.1 Cariometria do epitélio da língua............................. 38

5.3.2 Estereologia do epitélio da língua............................. 63

5.4 Avaliação dos resultados de palatos e gengiva..................... 88

5.4.1 Cariometria dos palatos duro e mole e região gengival.... 90

5.4.2 Estereologia dos palatos duro e mole e região gengival.... 109 
5.5 Avaliação da glândula salivar submandibular.

5.5.1 Cariometria das glândulas salivares submandibulares.....

5.5.2 Estereologia das glândulas salivares submandibulares...

6 DISCUSSÃO e CONCLUSÃO 


\section{INTRODUÇÃO REVISÃO DE LITERATURA}

Os primeiros agentes anti-retrovirais a entrarem no mercado foram os inibidores de transcriptase reversa análogos de nucleosídeos, depois vieram os inibidores de transcriptase reversa não análogos de nucleosídeos, e finalmente os inibidores de protease, como o ritonavir (Norvir), indinavir (Crixivan), saquinavir (Invirase), nelfinavir (Viracept), amprenavir, e lopinavir, hoje também já é possível se obter inibidores da fusão com a membrana celular (BARTLETT, 1996; PATICK \& POTTS, 1998; LENHARD et al., 2000; KUMAR et al., 2003; KING et al., 2004).

Os inibidores de protease (PIs) se apresentavam como uma boa alternativa às falhas terapêuticas observadas com o uso dos inibidores de transcriptase reversa, no entanto sua pouca absorção e rápido metabolismo hepático, associado aos efeitos anti-retrovirais dose-dependentes levaram a uma infinidade de efeitos tóxicos, como desconforto abdominal, vômito, diarréia, dor de cabeça e tontura. Hoje se reconhece também as complicações metabólicas (lipodistrofia, hipercolesterolemia, hipertrigliceridemia e hiperglicemia) como efeitos indesejáveis do uso de PIs (BARTLETT, 1996; LENHARD et al., 2000; XU et al., 2004)

O tratamento anti-HIV conhecido como HAART (Highly Active Antiretroviral Therapy, ou tratamento antiretroviral altamente ativo), também conhecido como "cocktail anti-HIV" se tornou comum por volta de 1996, e utiliza basicamente 3 ou 4 diferentes medicamentos antiretrovirais em combinação - geralmente dois inibidores de transcriptase reversa +1 ou 2 inibidores de protease. A introdução desse tipo de tratamento trouxe um grande impacto na morbidade e mortalidade de indivíduos infectados pelo HIV (LENHARD et al., 2000; KUMAR et al., 2003; WYNN et al., 2004).

A introdução do HAART como terapia anti HIV contribuiu para a diminuição da incidência de infecções oportunísticas, assim como também para a diminuição de neoplasias malignas, como o Sarcoma de Kaposi (KS) e o linfoma primário do sistema nervoso central (PCNSL = Primary central nervous system lymphoma). No entanto esse tratamento não apresentou os mesmos efeitos sobre o linfoma nãoHokgkin (NHL = Non-Hodgkin's Lymphoma) e alguns estudos têm apresentado números conflitantes e um impacto negativo sobre o desenvolvimento de neoplasias malignas cervicais. Então, parece que o HAART tem um bom desempenho em 
reduzir níveis virais (como os associados ao $\mathrm{KS}$ ), um resultado razoável em restaurar o sistema imune (como o envolvido no linfoma), mas não apresenta tão bons resultados em outras neoplasias (RABKIN, 2001; GATES \& KAPLAN, 2002; AHDIEH-GRANT et al., 2004).

Ritonavir é um dos quatro inibidores de protease sintéticos aprovados para uso como antiviral. Sua absorção oral é alta, e ele não é afetado pelo uso concomitante com alimentos. O ritonavir é primariamente metabolizado pela enzina citocromo P4503A4 (CYP3A4), mas também, em menor extensão, por outras enzimas. É também um potente inibidor da CYP3A4, e aumenta significativamente a meia vida de drogas também metabolizadas pelas enzimas Citocromo P450 (P450) fazendo com que a interação entre drogas metabolizadas por essas enzimas seja bastante importante na clínica, como a que acontece com alguns antimicrobianos (claritromicina, cetoconazol, rifabutina, rifampicina), anticonvulsivantes (fenitoína e carbamazepina) e outros antivirais (indinavir, saquinavir, nelfinavir) (BARRY et al., 1997; HSU et al., 1998).

O uso de inibidores de protease também apresenta alguns incovenientes como a alta dosagem necessária em alguns casos (400-600mg duas vezes ao dia quando administrado como monoterapia), desenvolvimento de resistência viral às drogas utilizadas, efeitos colaterais algumas vezes bastante inconvenientes ou intoleráveis para alguns pacientes, e dificuldades para o uso do medicamento por um tempo prolongado, em função do desenvolvimento de resistência ou por falta de aderência ao tratamento em função dos efeitos colaterais (RATHBUN \& ROSSI, 2002; WINSTON \& BOFFITO, 2005).

Os inibidores de protease atuam num estágio final do processo de replicação do HIV, sobre a enzima protease, responsável pelo processo pós translacional dos precursores gag e gag-pol, resultando na produção de vírions não infecciosos. Seus efeitos colaterais incluem alterações gastrintestinais como náuseas, vômito, diarréia e alteração do paladar, disfunções do metabolismo de lipídios e da glicose, disfunções sexuais toxicidade hepática, astenia e aumento do risco de sangramentos (RATHBUN \& ROSSI, 2002; KUMAR et al., 2003).

Embora os inibidores de protease tenham sido desenvolvidos para inibir especificamente as enzimas virais (basicamente a enzima aspartil-protease do HIV1), essa classe de drogas afeta diferentes processos metabolicos semelhantes, 
como se pode observar pelos efeitos colaterais do uso prolongado dessas drogas, como a hiperbilirrubinemia, a resistência à insulina, dislipidemia e alterações ósseas. Recentemente também, os inibidores de protease começaram a ser utilizados como drogas anti-tumor, para carcinomas de mama (SRIRANGAN et al., 2006); linfomas nâo-Hodgkins (BOSHOFF \& WEISS, 2002), mieloma múltiplo (IKEZOE et al., 2004), câncer de próstata (YANG et al., 2005) e carcinomas de cabeça e pescoço (MAGGIORELLA et al., 2005).

Ainda não se conhece os efeitos desse tipo de medicamento sobre os epitélios bucais, basicamente o epitélio de revestimento e o epitélio glandular.

\section{JUSTIFICATIVA E OBJETIVOS}

As complicações metabólicas e os efeitos colaterais associadas ao HAART são complexas e multifatoriais, e apesar de existirem complicações associadas ao vírus HIV e aos medicamentos tipo anti-transcriptase reversa, estudos têm indicado um alto risco de complicações associadas aos inibidores de protease (PIs), muito embora os mecanismos envolvidos ainda não estejam bem elucidados (LENHARD et al., 2000; XU et al., 2004).

Ritonavir (Norvir) tem sido considerado o protótipo do inibidor de protease, e associado às mais severas anormalidades metabólicas em humanos e em animais (TEMPLE et al., 2003). Apesar de serem poucos os estudos experimentais com esse medicamento, o Ritonavir (Norvir solução) já foi utilizado antes em administração oral $(10 \mathrm{mg} / \mathrm{Kg}$ em ratos Sprague-Dawley e macacos Rhesus; $45-60 \mathrm{mg} / \mathrm{Kg} / \mathrm{dia}$ ou $50 \mathrm{mg}$, ou $2 \mathrm{mg} / \mathrm{dia}$ em camundongos) sendo bem absorvida -80 a $100 \%$ de absorção, em todas as espécies animais. Ainda, nesses animais, a administração de Ritonavir por 2 semanas causou elevação plasmática de triglicérides e nos níveis séricos de ácidos graxos, assim como apresentou relação inversa com a adiponectina circulante. Alterações nos níveis glicêmicos foi observada algum tempo depois (LENHARD et al., 2000; KUMAR et al., 2002; RIDDLE et al., 2002; XU et al., 2004).

Em função da existência de efeitos adversos já observados, e da condição do 
ritonavir como protótipo desse tipo de medicação, nosso objetivo é avaliar o efeito desse medicamento sobre os epitélios de revestimento e glandular relacionados à cavidade bucal, de forma a identificar a possibilidade da existência de complicações bucais relacionadas ao uso de inibidores de protease.

\section{MATERIAIS E MÉTODOS}

Ratos albinos (Wistar) foram tratados diariamente com Ritonavir $(10 \mathrm{mg} / \mathrm{Kg}$ ) por períodos de 4 e 8 semanas. Foram avaliadas as taxas séricas de triglicérides, colesterol (total, HDL, LDL, VLDL) e glicemia ao final das 8 semanas. De forma a evitar fatores de conflito as amostras de sangue foram sempre colhidas no período do início da manhã, com os animais em jejum de 16 horas e sob anestesia. Foram utilizados kits comerciais da marca LABTEST Diagnóstica $\AA^{\circledR}$, e seguidas as intruções do fabricante para a avaliação.

Os animais foram divididos nos seguintes grupos:

1) Grupo controle (sem tratamento com ritonavir);

2) Grupo tratado com ritonavir por 4 semanas; e

3) Grupo tratado com ritonavir por 8 semanas

Os animais foram sacrificados por indução de parada cárdio-respiratória durante cirurgia sob anestesia (tribromoetanol $25 \mathrm{mg} / 100 \mathrm{~g}$ peso corporal), quando também se procedeu a retirada dos tecidos utilizados no estudo. Foram utilizadas a pele, língua e palato para avaliação dos epitélios de revestimento, e as glândulas salivares submandibulares para avaliação do epitélio glandular. As peças retiradas foram imediatamente levadas para fixar.

\section{Técnica histológica}

As peças assim obtidas foram imersas em formalina a $10 \%$ e deixadas a fixar por 24 horas. As peças assim fixadas foram desidratados por uma série crescente de álcoois e embebidos em parafina. Foram feitos cortes de $6 \mu \mathrm{m}$ de espessura os 
quais foram colocados sobre lâmina para serem trabalhados na seqüência adequada à coloração utilizada.

\section{Coloração pela Hematoxilina e Eosina}

Cortes corados com HE (hematoxilina e eosina) foram utilizados para avaliação histológica dos tecidos. Através de técnicas morfométricas - cariometria e estereologia - aplicadas aos cortes corados pelo HE, foram avaliados o diâmetro médio dos núcleos, volume, área e perímetro nucleares, relação entre os diâmetros maior e menor, índice de contorno, coeficiente de forma e excentricidade nucleares, relação núcleo/citoplasma, volume citoplasmático, volume médio da célula epitelial de cada área epitelial estudada, a sua densidade celular e espessura do epitélio de revestimento, assim como diâmetro médio de ácinos e ductos do epitélio glandular.

\section{Cariometria}

Para a avaliação dos parâmetros nucleares se obteve a medida dos diâmetros maior e menor. Para isso, cortes foram focalizados ao microscópio de luz visível (JENAMED) com objetiva de imersão (100 vezes) munido de câmara clara (JENA). Os núcleos são projetados sobre papel e as imagens obtidas (50 para cada camada epitelial de cada região de cada animal dos diferentes grupos estudados) foram contornados com lápis preto número 2 tomando-se o cuidado de se considerar apenas as imagens elípticas.

Em seguida se mediram os eixos maior (diâmetro maior) e menor (diâmetro menor) dessas imagens e se aplicou, a esses valores, programas desenvolvidos pelos Profs. Drs. Geraldo Maia Campos e Miguel Angel Sala Di Matteo do Departamento de Morfologia, Estomatologia e Fisiologia da Faculdade de Odontologia de Ribeirão Preto da Universidade de São Paulo (programas GMC e Nuclear).

Foram avaliados os núcleos das células das camadas basal e espinhosa + granulosa dos epitélios de revestimento, assim como ácinos, ductos estriados, 
ductos glandulares e ductos excretores das glândulas salivares de todas as áreas estudadas.

\section{Estereologia}

Para avaliação estereológica se utilizou uma grade idealizada por MERZ (1968) que consiste num quadrado que limita uma área teste, contendo um sistema de pontos marcados sobre linhas sinuosas formadas por uma sucessão de semicírculos encadeados (figura 1).

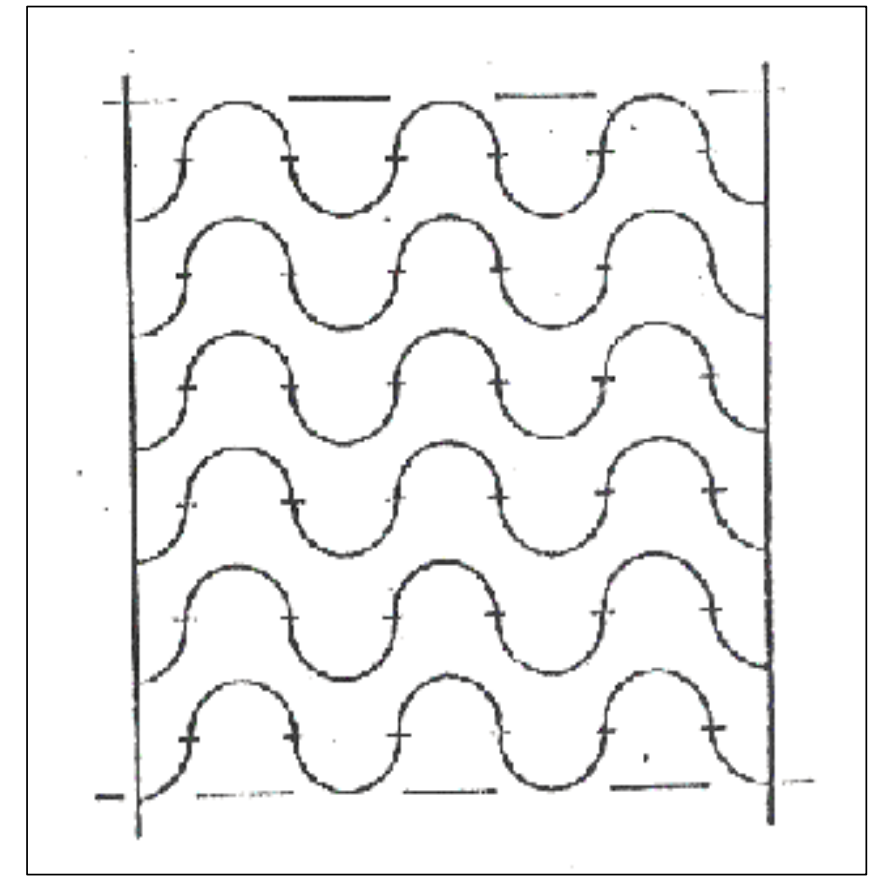

Figura 1 - Representação gráfica da grade idealizada por Merz (1968).

Os cortes foram focalizados ao microscópio de luz visível (JENAMED) com objetiva de aumento de acordo com a análise realizada, munido de câmara clara (JENA). As imagens obtidas são projetadas sobre a grade desenhada em papel.

A grade de MERZ pode ser utilizada tanto para contar pontos sobre uma determinada estrutura histológica como para contar intersecções entre duas estruturas contíguas, bastando para isso considerar o número de pontos que caem sobre a estrutura em estudo, no primeiro caso, ou o número de vezes em que as 
superfícies vizinhas cortam a linha curva no segundo caso. serão avaliados o diâmetro médio dos núcleos, volume, área e perímetro nucleares, relação entre os diâmetros maior e menor, índice de contorno, coeficiente de forma e excentricidade nucleares, relação núcleo/citoplasma, volume citoplasmático, volume médio da célula epitelial, de cada área epitelial estudada, a sua densidade celular e espessura do epitélio de recobrimento. Nas glândulas serão avaliados os mesmos parâmetros nucleares mais a espessura das paredes dos ductos secretores e a porcentagem relativa de cada elemento secretor (ácinos, ductos granulosos e ductos estriados), de acordo com trabalhos anteriores nos nossos laboratórios (KOMESU et al., 1998; KOMESU et al., 2000; MOTTA et al., 2001; TANGA et al., 2003; KOMESU et al., 2003).

\section{Forma de análise dos resultados}

Os valores obtidos foram tabelados para realização da análise estatística. Os dados colhidos estão apresentados em valores médios, e as diferenças são analisadas pelo teste estatístico adequado para a comparação entre as amostras avaliadas. Valores de $\mathrm{P} \leq 0.05$ são considerado como estatisticamente significante.

\section{EXECUÇÃO}

O trabalho foi desenvolvido no Departamento de Morfologia, Estomatologia e Fisiologia da Faculdade de Odontologia de Ribeirão Preto. O protocolo experimental foi aprovado pelo Comitê de Ética para o uso de animais em laboratório do Campus de Ribeirão Preto da Universidade de São Paulo e está em conformidade com os prinícipios Universais para o uso de Animais em Pesquisa e no Ensino - Protocolo no. 08.1.278.53.9. 


\section{RESULTADOS}

\subsection{Avaliação de triglicérides e colesterol}

Embora o colesterol e os triglicérides sejam ambos lipídios, ou gorduras, existem diferenças enormes entre eles. Os triglicérides são formados principalmente a partir dos carboidratos - açúcares e massas - e armazenados nas células como reserva calórica, sendo utilizados para obtenção de energia nos períodos de privação de alimento. Seu excesso pode causar depósitos, inclusive nos dutos pancreáticos, ocasionando doença inflamatória grave, a pancreatite.

O colesterol, por outro lado, tem mecanismo mais complexo. É formado pela absorção das gorduras saturadas e do colesterol de origem animal e também produzido pelo próprio fígado. De extrema importância para o organismo, é matériaprima de hormônios e faz parte da composição da célula. As duas principais frações do colesterol são o LDL e o HDL, transportados na corrente sanguínea, ligados a uma proteína, a lipoproteína.

O LDL colesterol - colesterol de baixo peso molecular - é produzido no fígado e circula pelo organismo levando esse colesterol às células. Quando em excesso, pode sofrer um processo de oxidação e passa a ser depositado nas paredes das artérias, dando origem aos "ateromas", que dão origem à arteriosclerose e, conseqüentemente, a doenças arteriais, como o enfarte agudo do miocárdio e o acidente vascular cerebral.

O HDLcolesterol - colesterol de alta densidade - tem como função "retirar" o excesso do LDL colesterol da corrente sanguínea, por isso é conhecido como o "bom colesterol". (meionorte.com, 2009).

O aumento dos níveis de colesterol acima de limites desejáveis é conhecido como hiperlipidemia, ou hipercolesterolemia, ou, algumas vezes, como dislipidemia. Drogas como os inibidores de protease que, aliados a fatores genéticos, idade, sexo e ao tempo prolongado de uso dos anti-retrovirais, são apontados como beneficiadores do aparecimento de alterações relacionados ás disfunções metabólicas dos lipídios.

O consumo exagerado de alimentos ricos em colesterol (carnes gordas, leite integral, queijos amarelos, bacon, manteiga, banha) pode fazer os níveis de colesterol aumentarem. Além disso, o excesso de peso pode fazer os níveis de 
colesterol e triglicérides subirem. Mulheres tendem a ter um aumento do colesterol após a menopausa. Finalmente, fatores genéticos podem ser responsáveis pelo aumento do colesterol em algumas pessoas, principalmente se houverem várias pessoas na mesma família com esse problema.

A concentração de lipoproteínas no sangue é influenciada por muitos fatores, dentre eles, os hábitos dietéticos recentes, variações de peso corporal, alterações endócrinas, exercício físico, e até mesmo a forma de coleta do sangue. Eentão a variação nas suas medidas são esperadas, sendo consideradas normais em cerca de $21 \%$ para os triglicérides, de até $11,6 \%$ para o colesterol total, e em torno de 7,5\% para o $\mathrm{HDL}$, mesmo em medidas sucessivas num mesmo indivíruo.

Para o colesterol total, triglicérides e HDL foram utilizados kits comerciais. Os valores para LDL e VLDL são calculados baseados Equação de Friedewald onde o LDL colesterol mg/dL = Colesterol total - HDL-colesterol - (Triglicerídeos/5 ou VLDL)

Nossos animais tiveram padronização dos procedimentos e métodos para a colheita de sangue, e todos os procedimentos foram realizados de acordo com as especificações do fabricante do Kit (LABTEST DIAGNÓSTICA®) no entanto, mesmo nessas condições espera-se uma variação intrínseca. Dessa forma, os valores obtidos para os todas as lipoproteínas neste trabalho são utilizados apenas para uma comparação entre os grupos, e não como avaliação específica de qualquer dos lipídeos séricos.

A tabela 1 apresenta os valores obtidos pela avaliação do colesterol total, HDL, LDL, VLDL e triglicerídeos dos animais controle e tratados com ritonavir. 
TABELA 1 - Avaliação da presença de triglicérides e colesterol em sangue de animais controle e tratados com inibidor de protease.

\begin{tabular}{|c|c|c|c|c|}
\hline \multirow{2}{*}{$\begin{array}{l}\text { PARÂMETRO } \\
\text { ESTUDADO }\end{array}$} & \multicolumn{2}{|c|}{ ANIMAIS CONTROLE } & \multicolumn{2}{|c|}{ TRATADOS } \\
\hline & 4 semanas & 8 semanas & 4 semanas & 8 semanas \\
\hline \multirow[t]{4}{*}{ Triglicerídeos } & $\begin{array}{l}47.58 \\
64.32 \\
36.12 \\
66.08 \\
86.34\end{array}$ & $\begin{array}{l}63.77 \\
78.30 \\
52.83 \\
61.89 \\
81.13\end{array}$ & $\begin{array}{c}76.98 \\
92.45 \\
101.32 \\
74.53 \\
98.11\end{array}$ & $\begin{array}{l}47.58 \\
74.01 \\
65.20 \\
76.65 \\
89.87\end{array}$ \\
\hline & $60.08 \pm 19.19$ & $67.58 \pm 14.08$ & $88.67 \pm 12.24$ & $70.66 \pm 15.64$ \\
\hline & & & $\begin{array}{l}U \text { canc. }=2 \\
P[U]=0.016\end{array}$ & $\begin{array}{l}U \text { canc. }=11 \\
P[U]=0.421\end{array}$ \\
\hline & & & $\uparrow$ & \\
\hline \multirow[t]{4}{*}{ Colesterol total } & $\begin{array}{l}60.12 \\
63.19 \\
61.53 \\
60.92 \\
67.73\end{array}$ & $\begin{array}{l}80.25 \\
96.30 \\
96.91 \\
90.49 \\
85.19\end{array}$ & $\begin{array}{l}78.89 \\
70.37 \\
75.93 \\
69.75 \\
69.88\end{array}$ & $\begin{array}{l}100.43 \\
087.91 \\
092.64 \\
104.91 \\
094.48\end{array}$ \\
\hline & $62.69 \pm 3.03$ & $89.82 \pm 7.17$ & $72.96 \pm 4.19$ & $96.07 \pm 6.67$ \\
\hline & & & $\begin{array}{l}U \text { canc. }=0 \\
P[U]=0.004\end{array}$ & $\begin{array}{l}U \text { canc. }=7 \\
P[U]=0.155\end{array}$ \\
\hline & & & $\uparrow$ & \\
\hline \multirow[t]{3}{*}{$\mathrm{HDL}$} & $\begin{array}{l}40.84 \\
43.34 \\
37.35 \\
38.47 \\
43.41\end{array}$ & $\begin{array}{l}37.33 \\
43.20 \\
44.67 \\
38.27 \\
45.60\end{array}$ & $\begin{array}{l}52.27 \\
36.27 \\
49.20 \\
35.73 \\
37.73\end{array}$ & $\begin{array}{l}52.16 \\
41.95 \\
48.78 \\
48.22 \\
45.02\end{array}$ \\
\hline & $40.68 \pm 2.76$ & $41.81 \pm 377$ & $42.24 \pm 7.86$ & $47.21 \pm 3.88$ \\
\hline & & & $\begin{array}{l}U \text { canc. }=11 \\
P[U]=0.421\end{array}$ & $\begin{array}{l}U \text { canc. }=5 \\
P[U]=0.075\end{array}$ \\
\hline \multirow[t]{4}{*}{ LDL } & $\begin{array}{c}9.79 \\
6.99 \\
16.96 \\
10.14 \\
7.06\end{array}$ & $\begin{array}{l}30.17 \\
37.44 \\
41.68 \\
39.85 \\
23.37\end{array}$ & $\begin{array}{c}11.23 \\
15.61 \\
6.47 \\
19.12 \\
12.53\end{array}$ & $\begin{array}{l}38.76 \\
31.16 \\
37.50 \\
41.36 \\
31.49\end{array}$ \\
\hline & $10.17 \pm 4.08$ & $34.50 \pm 3.77$ & $12.99 \pm 4.75$ & $36.05 \pm 4.53$ \\
\hline & & & $\begin{array}{l}U \text { canc. }=11 \\
P[U]=0.421\end{array}$ & $\begin{array}{l}U \text { canc. }=4 \\
P[U]=0.048\end{array}$ \\
\hline & & & & $\uparrow$ \\
\hline \multirow[t]{3}{*}{ VLDL } & $\begin{array}{c}9.51 \\
12.86 \\
7.22 \\
13.21 \\
17.26\end{array}$ & $\begin{array}{l}12.75 \\
15.66 \\
10.56 \\
12.37 \\
16.22\end{array}$ & $\begin{array}{l}15.39 \\
18.49 \\
20.26 \\
14.90 \\
19.62\end{array}$ & $\begin{array}{c}9.51 \\
14.80 \\
13.04 \\
15.33 \\
17.97\end{array}$ \\
\hline & $12.01 \pm 3.83$ & $13.51 \pm 2.92$ & $17.73 \pm 2.45$ & $14.13 \pm 3.12$ \\
\hline & & & $\begin{array}{l}U \text { canc. }=7 \\
P[U]=0.155\end{array}$ & $\begin{array}{l}U \text { canc. }=11 \\
P[U]=0.421\end{array}$ \\
\hline
\end{tabular}


Considerando-se apenas medida inicial dos controles, e comparando-se simultâneamente com os tratados (4 e 8 semanas) e aplicando-se o teste de Kruskal-Wallis, teremos:

TABELA 2 - Comparação estatística - Teste de Krukal- Wallis.

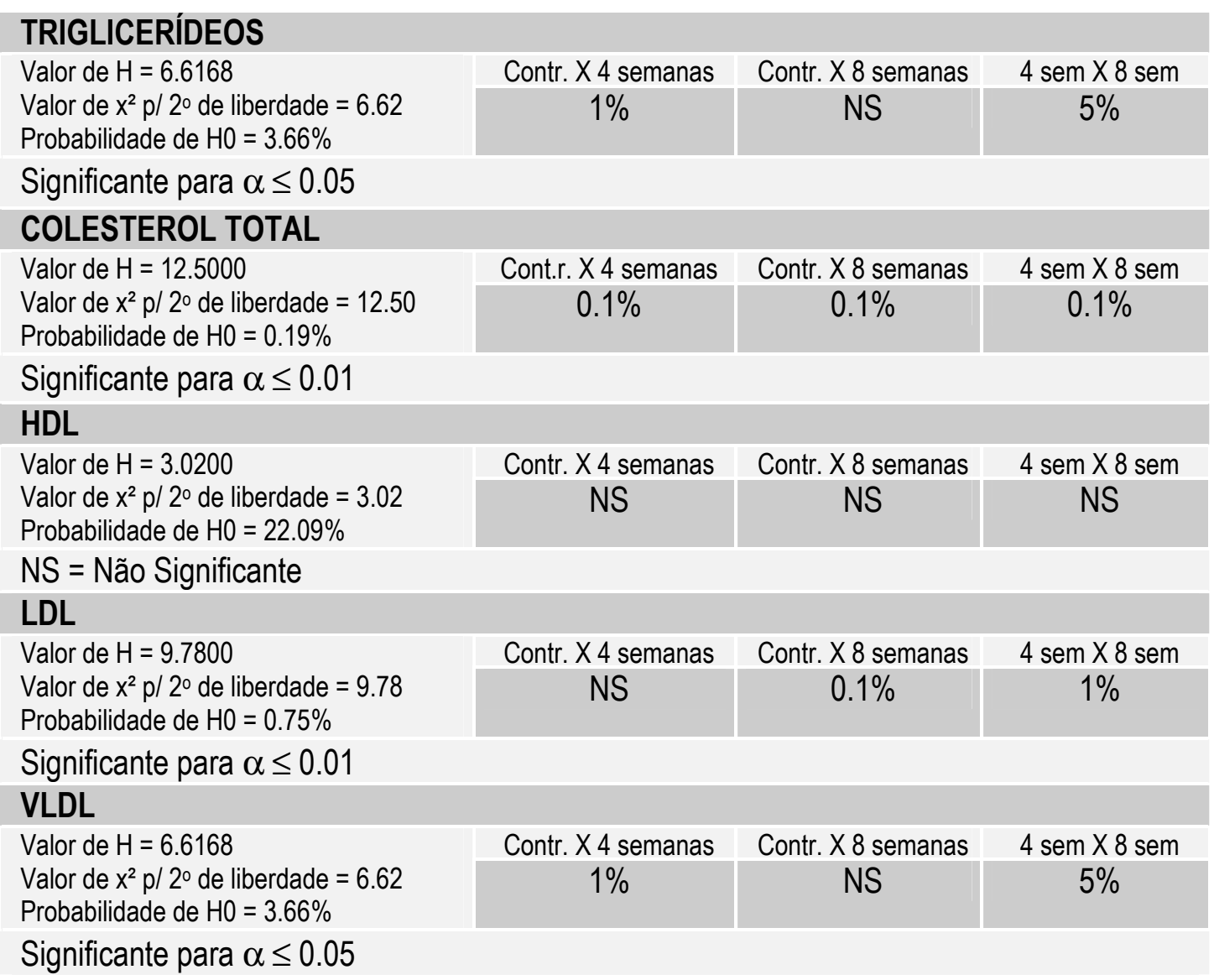

A análise dos resultados obtidos para as medidas de lipídios séricos em animais controle e após o uso de inibidores de protease nos mostra que, apesar da variação intrínseca às medidas dessas lipoproteínas, existe uma indicação clara de aumento dos lipídios séricos, principalmente dos mais preocupantes, como o LDL e o colesterol total. Os triglicerídeos e o VLDL também mostram uma tendência de aumento com o uso de inibidores de protease, porém menos marcante. 


\subsection{Avaliação do epitélio da pele}

O epitélio da pele do rato é do tipo estratificado queratinizado. É formado por camada basal, camada espinhosa, camada granulosa e camada córnea, camadas bem definidas. Em algumas áreas as camadas granulosa e espinhosa se confundem, o que dificulta sua avaliação em separado (Figura 2).

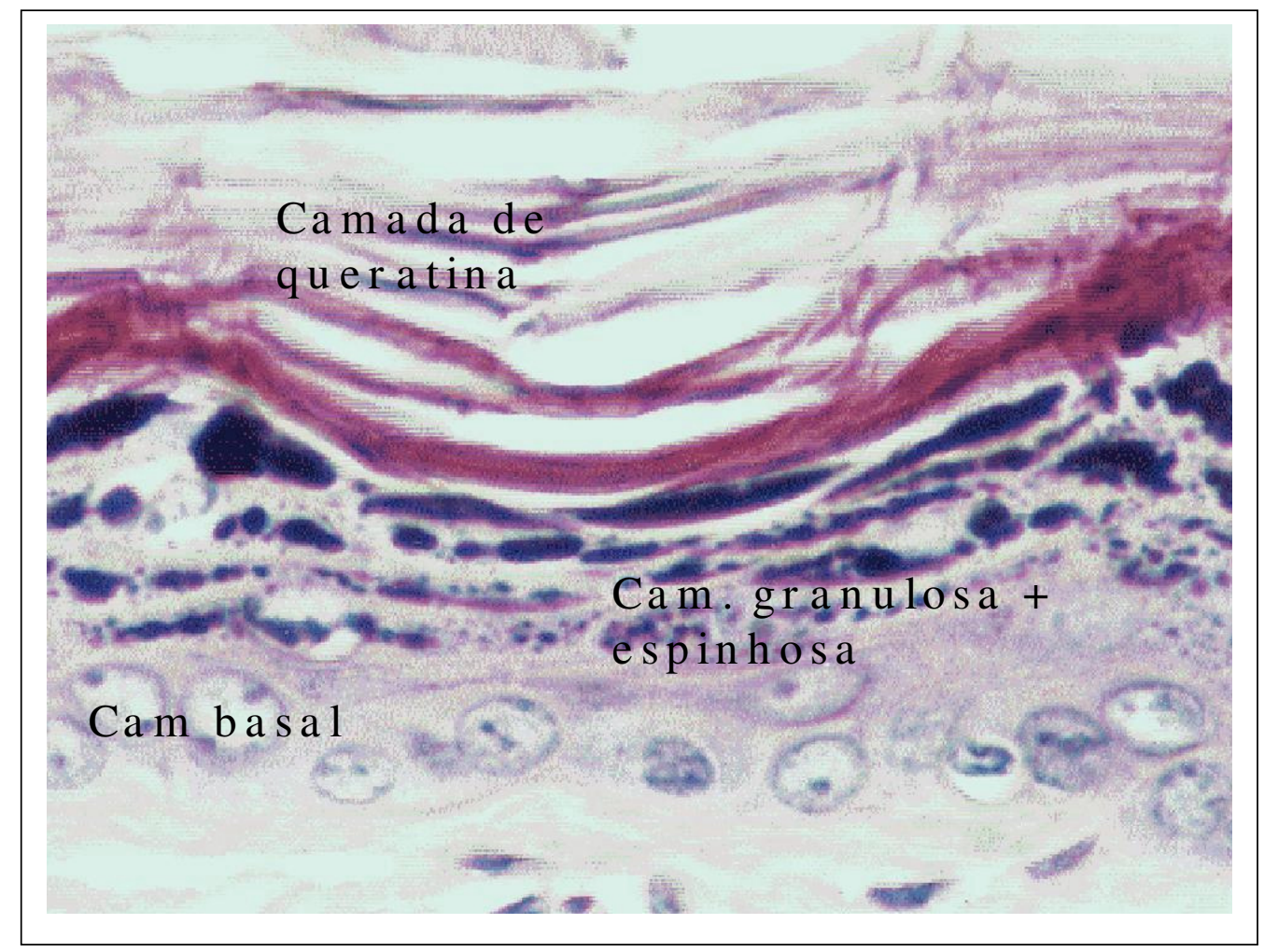

Figura 2 - Epitélio da pele - Aumento 40x/HE. Observe as camadas: basal (próxima do tecido conjuntivo); espinhosa (camadas de células com os núcleos espalhados), granulosa (entre a espinhosa e ceratina, pouco espessa); e ceratina (células descamando, já sem núcleos). 


\subsubsection{Cariometria do epitélio da pele}

Para o nosso estudo, as medidas nucleares e celulares epiteliais foram consideradas separadamente para: a) camada basal; e b) camada espinhosa + granulosa (que será, para efeito de simplificação, chamada apenas de camada espinhosa. As medidas gerais do epitélio foram consideradas separadamente para: a) camada basal; b) camada espinhosa + granulosa; c) camada de queratina ou camada córnea; e d) epitélio total.

Os animais foram sacrificados após 4 semanas ou 8 semanas de após o início da aplicação do medicamento estudado. Os valores obtidos estão expressos nas tabelas a seguir. 
TABELA 3 - Avaliação do tamanho dos núcleos das células do epitélio da pele dos animais controle e tratados com inibidor de protease.

\begin{tabular}{|c|c|c|c|c|c|c|}
\hline \multirow[t]{2}{*}{$\begin{array}{l}\text { Estrutura } \\
\text { Estudada }\end{array}$} & \multicolumn{2}{|c|}{ Animais Controle } & \multicolumn{2}{|c|}{$\begin{array}{c}\text { Tratados - } 4 \\
\text { semanas }\end{array}$} & \multicolumn{2}{|c|}{$\begin{array}{c}\text { Tratados-8 } \\
\text { semanas }\end{array}$} \\
\hline & C.basal & C.espinh. & C.basal & C.espinh. & C.basal & C.espinh. \\
\hline \multirow[t]{3}{*}{$\begin{array}{l}\text { Diâmetro } \\
\text { maior }\end{array}$} & $\begin{array}{l}6.42 \\
6.66 \\
7.06 \\
7.02 \\
6.38\end{array}$ & $\begin{array}{l}7.08 \\
6.92 \\
7.32 \\
7.20 \\
7.06\end{array}$ & $\begin{array}{l}7.02 \\
6.84 \\
7.08 \\
6.82 \\
7.08\end{array}$ & $\begin{array}{l}7.90 \\
7.96 \\
7.88 \\
7.66 \\
7.96\end{array}$ & $\begin{array}{l}6.48 \\
6.42 \\
6.62 \\
6.98 \\
6.68\end{array}$ & $\begin{array}{l}8.74 \\
7.76 \\
8.28 \\
7.72 \\
7.90\end{array}$ \\
\hline & $6.70 \pm 0.32$ & $7.11 \pm 0.15$ & $6.96 \pm 0.12$ & $7.87 \pm 0.12$ & $6.63 \pm 0.21$ & $8.8 \pm 0.43$ \\
\hline & & & $\uparrow$ & $\uparrow$ & $v$ & $\uparrow$ \\
\hline \multirow[t]{3}{*}{$\begin{array}{l}\text { Diâmetro } \\
\text { menor }\end{array}$} & $\begin{array}{l}5.42 \\
5.30 \\
5.42 \\
5.54 \\
5.22\end{array}$ & $\begin{array}{l}5.98 \\
5.82 \\
5.82 \\
5.58 \\
6.10\end{array}$ & $\begin{array}{l}5.40 \\
4.96 \\
5.46 \\
5.38 \\
5.74 \\
\end{array}$ & $\begin{array}{l}5.72 \\
5.22 \\
5.50 \\
5.64 \\
5.78\end{array}$ & $\begin{array}{l}5.52 \\
5.18 \\
5.26 \\
5.38 \\
5.50\end{array}$ & $\begin{array}{l}5.66 \\
5.22 \\
5.52 \\
5.44 \\
5.92\end{array}$ \\
\hline & $5.32 \pm 0.21$ & $5.86 \pm 0.19$ & $5.38 \pm 0.27$ & $5.57 \pm 0.22$ & $5.36 \pm 0.14$ & $5.55 \pm 0.26$ \\
\hline & & & $\uparrow$ & $\downarrow$ & $\uparrow$ & $\downarrow$ \\
\hline \multirow[t]{3}{*}{$\begin{array}{l}\text { Volume } \\
\text { nuclear }\end{array}$} & $\begin{array}{l}109.90 \\
111.16 \\
125.55 \\
129.51 \\
102.27\end{array}$ & $\begin{array}{l}147.50 \\
136.51 \\
148.58 \\
135.95 \\
150.02\end{array}$ & $\begin{array}{l}124.82 \\
107.11 \\
128.03 \\
118.33 \\
137.45\end{array}$ & $\begin{array}{l}160.79 \\
143.28 \\
149.94 \\
152.81 \\
165.48\end{array}$ & $\begin{array}{l}113.61 \\
101.46 \\
110.14 \\
122.08 \\
118.71\end{array}$ & $\begin{array}{l}184.05 \\
137.34 \\
163.96 \\
145.63 \\
171.10\end{array}$ \\
\hline & $\begin{array}{r}115.67 \\
\pm 11.42\end{array}$ & $143.63 \pm 6.89$ & $123.14 \pm 11.3$ & $154.46 \pm 8.79$ & $113.20 \pm 8.00$ & $\begin{array}{r}160.41 \\
\pm 18.94\end{array}$ \\
\hline & & & $\uparrow$ & $\uparrow$ & $\psi$ & $\uparrow$ \\
\hline \multirow[t]{3}{*}{ Área nuclear } & $\begin{array}{l}27.49 \\
27.77 \\
30.11 \\
30.66 \\
26.25\end{array}$ & $\begin{array}{l}33.43 \\
31.78 \\
33.62 \\
31.67 \\
33.91\end{array}$ & $\begin{array}{l}29.89 \\
26.88 \\
30.44 \\
28.90 \\
31.97\end{array}$ & $\begin{array}{l}35.47 \\
32.56 \\
33.91 \\
34.15 \\
36.13\end{array}$ & $\begin{array}{l}28.18 \\
26.14 \\
27.49 \\
29.55 \\
28.97\end{array}$ & $\begin{array}{l}38.83 \\
31.90 \\
35.94 \\
33.10 \\
36.88\end{array}$ \\
\hline & $28.45 \pm 1.86$ & $32,88 \pm 1,07$ & $29.61 \pm 1.89$ & $34.44 \pm 1.39$ & $28.06 \pm 1.32$ & $35.33 \pm 2.81$ \\
\hline & & & $\uparrow$ & $\uparrow$ & $\downarrow$ & $\uparrow$ \\
\hline \multirow[t]{3}{*}{$\begin{array}{l}\text { Perímetro } \\
\text { nuclear }\end{array}$} & $\begin{array}{l}18.65 \\
18.87 \\
19.71 \\
19.83 \\
18.29\end{array}$ & $\begin{array}{l}20.57 \\
20.07 \\
20.73 \\
20.18 \\
20.72\end{array}$ & $\begin{array}{l}19.62 \\
18.68 \\
19.91 \\
19.26 \\
20.22\end{array}$ & $\begin{array}{l}21.58 \\
20.98 \\
21.24 \\
21.04 \\
21.76\end{array}$ & $\begin{array}{l}18.90 \\
18.30 \\
18.75 \\
19.52 \\
19.20\end{array}$ & $\begin{array}{l}22.92 \\
20.62 \\
21.93 \\
20.87 \\
21.85\end{array}$ \\
\hline & $19.07 \pm 0.67$ & $21.45 \pm 0.30$ & $19.53 \pm 0.59$ & $21.32 \pm 0.33$ & $18.93 \pm 0.46$ & $21.63 \pm 0.92$ \\
\hline & & & & & $v$ & \\
\hline
\end{tabular}

Obs: Estão expressos nesta tabela os dados relativos a: Diâmetro maior em micrometros $(\mu \mathrm{m})$, diâmetro menor $(\mathrm{em} \mu \mathrm{m})$, perímetro do núcleo celular $(\mathrm{em} \mu \mathrm{m})$, área nuclear em micrometros quadrados $\left(\mu \mathrm{m}^{2}\right)$, e volume nuclear em micrometros cúbicos $\left(\mu \mathrm{m}^{3}\right)$. 
TABELA 4 - Avaliação dos efeitos da utilização de inibidor de protease sobre o tamanho dos núcleos das células da camada basal do epitélio da pele dos animais controles e tratados - Avaliação pelo teste Kruskal-Wallis.

\begin{tabular}{|c|c|c|c|}
\hline \multicolumn{4}{|l|}{ DIÂMETRO MAIOR } \\
\hline \multirow{2}{*}{$\begin{array}{l}\text { Valor de } \mathrm{H}=4.7706 \\
\text { Valor de } \mathrm{x}^{2} \mathrm{p} / 2^{\circ} \text { de liberdade }=4.77 \\
\text { Probabilidade de } \mathrm{H} 0=9.21 \%\end{array}$} & $\begin{array}{l}\text { Controle X } 4 \\
\text { semanas }\end{array}$ & $\begin{array}{c}\text { Controle X } 8 \\
\text { semanas }\end{array}$ & $\begin{array}{c}4 \operatorname{sem} X 8 \\
\text { sem }\end{array}$ \\
\hline & & NS & $5 \%$ \\
\hline \multicolumn{4}{|l|}{ Significante para $\alpha \leq 0.05$} \\
\hline \multicolumn{4}{|l|}{ DIÂMETRO MENOR } \\
\hline \multirow{2}{*}{$\begin{array}{l}\text { Valor de } \mathrm{H}=0.0953 \\
\text { Valor de } \mathrm{x}^{2} \mathrm{p} / 2^{\circ} \text { de liberdade }=0.10 \\
\text { Probabilidade de } \mathrm{H} 0=95.34 \%\end{array}$} & $\begin{array}{c}\text { Controle X } 4 \\
\text { semanas }\end{array}$ & $\begin{array}{l}\text { Controle X } 8 \\
\text { semanas }\end{array}$ & $\begin{array}{c}4 \text { sem } X 8 \\
\text { sem }\end{array}$ \\
\hline & NS & & NS \\
\hline \multicolumn{4}{|l|}{ Significante para $\alpha \leq 0.05$} \\
\hline \multicolumn{4}{|l|}{ VOLUME NUCLEAR } \\
\hline \multirow{2}{*}{$\begin{array}{l}\text { Valor de } \mathrm{H}=1.6800 \\
\text { Valor de } \mathrm{x}^{2} \mathrm{p} / 2^{\circ} \text { de liberdade }=1.68 \\
\text { Probabilidade de } \mathrm{H} 0=43.17 \%\end{array}$} & $\begin{array}{l}\text { Controle X } 4 \\
\text { semanas }\end{array}$ & $\begin{array}{c}\text { Controle X } 8 \\
\text { semanas }\end{array}$ & $\begin{array}{c}4 \text { sem } X 8 \\
\text { sem }\end{array}$ \\
\hline & NS & NS & NS \\
\hline Significante para $\alpha \leq 0.05$ & & & \\
\hline ÁREA NUCLEAR & & & \\
\hline $\begin{array}{l}\text { Valor de } \mathrm{H}=1.7481 \\
\text { Valor de } \mathrm{x}^{2} \mathrm{p} / 2^{\circ} \text { de liberdade }=1.75 \\
\text { Probabilidade de } \mathrm{H} 0=41.73 \%\end{array}$ & $\begin{array}{l}\text { Controle X } 4 \\
\text { semanas } \\
\text { NS }\end{array}$ & $\begin{array}{c}\text { Controle X } 8 \\
\text { semanas } \\
\text { NS }\end{array}$ & $\begin{array}{l}4 \operatorname{sem} X 8 \\
\text { sem } \\
\text { NS }\end{array}$ \\
\hline \multicolumn{4}{|l|}{ Significante para $\alpha \leq 0.05$} \\
\hline \multicolumn{4}{|l|}{ PERÍMETRO NUCLEAR } \\
\hline \multirow[t]{2}{*}{$\begin{array}{l}\text { Valor de } H=2.5800 \\
\text { Valor de } x^{2} p / 2^{\circ} \text { de liberdade }=2.58 \\
\text { Probabilidade de } H 0=27.53 \%\end{array}$} & $\begin{array}{l}\text { Controle X } 4 \\
\text { semanas }\end{array}$ & $\begin{array}{l}\text { Controle X } 8 \\
\text { semanas }\end{array}$ & $\begin{array}{l}4 \text { sem } X 8 \\
\text { sem }\end{array}$ \\
\hline & NS & NS & NS \\
\hline
\end{tabular}


TABELA 5 - Avaliação dos efeitos da utilização de inibidor de protease sobre o tamanho dos núcleos das células da camada espinhosa do epitélio da pele dos animais controles e tratados - Avaliação pelo teste Kruskal-Wallis.

\section{DIÂMETRO MAIOR}

Valor de $\mathrm{H}=9.4889$
Valor de $\mathrm{x}^{2} \mathrm{p} / 2^{\circ}$ de liberdade $=9.49$
Probabilidade de $\mathrm{HO}=0.87 \%$

Controle $X 4$
semanas
$1 \%$

Controle $X 8$
semanas
$0.1 \%$

$4 \operatorname{sem} \times 8$ sem

Significante para $\alpha \leq 0.01$

\section{DIÂMETRO MENOR}

Valor de $\mathrm{H}=4.8824$
Valor de $\mathrm{x}^{2} \mathrm{p} / 2^{\circ}$ de liberdade $=4.88$

Probabilidade de $\mathrm{HO}=8.71 \%$

\begin{tabular}{c|}
\hline $\begin{array}{c}\text { Controle } X 4 \\
\text { semanas } \\
\text { NS }\end{array}$ \\
\hline
\end{tabular}

\begin{tabular}{c|c}
$\begin{array}{c}\text { Controle X } 8 \\
\text { semanas }\end{array}$ & $\begin{array}{c}4 \text { sem } X 8 \\
\text { sem }\end{array}$ \\
$5 \%$ & NS
\end{tabular}

Significante para $\alpha \leq 0.05$

\section{VOLUME NUCLEAR}

Valor de $\mathrm{H}=3.4200$
Valor de $\mathrm{x}^{2} \mathrm{p} / 2^{\circ}$ de liberdade $=3.42$
Probabilidade de $\mathrm{H} 0=18.09 \%$

Controle X 4
semanas
NS

\begin{tabular}{c|c}
$\begin{array}{c}\text { Controle X } 8 \\
\text { semanas } \\
\text { NS }\end{array}$ & $\begin{array}{c}4 \text { sem } X 8 \\
\text { sem }\end{array}$ \\
NS
\end{tabular}

Significante para $\alpha \leq 0.05$
ÁREA NUCLEAR
Valor de $\mathrm{H}=3.6415$
Valor de $\mathrm{x}^{2} \mathrm{p} / 2^{\circ}$ de liberdade $=3.64$
Probabilidade de $\mathrm{HO}=16.19 \%$

Controle X 4
semanas
NS

\begin{tabular}{c|c}
$\begin{array}{c}\text { Controle X } 8 \\
\text { semanas } \\
\text { NS }\end{array}$ & $\begin{array}{c}4 \text { sem } X 8 \\
\text { sem }\end{array}$ \\
\hline NS
\end{tabular}

Significante para $\alpha \leq 0.05$

\section{PERIMETRO NUCLEAR}

Valor de $\mathrm{H}=7.9800$
Valor de $\mathrm{x}^{2} \mathrm{p} / 2^{\circ}$ de liberdade $=7.98$
Probababilidade de $\mathrm{HO}=1.85 \%$

Controle X 4
semanas
$1 \%$
Controle X 8
semanas
$1 \%$

4 sem $X 8$

$1 \%$

sem

Significante para $\alpha \leq 0.01$ 
TABELA 6 - Avaliação dos parâmetros avaliação da forma dos núcleos das células epiteliais da pele dos animais controles e tratados com inibidor de protease.

\begin{tabular}{|c|c|c|c|c|c|c|}
\hline \multirow[t]{2}{*}{$\begin{array}{l}\text { Estrutura } \\
\text { Estudada }\end{array}$} & \multicolumn{2}{|c|}{ Animais Controle } & \multicolumn{2}{|c|}{$\begin{array}{c}\text { Tratados - } 4 \\
\text { semanas }\end{array}$} & \multicolumn{2}{|c|}{$\begin{array}{c}\text { Tratados - } 8 \\
\text { semanas }\end{array}$} \\
\hline & C.Basal & C.Espinhosa & C.basal & C.espinhosa & C.basal & C.espinhosa \\
\hline \multirow{7}{*}{$\begin{array}{l}\text { Relação } \\
\text { DM/dm }\end{array}$} & 1.19 & 1.20 & 1.31 & 1.41 & 1.18 & 1.58 \\
\hline & 1.27 & 1.20 & 1.39 & 1.56 & 1.26 & 1.50 \\
\hline & 1.32 & 1.27 & 1.31 & 1.46 & 1.28 & 1.52 \\
\hline & 1.28 & 1.31 & 1.28 & 1.37 & 1.32 & 1.45 \\
\hline & 1.23 & 1.17 & 1.25 & 1.41 & 1.23 & 1.36 \\
\hline & $1.25 \pm 0.04$ & $1.23 \pm 0.05$ & $1.30 \pm 0.05$ & $1.44 \pm 0.07$ & $1.25 \pm 0.05$ & $1.48 \pm 0.08$ \\
\hline & & & $\uparrow$ & $\uparrow$ & & $\uparrow$ \\
\hline \multirow{7}{*}{$\begin{array}{l}\text { Relação } \\
\text { Vol./Área }\end{array}$} & 3.93 & 4.33 & 4.09 & 4.46 & 3.98 & 4.67 \\
\hline & 3.95 & 4.22 & 3.87 & 4.28 & 3.83 & 4.23 \\
\hline & 4.11 & 4.34 & 4.13 & 4.37 & 3.92 & 4.49 \\
\hline & 4.15 & 4.21 & 4.03 & 4.37 & 4.07 & 4.30 \\
\hline & 3.84 & 4.37 & 4.24 & 4.50 & 4.03 & 4.54 \\
\hline & $3.99 \pm 0.12$ & $4.29 \pm 0.07$ & $4.07 \pm 0.13$ & $4.39 \pm 0.08$ & $3.96 \pm 0.09$ & $4.44 \pm 0.17$ \\
\hline & & & $\uparrow$ & $\uparrow$ & $\downarrow$ & $\uparrow$ \\
\hline \multirow{7}{*}{$\begin{array}{c}\text { Índice } \\
\text { de } \\
\text { contorno }\end{array}$} & 3.57 & 3.58 & 3.60 & 3.64 & 3.57 & 3.70 \\
\hline & 3.59 & 3.58 & 3.63 & 3.69 & 3.59 & 3.67 \\
\hline & 3.61 & 3.59 & 3.60 & 3.66 & 3.60 & 3.67 \\
\hline & 3.60 & 3.60 & 3.60 & 3.62 & 3.61 & 3.65 \\
\hline & 3.58 & 3.57 & 3.59 & 3.64 & 3.58 & 3.62 \\
\hline & $3.59 \pm 0.01$ & $3.58 \pm 0.01$ & $3.60 \pm 0.01$ & $3.65 \pm 0.02$ & $3.59 \pm 0.01$ & $3.66 \pm 0.02$ \\
\hline & & & $\uparrow$ & $\uparrow$ & & $\uparrow$ \\
\hline \multirow{7}{*}{$\begin{array}{l}\text { Coeficiente } \\
\text { de forma }\end{array}$} & 0.99 & 0.98 & 0.97 & 0.95 & 0.99 & 0.94 \\
\hline & 0.97 & 0.98 & 0.96 & 0.93 & 0.97 & 0.92 \\
\hline & 0.97 & 0.97 & 0.97 & 0.94 & 0.97 & 0.93 \\
\hline & 0.97 & 0. & 0.97 & 0.96 & 0.98 & 0.96 \\
\hline & 0.98 & 0.99 & 0.98 & 0.95 & 0.97 & 0.94 \\
\hline & $0.97 \pm 0.00$ & $0.97 \pm 0.00$ & $0.97 \pm 0.00$ & $0.95 \pm 0.02$ & $0.97 \pm 0.00$ & $0.93 \pm 0.01$ \\
\hline & & & & $\downarrow$ & & $\downarrow$ \\
\hline \multirow{7}{*}{$\begin{array}{l}\text { Excentrici- } \\
\text { dade }\end{array}$} & 0.45 & 0.44 & 0.58 & 0.63 & 0.43 & 0.74 \\
\hline & 0.54 & 0.44 & 0.64 & 0.70 & 0.50 & 0.72 \\
\hline & 0.58 & 0.55 & 0.56 & 0.64 & 0.53 & 0.72 \\
\hline & 0.54 & 0.57 & 0.55 & 0.64 & 0.58 & 0.67 \\
\hline & 0.48 & 0.39 & 0.49 & 0.62 & 0.50 & 0.62 \\
\hline & $0.51 \pm 0.05$ & $0.47 \pm 0.07$ & $0.56 \pm 0.05$ & $0.64 \pm 0.03$ & $0.50 \pm 0.05$ & $0.67 \pm 0.08$ \\
\hline & & & $\downarrow$ & $\downarrow$ & $\downarrow$ & $\downarrow$ \\
\hline
\end{tabular}

Obs: Estão expressos nesta tabela os dados relativos a: Relação Diâmetro maior/Diâmetro menor (DM/dm), Relação volume/área (Vol./Área), coeficiente de forma, índice de contorno, e excentricidade. 
TABELA 7 - Avaliação dos efeitos da utilização de inibidor de protease sobre os parâmetros da forma dos núcleos das células da camada basal do epitélio da peles dos animais controles e tratados - Avaliação pelo teste Kruskal-Wallis.

\begin{tabular}{|c|c|c|c|}
\hline \multicolumn{4}{|c|}{ DIÂMETRO MAIOR / DIÂMETRO MENOR } \\
\hline $\begin{array}{l}\text { Valor de } \mathrm{H}=2.2076 \\
\text { Valor de } \mathrm{x}^{2} \mathrm{p} / 2^{\circ} \text { de liberdade }=2.21 \\
\text { Probabilidade de } \mathrm{H} 0=33.16 \%\end{array}$ & $\begin{array}{l}\text { Controle X } 4 \\
\text { semanas } \\
\text { NS }\end{array}$ & $\begin{array}{l}\text { Controle X8 } \\
\text { semanas } \\
\text { NS }\end{array}$ & $\begin{array}{l}4 \text { sem } X 8 \\
\text { sem } \\
\text { NS }\end{array}$ \\
\hline \multicolumn{4}{|l|}{ Significante para $\alpha \leq 0.05$} \\
\hline \multicolumn{4}{|c|}{ VOLUME NUCLEAR / ÁREA NUCLEAR } \\
\hline $\begin{array}{l}\text { Valor de } \mathrm{H}=2.0186 \\
\text { Valor de } \mathrm{x}^{2} \mathrm{p} / 2^{\circ} \text { de liberdade }=2.02 \\
\text { Probabilidade de } \mathrm{H} 0=36.45 \%\end{array}$ & $\begin{array}{l}\text { Controle X } 4 \\
\text { semanas } \\
\text { NS }\end{array}$ & $\begin{array}{l}\text { Controle X8 } \\
\text { semanas } \\
\text { NS }\end{array}$ & $\begin{array}{l}4 \text { sem } X 8 \\
\text { sem } \\
\text { NS }\end{array}$ \\
\hline \multicolumn{4}{|l|}{ Significante para $\alpha \leq 0.05$} \\
\hline \multicolumn{4}{|l|}{ ÍNDICE DE CONTORNO } \\
\hline $\begin{array}{l}\text { Valor de } \mathrm{H}=1.5641 \\
\text { Valor de } \mathrm{x}^{2} \mathrm{p} / 2^{\circ} \text { de liberdade }=1.56 \\
\text { Probabilidade de } \mathrm{H} 0=45.75 \%\end{array}$ & $\begin{array}{l}\text { Controle X } 4 \\
\text { semanas } \\
\text { NS }\end{array}$ & $\begin{array}{l}\text { Controle X } 8 \\
\text { semanas } \\
\text { NS }\end{array}$ & $\begin{array}{l}4 \text { sem } X 8 \\
\text { sem } \\
\text { NS }\end{array}$ \\
\hline \multicolumn{4}{|l|}{ Significante para $\alpha \leq 0.05$} \\
\hline \multicolumn{4}{|l|}{ COEFICIENTE DE FORMA } \\
\hline $\begin{array}{l}\text { Valor de } \mathrm{H}=2.6079 \\
\text { Valor de } \mathrm{x}^{2} \mathrm{p} / 2^{\circ} \text { de liberdade }=2.61 \\
\text { Probabilidade de } \mathrm{H} 0=27.15 \%\end{array}$ & $\begin{array}{l}\text { Controle X } 4 \\
\text { semanas } \\
\text { NS }\end{array}$ & $\begin{array}{l}\text { Controle X8 } \\
\text { semanas } \\
\text { NS }\end{array}$ & $\begin{array}{l}4 \text { sem } X 8 \\
\text { sem } \\
\text { NS }\end{array}$ \\
\hline \multicolumn{4}{|l|}{ Significante para $\alpha \leq 0.05$} \\
\hline \multicolumn{4}{|l|}{ EXCENTRICIDADE } \\
\hline $\begin{array}{l}\text { Valor de } \mathrm{H}=2.6079 \\
\text { Valor de } \mathrm{x}^{2} \mathrm{p} / 2^{\circ} \text { de liberdade }=2.61 \\
\text { Probabilidade de } \mathrm{H} 0=27.15 \%\end{array}$ & $\begin{array}{l}\text { Controle X } 4 \\
\text { semanas } \\
\text { NS }\end{array}$ & $\begin{array}{l}\text { Controle X } 8 \\
\text { semanas } \\
\text { NS }\end{array}$ & $\begin{array}{l}4 \text { sem } X 8 \\
\text { sem } \\
\text { NS }\end{array}$ \\
\hline
\end{tabular}


TABELA 8 - Avaliação dos efeitos da utilização de inibidor de protease sobre os parâmetros da forma dos núcleos das células da camada espinhosa do epitélio da pele dos animais controles e tratados - Avaliação pelo teste Kruskal-Wallis.

\begin{tabular}{|c|c|c|c|}
\hline \multicolumn{4}{|c|}{ DIÂMETRO MAIOR / DIÂMETRO MENOR } \\
\hline $\begin{array}{l}\text { Valor de } H=9.6545 \\
\text { Valor de } x^{2} p / 2^{\circ} \text { de liberdade }=9.65\end{array}$ & $\begin{array}{l}\text { Controle X } 4 \\
\text { semanas }\end{array}$ & $\begin{array}{l}\text { Controle X } 8 \\
\text { semanas }\end{array}$ & 4 sem $X 8$ sem \\
\hline $\begin{array}{l}\text { Probabilidade de } \mathrm{H} 0=0.80 \% \\
\text { Significante para } \alpha \leq 0.01\end{array}$ & Significante para $\alpha \leq 0.01$ & $0.1 \%$ & NS \\
\hline \multicolumn{4}{|l|}{ VOLUME NUCLEAR / ÁREA NUCLEAR } \\
\hline $\begin{array}{l}\text { Valor de } \mathrm{H}=3.4446 \\
\text { Valor de } \mathrm{x}^{2} \mathrm{p} / 2^{\circ} \text { de liberdade }=3.44\end{array}$ & $\begin{array}{l}\text { Controle X } 4 \\
\text { semanas } \\
\text { NS }\end{array}$ & $\begin{array}{l}\text { Controle X } 8 \\
\text { semanas }\end{array}$ & $4 \mathrm{sem} X 8 \mathrm{sem}$ \\
\hline \multirow{2}{*}{\multicolumn{4}{|c|}{$\begin{array}{l}\text { Significante para } \alpha \leq 0.05 \\
\text { iNDICE DE CONTORNO }\end{array}$}} \\
\hline & & & \\
\hline $\begin{array}{l}\text { Valor de } \mathrm{H}=9.2209 \\
\text { Valor de } \mathrm{x}^{2} \mathrm{p} / 2^{\circ} \text { de liberdade }=9.22 \\
\text { Probabilidade de } \mathrm{H} 0=0.99 \%\end{array}$ & $\begin{array}{l}\text { Controle X } 4 \\
\text { semanas } \\
1 \%\end{array}$ & $\begin{array}{l}\text { Controle X } 8 \\
\text { semanas } \\
0.1 \%\end{array}$ & 4 sem $X 8$ sem \\
\hline \multicolumn{4}{|l|}{$\begin{array}{l}\text { Significante para } \alpha \leq 0.01 \\
\text { COEFICIENTE DE FORMA }\end{array}$} \\
\hline $\begin{array}{l}\text { Valor de } \mathrm{H}=9.9398 \\
\text { Valor de } \mathrm{x}^{2} \mathrm{p} / 2^{\circ} \text { de liberdade }=9.93 \\
\text { Probabilidade de } \mathrm{H} 0=0.69 \%\end{array}$ & $\begin{array}{l}\text { Controle X } 4 \\
\text { semanas } \\
1 \%\end{array}$ & $\begin{array}{l}\text { Controle X } 8 \\
\text { semanas } \\
0.1 \%\end{array}$ & 4 sem $X 8$ sem \\
\hline \multicolumn{4}{|l|}{ Significante para $\alpha \leq 0.01$} \\
\hline \multicolumn{4}{|l|}{ EXCENTRICIDADE } \\
\hline $\begin{array}{l}\text { Valor de } \mathrm{H}=10.4295 \\
\text { Valor de } \mathrm{x}^{2} \mathrm{p} / 2^{\circ} \text { de liberdade }=10.43 \\
\text { Probabilidade de } \mathrm{H} 0=0.54 \%\end{array}$ & $\begin{array}{l}\text { Controle X } 4 \\
\text { semanas } \\
1 \%\end{array}$ & $\begin{array}{l}\text { Controle X } 8 \\
\text { semanas } \\
0.1 \%\end{array}$ & $4 \mathrm{sem} X 8 \mathrm{sem}$ \\
\hline & & & \\
\hline
\end{tabular}




\subsubsection{Estereologia do epitélio da pele}

TABELA 9 - Avaliação dos valores médios dos volumes celulares (em $\mu \mathrm{m}^{3}$ ) no epitélio da pele dos nimais controle e tratados com inibidor de protease.

\begin{tabular}{|c|c|c|c|c|c|c|}
\hline \multirow{2}{*}{$\begin{array}{l}\text { Estrutura } \\
\text { Estudada }\end{array}$} & \multicolumn{2}{|c|}{ Animais Controle } & \multicolumn{2}{|c|}{ Tratado- 4 semanas } & \multicolumn{2}{|c|}{ Tratados-8 semanas } \\
\hline & C.Basal & C.Espinhosa & C.basal & C.espinhosa & C.basal & C.espinhosa \\
\hline \multirow{7}{*}{$\begin{array}{l}\text { Volume } \\
\text { nuclear }\end{array}$} & 109.90 & 147.50 & 124.82 & 160.79 & 113.61 & 184.05 \\
\hline & 111.16 & 136 & 107 & & & \\
\hline & 125.55 & & 128 & & & 163.69 \\
\hline & 129.51 & & 118 & & & 145.63 \\
\hline & 102.27 & 150.02 & 137 & & 118 & 171.10 \\
\hline & $115.67 \pm 11.4$ & $143.71 \pm 6.89$ & $123.14 \pm 11.3$ & $154.06 \pm 9.45$ & $113.20 \pm 8.00$ & $160.41 \pm 18.9$ \\
\hline & & & $\uparrow$ & $\uparrow$ & $\downarrow$ & $\uparrow$ \\
\hline \multirow{7}{*}{$\begin{array}{l}\text { Volume } \\
\text { celular }\end{array}$} & 354.89 & 1128.21 & 462.61 & 2396.32 & 373.39 & 1764.24 \\
\hline & 267.41 & 1094.37 & 467.65 & 2125 & 341.09 & 1857.81 \\
\hline & 337.93 & 1110.15 & 497.11 & 2147.67 & 370.75 & 1866.04 \\
\hline & 267.46 & 88 & 481 & $22 \varepsilon$ & 36 & 37 \\
\hline & 231.72 & 1105.82 & 486.56 & 23 & 35 & 11 \\
\hline & $291.88 \pm 52.21$ & $1065.43 \pm 99.5$ & $479.10 \pm 14.05$ & $2253.53 \pm 14.3$ & $359.77 \pm 13.17$ & $1735.31 \pm 16.9$ \\
\hline & & & $\uparrow$ & $\uparrow$ & $\uparrow$ & $\uparrow$ \\
\hline \multirow{7}{*}{$\begin{array}{l}\text { Volume do } \\
\text { citoplasma }\end{array}$} & 244.99 & 880.71 & 337.79 & 2235.53 & 259.78 & 1580.19 \\
\hline & 156.25 & 957.86 & 360.54 & 1984.56 & 241.63 & 1720.47 \\
\hline & 212.38 & 961.57 & 339.08 & 1997 & 260 & 1702.35 \\
\hline & 137.95 & 752.66 & 363 & & 237 & 1482.74 \\
\hline & 129.45 & 955.80 & 349 & 214 & 234.86 & 1389.01 \\
\hline & $176.20 \pm 50.21$ & $901.72 \pm 89.88$ & $349.95 \pm 11.78$ & $2099.52 \pm 106.6$ & $246.97 \pm 12.31$ & $1574.95 \pm 141.8$ \\
\hline & & & $\uparrow$ & $\uparrow$ & $\uparrow$ & $\uparrow$ \\
\hline \multirow{7}{*}{$\begin{array}{c}\text { Relação } \\
\text { Núcleo/ } \\
\text { citoplasma }\end{array}$} & 0.4790 & 0.1630 & 0.3879 & 0.1081 & 0.4812 & 0.1332 \\
\hline & 0.6569 & 0.1534 & 0.4 & 0.1 & 0.6717 & 0.1267 \\
\hline & 0.4879 & 0.1695 & 0.36 & 0.1192 & 0.4947 & 0.1271 \\
\hline & 0.6991 & 0.2002 & 0.3997 & 0.12 & 0.5084 & 0.1517 \\
\hline & 0.9468 & 0.1632 & 0.4128 & 0.12 & 0.5418 & 0.1695 \\
\hline & $0.6539 \pm 0.19$ & $0.1699 \pm 0.02$ & $0.3978 \pm 0.02$ & $0.1232 \pm 0.01$ & $0.5396 \pm 0.08$ & $0.1416 \pm 0.02$ \\
\hline & & & $\downarrow$ & $\downarrow$ & $\downarrow$ & $\downarrow$ \\
\hline \multirow{7}{*}{$\begin{array}{l}\text { Densidade } \\
\text { numérica }\end{array}$} & 1.86 & 0.46 & 2.16 & 0.42 & 2.68 & 0.57 \\
\hline & 2.82 & 0.88 & 2.14 & 0.47 & 2.93 & 0.54 \\
\hline & 3.74 & 0.85 & 2.01 & 0.47 & 2.70 & 0.48 \\
\hline & 3.23 & 0.91 & 2.0 & 0.4 & 2.78 & 0.54 \\
\hline & 2.93 & 0. & 1.9 & 0.3 & 2.8 & 0.56 \\
\hline & $2,92 \pm 0.69$ & $0.80 \pm 0.19$ & $2.07 \pm 0.08$ & $0.44 \pm 0.04$ & $2.78 \pm 0.10$ & $0.54 \pm 0.03$ \\
\hline & & & 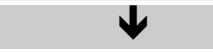 & L & 4 & , \\
\hline \multirow{7}{*}{$\begin{array}{l}\text { Densidade } \\
\text { de } \\
\text { superfície }\end{array}$} & 11.83 & 6.43 & 11.86 & 6.82 & 11.64 & 5.71 \\
\hline & 13.72 & & 10. & & 12. & 5.75 \\
\hline & 10.91 & 5.67 & 9.78 & 6.25 & 11.18 & 5.84 \\
\hline & 13.13 & 5.69 & 11.27 & 6.54 & 12.16 & 6.54 \\
\hline & 9.82 & 6.41 & 10.46 & 0.00 & & 6.75 \\
\hline & $11.88 \pm 1.59$ & $6.21 \pm 0.52$ & $10.76 \pm 0.81$ & $6.35 \pm 0.36$ & $11.96 \pm 0.56$ & $6.12 \pm 0.49$ \\
\hline & & & & & $\uparrow$ & 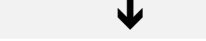 \\
\hline
\end{tabular}

Obs: Estão expressos nesta tabela os dados relativos a: volume nuclear, citoplasmático e celular (em micrometros cúbicos $-\mu \mathrm{m}^{3}$ ), relação núcleo/citoplasma, densidade numérica (número de células em uma área definida) e de superfície (número de células em uma extensão definida de superfície epitelial). 
TABELA 10 - Avaliação dos efeitos da utilização de inibidor de protease sobre os parâmetros dos valores médios dos volumes celulares $\left(\mathrm{em} \mu \mathrm{m}^{3}\right)$ na camada basal do epitélio da pele dos animais controle e tratados com inibidor de protease. - Avaliação pelo teste Kruskal-Wallis

\begin{tabular}{|c|c|c|c|}
\hline \multicolumn{4}{|l|}{ VOLUME NUCLEAR } \\
\hline \multirow{2}{*}{$\begin{array}{l}\text { Valor de } H=1.6800 \\
\text { Valor de } x^{2} p / 2^{\circ} \text { de liberdade }=1.68 \\
\text { Probabilidade de } H 0=43.17 \% \\
\text { NS = não significante }\end{array}$} & $\begin{array}{c}\text { Controle X } 4 \\
\text { semanas }\end{array}$ & $\begin{array}{c}\text { Controle X } 8 \\
\text { semanas }\end{array}$ & $4 \mathrm{sem} X 8 \mathrm{sem}$ \\
\hline & NS & NS & NS \\
\hline \multicolumn{4}{|l|}{ VOLUME CELULAR } \\
\hline \multirow{2}{*}{$\begin{array}{l}\text { Valor de } H=11.5800 \\
\text { Valor de } x^{2} p / 2^{\circ} \text { de liberdade }=11.58 \\
\text { Probabilidade de } H 0=0.31 \% \\
\text { Significante para } \alpha \leq 0.01\end{array}$} & $\begin{array}{c}\text { Controle X } 4 \\
\text { semanas }\end{array}$ & $\begin{array}{c}\text { Controle X } 8 \\
\text { semanas }\end{array}$ & 4 sem $X 8$ sem \\
\hline & $0.1 \%$ & $1 \%$ & $1 \%$ \\
\hline \multicolumn{4}{|l|}{ VOLUME DO CITOPLASMA } \\
\hline \multirow{2}{*}{$\begin{array}{l}\text { Valor de } H=11.1800 \\
\text { Valor de } x^{2} p / 2^{\circ} \text { de liberdade }=11.18 \\
\text { Probabilidade de } H 0=0.37 \% \\
\text { Significante para } \alpha \leq 0.01\end{array}$} & $\begin{array}{c}\text { Controle X } 4 \\
\text { semanas }\end{array}$ & $\begin{array}{c}\text { Controle X } 8 \\
\text { semanas }\end{array}$ & 4 sem $X 8$ sem \\
\hline & $0.1 \%$ & $5 \%$ & $1 \%$ \\
\hline \multicolumn{4}{|l|}{ RELAÇÃO NUCLEO/CITOPLASMA } \\
\hline \multirow{2}{*}{$\begin{array}{l}\text { Valor de } H=9.5000 \\
\text { Valor de } x^{2} p / 2^{\circ} \text { de liberdade }=9.50 \\
\text { Probabilidade de } H 0=0.87 \% \\
\text { Significante para } \alpha \leq 0.01\end{array}$} & $\begin{array}{c}\text { Controle X } 4 \\
\text { semanas }\end{array}$ & $\begin{array}{c}\text { Controle X } 8 \\
\text { semanas }\end{array}$ & 4 sem $X 8$ sem \\
\hline & 0.1 & NS & $1 \%$ \\
\hline \multicolumn{4}{|l|}{ DENSIDADE NUMÉRICA } \\
\hline \multirow{3}{*}{$\begin{array}{l}\text { Valor de } H=6.1360 \\
\text { Valor de } x^{2} p / 2^{\circ} \text { de liberdade }=6.14 \\
\text { Probabilidade de } H 0=4.65 \% \\
\text { Significante para } \alpha \leq 0.05\end{array}$} & $\begin{array}{c}\text { Controle X } 4 \\
\text { semanas }\end{array}$ & $\begin{array}{c}\text { Controle X } 8 \\
\text { semanas }\end{array}$ & $4 \mathrm{sem} X 8 \mathrm{sem}$ \\
\hline & & & $5 \%$ \\
\hline & & & \\
\hline \multicolumn{4}{|l|}{ DENSIDADE DE SUPERFÍCIE } \\
\hline \multirow{2}{*}{$\begin{array}{l}\text { Valor de } H=3.5000 \\
\text { Valor de } x^{2} p / 2^{\circ} \text { de liberdade }=3.50 \\
\text { Probabilidade de } H 0=17.38 \%\end{array}$} & $\begin{array}{c}\text { Controle X } 4 \\
\text { semanas }\end{array}$ & $\begin{array}{c}\text { Controle X } 8 \\
\text { semanas }\end{array}$ & 4 sem $X 8$ sem \\
\hline & & & NS \\
\hline
\end{tabular}


TABELA 11 - Avaliação dos efeitos da utilização de inibidor de protease sobre os parâmetros dos valores médios dos volumes celulares $\left(\mathrm{em} \mu \mathrm{m}^{3}\right)$ na camada espinhosa do epitélio da pele dos animais controle e tratados com inibidor de protease. Avaliação pelo Kruskal-Wallis.

\section{VOLUME NUCLEAR}

\begin{tabular}{|c|c|c|c|}
\hline $\begin{array}{l}\text { Valor de } \mathrm{H}=3.4200 \\
\text { Valor de } \mathrm{x}^{2} \mathrm{p} / 2^{\circ} \text { de liberdade }=3.42 \\
\text { Probabilidade de } \mathrm{H} 0=18.09 \%\end{array}$ & $\begin{array}{l}\text { Controle X } 4 \\
\text { semanas } \\
\text { NS }\end{array}$ & $\begin{array}{l}\text { Controle X } 8 \\
\text { semanas } \\
\text { NS }\end{array}$ & 4 sem $X 8$ sem \\
\hline \multicolumn{4}{|l|}{ NS = Não significante } \\
\hline \multicolumn{4}{|l|}{ VOLUME CELULAR } \\
\hline $\begin{array}{l}\text { Valor de } \mathrm{H}=12500 \\
\text { Valor de } \mathrm{x}^{2} \mathrm{p} / 2^{\circ} \text { de liberdade }=12.50 \\
\text { Probabilidade de } \mathrm{H} 0=0.19 \%\end{array}$ & $\begin{array}{c}\text { Controle X } 4 \\
\text { semanas } \\
0.1 \%\end{array}$ & $\begin{array}{c}\text { Controle X } 8 \\
\text { semanas } \\
0.1 \%\end{array}$ & 4 sem $X 8$ sem \\
\hline
\end{tabular}

\section{VOLUME DO CITOPLASMA}

Valor de $\mathrm{H}=12.5000$

Valor de $x^{2} \mathrm{p} / 2^{\circ}$ de liberdade $=12.50$

Probabilidade de $\mathrm{H} 0=0.19 \%$

Significante para $\alpha \leq 0.01$

\begin{tabular}{c|c|c}
$\begin{array}{c}\text { Controle X 4 } \\
\text { semanas } \\
0.1 \%\end{array}$ & $\begin{array}{c}\text { Controle X 8 } \\
\text { semanas } \\
0.1 \%\end{array}$ & $\begin{array}{c}4 \text { sem } X 8 \text { sem } \\
0.1 \%\end{array}$
\end{tabular}

\section{RELAÇÃO NUCLEO/CITOPLASMA}

Valor de $\mathrm{H}=9.2600$

Valor de $x^{2} p / 2^{\circ}$ de liberdade $=9.26$

Probabilidade de $\mathrm{HO}=0.98 \%$

Significante para $\alpha \leq 0.01$

\section{DENSIDADE NUMÉRICA}

\section{Valor de $\mathrm{H}=8.8115$}

Valor de $\mathrm{x}^{2} \mathrm{p} / 2^{\circ}$ de liberdade $=8.81$

Probabilidade de $\mathrm{H} 0=1.22 \%$

Significante para $\alpha \leq 0.01$

\section{DENSIDADE DE SUPERFÍCIE}

Valor de $\mathrm{H}=0.5419$

Valor de $\mathrm{x}^{2} \mathrm{p} / 2^{\circ}$ de liberdade $=0.54$

Probabilidade de $\mathrm{H} 0=76.26 \%$

\author{
Controle X 4 \\ semanas \\ NS
}

semanas

\begin{tabular}{c|c}
$\begin{array}{c}\text { Controle } X 8 \\
\text { semanas } \\
5 \%\end{array}$ & 4 sem $X 8$ sem \\
\hline
\end{tabular}
$5 \%$

Controle X 8

4 sem $X 8$ sem semanas

NS $5 \%$

Significante para $\alpha \leq 0.05$

\begin{tabular}{c|c}
$\begin{array}{c}\text { Controle X } 8 \\
\text { semanas } \\
\text { NS }\end{array}$ & 4 sem X 8 sem \\
\hline
\end{tabular}


TABELA 12 - Avaliação da espessura $(e m \mu \mathrm{m})$ do epitélio da pele dos animais controle e tratados com inibidores de protease.

\begin{tabular}{|c|c|c|c|c|}
\hline $\begin{array}{l}\text { Grupos } \\
\text { Estudados }\end{array}$ & Camada basal & C.espinhosa & C.de queratina & Epitélio total \\
\hline $\begin{array}{l}\text { Animais } \\
\text { Controle }\end{array}$ & $\begin{array}{r}11.15 \\
17.13 \\
10.77 \\
10.36 \\
1 \cap 5 \sqsubset \\
12.39 \pm 2.77\end{array}$ & $\begin{array}{c}29.19 \\
23.22 \\
21.05 \\
19.88 \\
n \simeq 5 \sqsubset \\
23.98 \pm \mathbf{3 . 8 6}\end{array}$ & $\begin{array}{c}31.88 \\
34.92 \\
26.59 \\
27.61 \\
\text { nก } 57 \\
\mathbf{3 1 . 9 1} \pm \mathbf{5 . 3 7}\end{array}$ & $\begin{array}{r}72.22 \\
75.27 \\
58.41 \\
57.85 \\
70 \simeq 7 \\
68.48 \pm 9.73\end{array}$ \\
\hline $\begin{array}{l}\text { Inibidor de } \\
\text { protease por } \\
4 \text { semanas }\end{array}$ & $\begin{array}{c}8.44 \\
9.38 \\
9.49 \\
8.83 \\
\text { n } \\
9.10 \pm 0.45 \\
\downarrow\end{array}$ & $\begin{array}{c}14.30 \\
16.25 \\
16.15 \\
14.67 \\
15 \text { 1n } \\
\mathbf{1 5 . 3 7} \pm \mathbf{0 . 8 7} \\
\boldsymbol{\downarrow}\end{array}$ & $\begin{array}{c}19.39 \\
22.49 \\
19.21 \\
21.00 \\
1 \cap 71 \\
\mathbf{1 0 . 3 6} \pm \mathbf{1 . 3 8} \\
\downarrow\end{array}$ & $\begin{array}{c}42.13 \\
48.12 \\
44.85 \\
45.50 \\
1157 \\
\mathbf{4 5 . 0 3} \pm \mathbf{2 . 1 5} \\
\boldsymbol{\downarrow}\end{array}$ \\
\hline $\begin{array}{l}\text { Inibidor de } \\
\text { protease por } \\
8 \text { semanas }\end{array}$ & $\begin{array}{c}8.37 \\
8.01 \\
8.72 \\
7.74 \\
77\ulcorner \\
\mathbf{8 . 1 2} \pm \mathbf{0 . 4 2} \\
\boldsymbol{\downarrow}\end{array}$ & $\begin{array}{c}15.99 \\
13.94 \\
16.12 \\
14.90 \\
110 n \\
\mathbf{1 5 . 0 6 \pm 0 . 9 7} \\
\boldsymbol{\Downarrow}\end{array}$ & $\begin{array}{c}29.50 \\
26.70 \\
28.77 \\
26.46 \\
n\urcorner n \cap \\
\mathbf{2 7 . 7 6} \pm \mathbf{1 . 3 2} \\
\boldsymbol{\Downarrow}\end{array}$ & $\begin{array}{c}54.86 \\
49.65 \\
55.61 \\
49.10 \\
1 n \text { 1n } \\
\mathbf{5 1 . 7 4} \pm \mathbf{3 . 2 1} \\
\boldsymbol{\Downarrow}\end{array}$ \\
\hline
\end{tabular}


TABELA 13 - Avaliação dos efeitos da utilização de inibidor de protease sobre a espessura $(\mathrm{em} \mu \mathrm{m})$ no epitélio da pele dos animais controle e tratados. - Avaliação pelo teste Kruskal-Wallis.

\section{ESPESSURA DA CAMADA BASAL}

Valor de $\mathrm{H}=120200$

Contr. X 4 sem.

Contr. X 8 sem.

4 sem $X 8$ sem

Valor de $\mathrm{x}^{2} \mathrm{p} / 2^{\circ}$ de liberdade $=12.02$

Probabilidade de $\mathrm{HO}=0.25 \%$

$0.1 \%$

$0.1 \%$

$1 \%$

Significante para $\alpha \leq 0.01$

\section{ESPESSURA DA CAMADA ESPINHOSA}

Valor de $\mathrm{H}=9.6200$

Valor de $\mathrm{x}^{2} \mathrm{p} / 2^{\circ}$ de liberdade $=9.62$

Probabilidade de $\mathrm{H} 0=0.81 \%$

Contr. X 4 sem.

Contr. X 8 sem.

4 sem $X 8$ sem

Significante para $\alpha \leq 0.01$

$1 \%$

$0.1 \%$

NS

\section{ESPESSURA DA CAMADA DE QUERATINA}

Valor de $\mathrm{H}=10.2200$

Controle X 4 sem

Contr. X 8 sem.

4 sem $X 8$ sem

Valor de $x^{2} p / 2^{\circ}$ de liberdade $=10.22$

Probabilidade de $\mathrm{H} 0=0.60 \%$

$0.1 \%$

NS

$1 \%$

Significante para $\alpha \leq 0.01$

\section{ESPESSURA DO EPITÉLIO TOTAL}

Valor de $\mathrm{H}=12.5000$

Valor de $x^{2} p / 2^{\circ}$ de liberdade $=12.50$

Probabilidade de $\mathrm{H} 0=0.19 \%$

Controle X 4 sem.

$0.1 \%$

Significante para $\alpha \leq 0.01$

TABELA 14 - Avaliação da Relação superfície externa/ Superfície basal do epitélio da pele dos animais controle e tratados com inibidor de protease.

\begin{tabular}{|c|c|c|}
\hline $\begin{array}{c}\text { Animais } \\
\text { Controle }\end{array}$ & $\begin{array}{r}\text { Inibidor de protease por } \\
\mathbf{4} \text { semanas }\end{array}$ & $\begin{array}{c}\text { Inibidor de protease por } \\
\mathbf{8} \text { semanas }\end{array}$ \\
\hline 1.0721 & 1.0110 & 0.9000 \\
1.0057 & 1.0540 & 1.0000 \\
1.0812 & 1.0000 & 0.9790 \\
1.0930 & 1.0310 & 1.0000 \\
1.0537 & 1.0000 & 0.9900 \\
\hline $\mathbf{1 . 0 6 1 1} \pm \mathbf{0 . 0 3}$ & $\mathbf{1 . 0 1 9 2 \pm 0 . 0 2}$ & $\mathbf{0 . 9 7 3 8 \pm 0 . 0 4}$ \\
\hline
\end{tabular}


TABELA 15 - Avaliação dos efeitos da utilização de inibidor de protease sobre os parâmetros dos valores médios da Relação superfície externa/ Superfície basal $(e m \mu \mathrm{m})$ no epitélio da pele dos animais controle e tratados. - Avaliação pelo teste Kruskal-Wallis

RELAÇÃO SUPERFÍCIE EXTERNA/SUPERFÍCIE BASAL DO EPITÉLIO DA PELE

Valor de $\mathrm{H}=9.9171$

Valor de $x^{2} \mathrm{p} / 2^{\circ}$ de liberdade $=9.92$

Probabilidade de $\mathrm{H} 0=0.70 \%$

Significante para $\alpha \leq 0.01$

\begin{tabular}{c|c|c}
$\begin{array}{c}\text { Controle X } 4 \\
\text { semanas }\end{array}$ & $\begin{array}{c}\text { Controle X 8 } \\
\text { semanas }\end{array}$ & 4 sem X 8 sem \\
\hline $5 \%$ & $0.1 \%$ & $1 \%$ \\
\hline
\end{tabular}

A avaliação cariométrica e estereologica do epitélio da pele dos animais tratados com inibidor de protease quando comparado aos seus controles nos mostram que:

1) os volumes nucleares estão aumentados, tanto na camada basal como na camada espinhosa;

2) a análise da forma nuclear mostra núcleos ligeiramente mais alongados, porém apenas na camada espinhosa do epitélio da pele;

3) os volumes celulares se apresentam também aumentados, tanto na camada basal como na camada espinhosa do epitélio da pele dos animais tratados com inibidor de protease, e esse efeito é observado já nos primeiros períodos de uso do medicamento;

4) apesar do aumento dos volumes nucleares e celulares, é possível observar uma marcante diminuição da espessura epitelial (camadas basal e espinhosa), e também uma diminuição das pregas epiteliais (ver tabelas 14 e 15), o que pode significar um aumento de suscetibilidade desse epitélio a lesões frente a traumas e injúrias. 


\subsection{Avaliação do epitélio da língua}

O rico suprimento sangüíneo da língua permite uma rápida renovação celular da sua superfície epitelial, se as alterações sistêmicas se manifestam rapidamente na superfície da língua (BEAVEN \& BROOKS, 1988).

A língua do rato pode ser histologicamente dividida em 4 áreas distintas: 1) a região dorsal anterior; 2) a região dorsal intermediária; 3) região dorsal posterior; e 4) a região ventral. As figuras posteriores mostram as diferenças anatômicas de cada uma dessas regiões:

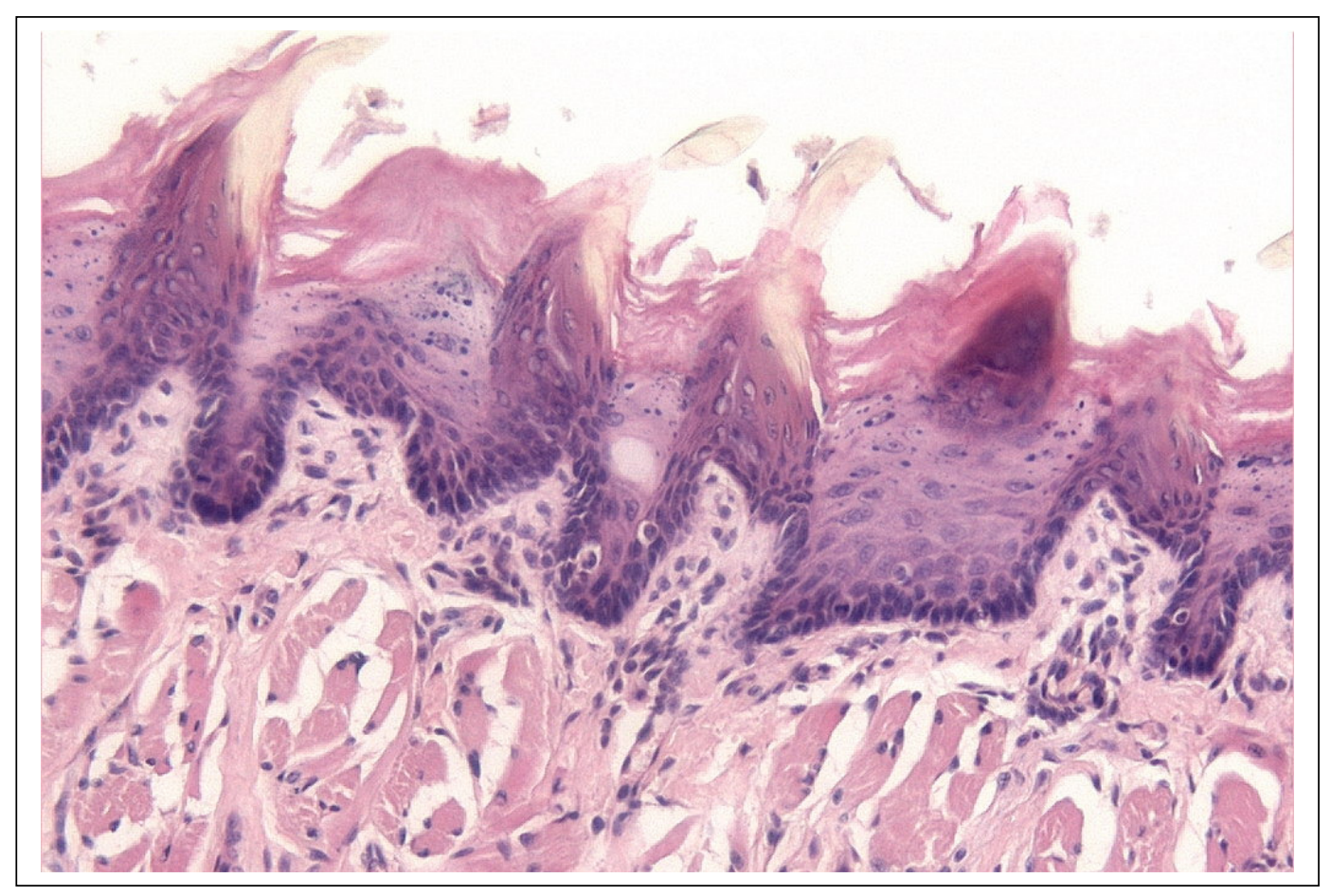

FIGURA 3 - Histomorfologia da região dorsal anterior da língua de animal controle. Observe as papilas e a relação epitélio/conjuntivo. Aumento 40x. 


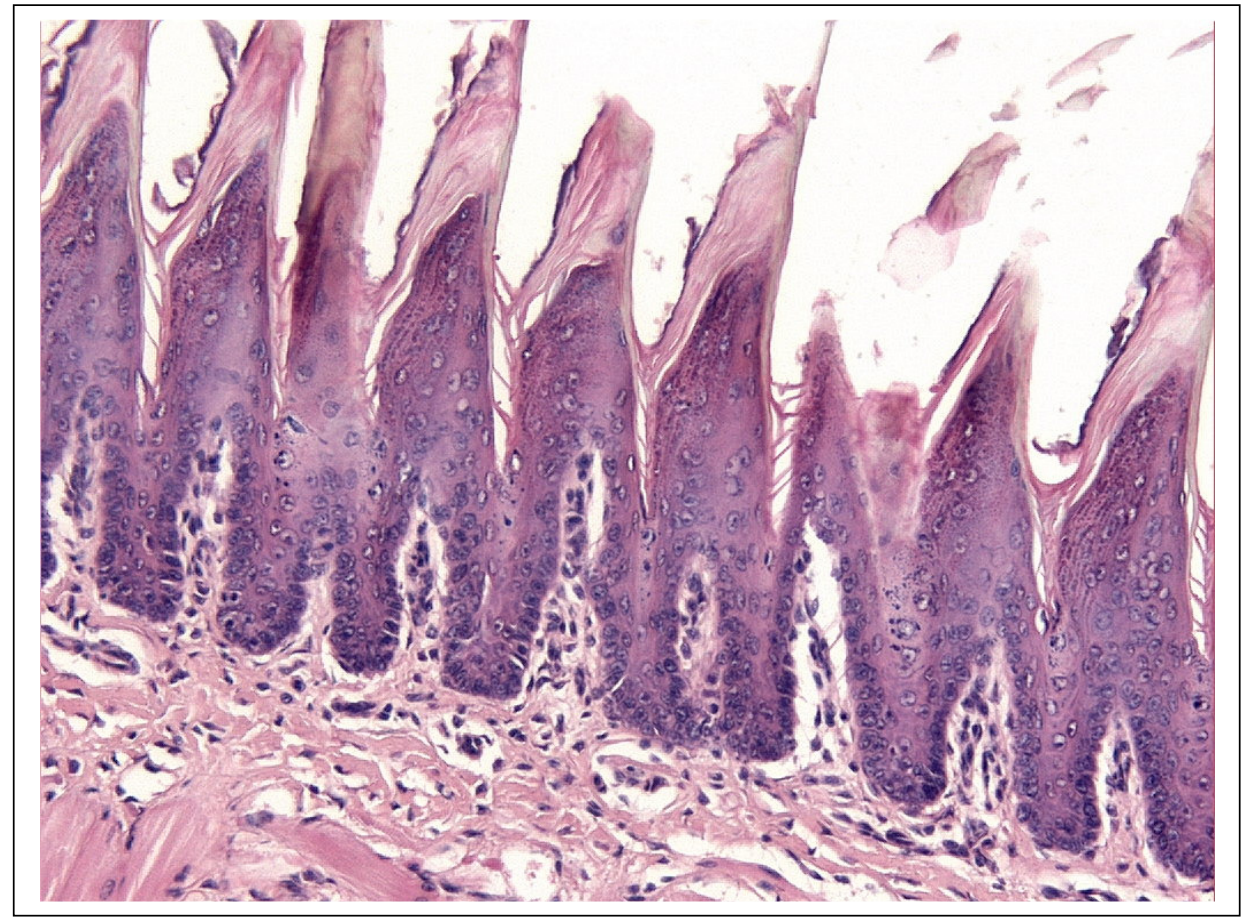

FIGURA 4 - Histomorfologia da região dorsal intermediária da língua de animal controle. Observe as papilas e a relação epitélio/conjuntivo. Aumento 20x.

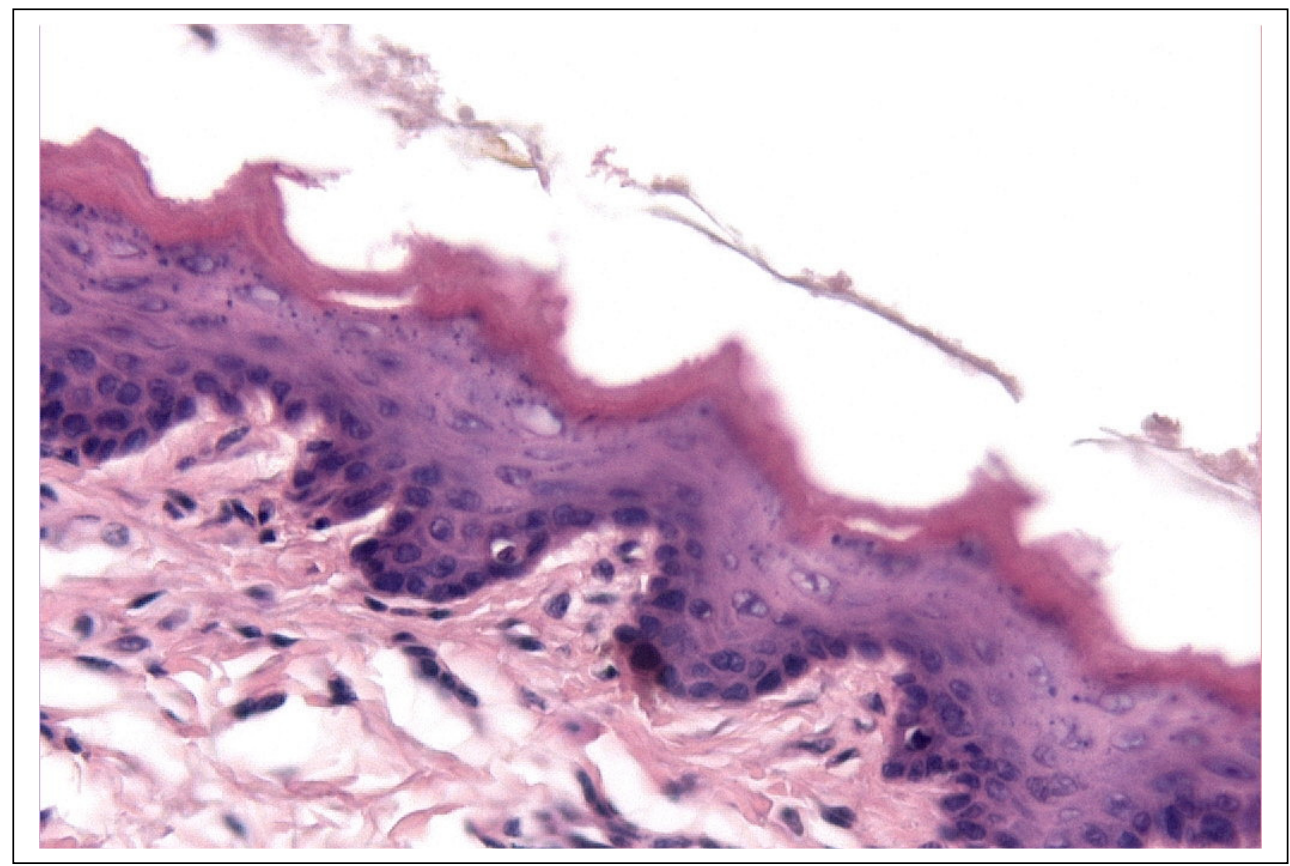

FIGURA 5 - Histomorfologia da região dorsal posterior da língua de animal controle. Observe a relação epitélio/conjuntivo. Aumento 40x. 


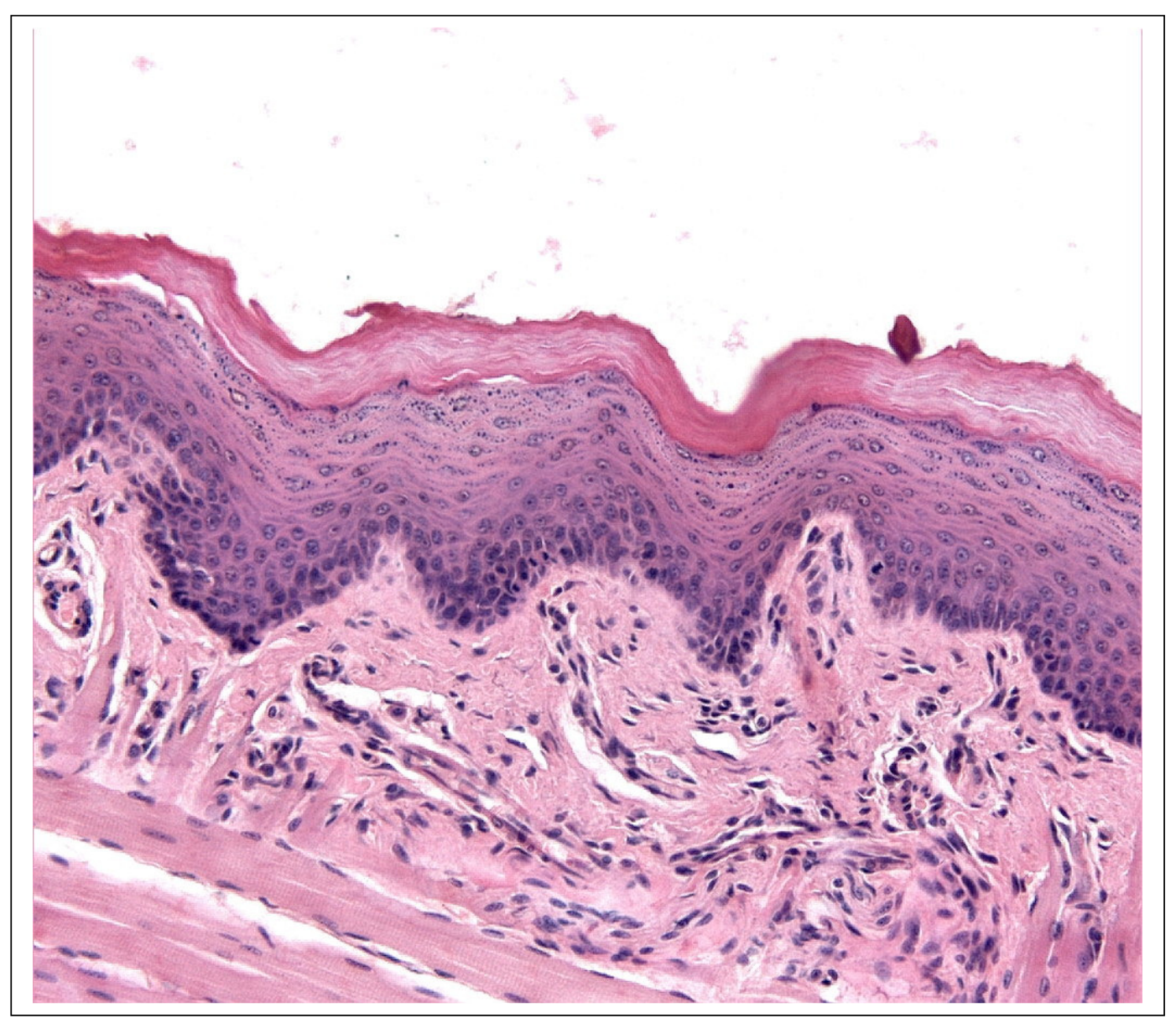

FIGURA 6 - Histomorfologia da região ventral da língua de animal controle. Observe as camadas basal, espinhosa e córnea bem identificáveis, e observe também a relação epitélio/conjuntivo. Aumento 20x

As tabelas a seguir nos mostram os valores obtidos pela avaliação dos parâmetros cariométricos e estereológicos das células do epitélio da língua. 


\subsection{1 - Cariometria do epitélio da língua}

TABELA 16 - Avaliação do tamanho dos núcleos das células do epitélio da língua (região dorsal anterior) dos animais controle e tratados com inibidor de protease.

\begin{tabular}{|c|c|c|c|c|c|c|}
\hline \multirow{2}{*}{$\begin{array}{l}\text { Estrutura } \\
\text { Estudada }\end{array}$} & \multicolumn{2}{|c|}{ Animais Controle } & \multicolumn{2}{|c|}{ Tratados - 4 semanas } & \multicolumn{2}{|c|}{ Tratados - 8 semanas } \\
\hline & C.Basal & C.Espinhosa & C.basal & C.espinhosa & C.basal & C.espinhosa \\
\hline \multirow{7}{*}{$\begin{array}{l}\text { Diâmetro } \\
\text { maior }\end{array}$} & 5.24 & 5.26 & 5.96 & 6.68 & 6.10 & 7.14 \\
\hline & 5.70 & 5.88 & 6.00 & 7.06 & 6.26 & 7.14 \\
\hline & 5.84 & 5.50 & 6.18 & 6.86 & 6.36 & 6.92 \\
\hline & 5.80 & 5.54 & 6.32 & 7.16 & 6.10 & 6.72 \\
\hline & 5.64 & 5.80 & 6.00 & 6.78 & 6.10 & 6.88 \\
\hline & $5.64 \pm 0.23$ & $5.59 \pm 0.28$ & $6.09 \pm 0.15$ & $6.90 \pm 0.19$ & $6.18 \pm 0.12$ & $6.96 \pm 0.18$ \\
\hline & & & $\uparrow$ & $\uparrow$ & $\uparrow$ & $\uparrow$ \\
\hline \multirow{7}{*}{$\begin{array}{l}\text { Diâmetro } \\
\text { menor }\end{array}$} & 4.20 & 4.40 & 4.46 & 5.18 & 4.18 & 5.18 \\
\hline & 4.28 & 4.54 & 4.58 & 5.24 & 4.04 & 4.94 \\
\hline & 3.94 & 4.56 & 4.16 & 4.94 & 3.94 & 4.94 \\
\hline & 4.10 & 4.82 & 4.56 & 5.32 & 4.12 & 4.80 \\
\hline & 3.84 & 4.46 & 4.52 & 5.38 & 4.20 & 5.06 \\
\hline & $4.07 \pm 0.18$ & $4.55 \pm 0.16$ & $4.45 \pm 0.17$ & $5.21 \pm 0.17$ & $4.09 \pm 0.10$ & $4.98 \pm 0.14$ \\
\hline & & & 个 & $\uparrow$ & $\uparrow$ & $\uparrow$ \\
\hline \multirow{7}{*}{$\begin{array}{l}\text { Volume } \\
\text { nuclear }\end{array}$} & 55.41 & 58.96 & 72.80 & 107.83 & 69.19 & 118.97 \\
\hline & 64.63 & 73.03 & 76.46 & 119.76 & 67.82 & 113.18 \\
\hline & 60.18 & 66.85 & 69.53 & 105.32 & 67.24 & 104.83 \\
\hline & 61.69 & 73.91 & 81.60 & 124.99 & 67.44 & 097.54 \\
\hline & 54.70 & 69.62 & 74.39 & 117.83 & 69.00 & 110.18 \\
\hline & $59.32 \pm 4.21$ & $68.47 \pm 6.01$ & $74.95 \pm 4.49$ & $115.14 \pm 8.29$ & $68.13 \pm 0.90$ & $108.94 \pm 8.16$ \\
\hline & & & $\uparrow$ & $\uparrow$ & $\uparrow$ & $\uparrow$ \\
\hline \multirow{7}{*}{$\begin{array}{c}\text { Área } \\
\text { nuclear }\end{array}$} & 17.36 & 18.19 & 20.89 & 27.17 & 20.12 & 29.04 \\
\hline & 19.24 & 20.94 & 21.60 & 29.12 & 19.90 & 29.90 \\
\hline & 18.24 & 19.73 & 20.23 & 26.70 & 19.76 & 26.73 \\
\hline & 18.66 & 21.08 & 22.60 & 29.96 & 19.79 & 25.37 \\
\hline & 17.12 & 20.31 & 21.25 & 28.76 & 20.15 & 27.44 \\
\hline & $18.12 \pm 0.88$ & $20.05 \pm 1,17$ & $21.31 \pm 0.87$ & $28.34 \pm 1.36$ & $19.94 \pm 0.18$ & $27.69 \pm 1.80$ \\
\hline & & & $\uparrow$ & $\uparrow$ & $\uparrow$ & $\uparrow$ \\
\hline \multirow{7}{*}{$\begin{array}{c}\text { Perímetro } \\
\text { nuclear }\end{array}$} & 14.91 & 15.23 & 16.49 & 19.19 & 16.35 & 18.91 \\
\hline & 15.79 & 16.48 & 16.73 & 19.75 & 16.24 & 18.26 \\
\hline & 15.55 & 15.87 & 16.43 & 18.69 & 16.44 & 18.80 \\
\hline & 15.71 & 16.31 & 17.24 & 19.46 & 16.40 & 19.17 \\
\hline & 15.07 & 16.22 & 16.64 & 18.74 & 16.32 & 19.51 \\
\hline & $15.40 \pm 0.39$ & $16.02 \pm 0.49$ & $16.70 \pm 0.32$ & $19.16 \pm 0.45$ & $16.35 \pm 0.07$ & $18.93 \pm 0.46$ \\
\hline & & & $\uparrow$ & $\uparrow$ & $\uparrow$ & $\uparrow$ \\
\hline
\end{tabular}

Obs: Estão expressos nesta tabela os dados relativos a: Diâmetro maior em micrometros $(\mu \mathrm{m})$, diâmetro menor $(\mathrm{em} \mu \mathrm{m})$, perímetro do núcleo celular $(\mathrm{em} \mu \mathrm{m})$, área nuclear em micrometros quadrados $\left(\mu \mathrm{m}^{2}\right)$, e volume nuclear em micrometros cúbicos $\left(\mu \mathrm{m}^{3}\right)$. 
TABELA 17 - Avaliação dos efeitos da utilização de inibidor de protease sobre os parâmetros do tamanho dos núcleos das células da camada basal do epitélio da língua (região dorsal anterior) dos animais controles e tratados - Avaliação pelo teste Kruskal-Wallis.

\title{
DIÂMETRO MAIOR
}

Valor de $\mathrm{H}=10.0699$

Valor de $\mathrm{x}^{2} \mathrm{p} / 2^{\circ}$ de liberdade $=10.07$

Probabilidade de $\mathrm{HO}=0.65 \%$

Controle X 4

semanas

$1 \%$

Significante para $\alpha \leq 0.01$

\begin{tabular}{c|c}
$\begin{array}{c}\text { Controle } X 8 \\
\text { semanas } \\
0.1 \%\end{array}$ & 4 sem $X 8$ sem \\
\hline
\end{tabular}

\section{DIÂMETRO MENOR}

Valor de $\mathrm{H}=6.6437$

Valor de $x^{2} p / 2^{\circ}$ de liberdade $=6.64$

Probabilidade de $\mathrm{HO}=3.71 \%$

Significante para $\alpha \leq 0.05$

\begin{tabular}{|c|c|c|}
\hline $\begin{array}{c}\text { Controle X 4 } \\
\text { semanas } \\
5 \%\end{array}$ & $\begin{array}{c}\text { Controle X 8 } \\
\text { semanas } \\
\text { NS }\end{array}$ & 4 sem X 8 sem \\
\hline
\end{tabular}

\section{VOLUME NUCLEAR}

Valor de $\mathrm{H}=12.5000$

Valor de $x^{2} \mathrm{p} / 2^{\circ}$ de liberdade $=12.50$

Probabilidade de $\mathrm{H} 0=0.19 \%$

Significante para $\alpha \leq 0.01$

\section{ÁREA NUCLEAR}

Valor de $\mathrm{H}=12.5000$

Valor de $x^{2} p / 2^{\circ}$ de liberdade $=12.50$

Probabilidade de $\mathrm{HO}=0.19 \%$

Significante para $\alpha \leq 0.01$

\section{PERIMETRO NUCLEAR}

Valor de $\mathrm{H}=12.0200$

Valor de $x^{2} p / 2^{\circ}$ de liberdade $=12.02$

Probabilidade de $\mathrm{HO}=0.25 \%$

\begin{tabular}{c|c|c}
$\begin{array}{c}\text { Controle X } 4 \\
\text { semanas } \\
0.1 \%\end{array}$ & $\begin{array}{c}\text { Controle X 8 } \\
\text { semanas } \\
0.1 \%\end{array}$ & 4 sem X 8 sem \\
\hline
\end{tabular}

Significante para $\alpha \leq 0.01$

\begin{tabular}{|c|c|c|}
\hline $\begin{array}{c}\text { Controle X } 4 \\
\text { semanas } \\
0.1 \%\end{array}$ & $\begin{array}{c}\text { Controle X 8 } \\
\text { semanas }\end{array}$ & 4 sem X 8 sem \\
$0.1 \%$ & $1 \%$ \\
\hline
\end{tabular}

\section{(n)}


TABELA 18- Avaliação dos efeitos da utilização de inibidor de protease sobre os parâmetros do tamanho dos núcleos das células da camada espinhosa do epitélio da língua (região dorsal anterior) dos animais controles e tratados - Avaliação pelo teste Kruskal-Wallis.

\begin{tabular}{|c|c|c|c|}
\hline \multicolumn{4}{|l|}{ DIÂMETRO MAIOR } \\
\hline \multirow{2}{*}{$\begin{array}{l}\text { Valor de } H=9.5170 \\
\text { Valor de } x^{2} p / 2^{\circ} \text { de liberdade }=9.52 \\
\text { Probabilidade de } H 0=0.86 \%\end{array}$} & Controle X 4 & Controle X 8 & $4 \mathrm{sem} X 8 \mathrm{sem}$ \\
\hline & $\begin{array}{c}\text { semanas } \\
1 \%\end{array}$ & $\begin{array}{c}\text { semanas } \\
0.1 \%\end{array}$ & \\
\hline \\
\hline \multicolumn{4}{|l|}{ DIÂMETRO MENOR } \\
\hline \multirow{2}{*}{$\begin{array}{l}\text { Valor de } H=10.5391 \\
\text { Valor de } x^{2} p / 2^{\circ} \text { de liberdade }=10.54 \\
\text { Probabilidade de } H 0=0.51 \%\end{array}$} & $\begin{array}{l}\text { Controle X } 4 \\
\text { semanas }\end{array}$ & $\begin{array}{c}\text { Controle X } 8 \\
\text { semanas }\end{array}$ & $4 \mathrm{sem} X 8 \mathrm{sem}$ \\
\hline & $0.1 \%$ & $1 \%$ & $5 \%$ \\
\hline \multicolumn{4}{|l|}{ Significante para $\alpha \leq 0.01$} \\
\hline \multicolumn{4}{|l|}{ VOLUME NUCLEAR } \\
\hline \multirow{2}{*}{$\begin{array}{l}\text { Valor de } \mathrm{H}=9.9800 \\
\text { Valor de } \mathrm{x}^{2} \mathrm{p} / 2^{\circ} \text { de liberdade }=9.98 \\
\text { Probabilidade de } \mathrm{H} 0=0.68 \%\end{array}$} & Controle X 4 & Controle X 8 & $4 \mathrm{sem} X 8 \mathrm{sem}$ \\
\hline & $0.1 \%$ & $1 \%$ & NS \\
\hline \multirow{2}{*}{\multicolumn{4}{|c|}{$\begin{array}{l}\text { Significante para } \alpha \leq 0.01 \\
\text { ÁREA NUCLEAR }\end{array}$}} \\
\hline & & & \\
\hline \multirow{2}{*}{$\begin{array}{l}\text { Valor de } H=9.5000 \\
\text { Valor de } x^{2} p / 2^{\circ} \text { de liberdade }=9.50 \\
\text { Probabilidade de } \mathrm{H} 0=0.87 \%\end{array}$} & $\begin{array}{l}\text { Controle X } 4 \\
\text { semanas }\end{array}$ & $\begin{array}{c}\text { Controle X } 8 \\
\text { semanas }\end{array}$ & $4 \mathrm{sem} X 8 \mathrm{sem}$ \\
\hline & $0.1 \%$ & $1 \%$ & NS \\
\hline \multicolumn{4}{|l|}{ Significante para $\alpha \leq 0.01$} \\
\hline \multicolumn{4}{|l|}{ PERÍMETRO NUCLEAR } \\
\hline \multirow{2}{*}{$\begin{array}{l}\text { Valor de } H=9.5000 \\
\text { Valor de } x^{2} p / 2^{\circ} \text { de liberdade }=9.50 \\
\text { Probabilidade de } H 0=0.87 \%\end{array}$} & $\begin{array}{c}\text { Controle X } 4 \\
\text { semanas }\end{array}$ & $\begin{array}{l}\text { Controle X } 8 \\
\text { semanas }\end{array}$ & $4 \mathrm{sem} X 8 \mathrm{sem}$ \\
\hline & $0.1 \%$ & $1 \%$ & NS \\
\hline Significante para $\alpha \leq 0.01$ & & & \\
\hline
\end{tabular}


TABELA 19 - Avaliação dos parâmetros avaliação da forma dos núcleos das células epiteliais da língua (região dorsal anterior) dos animais controles e tratados com inibidor de protease.

\begin{tabular}{|c|c|c|c|c|c|c|}
\hline \multirow{2}{*}{$\begin{array}{l}\text { Estrutura } \\
\text { Estudada }\end{array}$} & \multicolumn{2}{|c|}{ Animais Controle } & \multicolumn{2}{|c|}{ Tratados - 4 semanas } & \multicolumn{2}{|c|}{ Tratados - 8 semanas } \\
\hline & C.Basal & C.Espinhosa & C.basal & C.espinhosa & C.basal & C.espinhosa \\
\hline Relação & 1.29 & 1.22 & 1.37 & 1.31 & 1.49 & 1.40 \\
\hline \multirow[t]{6}{*}{$\mathrm{DM} / \mathrm{dm}$} & 1.36 & 1.33 & 1.33 & 1.37 & 1.59 & 1.47 \\
\hline & 1.53 & 1.23 & 1.52 & 1.41 & 1.66 & 1.43 \\
\hline & 1.46 & 1.16 & 1.41 & 1.37 & 1.52 & 1.42 \\
\hline & 1.53 & 1.32 & 1.36 & 1.28 & 1.48 & 1.38 \\
\hline & $1.43 \pm 0.10$ & $1.25 \pm 0.07$ & $1.39 \pm 0.07$ & $1.34 \pm 0.05$ & $1.54 \pm 0.07$ & $1.42 \pm 0.03$ \\
\hline & & & $\downarrow$ & $\uparrow$ & $\uparrow$ & $\uparrow$ \\
\hline \multirow{7}{*}{$\begin{array}{c}\text { Relação } \\
\text { Vol./Área }\end{array}$} & 3.11 & 3.20 & 3.42 & 3.91 & 3.35 & 4.04 \\
\hline & 3.28 & 3.43 & 3.48 & 4.04 & 3.34 & 3.95 \\
\hline & 3.18 & 3.33 & 3.37 & 3.87 & 3.32 & 3.88 \\
\hline & 3.23 & 3.44 & 3.57 & 4.10 & 3.33 & 3.77 \\
\hline & 3.08 & 3.38 & 3.46 & 4.01 & 3.36 & 3.92 \\
\hline & $3.17 \pm 0.08$ & $3.35 \pm 0.09$ & $3.46 \pm 0.07$ & $3.98 \pm 0.09$ & $3.34 \pm 0.01$ & $3.91 \pm 0.09$ \\
\hline & & & $\uparrow$ & $\uparrow$ & $\uparrow$ & $\uparrow$ \\
\hline \multirow{7}{*}{$\begin{array}{l}\text { Índice de } \\
\text { contorno }\end{array}$} & 3.61 & 3.58 & 3.63 & 3.61 & 3.66 & 3.63 \\
\hline & 3.63 & 3.62 & 3.62 & 3.62 & 3.68 & 3.64 \\
\hline & 3.68 & 3.59 & 3.68 & 3.64 & 3.73 & 3.65 \\
\hline & 3.66 & 3.57 & 3.64 & 3.63 & 3.70 & 3.66 \\
\hline & 3.69 & 3.61 & 3.62 & 3.60 & 3.66 & 3.63 \\
\hline & $3.65 \pm 0.03$ & $3.59 \pm 0.02$ & $3.63 \pm 0.02$ & $3.62 \pm 0.01$ & $3.68 \pm 0.02$ & $3.64 \pm 0.01$ \\
\hline & & & $\downarrow$ & $\uparrow$ & $\uparrow$ & $\uparrow$ \\
\hline \multirow{7}{*}{$\begin{array}{l}\text { Coeficiente } \\
\text { De forma }\end{array}$} & 0.97 & 0.98 & 0.96 & 0.97 & 0.94 & 0.95 \\
\hline & 0.96 & 0.96 & 0.96 & 0.96 & 0.92 & 0.94 \\
\hline & 0.93 & 0.98 & 0.93 & 0.95 & 0.91 & 0.95 \\
\hline & 0.94 & 0.99 & 0.95 & 0.96 & 0.93 & 0.95 \\
\hline & 0.93 & 0.96 & 0.96 & 0.97 & 0.94 & 0.95 \\
\hline & $0.94 \pm 0.01$ & $0.97 \pm 0.01$ & $0.95 \pm 0.01$ & $0.96 \pm 0.00$ & $0.92 \pm 0.01$ & $0.94 \pm 0.00$ \\
\hline & & & $\uparrow$ & $\downarrow$ & $\downarrow$ & $\downarrow$ \\
\hline \multirow{7}{*}{$\begin{array}{l}\text { Excentrici- } \\
\text { dade }\end{array}$} & 0.49 & 0.41 & 0.59 & 0.53 & 0.68 & 0.58 \\
\hline & 0.58 & 0.51 & 0.55 & 0.61 & 0.69 & 0.63 \\
\hline & 0.69 & 0.41 & 0.70 & 0.66 & 0.77 & 0.64 \\
\hline & 0.63 & 0.35 & 0.63 & 0.60 & 0.74 & 0.68 \\
\hline & 0.67 & 0.54 & 0.57 & 0.52 & 0.70 & 0.63 \\
\hline & $0.61 \pm 0.08$ & $0.44 \pm 0.07$ & $0.60 \pm 0.05$ & $0.58 \pm 0.05$ & $0.71 \pm 0.03$ & $0.63 \pm 0.03$ \\
\hline & & & $\downarrow$ & $\uparrow$ & $\uparrow$ & $\uparrow$ \\
\hline
\end{tabular}

Obs: Estão expressos nesta tabela os dados relativos a: Relação Diâmetro maior/Diâmetro menor (DM/dm), Relação volume/área (Vol./Área), coeficiente de forma, índice de contorno, e excentricidade. 
TABELA 20 - Avaliação dos efeitos da utilização de inibidor de protease sobre os parâmetros da forma dos núcleos das células da camada basal do epitélio da língua (região dorsal anterior) dos animais controles e tratados - Avaliação pelo teste Kruskal-Wallis

\begin{tabular}{|c|c|c|c|}
\hline \multicolumn{4}{|c|}{ DIÂMETRO MAIOR / DIÂMETRO MENOR } \\
\hline \multirow{3}{*}{$\begin{array}{l}\text { Valor de } \mathrm{H}=4.5594 \\
\text { Valor de } \mathrm{x}^{2} \mathrm{p} / 2^{\circ} \text { de liberdade }=4.56 \\
\text { Probabilidade de } \mathrm{H} 0=10.23 \%\end{array}$} & Controle X 4 & Controle X 8 & 4 sem $X 8$ sem \\
\hline & semanas & semanas & \\
\hline & & NS & $5 \%$ \\
\hline \multicolumn{4}{|l|}{ Significante para $\alpha \leq 0.05$} \\
\hline \multicolumn{4}{|c|}{ VOLUME NUCLEAR / ÁREA NUCLEAR } \\
\hline \multirow{2}{*}{$\begin{array}{l}\text { Valor de } \mathrm{H}=12.5000 \\
\text { Valor de } \mathrm{x}^{2} \mathrm{p} / 2^{\circ} \text { de liberdade }=12.50 \\
\text { Probabilidade de } \mathrm{HO}=0.19 \%\end{array}$} & Controle X 4 & Controle X 8 & $4 \mathrm{sem} X 8 \mathrm{sem}$ \\
\hline & $\begin{array}{c}\text { semanas } \\
0.1 \%\end{array}$ & $\begin{array}{l}\text { semanas } \\
0.1 \%\end{array}$ & \\
\hline \multirow{2}{*}{\multicolumn{4}{|c|}{$\begin{array}{l}\text { Significante para } \alpha \leq 0.01 \\
\text { ÍNDICE DE CONTORNO }\end{array}$}} \\
\hline & & & \\
\hline \multirow{2}{*}{$\begin{array}{l}\text { Valor de } H=4.5258 \\
\text { Valor de } x^{2} p / 2^{\circ} \text { de liberdade }=4.53 \\
\text { Probabilidade de } H 0=10.40 \%\end{array}$} & Controle X 4 & Controle X 8 & 4 sem $X 8$ sem \\
\hline & NS & NS & $5 \%$ \\
\hline \multirow{2}{*}{\multicolumn{4}{|c|}{$\begin{array}{l}\text { Significante para } \alpha \leq 0.05 \\
\text { COEFICIENTE DE FORMA }\end{array}$}} \\
\hline & \multicolumn{3}{|c|}{ COEFICIENTE DE FORMA } \\
\hline \multirow{2}{*}{$\begin{array}{l}\text { Valor de } \mathrm{H}=4.5604 \\
\text { Valor de } \mathrm{x}^{2} \mathrm{p} / 2^{\circ} \text { de liberdade }=4,56 \\
\text { Probabilidade de } \mathrm{H} 0=10.23 \%\end{array}$} & Controle X 4 & Controle X 8 & 4 sem $X 8$ sem \\
\hline & $\begin{array}{l}\text { semanas } \\
\text { NS }\end{array}$ & $\begin{array}{l}\text { semanas } \\
\text { NS }\end{array}$ & $5 \%$ \\
\hline \multicolumn{4}{|l|}{ Significante para $\alpha \leq 0.05$} \\
\hline \multicolumn{4}{|l|}{ EXCENTRICIDADE } \\
\hline \multirow{2}{*}{$\begin{array}{l}\text { Valor de } \mathrm{H}=6.6557 \\
\text { Valor de } \mathrm{x}^{2} \mathrm{p} / 2^{\circ} \text { de liberdade }=6.66 \\
\text { Probabilidade de } \mathrm{H} 0=3.59 \%\end{array}$} & Controle X 4 & Controle X 8 & 4 sem $X 8$ sem \\
\hline & $\begin{array}{l}\text { semanas } \\
\text { NS }\end{array}$ & $\begin{array}{c}\text { semanas } \\
5 \%\end{array}$ & $5 \%$ \\
\hline Significante para $\alpha \leq 0.05$ & & & \\
\hline
\end{tabular}


TABELA 21 - Avaliação dos efeitos da utilização de inibidor de protease sobre os parâmetros da forma dos núcleos das células da camada espinhosa do epitélio da língua (região dorsal anterior) dos animais controles e tratados - Avaliação pelo teste Kruskal-Wallis

\begin{tabular}{|c|c|c|c|}
\hline \multicolumn{4}{|c|}{ DIÂMETRO MAIOR / DIÂMETRO MENOR } \\
\hline \multirow{2}{*}{$\begin{array}{l}\text { Valor de } H=9.7574 \\
\text { Valor de } x^{2} p / 2^{\circ} \text { de liberdade }=9.76 \\
\text { Probabilidade de } H 0=0.76 \%\end{array}$} & $\begin{array}{c}\text { Controle X } 4 \\
\text { semanas }\end{array}$ & $\begin{array}{c}\text { Controle X } 8 \\
\text { semanas }\end{array}$ & $4 \mathrm{sem} X 8 \mathrm{sem}$ \\
\hline & $5 \%$ & $0.1 \%$ & $5 \%$ \\
\hline \multicolumn{4}{|l|}{ Significante para $\alpha \leq 0.01$} \\
\hline \multicolumn{4}{|c|}{ VOLUME NUCLEAR / ÁREA NUCLEAR } \\
\hline \multirow{2}{*}{$\begin{array}{l}\text { Valor de } H=9.7123 \\
\text { Valor de } \mathrm{x}^{2} \mathrm{p} / 2^{\circ} \text { de liberdade }=9.71 \\
\text { Probabilidade de } \mathrm{H} 0=0.78 \%\end{array}$} & $\begin{array}{c}\text { Controle X } 4 \\
\text { semanas }\end{array}$ & $\begin{array}{c}\text { Controle X } 8 \\
\text { semanas }\end{array}$ & 4 sem $X 8$ sem \\
\hline & $0.1 \%$ & $1 \%$ & NS \\
\hline \multicolumn{4}{|l|}{ Significante para $\alpha \leq 0.01$} \\
\hline \multicolumn{4}{|l|}{ ÍNDICE DE CONTORNO } \\
\hline \multirow{2}{*}{$\begin{array}{l}\text { Valor de } H=9.1494 \\
\text { Valor de } x^{2} p / 2^{\circ} \text { de liberdade }=9.15 \\
\text { Probabilidade de } H 0=1.03 \%\end{array}$} & $\begin{array}{c}\text { Controle X } 4 \\
\text { semanas }\end{array}$ & $\begin{array}{c}\text { Controle X } 8 \\
\text { semanas }\end{array}$ & 4 sem $X 8$ sem \\
\hline & $5 \%$ & $0.1 \%$ & $5 \%$ \\
\hline \multicolumn{4}{|l|}{ Significante para $\alpha \leq 0.01$} \\
\hline \multicolumn{4}{|l|}{ COEFICIENTE DE FORMA } \\
\hline \multirow{2}{*}{$\begin{array}{l}\text { Valor de } \mathrm{H}=9.6091 \\
\text { Valor de } \mathrm{x}^{2} \mathrm{p} / 2^{\circ} \text { de liberdade }=9.61 \\
\text { Probabilidade de } \mathrm{H} 0=0.82 \%\end{array}$} & $\begin{array}{c}\text { Controle X } 4 \\
\text { semanas }\end{array}$ & $\begin{array}{c}\text { Controle X } 8 \\
\text { semanas }\end{array}$ & 4 sem $X 8$ sem \\
\hline & NS & $0.1 \%$ & $1 \%$ \\
\hline \multicolumn{4}{|l|}{ Significante para $\alpha \leq 0.01$} \\
\hline \multicolumn{4}{|l|}{ EXCENTRICIDADE } \\
\hline \multirow{2}{*}{$\begin{array}{l}\text { Valor de } H=9.0925 \\
\text { Valor de } x^{2} p / 2^{\circ} \text { de liberdade }=9.09 \\
\text { Probabilidade de } H 0=1.06 \%\end{array}$} & $\begin{array}{c}\text { Controle X } 4 \\
\text { semanas }\end{array}$ & $\begin{array}{c}\text { Controle X } 8 \\
\text { semanas }\end{array}$ & 4 sem $X 8$ sem \\
\hline & $5 \%$ & $0.1 \%$ & NS \\
\hline
\end{tabular}


TABELA 22 - Avaliação do tamanho dos núcleos das células do epitélio da língua (região dorsal intermediária) dos animais controle e tratados com inibidor de protease.

\begin{tabular}{|c|c|c|c|c|c|c|}
\hline \multirow{2}{*}{$\begin{array}{l}\text { Estrutura } \\
\text { Estudada }\end{array}$} & \multicolumn{2}{|c|}{ Animais Controle } & \multicolumn{2}{|c|}{ Tratados - 4 semanas } & \multicolumn{2}{|c|}{ Tratados - 8 semanas } \\
\hline & C.Basal & C.Espinn. & C.basal & C.espinh. & C.basal & C.espinh. \\
\hline \multirow{7}{*}{$\begin{array}{l}\text { Diâmetro } \\
\text { maior }\end{array}$} & 4.94 & 5.54 & 5.26 & 5.48 & 5.88 & 6.22 \\
\hline & 5.30 & 5.32 & 5.72 & 5.72 & 5.80 & 6.00 \\
\hline & 4.98 & 5.26 & 5.64 & 5.86 & 5.68 & 5.84 \\
\hline & 5.22 & 5.66 & 5.60 & 5.96 & 5.80 & 5.68 \\
\hline & 5.18 & 5.30 & 5.50 & 5.68 & 5.76 & 5.76 \\
\hline & $5.12 \pm 0.15$ & $5.41 \pm 0.17$ & $5.54 \pm 0.17$ & $5.74 \pm 0.18$ & $5.78 \pm 0.07$ & $5.90 \pm 0.21$ \\
\hline & & & $\uparrow$ & $\uparrow$ & $\uparrow$ & $\uparrow$ \\
\hline \multirow{7}{*}{$\begin{array}{l}\text { Diâmetro } \\
\text { menor }\end{array}$} & 4.20 & 4.46 & 4.20 & 4.42 & 4.56 & 4.46 \\
\hline & 4.48 & 4.38 & 4.54 & 4.68 & 4.28 & 4.42 \\
\hline & 4.10 & 4.28 & 4.44 & 4.60 & 4.46 & 4.36 \\
\hline & 4.40 & 4.60 & 4.30 & 4.62 & 4.46 & 4.38 \\
\hline & 4.32 & 4.36 & 4.36 & 4.38 & 4.34 & 4.44 \\
\hline & $4.30 \pm 0.15$ & $4.41 \pm 0.12$ & $4.56 \pm 0.55$ & $4.54 \pm 0.13$ & $4.42 \pm 0.11$ & $4.41 \pm 0.04$ \\
\hline & & & $\uparrow$ & $\uparrow$ & $\uparrow$ & \\
\hline \multirow{7}{*}{$\begin{array}{l}\text { Volume } \\
\text { nuclear }\end{array}$} & 50.77 & 59.36 & 55.51 & 63.69 & 72.05 & 77.15 \\
\hline & 62.04 & 70.25 & 65.33 & 74.01 & 65.62 & 72.56 \\
\hline & 49.53 & 57.08 & 56.43 & 74.18 & 67.45 & 67.56 \\
\hline & 52.99 & 59.82 & 62.37 & 76.47 & 68.81 & 65.81 \\
\hline & 57.06 & 65.32 & 62.29 & 65.65 & 66.56 & 68.11 \\
\hline & $54.47 \pm 5.10$ & $62.36 \pm 5.34$ & $60.38 \pm 4.22$ & $70.80 \pm 5.72$ & $68.09 \pm 2.50$ & $70.23 \pm 4.59$ \\
\hline & & & $\uparrow$ & $\uparrow$ & $\uparrow$ & $\uparrow$ \\
\hline \multirow{7}{*}{$\begin{array}{c}\text { Área } \\
\text { nuclear }\end{array}$} & 16.38 & 19.45 & 18.85 & 19.54 & 19.67 & 16.93 \\
\hline & 18.72 & 18.33 & 18.88 & 21.61 & 20.20 & 16.50 \\
\hline & 16.12 & 17.75 & 19.68 & 21.19 & 19.89 & 16.14 \\
\hline & 18.13 & 20.45 & 20.44 & 21.11 & 19.49 & 15.98 \\
\hline & 17.70 & 18.22 & 17.42 & 19.09 & 21.11 & 16.12 \\
\hline & $17.41 \pm 1.12$ & $18.84 \pm 1,09$ & $19.05 \pm 1.12$ & $20.50 \pm 1.11$ & $20.07 \pm 0.63$ & $16.33 \pm 0.88$ \\
\hline & & & $\uparrow$ & $\uparrow$ & $\uparrow$ & $\downarrow$ \\
\hline \multirow{7}{*}{$\begin{array}{l}\text { Perímetro } \\
\text { nuclear }\end{array}$} & 14.40 & 15.78 & 14.93 & 15.90 & 15.90 & 16.93 \\
\hline & 15.42 & 15.30 & 16.19 & 16.72 & 16.23 & 16.50 \\
\hline & 14.32 & 15.05 & 15.92 & 16.52 & 16.02 & 16.14 \\
\hline & 15.16 & 16.19 & 15.65 & 16.40 & 15.96 & 15.98 \\
\hline & 14.97 & 15.23 & 15.57 & 15.62 & 16.58 & 16.12 \\
\hline & $14.85 \pm 0.47$ & $15.51 \pm 0.46$ & $15.65 \pm 0.47$ & $16.23 \pm 0.45$ & $16.13 \pm 0.27$ & $16.33 \pm 0.38$ \\
\hline & & & $\uparrow$ & $\uparrow$ & $\uparrow$ & $\uparrow$ \\
\hline
\end{tabular}

Obs: Estão expressos nesta tabela os dados relativos a: Diâmetro maior em micrometros $(\mu \mathrm{m})$, diâmetro menor $(\mathrm{em} \mu \mathrm{m})$, perímetro do núcleo celular (em $\mu \mathrm{m})$, área nuclear em micrometros quadrados $\left(\mu \mathrm{m}^{2}\right)$, e volume nuclear em micrometros cúbicos $\left(\mu \mathrm{m}^{3}\right)$. 
TABELA 23 - Avaliação dos efeitos da utilização de inibidor de protease sobre os parâmetros do tamanho dos núcleos das células da camada basal do epitélio da língua (região dorsal intermediária) dos animais controles e tratados - Avaliação pelo teste Kruskal-Wallis.

\section{DIÂMETRO MAIOR}

Valor de $\mathrm{H}=11.5406$

Valor de $x^{2} p / 2^{\circ}$ de liberdade $=11.54$

Probabilidade de $\mathrm{HO}=0.31 \%$

Significante para $\alpha \leq 0.01$

\begin{tabular}{|c|c|c|}
\hline $\begin{array}{c}\text { Controle X } 4 \\
\text { semanas }\end{array}$ & $\begin{array}{c}\text { Controle X } 8 \\
\text { semanas } \\
1 \%\end{array}$ & 4 sem X 8 sem \\
\hline & $0.1 \%$ & $1 \%$ \\
\hline
\end{tabular}

\section{DIÂMETRO MENOR}

Valor de $\mathrm{H}=1.5405$

Valor de $x^{2} p / 2^{\circ}$ de liberdade $=1.54$

Probabilidade de $\mathrm{H} 0=46.29 \%$

\begin{tabular}{|c|c|c|}
\hline $\begin{array}{c}\text { Controle X 4 } \\
\text { semanas }\end{array}$ & $\begin{array}{c}\text { Controle X 8 } \\
\text { semanas } \\
\text { NS }\end{array}$ & $\begin{array}{c}4 \text { sem X 8 sem } \\
\text { NS }\end{array}$ \\
\hline
\end{tabular}

Significante para $\alpha \leq 0.05$

\section{VOLUME NUCLEAR}

Valor de $\mathrm{H}=8.8800$

Valor de $x^{2} p / 2^{\circ}$ de liberdade $=8.88$

Probabilidade de $\mathrm{HO}=1.18 \%$

\begin{tabular}{c|c|c|}
\hline $\begin{array}{c}\text { Controle X } 4 \\
\text { semanas }\end{array}$ & $\begin{array}{c}\text { Controle X 8 } \\
\text { semanas }\end{array}$ & 4 sem X 8 sem \\
\hline $5 \%$ & $0.1 \%$ & NS \\
\hline
\end{tabular}

Significante para $\alpha \leq 0.01$

\section{ÁREA NUCLEAR}

Valor de $\mathrm{H}=8.5400$

Valor de $\mathrm{x}^{2} \mathrm{p} / 2^{\circ}$ de liberdade $=8.54$

Probabilidade de $\mathrm{HO}=1.40 \%$

\begin{tabular}{|c|c|c|}
\hline $\begin{array}{c}\text { Controle X } 4 \\
\text { semanas } \\
5 \%\end{array}$ & $\begin{array}{c}\text { Controle X 8 } \\
\text { semanas } \\
1 \%\end{array}$ & 4 sem X 8 sem \\
\hline
\end{tabular}

Significante para $\alpha \leq 0.01$

PERÍMETRO NUCLEAR

Valor de $\mathrm{H}=9.2600$

Valor de $x^{2} p / 2^{\circ}$ de liberdade $=9.26$

Probabilidade de $\mathrm{HO}=0.98 \%$

\begin{tabular}{|c|c|c|}
\hline $\begin{array}{c}\text { Controle X } 4 \\
\text { semanas }\end{array}$ & $\begin{array}{c}\text { Controle X } 8 \\
\text { semanas }\end{array}$ & 4 sem $X 8$ sem \\
\hline 50 & $0.1 \%$ & $5 \%$ \\
\hline
\end{tabular}

Significante para $\alpha \leq 0.01$ 
TABELA 24 - Avaliação dos efeitos da utilização de inibidor de protease sobre os parâmetros do tamanho dos núcleos das células da camada espinhosa do epitélio da língua (região dorsal intermediária) dos animais controles e tratados - Avaliação pelo teste Kruskal-Wallis.

\section{DIÂMETRO MAIOR}

Valor de $\mathrm{H}=8.6705$

Valor de $\mathrm{x}^{2} \mathrm{p} / 2^{\circ}$ de liberdade $=8.67$

Probabilidade de $\mathrm{H} 0=1.31 \%$

\begin{tabular}{c|c|c|}
$\begin{array}{c}\text { Controle X } 4 \\
\text { semanas } \\
5 \%\end{array}$ & $\begin{array}{c}\text { Controle X 8 } \\
\text { semanas } \\
1 \%\end{array}$ & 4 sem X 8 sem \\
\hline
\end{tabular}

Significante para $\alpha \leq 0.01$

\section{DIÂMETRO MENOR}

Valor de $\mathrm{H}=3.0236$

Valor de $\mathrm{x}^{2} \mathrm{p} / 2^{\circ}$ de liberdade $=3.03$

Probabilidade de $\mathrm{H} 0=22.00 \%$

Controle X 4 semanas NS

Significante para $\alpha \leq 0.05$

\section{VOLUME NUCLEAR}

Valor de $\mathrm{H}=5.4200$

Valor de $\mathrm{x}^{2} \mathrm{p} / 2^{\circ}$ de liberdade $=5.42$

Probabilidade de $\mathrm{H} 0=6.65 \%$

Significante para $\alpha \leq 0.05$

\section{ÁREA NUCLEAR}

Valor de $\mathrm{H}=11.1800$

Valor de $x^{2} p / 2^{\circ}$ de liberdade $=$

11.18

Probabilidade de $\mathrm{H} 0=0.37 \%$

Significante para $\alpha \leq 0.01$

\section{PERIMETRO NUCLEAR}

Valor de $\mathrm{H}=5.4600$

Valor de $\mathrm{x}^{2} \mathrm{p} / 2^{\circ}$ de liberdade $=5.46$

Probabilidade de $\mathrm{H} 0=6.52 \%$

Controle X 4
semanas
$5 \%$

Controle X 4

semanas

$5 \%$

Controle X 4

Controle X 8

4 sem $X 8$ sem

semanas

semanas

Controle X $8 \quad 4$ sem X 8 sem semanas

NS

NS

Significante para $\alpha \leq 0.05$

\begin{tabular}{|c|c|}
\hline $\begin{array}{c}\text { Controle X } 8 \\
\text { semanas } \\
5 \%\end{array}$ & 4 sem X 8 sem \\
\hline & NS \\
\hline
\end{tabular}

Controle X $8 \quad 4$ sem X 8 sem semanas

\begin{tabular}{l|l}
$1 \%$ & $0.1 \%$
\end{tabular}


TABELA 25 - Avaliação dos parâmetros avaliação da forma dos núcleos das células epiteliais da língua (região dorsal intermediária) dos animais controles e tratados com inibidor de protease.

\begin{tabular}{|c|c|c|c|c|c|c|}
\hline \multirow{2}{*}{$\begin{array}{l}\text { Estrutura } \\
\text { Estudada }\end{array}$} & \multicolumn{2}{|c|}{ Animais Controle } & \multicolumn{2}{|c|}{ Tratados - 4 semanas } & \multicolumn{2}{|c|}{ Tratados - 8 semanas } \\
\hline & C.Basal & C.Espinhosa & C.basal & C.espinhosa & C.basal & C.espinhosa \\
\hline \multirow{7}{*}{$\begin{array}{l}\text { Relação } \\
\text { DM/dm }\end{array}$} & 1.20 & 1.26 & 1.28 & 1.26 & 1.31 & 1.42 \\
\hline & 1.21 & 1.23 & 1.33 & 1.23 & 1.38 & 1.38 \\
\hline & 1.24 & 1.24 & 1.29 & 1.29 & 1.30 & 1.36 \\
\hline & 1.20 & 1.25 & 1.28 & 1.32 & 1.33 & 1.33 \\
\hline & 1.21 & 1.23 & 1.27 & 1.32 & 1.35 & 1.32 \\
\hline & $1.21 \pm 0.01$ & $1.24 \pm 0.01$ & $1.29 \pm 0.02$ & $1.28 \pm 0.03$ & $1.33 \pm 0.03$ & $1.36 \pm 0.04$ \\
\hline & & & $\uparrow$ & $\uparrow$ & $\uparrow$ & $\uparrow$ \\
\hline \multirow{7}{*}{$\begin{array}{l}\text { Relação } \\
\text { Vol./Área }\end{array}$} & 3.03 & 3.30 & 3.25 & 3.31 & 3.32 & 3.50 \\
\hline & 3.24 & 3.21 & 3.26 & 3.48 & 3.37 & 3.42 \\
\hline & 3.00 & 3.15 & 3.32 & 3.45 & 3.34 & 3.35 \\
\hline & 3.18 & 3.39 & 3.39 & 3.44 & 3.31 & 3.31 \\
\hline & 3.15 & 3.20 & 3.12 & 3.27 & 3.44 & 3.36 \\
\hline & $3.12 \pm 0.10$ & $3.25 \pm 0.09$ & $3.26 \pm 0.09$ & $3.39 \pm 0.09$ & $3.35 \pm 0.05$ & $3.38 \pm 0.11$ \\
\hline & & & $\uparrow$ & $\uparrow$ & $\uparrow$ & $\uparrow$ \\
\hline \multirow{7}{*}{$\begin{array}{l}\text { Índice de } \\
\text { contorno }\end{array}$} & 3.58 & 3.59 & 3.60 & 3.61 & 3.62 & 3.64 \\
\hline & 3.59 & 3.59 & 3.62 & 3.61 & 3.62 & 3.63 \\
\hline & 3.59 & 3.59 & 3.60 & 3.60 & 3.61 & 3.63 \\
\hline & 3.58 & 3.59 & 3.60 & 3.59 & 3.63 & 3.61 \\
\hline & 3.58 & 3.58 & 3.60 & 3.59 & 3.61 & 3.61 \\
\hline & $3.58 \pm 0.00$ & $3.58 \pm 0.00$ & $3.60 \pm 0.00$ & $3.65 \pm 0.02$ & $3.59 \pm 0.01$ & $3.66 \pm 0.02$ \\
\hline & & & $\uparrow$ & $\uparrow$ & $\uparrow$ & $\uparrow$ \\
\hline \multirow{7}{*}{$\begin{array}{c}\text { Coeficiente } \\
\text { de forma }\end{array}$} & 0.98 & 0.97 & 0.97 & 0.97 & 0.96 & 0.95 \\
\hline & 0.98 & 0.98 & 0.97 & 0.96 & 0.96 & 0.95 \\
\hline & 0.98 & 0.98 & 0.97 & 0.97 & 0.97 & 0.96 \\
\hline & 0.98 & 0.97 & 0.96 & 0.98 & 0.95 & 0.96 \\
\hline & 0.98 & 0.98 & 0.97 & 0.97 & 0.97 & 0.96 \\
\hline & $0.98 \pm 0.00$ & $0.97 \pm 0.00$ & $0.97 \pm 0.00$ & $0.97 \pm 0.00$ & $0.96 \pm 0.00$ & $0.95 \pm 0.00$ \\
\hline & & & $\downarrow$ & & $\downarrow$ & $\downarrow$ \\
\hline \multirow{7}{*}{$\begin{array}{l}\text { Excentrici- } \\
\text { dade }\end{array}$} & 0.38 & 0.48 & 0.50 & 0.55 & 0.57 & 0.62 \\
\hline & 0.37 & 0.43 & 0.53 & 0.53 & 0.49 & 0.60 \\
\hline & 0.43 & 0.47 & 0.51 & 0.53 & 0.51 & 0.57 \\
\hline & 0.38 & 0.47 & 0.52 & 0.47 & 0.57 & 0.54 \\
\hline & 0.43 & 0.45 & 0.51 & 0.46 & 0.53 & 0.54 \\
\hline & $0.39 \pm 0.06$ & $0.46 \pm 0.02$ & $0.51 \pm 0.01$ & $0.50 \pm 0.04$ & $0.53 \pm 0.03$ & $0.57 \pm 0.03$ \\
\hline & & & 个 & $\uparrow$ & $\uparrow$ & $\uparrow$ \\
\hline
\end{tabular}

Obs: Estão expressos nesta tabela os dados relativos a: Relação Diâmetro maior/Diâmetro menor (DM/dm), Relação volume/área (Vol./Área), coeficiente de forma, índice de contorno, e excentricidade. 
TABELA 26 - Avaliação dos efeitos da utilização de inibidor de protease sobre os parâmetros da forma dos núcleos das células da camada basal do epitélio da língua (região dorsal intermediária) dos animais controles e tratados - Avaliação pelo teste Kruskal-Wallis

\section{DIÂMETRO MAIOR / DIÂMETRO MENOR}

\section{Valor de $\mathrm{H}=11.4568$}

Valor de $x^{2} p / 2^{\circ}$ de liberdade $=11.46$

Probabilidade de $\mathrm{H} 0=0.33 \%$

Significante para $\alpha \leq 0.01$

\section{VOLUME NUCLEAR / ÁREA NUCLEAR}

\section{Valor de $\mathrm{H}=8.7206$}

Valor de $x^{2} p / 2^{\circ}$ de liberdade $=8.72$

Probabilidade de $\mathrm{H} 0=1.28 \%$

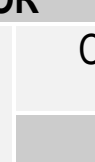

\begin{tabular}{c|c|c|}
\hline $\begin{array}{c}\text { Controle } \mathrm{X} 4 \\
\text { semanas } \\
1 \%\end{array}$ & $\begin{array}{c}\text { Controle } \mathrm{X} 8 \\
\text { semanas } \\
0.1 \%\end{array}$ & 4 sem $\mathrm{X} 8 \mathrm{sem}$ \\
\hline
\end{tabular}

Significante para $\alpha \leq 0.01$

\section{ÍNDICE DE CONTORNO}

\section{Valor de $\mathrm{H}=11.5941$}

Valor de $\mathrm{x}^{2} \mathrm{p} / 2^{\circ}$ de liberdade $=11.59$

Probabilidade de $\mathrm{H} 0=0.30 \%$

Co

\begin{tabular}{c|c|c}
$\begin{array}{c}\text { Controle } \mathrm{X} 4 \\
\text { semanas } \\
5 \%\end{array}$ & $\begin{array}{c}\text { Controle } \mathrm{X} 8 \\
\text { semanas } \\
0.1 \%\end{array}$ & 4 sem $\mathrm{X} 8$ sem \\
\hline
\end{tabular}

Significante para $\alpha \leq 0.01$

\section{COEFICIENTE DE FORMA}

\begin{tabular}{|c|c|c|c|}
\hline $\begin{array}{l}\text { Valor de } \mathrm{H}=11.1553 \\
\text { Valor de } \mathrm{x}^{2} \mathrm{p} / 2^{\circ} \text { de liberdade }=11.16 \\
\text { Probabilidade de } \mathrm{H} 0=0.38 \%\end{array}$ & $\begin{array}{c}\text { Controle X } 4 \\
\text { semanas } \\
0.1 \%\end{array}$ & $\begin{array}{l}\text { Controle X } 8 \\
\text { semanas } \\
0.1 \%\end{array}$ & $\begin{array}{c}4 \operatorname{sem} X 8 \text { sem } \\
\text { NS }\end{array}$ \\
\hline $\begin{array}{l}\text { Significante para } \alpha \leq 0.01 \\
\text { EXCENTRICIDADE }\end{array}$ & & & \\
\hline $\begin{array}{l}\text { Valor de } \mathrm{H}=9.8355 \\
\text { Valor de } \mathrm{x}^{2} \mathrm{p} / 2^{\circ} \text { de liberdade }=9.84 \\
\text { Probabilidade de } \mathrm{H} 0=0.73 \%\end{array}$ & $\begin{array}{c}\text { Controle X } 4 \\
\text { semanas } \\
1 \%\end{array}$ & $\begin{array}{l}\text { Controle X } 8 \\
\text { semanas } \\
0.1 \%\end{array}$ & $\begin{array}{c}4 \text { sem } X 8 \text { sem } \\
\text { NS }\end{array}$ \\
\hline Significante para $\alpha \leq 0.01$ & & & \\
\hline
\end{tabular}


TABELA 27 - Avaliação dos efeitos da utilização de inibidor de protease sobre os parâmetros da forma dos núcleos das células da camada espinhosa do epitélio da língua (região dorsal intermediária) dos animais controles e tratados - Avaliação pelo teste Kruskal-Wallis

\section{DIÂMETRO MAIOR / DIÂMETRO MENOR}

Valor de $\mathrm{H}=10.2497$

Valor de $x^{2} p / 2^{\circ}$ de liberdade $=10.25$

Probabilidade de $\mathrm{HO}=0.59 \%$

\begin{tabular}{c|c|c}
$\begin{array}{c}\text { Controle X } 4 \\
\text { semanas } \\
\text { NS }\end{array}$ & $\begin{array}{c}\text { Controle X 8 } \\
\text { semanas } \\
0.1 \%\end{array}$ & 4 sem X 8 sem \\
\hline
\end{tabular}

Significante para $\alpha \leq 0.01$

\section{VOLUME NUCLEAR / ÁREA NUCLEAR}

Valor de $\mathrm{H}=6.0265$

Valor de $x^{2} p / 2^{\circ}$ de liberdade $=6.03$

Probabilidade de $\mathrm{HO}=4.91 \%$

Significante para $\alpha \leq 0.05$

\section{Cont}

Controle X 4 semanas $5 \%$
Controle X $8 \quad 4$ sem $X 8$ sem semanas $5 \%$

\section{ÍNDICE DE CONTORNO}

Valor de $\mathrm{H}=10.6117$

Valor de $x^{2} \mathrm{p} / 2^{\circ}$ de liberdade $=10.61$

Probabilidade de $\mathrm{HO}=0.50 \%$

Significante para $\alpha \leq 0.01$

\section{COEFICIENTE DE FORMA}

Valor de $\mathrm{H}=9.9214$

Valor de $x^{2} p / 2^{\circ}$ de liberdade $=9.92$

Probabilidade de $\mathrm{HO}=0.70 \%$

Significante para $\alpha \leq 0.01$

\section{EXCENTRICIDADE}

Valor de $\mathrm{H}=9.4816$

Valor de $x^{2} p / 2^{\circ}$ de liberdade $=9.48$

Probabilidade de $\mathrm{HO}=0.87 \%$

Significante para $\alpha \leq 0.01$

\begin{tabular}{c|c|c}
$\begin{array}{c}\text { Controle X } 4 \\
\text { semanas } \\
5 \%\end{array}$ & $\begin{array}{c}\text { Controle } X 8 \\
\text { semanas } \\
0.1 \%\end{array}$ & 4 sem $X 8$ sem \\
\hline
\end{tabular}

\begin{tabular}{c|c|c|}
$\begin{array}{c}\text { Controle } \mathrm{X} 4 \\
\text { semanas } \\
\text { NS }\end{array}$ & $\begin{array}{c}\text { Controle } \mathrm{X} 8 \\
\text { semanas }\end{array}$ & 4 sem $\mathrm{X} 8 \mathrm{sem}$ \\
\hline $0.1 \%$ & $1 \%$ \\
\hline
\end{tabular}
Controle X 4
semanas
NS

Controle X 8

4 sem $X 8$ sem semanas 
TABELA 28 - Avaliação do tamanho dos núcleos das células do epitélio da língua (região dorsal posterior) dos animais controle e tratados com inibidor de protease.

\begin{tabular}{|c|c|c|c|c|c|c|}
\hline \multirow{2}{*}{$\begin{array}{l}\text { Estrutura } \\
\text { Estudada }\end{array}$} & \multicolumn{2}{|c|}{ Animais Controle } & \multicolumn{2}{|c|}{ Tratados - 4 semanas } & \multicolumn{2}{|c|}{ Tratados - 8 semanas } \\
\hline & C.Basal & C.Espinhosa & C.basal & C.espinhosa & C.basal & C.espinhosa \\
\hline \multirow{7}{*}{$\begin{array}{l}\text { Diâmetro } \\
\text { maior }\end{array}$} & 6.20 & 6.42 & 5.22 & 6.76 & 6.66 & 7.30 \\
\hline & 6.02 & 6.40 & 5.32 & 6.96 & 6.68 & 7.10 \\
\hline & 6.26 & 6.42 & 5.54 & 6.46 & 6.96 & 7.10 \\
\hline & 6.20 & 6.28 & 5.48 & 6.36 & 6.50 & 6.76 \\
\hline & 6.10 & 6.36 & 5.36 & 6.50 & 6.52 & 6.82 \\
\hline & $6.15 \pm 0.09$ & $6.37 \pm 0.05$ & $5.38 \pm 0.12$ & $6.60 \pm 0.24$ & $6.66 \pm 0.18$ & $7.01 \pm 0.22$ \\
\hline & & & $\downarrow$ & $\uparrow$ & $\uparrow$ & $\uparrow$ \\
\hline \multirow{7}{*}{$\begin{array}{l}\text { Diâmetro } \\
\text { menor }\end{array}$} & 4.68 & 4.96 & 4.38 & 5.60 & 5.28 & 5.46 \\
\hline & 4.84 & 4.86 & 4.32 & 5.84 & 5.04 & 5.46 \\
\hline & 4.98 & 5.24 & 4.50 & 5.44 & 5.44 & 5.98 \\
\hline & 5.00 & 5.10 & 4.50 & 5.24 & 4.98 & 5.04 \\
\hline & 5.10 & 5.06 & 4.34 & 5.22 & 4.96 & 5.40 \\
\hline & $4.92 \pm 0.16$ & $5.04 \pm 0.14$ & $4.40 \pm 0.08$ & $5.46 \pm 0.25$ & $5.14 \pm 0.21$ & $5.46 \pm 0.33$ \\
\hline & & & $\downarrow$ & $\uparrow$ & $\uparrow$ & $\uparrow$ \\
\hline \multirow{7}{*}{$\begin{array}{l}\text { Volume } \\
\text { nuclear }\end{array}$} & 83.29 & 095.66 & 57.89 & 123.49 & 108.13 & 134.73 \\
\hline & 83.49 & 091.64 & 58.35 & 138.39 & 102.87 & 130.09 \\
\hline & 93.18 & 103.70 & 65.60 & 110.08 & 125.54 & 146.98 \\
\hline & 92.15 & 096.43 & 64.86 & 103.10 & 101.29 & 107.23 \\
\hline & 92.33 & 098.16 & 59.82 & 105.61 & 098.19 & 119.44 \\
\hline & $88.88 \pm 5.03$ & $97.11 \pm 4.38$ & $61.30 \pm 3.66$ & $116.13 \pm 14.72$ & $107.69 \pm 15.35$ & $127.69 \pm 15.11$ \\
\hline & & & $\downarrow$ & $\uparrow$ & $\uparrow$ & $\uparrow$ \\
\hline \multirow[t]{7}{*}{ Área nuclear } & 22.84 & 25.05 & 17.97 & 29.75 & 27.19 & 31.43 \\
\hline & 22.90 & 24.41 & 18.06 & 32.04 & 26.37 & 30.65 \\
\hline & 24.61 & 26.48 & 19.56 & 27.60 & 29.92 & 33.43 \\
\hline & 24.43 & 25.24 & 19.38 & 26.30 & 25.87 & 26.91 \\
\hline & 24.50 & 25.43 & 18.33 & 26.77 & 25.45 & 29.01 \\
\hline & $23.85 \pm 0.90$ & $25.32 \pm 0.75$ & $18.66 \pm 0.75$ & $28.49 \pm 2.38$ & $26.96 \pm 1.77$ & $30.28 \pm 2.46$ \\
\hline & & & $\downarrow$ & $\uparrow$ & $\uparrow$ & $\uparrow$ \\
\hline \multirow{7}{*}{$\begin{array}{c}\text { Perímetro } \\
\text { nuclear }\end{array}$} & 17.21 & 17.98 & 15.13 & 19.49 & 18.74 & 28.18 \\
\hline & 17.14 & 17.80 & 15.21 & 28.17 & 18.54 & 19.85 \\
\hline & 17.73 & 18.39 & 15.84 & 18.75 & 19.58 & 28.61 \\
\hline & 17.67 & 17.94 & 15.74 & 18.29 & 18.29 & 18.67 \\
\hline & 17.65 & 18.02 & 15.30 & 18.49 & 18.16 & 19.30 \\
\hline & $17.48 \pm 0.28$ & $18.02 \pm 0.87$ & $15.44 \pm 0.32$ & $20.83 \pm 4.14$ & $18.66 \pm 0.56$ & $22.92 \pm 5.01$ \\
\hline & & & $\downarrow$ & $\uparrow$ & $\uparrow$ & $\uparrow$ \\
\hline
\end{tabular}

Obs: Estão expressos nesta tabela os dados relativos a: Diâmetro maior em micrometros $(\mu \mathrm{m})$, diâmetro menor $(\mathrm{em} \mu \mathrm{m})$, perímetro do núcleo celular (em $\mu \mathrm{m})$, área nuclear em micrometros quadrados $\left(\mu \mathrm{m}^{2}\right)$, e volume nuclear em micrometros cúbicos $\left(\mu \mathrm{m}^{3}\right)$. 
TABELA 29 - Avaliação dos efeitos da utilização de inibidor de protease sobre o tamanho dos núcleos das células da camada basal do epitélio da língua (região dorsal posterior) dos animais controles e tratados Avaliação pelo teste Kruskal-Wallis

DIÂMETRO MAIOR

Valor de $\mathrm{H}=12.5224$

Valor de $\mathrm{x}^{2} \mathrm{p} / 2^{\circ}$ de liberdade $=12.52$

Probabilidade de $\mathrm{H} 0=0.19 \%$

Significante para $\alpha \leq 0.01$

\section{DIÂMETRO MENOR}

Valor de $\mathrm{H}=10.1312$

Valor de $\mathrm{x}^{2} \mathrm{p} / 2^{\circ}$ de liberdade $=10.13$

Probabilidade de $\mathrm{H} 0=0.63 \%$

Significante para $\alpha \leq 0.01$

\section{VOLUME NUCLEAR}

Valor de $\mathrm{H}=12.5000$

Valor de $x^{2} p / 2^{\circ}$ de liberdade $=12.50$

Probabilidade de $\mathrm{H} 0=0.19 \%$

Significante para $\alpha \leq 0.01$

\section{ÁREA NUCLEAR}

Valor de $\mathrm{H}=12.5000$

Valor de $x^{2} p / 2^{\circ}$ de liberdade $=12.50$

Probabilidade de $\mathrm{H} 0=0.19 \%$

Controle X 4 semanas

$0.1 \%$

Controle X 4

semanas

$1 \%$

\section{Controle X 4 \\ semanas}

$0.1 \%$

Controle X 8 semanas

\begin{tabular}{c|c}
$\begin{array}{c}\text { Controle } X 8 \\
\text { semanas } \\
\text { NS }\end{array}$ & 4 sem $X 8$ sem \\
\hline & $0.1 \%$
\end{tabular}

Significante para $\alpha \leq 0.01$

\section{PERÍMETRO NUCLEAR}

Valor de $\mathrm{H}=12.5000$

Valor de $\mathrm{x}^{2} \mathrm{p} / 2^{\circ}$ de liberdade $=12.50$

Probabilidade de $\mathrm{H} 0=0.19 \%$

Significante para $\alpha \leq 0.01$
Controle X $8 \quad 4$ sem X 8 sem semanas

$0.1 \% \quad 0.1 \%$


TABELA 30 - Avaliação dos efeitos da utilização de inibidor de protease sobre o tamanho dos núcleos das células da camada espinhosa do epitélio da língua (região dorsal posterior) dos animais controles e tratados Avaliação pelo teste Kruskal-Wallis

DIÂMETRO MAIOR

Valor de $\mathrm{H}=9.7647$

Valor de $x^{2} \mathrm{p} / 2^{\circ}$ de liberdade $=9.76$

Probabilidade de $\mathrm{H} 0=0.76 \%$

Significante para $\alpha \leq 0.01$

\begin{tabular}{|c|c|c|}
$\begin{array}{c}\text { Controle X } 4 \\
\text { semanas } \\
5 \%\end{array}$ & $\begin{array}{c}\text { Controle X } 8 \\
\text { semanas } \\
0.1 \%\end{array}$ & 4 sem X 8 sem \\
\hline
\end{tabular}

DIÂMETRO MENOR

Valor de $\mathrm{H}=6.3276$

Valor de $\mathrm{x}^{2} \mathrm{p} / 2^{\circ}$ de liberdade $=6.33$

Probabilidade de $\mathrm{H} 0=4.23 \%$

Significante para $\alpha \leq 0.05$

\section{VOLUME NUCLEAR}

Valor de $\mathrm{H}=9.3600$

Valor de $\mathrm{x}^{2} \mathrm{p} / 2^{\circ}$ de liberdade $=9.36$

Probabilidade de $\mathrm{H} 0=0.93 \%$

Controle X 4

semanas

$5 \%$

Controle X 8 semanas

$5 \%$

4 sem $X 8$ sem

NS

Significante para $\alpha \leq 0.01$

\section{ÁREA NUCLEAR}

Valor de $\mathrm{H}=9.3600$

Valor de $\mathrm{x}^{2} \mathrm{p} / 2^{\circ}$ de liberdade $=9.36$

Probabilidade de $\mathrm{H} 0=0.93 \%$

Controle X 4

Controle X 8

4 sem $X 8$ sem semanas semanas

\begin{tabular}{l|l}
$1 \%$ & $0.1 \%$
\end{tabular}

NS

Significante para $\alpha \leq 0.01$

\section{PERÍMETRO NUCLEAR}

Valor de $\mathrm{H}=9.6200$

Valor de $x^{2} p / 2^{\circ}$ de liberdade $=9.62$

Probabilidade de $\mathrm{H} 0=0.81 \%$

Controle X 4

Controle X 8

4 sem $X 8$ sem semanas $1 \%$ semanas $0.1 \%$ NS

Significante para $\alpha \leq 0.01$

\begin{tabular}{c|c|c}
$\begin{array}{c}\text { Controle X } 4 \\
\text { semanas } \\
1 \%\end{array}$ & $\begin{array}{c}\text { Controle X } 8 \\
\text { semanas } \\
0.1 \%\end{array}$ & 4 sem X 8 sem \\
\hline
\end{tabular}


TABELA 31 - Avaliação dos parâmetros avaliação da forma dos núcleos das células epiteliais da língua (região dorsal posterior) pele dos animais controles e tratados com inibidor de protease.

\begin{tabular}{|c|c|c|c|c|c|c|}
\hline \multirow{2}{*}{$\begin{array}{l}\text { Estrutura } \\
\text { Estudada }\end{array}$} & \multicolumn{2}{|c|}{ Animais Controle } & \multicolumn{2}{|c|}{ Tratados - 4 semanas } & \multicolumn{2}{|c|}{ Tratados - 8 semanas } \\
\hline & C.Basal & C.Espinhosa & C.basal & C.espinhosa & C.basal & C.espinhosa \\
\hline \multirow{7}{*}{$\begin{array}{l}\text { Relação } \\
\mathrm{DM} / \mathrm{dm}\end{array}$} & 1.35 & 1.32 & 1.21 & 1.23 & 1.31 & 1.36 \\
\hline & 1.27 & 1.34 & 1.25 & 1.21 & 1.35 & 1.32 \\
\hline & 1.27 & 1.24 & 1.26 & 1.20 & 1.31 & 1.20 \\
\hline & 1.26 & 1.24 & 1.24 & 1.23 & 1.35 & 1.37 \\
\hline & 1.21 & 1.27 & 1.26 & 1.26 & 1.34 & 1.29 \\
\hline & $1.27 \pm 0.05$ & $1.28 \pm 0.04$ & $1.23 \pm 0.02$ & $1.22 \pm 0.02$ & $1.33 \pm 0.02$ & $1.30 \pm 0.06$ \\
\hline & & $\downarrow$ & $\downarrow$ & & $\uparrow$ & $\uparrow$ \\
\hline \multirow{7}{*}{$\begin{array}{l}\text { Relação } \\
\text { Vol./Área }\end{array}$} & 3.58 & 3.75 & 3.18 & 4.09 & 3.90 & 4.19 \\
\hline & 3.58 & 3.70 & 3.19 & 4.24 & 3.85 & 4.14 \\
\hline & 3.71 & 3.86 & 3.32 & 3.94 & 4.09 & 4.33 \\
\hline & 3.70 & 3.77 & 3.30 & 3.84 & 3.80 & 3.88 \\
\hline & 3.71 & 3.77 & 3.21 & 3.97 & 3.75 & 4.03 \\
\hline & $3.65 \pm 0.06$ & $3.77 \pm 0.05$ & $3.24 \pm 0.06$ & $3.99 \pm 0.16$ & $3.87 \pm 0.13$ & $4.11 \pm 0.16$ \\
\hline & & $\downarrow$ & $\uparrow$ & & $\uparrow$ & 个 \\
\hline \multirow{7}{*}{$\begin{array}{l}\text { Índice de } \\
\text { contorno }\end{array}$} & 3.62 & 3.61 & 3.58 & 3.59 & 3.61 & 3.62 \\
\hline & 3.60 & 3.62 & 3.59 & 3.58 & 3.62 & 3.61 \\
\hline & 3.59 & 3.59 & 3.59 & 3.58 & 3.61 & 3.58 \\
\hline & 3.59 & 3.58 & 3.59 & 3.59 & 3.62 & 3.63 \\
\hline & 3.58 & 3.59 & 3.59 & 3.59 & 3.62 & 3.60 \\
\hline & $3.59 \pm 0.01$ & $3.59 \pm 0.01$ & $3.58 \pm 0.00$ & $3.58 \pm 0.00$ & $3.61 \pm 0.00$ & $3.60 \pm 0.01$ \\
\hline & & $\downarrow$ & $\downarrow$ & & $\uparrow$ & $\uparrow$ \\
\hline \multirow{7}{*}{$\begin{array}{l}\text { Coeficiente } \\
\text { De forma }\end{array}$} & 0.96 & 0.96 & 0.98 & 0.98 & 0.96 & 0.96 \\
\hline & 0.97 & 0.96 & 0.98 & 0.98 & 0.96 & 0.97 \\
\hline & 0.97 & 0.98 & 0.97 & 0.98 & 0.97 & 0.98 \\
\hline & 0.97 & 0.98 & 0.98 & 0.98 & 0.96 & 0.96 \\
\hline & 0.98 & 0.97 & 0.97 & 0.98 & 0.96 & 0.97 \\
\hline & $0.96 \pm 0.00$ & $0.96 \pm 0.00$ & $0.97 \pm 0.00$ & $0.98 \pm 0.00$ & $0.96 \pm 0.00$ & $0.96 \pm 0.00$ \\
\hline & & $\uparrow$ & $\uparrow$ & & & \\
\hline \multirow{7}{*}{$\begin{array}{l}\text { Excentrici- } \\
\text { dade }\end{array}$} & 0.59 & 0.54 & 0.41 & 0.44 & 0.52 & 0.60 \\
\hline & 0.47 & 0.57 & 0.47 & 0.44 & 0.56 & 0.57 \\
\hline & 0.55 & 0.48 & 0.47 & 0.40 & 0.55 & 0.44 \\
\hline & 0.48 & 0.52 & 0.45 & 0.45 & 0.56 & 0.58 \\
\hline & 0.44 & 0.51 & 0.49 & 0.52 & 0.55 & 0.51 \\
\hline & $0.50 \pm 0.06$ & $0.52 \pm 0.03$ & $0.45 \pm 0.03$ & $0.45 \pm 0.04$ & $0.54 \pm 0.01$ & $0.54 \pm 0.06$ \\
\hline & & $\downarrow$ & $\downarrow$ & & 个 & $\uparrow$ \\
\hline
\end{tabular}

Obs: Estão expressos nesta tabela os dados relativos a: Relação Diâmetro maior/Diâmetro menor (DM/dm), Relação volume/área (Vol./Área), coeficiente de forma, índice de contorno, e excentricidade. 
TABELA 32 - Avaliação dos efeitos da utilização de inibidor de protease sobre os parâmetros da forma dos núcleos das células da camada basal do epitélio da língua (região dorsal posterior) dos animais controles e tratados - Avaliação pelo teste Kruskal-Wallis.

\section{DIÂMETRO MAIOR / DIÂMETRO MENOR}

Valor de $\mathrm{H}=8.4000$

Valor de $\mathrm{x}^{2} \mathrm{p} / 2^{\circ}$ de liberdade $=8.40$

Probabilidade de $\mathrm{H} 0=1.50 \%$

Significante para $\alpha \leq 0.01$

\section{VOLUME NUCLEAR / ÁREA NUCLEAR}

Valor de $\mathrm{H}=12.5448$

Valor de $\mathrm{x}^{2} \mathrm{p} / 2^{\circ}$ de liberdade $=12.54$

Probabilidade de $\mathrm{H} 0=0.19 \%$

Significante para $\alpha \leq 0.01$

\section{INDICE DE CONTORNO}

Valor de $\mathrm{H}=8.2908$

Valor de $\mathrm{x}^{2} \mathrm{p} / 2^{\circ}$ de liberdade $=8.29$

Probabilidade de $\mathrm{H} 0=1.58 \%$

\begin{tabular}{|c|c|c|}
\hline $\begin{array}{c}\text { Controle X } 4 \\
\text { semanas } \\
\text { NS }\end{array}$ & $\begin{array}{c}\text { Controle X } 8 \\
\text { semanas } \\
5 \%\end{array}$ & 4 sem X 8 sem \\
\hline
\end{tabular}

Significante para $\alpha \leq 0.01$

\section{COEFICIENTE DE FORMA}

\begin{tabular}{|c|c|c|c|}
\hline $\begin{array}{l}\text { Valor de } \mathrm{H}=7.8117 \\
\text { Valor de } \mathrm{x}^{2} \mathrm{p} / 2^{\circ} \text { de liberdade }=7.81 \\
\text { Probabilidade de } \mathrm{H} 0=2.01 \%\end{array}$ & $\begin{array}{l}\text { Controle X } 4 \\
\text { semanas } \\
\text { NS }\end{array}$ & $\begin{array}{l}\text { Controle X } 8 \\
\text { semanas } \\
5 \%\end{array}$ & $4 \mathrm{sem} X 8 \mathrm{sem}$ \\
\hline \multirow{2}{*}{\multicolumn{4}{|c|}{$\begin{array}{l}\text { Significante para } \alpha \leq 0.05 \\
\text { EXCENTRICIDADE }\end{array}$}} \\
\hline & & & \\
\hline $\begin{array}{l}\text { Valor de } \mathrm{H}=6.5858 \\
\text { Valor de } \mathrm{x}^{2} \mathrm{p} / 2^{\circ} \text { de liberdade }=6.59 \\
\text { Probabilidade de } \mathrm{H} 0=3.71 \%\end{array}$ & $\begin{array}{l}\text { Controle X } 4 \\
\text { semanas } \\
\text { NS }\end{array}$ & $\begin{array}{l}\text { Controle X } 8 \\
\text { semanas } \\
\text { NS }\end{array}$ & $4 \mathrm{sem} X 8 \mathrm{sem}$ \\
\hline ignificante para $\alpha \leq 0$. & & & \\
\hline
\end{tabular}


TABELA 33 - Avaliação dos efeitos da utilização de inibidor de protease sobre os parâmetros da forma dos núcleos das células da camada espinhosa do epitélio da língua (região dorsal posterior) dos animais controles e tratados - Avaliação pelo teste Kruskal-Wallis.

\section{DIÂMETRO MAIOR / DIÂMETRO MENOR}

Valor de $\mathrm{H}=5.3230$

Valor de $x^{2} p / 2^{\circ}$ de liberdade $=5.32$

Probabilidade de $\mathrm{H} 0=6.98 \%$

\begin{tabular}{c|c|c|}
$\begin{array}{c}\text { Controle } \mathrm{X} 4 \\
\text { semanas } \\
\text { NS }\end{array}$ & $\begin{array}{c}\text { Controle } \mathrm{X} 8 \\
\text { semanas } \\
\text { NS }\end{array}$ & 4 sem $X 8$ sem \\
\hline
\end{tabular}

Significante para $\alpha \leq 0.05$

\section{VOLUME NUCLEAR / ÁREA NUCLEAR}

\section{Valor de $\mathrm{H}=9.1564$}

Valor de $\mathrm{x}^{2} \mathrm{p} / 2^{\circ}$ de liberdade $=9.16$

Probabilidade de $\mathrm{H} 0=1.03 \%$

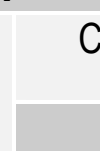

Controle X 4 Controle X 8 4 sem X 8 sem semanas semanas

\begin{tabular}{l|l|l|}
\hline $1 \%$ & $0.1 \%$ & NS
\end{tabular}

Significante para $\alpha \leq 0.01$

\section{ÍNDICE DE CONTORNO}

\begin{tabular}{|c|c|c|c|}
\hline $\begin{array}{l}\text { Valor de } \mathrm{H}=3.7598 \\
\text { Valor de } \mathrm{x}^{2} \mathrm{p} / 2^{\circ} \text { de liberdade }=3.76 \\
\text { Probabilidade de } \mathrm{H} 0=15.26 \%\end{array}$ & $\begin{array}{l}\text { Controle X4 } \\
\text { semanas } \\
\text { NS }\end{array}$ & $\begin{array}{l}\text { Controle X } 8 \\
\text { semanas } \\
\text { NS }\end{array}$ & $\begin{array}{c}4 \text { sem } X 8 \text { sem } \\
\text { NS }\end{array}$ \\
\hline Significante para $\alpha \leq 0.05$ & & & \\
\hline COEFICIENTE DE FORMA & & & \\
\hline $\begin{array}{l}\text { Valor de } H=5.7515 \\
\text { Valor de } x^{2} p / 2^{\circ} \text { de liberdade }=5.75 \\
\text { Probabilidade de } H 0=5.64 \%\end{array}$ & $\begin{array}{c}\text { Controle X } 4 \\
\text { semanas } \\
5 \%\end{array}$ & $\begin{array}{l}\text { Controle X } 8 \\
\text { semanas } \\
\text { NS }\end{array}$ & $\begin{array}{c}4 \text { sem } \times 8 \text { sem } \\
5 \%\end{array}$ \\
\hline Significante para $\alpha \leq 0.05$ & & & \\
\hline EXCENTRICIDADE & & & \\
\hline $\begin{array}{l}\text { Valor de } \mathrm{H}=5.3519 \\
\text { Valor de } \mathrm{x}^{2} \mathrm{p} / 2^{\circ} \text { de liberdade }=5.35 \\
\text { Probabilidade de } \mathrm{H} 0=6.88 \%\end{array}$ & $\begin{array}{l}\text { Controle X } 4 \\
\text { semanas } \\
\text { NS }\end{array}$ & $\begin{array}{l}\text { Controle X } 8 \\
\text { semanas } \\
\text { NS }\end{array}$ & 4 sem $X 8$ sem \\
\hline
\end{tabular}


TABELA 34 - Avaliação do tamanho dos núcleos das células do epitélio da língua (região ventral) dos animais controle e tratados com inibidor de protease.

\begin{tabular}{|c|c|c|c|c|c|c|}
\hline \multirow{2}{*}{$\begin{array}{l}\text { Estrutura } \\
\text { Estudada }\end{array}$} & \multicolumn{2}{|c|}{ Animais Controle } & \multicolumn{2}{|c|}{ Tratados - 4 semanas } & \multicolumn{2}{|c|}{ Tratados - 8 semanas } \\
\hline & C.Basal & $\begin{array}{c}\text { C.Espinhos } \\
\text { a }\end{array}$ & C.basal & C.espinhosa & C.basal & C.espinhosa \\
\hline \multirow[t]{3}{*}{$\begin{array}{l}\text { Diâmetro } \\
\text { maior }\end{array}$} & $\begin{array}{l}5.94 \\
6.30 \\
5.58 \\
6.20 \\
5.62\end{array}$ & $\begin{array}{l}5.90 \\
6.24 \\
5.76 \\
5.88 \\
5.56\end{array}$ & $\begin{array}{l}5.90 \\
6.54 \\
6.40 \\
6.76 \\
6.16\end{array}$ & $\begin{array}{l}6.58 \\
6.92 \\
6.78 \\
7.06 \\
6.64\end{array}$ & $\begin{array}{l}6.62 \\
6.28 \\
6.38 \\
6.70 \\
6.42\end{array}$ & $\begin{array}{l}6.80 \\
6.46 \\
6.82 \\
6.64 \\
6.48\end{array}$ \\
\hline & $5.92 \pm 0.32$ & $5.86 \pm 0.24$ & $6.35 \pm 0.33$ & $6.79 \pm 0.19$ & $6.48 \pm 0.17$ & $6.64 \pm 0.17$ \\
\hline & & & 个 & 个 & 个 & $\uparrow$ \\
\hline \multirow[t]{3}{*}{$\begin{array}{l}\text { Diâmetro } \\
\text { menor }\end{array}$} & $\begin{array}{l}4.32 \\
4.52 \\
4.56 \\
4.30 \\
4.26\end{array}$ & $\begin{array}{l}4.96 \\
4.80 \\
4.72 \\
4.68 \\
4.40\end{array}$ & $\begin{array}{l}4.90 \\
4.74 \\
4.98 \\
4.46 \\
4.60\end{array}$ & $\begin{array}{l}5.36 \\
5.48 \\
5.82 \\
5.10 \\
5.02\end{array}$ & $\begin{array}{l}4.80 \\
4.70 \\
4.72 \\
4.82 \\
4.82 \\
\end{array}$ & $\begin{array}{l}5.00 \\
4.86 \\
5.08 \\
4.76 \\
4.84\end{array}$ \\
\hline & $4.39 \pm 0.13$ & $4.71 \pm 0.20$ & $4.73 \pm 0.21$ & $5.35 \pm 0.31$ & $4.77 \pm 0.05$ & $4.90 \pm 0.12$ \\
\hline & & & 个 & 个 & $\uparrow$ & $\uparrow$ \\
\hline \multirow[t]{3}{*}{$\begin{array}{l}\text { Volume } \\
\text { nuclear }\end{array}$} & $\begin{array}{l}69.11 \\
80.70 \\
67.81 \\
73.09 \\
62.17\end{array}$ & $\begin{array}{l}85.05 \\
86.67 \\
76.23 \\
77.01 \\
64.07\end{array}$ & $\begin{array}{l}87.21 \\
91.28 \\
95.69 \\
83.39 \\
75.18\end{array}$ & $\begin{array}{l}114.68 \\
129.92 \\
133.19 \\
110.72 \\
101.72\end{array}$ & $\begin{array}{l}95.29 \\
84.85 \\
87.23 \\
97.15 \\
90.67\end{array}$ & $\begin{array}{l}105.13 \\
093.38 \\
107.96 \\
094.65 \\
093.20\end{array}$ \\
\hline & $70.57 \pm 6.87$ & $77.80 \pm 8.98$ & $86.55 \pm 7.83$ & $118.03 \pm 13.25$ & $91.03 \pm 5.20$ & $98.86 \pm 7.10$ \\
\hline & & & 个 & $\uparrow$ & 个 & $\uparrow$ \\
\hline \multirow[t]{3}{*}{ Área nuclear } & $\begin{array}{l}20.15 \\
22.38 \\
19.95 \\
20.92 \\
18.80\end{array}$ & $\begin{array}{l}23.12 \\
23.50 \\
21.49 \\
21.65 \\
19.21\end{array}$ & $\begin{array}{l}21.33 \\
22.98 \\
25.09 \\
24.36 \\
23.64\end{array}$ & $\begin{array}{l}26.03 \\
27.66 \\
31.18 \\
30.44 \\
28.13\end{array}$ & $\begin{array}{l}25.01 \\
23.18 \\
23.62 \\
25.35 \\
24.24\end{array}$ & $\begin{array}{l}26.72 \\
24.69 \\
27.24 \\
24.90 \\
24.63\end{array}$ \\
\hline & $20.44 \pm 1.32$ & $21.79 \pm 1,57$ & $23.48 \pm 1.43$ & $28.68 \pm 2.10$ & $24.28 \pm 0.91$ & $25.63 \pm 1.24$ \\
\hline & & & 个 & $\uparrow$ & 个 & $\uparrow$ \\
\hline \multirow[t]{2}{*}{$\begin{array}{l}\text { Perímetro } \\
\text { nuclear }\end{array}$} & $\begin{array}{l}16.26 \\
17.15 \\
16.01 \\
16.67 \\
15.63\end{array}$ & $\begin{array}{l}17.11 \\
17.45 \\
16.52 \\
16.68 \\
15.73\end{array}$ & $\begin{array}{l}17.47 \\
17.90 \\
17.97 \\
17.47 \\
16.59\end{array}$ & $\begin{array}{l}18.94 \\
19.81 \\
19.85 \\
19.03 \\
18.34\end{array}$ & $\begin{array}{l}18.08 \\
17.37 \\
17.57 \\
18.25 \\
17.79\end{array}$ & $\begin{array}{l}18.68 \\
17.90 \\
18.82 \\
18.05 \\
17.91\end{array}$ \\
\hline & $16.34 \pm 0.58$ & $16.69 \pm 0.65$ & $17.48 \pm 0.54$ & $19.19 \pm 0.63$ & $17.81 \pm 0.35$ & $18.27 \pm 0.44$ \\
\hline
\end{tabular}

Obs: Estão expressos nesta tabela os dados relativos a: Diâmetro maior em micrometros $(\mu \mathrm{m})$, diâmetro menor $(\mathrm{em} \mu \mathrm{m})$, perímetro do núcleo celular $(\mathrm{em} \mu \mathrm{m})$, área nuclear em micrometros quadrados $\left(\mu \mathrm{m}^{2}\right)$, e volume nuclear em micrometros cúbicos $\left(\mu \mathrm{m}^{3}\right)$. 
TABELA 35 - Avaliação dos efeitos da utilização de inibidor de protease sobre os parâmetros do tamanho dos núcleos das células da camada basal do epitélio da língua (região ventral) dos animais controles e tratados Avaliação pelo teste Kruskal-Wallis.

\section{DIÂMETRO MAIOR}

Valor de $\mathrm{H}=5.8200$

Valor de $\mathrm{x}^{2} \mathrm{p} / 2^{\circ}$ de liberdade $=5.82$

Probabilidade de $\mathrm{H} 0=5.45 \%$

Controle X 4

Controle X 8

4 sem $X 8$ sem

Significante para $\alpha \leq 0.05$

\section{DIÂMETRO MENOR}

semanas semanas

NS

$5 \%$

NS

Valor de $\mathrm{H}=7.9943$

Valor de $x^{2} p / 2^{\circ}$ de liberdade $=7.99$

Probabilidade de $\mathrm{H} 0=1.84 \%$

Significante para $\alpha \leq 0.01$

\section{VOLUME NUCLEAR}

Valor de $\mathrm{H}=9.1400$

Valor de $x^{2} p / 2^{\circ}$ de liberdade $=9.14$

Probabilidade de $\mathrm{H} 0=1.04 \%$

Controle X 4 semanas

$1 \%$

Controle X 4 semanas

$1 \%$

\begin{tabular}{c|c}
$\begin{array}{c}\text { Controle X } 8 \\
\text { semanas } \\
1 \%\end{array}$ & 4 sem $X 8$ sem \\
\hline
\end{tabular}

Significante para $\alpha \leq 0.01$

\section{ÁREA NUCLEAR}

Valor de $\mathrm{H}=8.9600$

Valor de $x^{2} \mathrm{p} / 2^{\circ}$ de liberdade $=8.96$

Probabilidade de $\mathrm{H} 0=1.13 \%$

\begin{tabular}{c|c|c}
$\begin{array}{c}\text { Controle } \mathrm{X} 4 \\
\text { semanas } \\
1 \%\end{array}$ & $\begin{array}{c}\text { Controle } \mathrm{X} 8 \\
\text { semanas } \\
0.1 \%\end{array}$ & 4 sem $\mathrm{X} 8 \mathrm{sem}$ \\
\hline
\end{tabular}

Significante para $\alpha \leq 0.01$

\section{PERÍMETRO NUCLEAR}

Valor de $\mathrm{H}=8.5553$

Valor de $x^{2} \mathrm{p} / 2^{\circ}$ de liberdade $=8.56$

Probabilidade de $\mathrm{Ho}=1.39 \%$

Controle X 4
semanas
$5 \%$

Controle X $8 \quad 4$ sem $X 8$ sem

Significante para $\alpha \leq 0.01$
Controle X $8 \quad 4$ sem X 8 sem semanas

$0.1 \% \quad$ NS


TABELA 36 - Avaliação dos efeitos da utilização de inibidor de protease sobre os parâmetros do tamanho dos núcleos das células da camada espinhosa do epitélio da língua (região ventral) dos animais controles e tratados Avaliação pelo teste Kruskal-Wallis.

\section{DIÂMETRO MAIOR}

Valor de $\mathrm{H}=9.8927$

Valor de $x^{2} p / 2^{\circ}$ de liberdade $=9.89$

Probabilidade de $\mathrm{H} 0=0.71 \%$

Controle X 4

Controle X 8

4 sem $X 8$ sem

Significante para $\alpha \leq 0.01$

\section{DIÂMETRO MENOR}

Valor de $\mathrm{H}=10.2600$

Valor de $x^{2} p / 2^{\circ}$ de liberdade $=10.26$

Probabilidade de $\mathrm{H} 0=0.59 \%$

semanas semanas

$0.1 \%$

$1 \%$

NS

Significante para $\alpha \leq 0.01$

VOLUME NUCLEAR

Valor de $\mathrm{H}=11.5800$

Valor de $x^{2} \mathrm{p} / 2^{\circ}$ de liberdade $=11.58$

Probabilidade de $\mathrm{Ho}=0.31 \%$

Significante para $\alpha \leq 0.01$

\section{ÁREA NUCLEAR}

Valor de $\mathrm{H}=11.5800$

Valor de $\mathrm{x}^{2} \mathrm{p} / 2^{\circ}$ de liberdade $=11.58$

Probabilidade de $\mathrm{H} 0=0.31 \%$

Significante para $\alpha \leq 0.01$

\section{PERÍMETRO NUCLEAR}

Valor de $\mathrm{H}=11.5200$

Valor de $x^{2} \mathrm{p} / 2^{\circ}$ de liberdade $=11.52$

Probabilidade de $\mathrm{H} 0=0.32 \%$

Significante para $\alpha \leq 0.01$

\begin{tabular}{c|c|c}
$\begin{array}{c}\text { Controle X } 4 \\
\text { semanas } \\
0.1 \%\end{array}$ & $\begin{array}{c}\text { Controle X } 8 \\
\text { semanas } \\
1 \%\end{array}$ & 4 sem $X 8$ sem \\
\hline
\end{tabular}

\begin{tabular}{|c|c|c|}
\hline $\begin{array}{c}\text { Controle X } 4 \\
\text { semanas }\end{array}$ & $\begin{array}{c}\text { Controle } \mathrm{X} 8 \\
\text { semanas }\end{array}$ & 4 sem $\mathrm{X} 8$ sem \\
\hline $0.1 \%$ & $1 \%$ & $1 \%$ \\
\hline
\end{tabular}

Contr

\begin{tabular}{c|c}
$\begin{array}{c}\text { Controle } X 8 \\
\text { semanas } \\
5 \%\end{array}$ & 4 sem $X 8$ sem \\
\hline & $1 \%$
\end{tabular}

$5 \%$

$1 \%$ semanas

$$
0.1 \%
$$

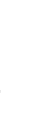


TABELA 37 - Avaliação dos parâmetros avaliação da forma dos núcleos das células epiteliais da língua (região ventral) dos animais controles e tratados com inibidor de protease.

\begin{tabular}{|c|c|c|c|c|c|c|}
\hline \multirow{2}{*}{$\begin{array}{l}\text { Estrutura } \\
\text { Estudada }\end{array}$} & \multicolumn{2}{|c|}{ Animais Controle } & \multicolumn{2}{|c|}{ Tratados - 4 semanas } & \multicolumn{2}{|c|}{ Tratados - 8 semanas } \\
\hline & C.Basal & C.Espinhosa & C.basal & C.espinhosa & C.basal & C.espinhosa \\
\hline Relação & 1.42 & 1.20 & 1.31 & 1.34 & 1.40 & 1.39 \\
\hline \multirow[t]{6}{*}{$\mathrm{DM} / \mathrm{dm}$} & 1.42 & 1.32 & 1.49 & 1.39 & 1.36 & 1.35 \\
\hline & 1.25 & 1.23 & 1.31 & 1.19 & 1.38 & 1.36 \\
\hline & 1.48 & 1.29 & 1.41 & 1.31 & 1.42 & 1.41 \\
\hline & 1.35 & 1.28 & 1.28 & 1.27 & 1.37 & 1.37 \\
\hline & $1.38 \pm 0.08$ & $1.26 \pm 0.04$ & $1.36 \pm 0.08$ & $1.30 \pm 0.07$ & $1.38 \pm 0.05$ & $1.37 \pm 0.02$ \\
\hline & & & $\downarrow$ & $\uparrow$ & & $\uparrow$ \\
\hline \multirow{7}{*}{$\begin{array}{c}\text { Relação } \\
\text { Vol./Área }\end{array}$} & 3.25 & 3.60 & 3.46 & 3.82 & 3.75 & 3.87 \\
\hline & 3.42 & 3.63 & 3.59 & 3.94 & 3.61 & 3.72 \\
\hline & 3.35 & 3.47 & 3.75 & 4.18 & 3.64 & 3.91 \\
\hline & 3.54 & 3.48 & 3.70 & 4.13 & 3.77 & 3.74 \\
\hline & 3.36 & 3.28 & 3.65 & 3.96 & 3.69 & 3.72 \\
\hline & $3.38 \pm 0.10$ & $3.49 \pm 0.13$ & $3.63 \pm 0.11$ & $4.00 \pm 0.14$ & $3.69 \pm 0.06$ & $3.79 \pm 0.09$ \\
\hline & & & $\uparrow$ & $\uparrow$ & $\uparrow$ & $\uparrow$ \\
\hline \multirow{7}{*}{$\begin{array}{l}\text { Índice de } \\
\text { contorno }\end{array}$} & 3.64 & 3.58 & 3.61 & 3.62 & 3.63 & 3.63 \\
\hline & 3.64 & 3.61 & 3.67 & 3.64 & 3.62 & 3.62 \\
\hline & 3.60 & 3.58 & 3.61 & 3.58 & 3.63 & 3.62 \\
\hline & 3.67 & 3.61 & 3.64 & 3.61 & 3.64 & 3.63 \\
\hline & 3.62 & 3.60 & 3.60 & 3.60 & 3.63 & 3.63 \\
\hline & $3.63 \pm 0.02$ & $3.59 \pm 0.01$ & $3.62 \pm 0.02$ & $3.61 \pm 0.02$ & $3.63 \pm 0.00$ & $3.62 \pm 0.00$ \\
\hline & & & $\downarrow$ & $\uparrow$ & & $\uparrow$ \\
\hline \multirow{7}{*}{$\begin{array}{l}\text { Coeficiente } \\
\text { de forma }\end{array}$} & 0.96 & 0.97 & 0.97 & 0.97 & 0.95 & 0.96 \\
\hline & 0.94 & 0.97 & 0.95 & 0.97 & 0.96 & 0.96 \\
\hline & 0.97 & 0.98 & 0.97 & 0.98 & 0.96 & 0.96 \\
\hline & 0.95 & 0.96 & 0.94 & 0.95 & 0.95 & 0.95 \\
\hline & 0.95 & 0.98 & 0.97 & 0.96 & 0.96 & 0.96 \\
\hline & $0.95 \pm 0.01$ & $0.97 \pm 0.00$ & $0.96 \pm 0.01$ & $0.96 \pm 0.01$ & $0.95 \pm 0.00$ & $0.95 \pm 0.00$ \\
\hline & & & $\uparrow$ & $\downarrow$ & & $\downarrow$ \\
\hline \multirow{7}{*}{$\begin{array}{l}\text { Excentrici- } \\
\text { dade }\end{array}$} & 0.61 & 0.43 & 0.53 & 0.56 & 0.64 & 0.63 \\
\hline & 0.64 & 0.52 & 0.68 & 0.59 & 0.59 & 0.59 \\
\hline & 0.42 & 0.47 & 0.56 & 0.48 & 0.60 & 0.62 \\
\hline & 0.63 & 0.48 & 0.63 & 0.56 & 0.62 & 0.66 \\
\hline & 0.57 & 0.50 & 0.48 & 0.47 & 0.56 & 0.58 \\
\hline & $0.57 \pm 0.09$ & $0.48 \pm 0.03$ & $0.57 \pm 0.07$ & $0.53 \pm 0.05$ & $0.60 \pm 0.03$ & $0.61 \pm 0.03$ \\
\hline & & & & $\uparrow$ & $\uparrow$ & $\uparrow$ \\
\hline
\end{tabular}

Obs: Estão expressos nesta tabela os dados relativos a: Relação Diâmetro maior/Diâmetro menor (DM/dm), Relação volume/área (Vol./Área), coeficiente de forma, índice de contorno, e excentricidade. 
TABELA 38 - Avaliação dos efeitos da utilização de inibidor de protease sobre os parâmetros da forma dos núcleos das células da camada basal do epitélio da língua (região ventral) dos animais controles e tratados Avaliação pelo teste Kruskal-Wallis

\section{DIÂMETRO MAIOR / DIÂMETRO MENOR}

\begin{tabular}{|c|c|c|c|}
\hline $\begin{array}{l}\text { Valor de } \mathrm{H}=0.5650 \\
\text { Valor de } \mathrm{x}^{2} \mathrm{p} / 2^{\circ} \text { de liberdade }=0.57 \\
\text { Probabilidade de } \mathrm{H} 0=73.39 \%\end{array}$ & $\begin{array}{l}\text { Controle X } 4 \\
\text { semanas } \\
\text { NS }\end{array}$ & $\begin{array}{l}\text { Controle X } 8 \\
\text { semanas } \\
\text { NS }\end{array}$ & $\begin{array}{c}4 \text { sem } X 8 \text { sem } \\
\text { NS }\end{array}$ \\
\hline \multicolumn{4}{|l|}{ Significante para $\alpha \leq 0.05$} \\
\hline \multicolumn{4}{|l|}{ VOLUME NUCLEAR / ÁREA NUCLEAR } \\
\hline \multirow{2}{*}{$\begin{array}{l}\text { Valor de } \mathrm{H}=9.0612 \\
\text { Valor de } \mathrm{x}^{2} \mathrm{p} / 2^{\circ} \text { de liberdade }=9.06 \\
\text { Probabilidade de } \mathrm{H} 0=1.08 \%\end{array}$} & $\begin{array}{c}\text { Controle X } 4 \\
\text { semanas }\end{array}$ & $\begin{array}{c}\text { Controle X } 8 \\
\text { semanas }\end{array}$ & 4 sem $X 8$ sem \\
\hline & & $0.1 \%$ & NS \\
\hline \multicolumn{4}{|l|}{ Significante para $\alpha \leq 0.01$} \\
\hline \multicolumn{4}{|l|}{ ÍNDICE DE CONTORNO } \\
\hline \multirow{2}{*}{$\begin{array}{l}\text { Valor de } \mathrm{H}=0.5321 \\
\text { Valor de } \mathrm{x}^{2} \mathrm{p} / 2^{\circ} \text { de liberdade }=0.53 \\
\text { Probabilidade de } \mathrm{H} 0=76.64 \%\end{array}$} & $\begin{array}{c}\text { Controle X } 4 \\
\text { semanas }\end{array}$ & $\begin{array}{c}\text { Controle X } 8 \\
\text { semanas }\end{array}$ & 4 sem $X 8$ sem \\
\hline & \multicolumn{3}{|c|}{ Significante para $\alpha \leq 0.05$} \\
\hline \multicolumn{4}{|l|}{ COEFICIENTE DE FORMA } \\
\hline \multirow[t]{2}{*}{$\begin{array}{l}\text { Valor de } \mathrm{H}=0.8794 \\
\text { Valor de } \mathrm{x}^{2} \mathrm{p} / 2^{\circ} \text { de liberdade }=0.88 \\
\text { Probabilidade de } \mathrm{H} 0=64.42 \%\end{array}$} & $\begin{array}{c}\text { Controle X } 4 \\
\text { semanas } \\
\text { NS }\end{array}$ & $\begin{array}{l}\text { Controle X } 8 \\
\text { semanas } \\
\text { NS }\end{array}$ & 4 sem $X 8$ sem \\
\hline & \multicolumn{3}{|c|}{ Significante para $\alpha \leq 0.05$} \\
\hline \multicolumn{4}{|l|}{ EXCENTRICIDADE } \\
\hline \multirow[t]{2}{*}{$\begin{array}{l}\text { Valor de } \mathrm{H}=0.2614 \\
\text { Valor de } \mathrm{x}^{2} \mathrm{p} / 2^{\circ} \text { de liberdade }=0.26 \\
\text { Probabilidade de } \mathrm{H} 0=87.75 \%\end{array}$} & $\begin{array}{l}\text { Controle X } 4 \\
\text { semanas } \\
\text { NS }\end{array}$ & $\begin{array}{l}\text { Controle X } 8 \\
\text { semanas } \\
\text { NS }\end{array}$ & 4 sem $X 8$ sem \\
\hline & & & \\
\hline
\end{tabular}


TABELA 39 - Avaliação dos efeitos da utilização de inibidor de protease sobre os parâmetros da forma dos núcleos das células da camada espinhosa do epitélio da língua (região ventral) dos animais controles e tratados Avaliação pelo teste Kruskal-Wallis

\section{DIÂMETRO MAIOR / DIÂMETRO MENOR}

\section{Valor de $\mathrm{H}=7.4984$}

Valor de $x^{2} p / 2^{\circ}$ de liberdade $=7.50$

Probabilidade de $\mathrm{H} 0=2.35 \%$

Significante para $\alpha \leq 0.05$

\section{VOLUME NUCLEAR / ÁREA NUCLEAR}

Valor de $\mathrm{H}=11.6007$

Valor de $x^{2} \mathrm{p} / 2^{\circ}$ de liberdade $=11.60$

Probabilidade de $\mathrm{H} 0=0.30 \%$

Significante para $\alpha \leq 0.01$

\section{ÍNDICE DE CONTORNO}

Valor de $\mathrm{H}=6.9046$

Valor de $x^{2} \mathrm{p} / 2^{\circ}$ de liberdade $=6.90$

Probabilidade de $\mathrm{H} 0=3.17 \%$

Significante para $\alpha \leq 0.05$

\section{COEFICIENTE DE FORMA}

Valor de $\mathrm{H}=5.3420$

Valor de $x^{2} p / 2^{\circ}$ de liberdade $=5.34$

Probabilidade de $\mathrm{H} 0=6.92 \%$

Controle X 4
semanas
NS

Controle X 4

semanas

$0.1 \%$
Controle X 8 semanas $1 \%$
4 sem $X 8$ sem

semanas

$5 \%$

Significante para $\alpha \leq 0.05$

\section{EXCENTRICIDADE}

Valor de $\mathrm{H}=9.4022$

Valor de $x^{2} p / 2^{\circ}$ de liberdade $=9.40$

Probabilidade de $\mathrm{H} 0=0.91 \%$

\begin{tabular}{|c|c|c|}
\hline $\begin{array}{c}\text { Controle X 4 } \\
\text { semanas } \\
\text { NS }\end{array}$ & $\begin{array}{c}\text { Controle X 8 } \\
\text { semanas } \\
5 \%\end{array}$ & 4 sem X 8 sem \\
\hline $\begin{array}{c}\text { Controle X } 4 \\
\text { semanas } \\
\text { NS }\end{array}$ & $\begin{array}{c}\text { Controle X 8 } \\
\text { semanas } \\
0.1 \%\end{array}$ & 4 sem X 8 sem \\
\hline
\end{tabular}

Significante para $\alpha \leq 0.01$ 
A avaliação cariométrica das células do epitélio das diferentes regiões da língua dos animais estuddados nos mostra que:

1) Em todas as regiões se observa um aumento dos volumes nucleares, tanto nas camadas basal como espinhosa do epitélio da mucosa lingual;

2) Na região dorsal anterior esse aumento se dá já a partir de 4 semanas de uso do inibidor de protease, sendo mesmo mais marcante nos primeiros momento de uso do medicamento, mas o efeito continua com o uso prolongado;

3) $\mathrm{Na}$ região dorsal intermediária $\mathrm{O}$ aumento do volume nuclear é mais expressivo na camada basal, embora também ocorra na camada espinhosa;

4) Na região dorsal posterior as diferenças mais marcantes são observadas na camada espinhosa;

5) Na região ventral os aumentos de volume nuclear acontecem de forma bem marcante nas duas camadas epiteliais;

6) Existe ainda uma tendência dos núcleas para acentuarem uma forma alongada, e isso acontece em todas as regiões da língua, apenas com menor expressão na região ventral. 


\subsubsection{Estereologia do epitélio da língua}

TABELA 40 - Avaliação dos valores médios dos volumes celulares (em $\mu \mathrm{m}^{3}$ ) no epitélio da língua (região dorsal anterior) dos animais controle e tratados com inibidor de protease.

\begin{tabular}{|c|c|c|c|c|c|c|}
\hline \multirow{2}{*}{$\begin{array}{l}\text { Estrutura } \\
\text { Estudada }\end{array}$} & \multicolumn{2}{|c|}{ Animais Controle } & \multicolumn{2}{|c|}{ Tratados - 4 semanas } & \multicolumn{2}{|c|}{ Tratados - 8 semanas } \\
\hline & C.Basal & C.Espinhosa & C.basal & C.espinhosa & C.basal & C.espinhosa \\
\hline \multirow[t]{3}{*}{ Volume nuclear } & $\begin{array}{l}55.41 \\
62.63 \\
58.18 \\
61.69 \\
54.70\end{array}$ & $\begin{array}{l}58.96 \\
73.03 \\
66.85 \\
73.91 \\
69.62\end{array}$ & $\begin{array}{l}72.80 \\
73.46 \\
69.53 \\
67.60 \\
74.39\end{array}$ & $\begin{array}{l}107.83 \\
119.76 \\
105.32 \\
124.99 \\
117.83\end{array}$ & $\begin{array}{l}68.75 \\
67.00 \\
67.24 \\
67.44 \\
69.00\end{array}$ & $\begin{array}{c}118.97 \\
113.18 \\
104.83 \\
97.54 \\
110.18\end{array}$ \\
\hline & $58.52 \pm 3.58$ & $68.47 \pm 6.01$ & $71.55 \pm 2.87$ & $115.14 \pm 8.29$ & $67.88 \pm 0.92$ & $108.94 \pm 8.16$ \\
\hline & & & 个 & $\uparrow$ & $\uparrow$ & $\uparrow$ \\
\hline \multirow[t]{3}{*}{ Volume celular } & $\begin{array}{l}59.42 \\
64.18 \\
62.13 \\
57.25 \\
58.63\end{array}$ & $\begin{array}{l}208.67 \\
206.98 \\
217.85 \\
211.50 \\
193.80\end{array}$ & $\begin{array}{l}72.86 \\
75.97 \\
70.94 \\
78.32 \\
74.33\end{array}$ & $\begin{array}{l}278.36 \\
297.07 \\
261.53 \\
291.37 \\
278.89\end{array}$ & $\begin{array}{l}68.25 \\
67.58 \\
68.00 \\
67.75 \\
69.75\end{array}$ & $\begin{array}{l}430.89 \\
430.10 \\
408.71 \\
410.92 \\
453.69\end{array}$ \\
\hline & $60.32 \pm 0.51$ & $207.76 \pm 8.83$ & $74.48 \pm 2.83$ & $281.44 \pm 13.74$ & $68.26 \pm 0.86$ & $426.86 \pm 18.23$ \\
\hline & & & $\uparrow$ & $\uparrow$ & $\uparrow$ & $\uparrow$ \\
\hline \multirow[t]{3}{*}{$\begin{array}{l}\text { Volume do } \\
\text { citoplasma }\end{array}$} & $\begin{array}{l}1.24 \\
1.55 \\
0.44 \\
2.55 \\
3.22\end{array}$ & $\begin{array}{l}134.76 \\
140.13 \\
144.82 \\
141.88 \\
134.84\end{array}$ & $\begin{array}{l}3.33 \\
2.51 \\
3.34 \\
3.93 \\
1.53\end{array}$ & $\begin{array}{l}173.04 \\
177.31 \\
136.54 \\
173.54 \\
171.06\end{array}$ & $\begin{array}{l}0.50 \\
0.58 \\
0.56 \\
0.51 \\
0.75\end{array}$ & $\begin{array}{l}311.92 \\
316.92 \\
311.17 \\
306.09 \\
343.51\end{array}$ \\
\hline & $1.80 \pm 1.09$ & $138.28 \pm 4.42$ & $2.92 \pm 0.93$ & $166.29 \pm 16.78$ & $0.58 \pm 0.10$ & $317.92 \pm 14.81$ \\
\hline & & & $\uparrow$ & $\uparrow$ & $\downarrow$ & $\uparrow$ \\
\hline \multirow[t]{3}{*}{$\begin{array}{c}\text { Relação Núcleo/ } \\
\text { citoplasma }\end{array}$} & $\begin{array}{l}0.5152 \\
0.5385 \\
0.5385 \\
0.5152 \\
0.5152\end{array}$ & $\begin{array}{l}0.1494 \\
0.1236 \\
0.1364 \\
0.1236 \\
0.1364\end{array}$ & $\begin{array}{l}0.5625 \\
0.5625 \\
0.5625 \\
0.5873 \\
0.5625\end{array}$ & $\begin{array}{l}0.1905 \\
0.1905 \\
0.1905 \\
0.2048 \\
0.2048\end{array}$ & $\begin{array}{l}0.5385 \\
0.5385 \\
0.5385 \\
0.5385 \\
0.5385\end{array}$ & $\begin{array}{l}0.0989 \\
0.1111 \\
0.1111 \\
0.1111 \\
0.0989\end{array}$ \\
\hline & $0.5245 \pm 0.01$ & $0.1339 \pm 0.01$ & $0.5674 \pm 0.01$ & $0.1962 \pm 0.01$ & $0.5385 \pm 0.00$ & $0.1062 \pm 0.00$ \\
\hline & & & $\uparrow$ & $\uparrow$ & $\uparrow$ & $\downarrow$ \\
\hline \multirow[t]{3}{*}{$\begin{array}{l}\text { Densidade } \\
\text { numérica }\end{array}$} & $\begin{array}{l}16.83 \\
16.08 \\
16.36 \\
17.78 \\
17.31\end{array}$ & $\begin{array}{l}4.79 \\
4.83 \\
4.59 \\
4.32 \\
4.95\end{array}$ & $\begin{array}{l}13.73 \\
13.16 \\
14.51 \\
12.30 \\
13.45\end{array}$ & $\begin{array}{l}3.73 \\
3.37 \\
3.98 \\
3.43 \\
3.59\end{array}$ & $\begin{array}{l}14.65 \\
14.80 \\
14.71 \\
14.76 \\
14.34\end{array}$ & $\begin{array}{l}1.96 \\
2.33 \\
2.63 \\
2.43 \\
2.20\end{array}$ \\
\hline & $16.87 \pm 0.69$ & $4.69 \pm 0.24$ & $13.43 \pm 0.80$ & $3.62 \pm 0.24$ & $14.65 \pm 0.18$ & $2.31 \pm 0.25$ \\
\hline & & & $\downarrow$ & $\downarrow$ & $v$ & $\downarrow$ \\
\hline \multirow[t]{3}{*}{$\begin{array}{l}\text { Densidade de } \\
\text { superfície }\end{array}$} & $\begin{array}{l}14.72 \\
14.17 \\
13.79 \\
14.89 \\
14.72\end{array}$ & $\begin{array}{l}1.39 \\
1.67 \\
1.31 \\
1.37 \\
1.41\end{array}$ & $\begin{array}{l}14.35 \\
13.80 \\
14.37 \\
13.18 \\
13.04\end{array}$ & $\begin{array}{l}1.82 \\
2.09 \\
2.11 \\
1.93 \\
2.11\end{array}$ & $\begin{array}{l}13.45 \\
14.72 \\
12.26 \\
13.34 \\
14.35\end{array}$ & $\begin{array}{l}1.35 \\
1.37 \\
1.36 \\
1.35 \\
1.37\end{array}$ \\
\hline & $16.87 \pm 1.59$ & $1.43 \pm 0.13$ & $13.74 \pm 0.62$ & $2.01 \pm 0.13$ & $13.62 \pm 0.96$ & $1.36 \pm 0.01$ \\
\hline & & & $\downarrow$ & $\uparrow$ & $\downarrow$ & $\downarrow$ \\
\hline
\end{tabular}

Obs: Estão expressos nesta tabela os dados relativos a: volume nuclear, citoplasmático e celular (em micrometros cúbicos $-\mu \mathrm{m}^{3}$ ), relação núcleo/citoplasma, densidade numérica (número de células em uma área definida) e de superfície (número de células em uma extensão definida de superfície epitelial). 
TABELA 41 - Avaliação dos efeitos da utilização de inibidor de protease sobre os parâmetros dos valores médios dos volumes celulares $\left(\mathrm{em} \mu \mathrm{m}^{3}\right)$ na camada basal do epitélio da língua (região dorsal anterior) dos animais controle e tratados com inibidor de protease. - Avaliação pelo teste Kruskal-Wallis

\section{VOLUME NUCLEAR}

Valor de $\mathrm{H}=11.5800$

Valor de $x^{2} \mathrm{p} / 2^{\circ}$ de liberdade $=11.58$

Probabilidade de $\mathrm{H} 0=0.31 \%$

\begin{tabular}{c|c|c|}
$\begin{array}{c}\text { Controle X } 4 \\
\text { semanas }\end{array}$ & $\begin{array}{c}\text { Controle X } 8 \\
\text { semanas } \\
0.1 \%\end{array}$ & $\begin{array}{c}4 \% \\
1 \%\end{array}$ \\
\hline
\end{tabular}

Significante para $\alpha \leq 0.01$

\section{VOLUME CELULAR}

Valor de $\mathrm{H}=12.5000$

Valor de $\mathrm{x}^{2} \mathrm{p} / 2^{\circ}$ de liberdade $=12.50$

Probabilidade de $\mathrm{H} 0=0.19 \%$

\begin{tabular}{c|c|c|}
$\begin{array}{c}\text { Controle X } 4 \\
\text { semanas }\end{array}$ & $\begin{array}{c}\text { Controle X 8 } \\
\text { semanas }\end{array}$ & 4 sem $X 8$ sem \\
$0.1 \%$ & $0.1 \%$ & $0.1 \%$ \\
\hline
\end{tabular}

Significante para $\alpha \leq 0.01$

\section{VOLUME DO CITOPLASMA}

Valor de $\mathrm{H}=8.0000$
Valor de $\mathrm{x}^{2} \mathrm{p} / 2^{\circ}$ de liberdade $=8.00$

Probabilidade de $\mathrm{HO}=1.83 \%$

\begin{tabular}{|c|c|c|}
\hline $\begin{array}{c}\text { Controle X 4 } \\
\text { semanas } \\
\text { NS }\end{array}$ & $\begin{array}{c}\text { Controle X 8 } \\
\text { semanas } \\
\text { NS }\end{array}$ & 4 sem X 8 sem \\
\hline
\end{tabular}

\section{Significante para $\alpha \leq 0.01$ \\ RELAÇÃO NUCLEO/CITOPLASMA}

Valor de $\mathrm{H}=11.9270$

Valor de $x^{2} p / 2^{\circ}$ de liberdade $=11.93$

Probabilidade de $\mathrm{H} 0=0.26 \%$

\section{Cor}

Controle X 4

semanas

$0.1 \%$
Controle X $8 \quad 4$ sem $X 8$ sem semanas

\begin{tabular}{l|l}
$5 \%$ & $0.1 \%$
\end{tabular}

Significante para $\alpha \leq 0.01$

\section{DENSIDADE NUMÉRICA}

Valor de $\mathrm{H}=12.0200$

Valor de $x^{2} p / 2^{\circ}$ de liberdade $=12.02$

Probabilidade de $\mathrm{HO}=0.25 \%$

Con

Controle X 4

semanas

Controle X 8

4 sem $X 8$ sem

$0.1 \%$ semanas $0.1 \%$ $1 \%$

Significante para $\alpha \leq 0.01$

\section{DENSIDADE DE SUPERFÍCIE}

Valor de $\mathrm{H}=3.4054$

Valor de $x^{2} \mathrm{p} / 2^{\circ}$ de liberdade $=3.41$

Probabilidade de $\mathrm{HO}=18.22 \%$

Controle X 4
semanas
NS

Controle X 8

4 sem $X 8$ sem semanas NS NS

Significante para $\alpha \leq 0.05$ 
TABELA 42 - Avaliação dos efeitos da utilização de inibidor de protease sobre os parâmetros dos valores médios dos volumes celulares $\left(\mathrm{em} \mu \mathrm{m}^{3}\right)$ na camada espinhosa do epitélio da língua (região dorsal anterior) dos animais controle e tratados com inibidor de protease. - Avaliação pelo teste Kruskal-Wallis

\begin{tabular}{|c|c|c|c|}
\hline \multicolumn{4}{|l|}{ VOLUME NUCLEAR } \\
\hline \multirow{2}{*}{$\begin{array}{l}\text { Valor de } H=9.9800 \\
\text { Valor de } x^{2} p / 2^{\circ} \text { de liberdade }=9.98 \\
\text { Probabilidade de } H 0=0.68 \%\end{array}$} & $\begin{array}{l}\text { Controle X } 4 \\
\text { semanas }\end{array}$ & $\begin{array}{c}\text { Controle } X 8 \\
\text { semanas }\end{array}$ & 4 sem $X 8$ sem \\
\hline & $0.1 \%$ & $1 \%$ & NS \\
\hline \multicolumn{4}{|l|}{ Significante para $\alpha \leq 0.01$} \\
\hline \multicolumn{4}{|l|}{ VOLUME CELULAR } \\
\hline \multirow{2}{*}{$\begin{array}{l}\text { Valor de } \mathrm{H}=12.5000 \\
\text { Valor de } \mathrm{x}^{2} \mathrm{p} / 2^{\circ} \text { de liberdade }=12.50 \\
\text { Probabilidade de } \mathrm{H} 0=0.19 \%\end{array}$} & $\begin{array}{l}\text { Controle X } 4 \\
\text { semanas }\end{array}$ & $\begin{array}{l}\text { Controle X } 8 \\
\text { semanas }\end{array}$ & 4 sem $X 8$ sem \\
\hline & $0.1 \%$ & $0.1 \%$ & $0.1 \%$ \\
\hline \multicolumn{4}{|l|}{ Significante para $\alpha \leq 0.01$} \\
\hline \multicolumn{4}{|l|}{ VOLUME DO CITOPLASMA } \\
\hline \multirow{2}{*}{$\begin{array}{l}\text { Valor de } H=11.1800 \\
\text { Valor de } x^{2} p / 2^{\circ} \text { de liberdade }=11.18 \\
\text { Probabilidade de } H 0=0.37 \%\end{array}$} & $\begin{array}{l}\text { Controle X } 4 \\
\text { semanas }\end{array}$ & $\begin{array}{l}\text { Controle X } 8 \\
\text { semanas }\end{array}$ & 4 sem $X 8$ sem \\
\hline & $5 \%$ & $0.1 \%$ & $1 \%$ \\
\hline \multicolumn{4}{|l|}{$\begin{array}{l}\text { Significante para } \alpha \leq 0.01 \\
\text { RELAÇÃO NUCLEO/CITOPLASMA }\end{array}$} \\
\hline \multirow{2}{*}{$\begin{array}{l}\text { Valor de } \mathrm{H}=12.7737 \\
\text { Valor de } \mathrm{x}^{2} \mathrm{p} / 2^{\circ} \text { de liberdade }=12.77 \\
\text { Probabilidade de } \mathrm{HO}=0.17 \%\end{array}$} & $\begin{array}{l}\text { Controle X } 4 \\
\text { semanas }\end{array}$ & $\begin{array}{l}\text { Controle X } 8 \\
\text { semanas }\end{array}$ & 4 sem $X 8$ sem \\
\hline & $0.1 \%$ & $0.1 \%$ & $0.1 \%$ \\
\hline \multicolumn{4}{|l|}{$\begin{array}{l}\text { Significante para } \alpha \leq 0.01 \\
\text { DENSIDADE NUMÉRICA }\end{array}$} \\
\hline \multirow{2}{*}{$\begin{array}{l}\text { Valor de } \mathrm{H}=12.5000 \\
\text { Valor de } \mathrm{x}^{2} \mathrm{p} / 2^{\circ} \text { de liberdade }=12.50 \\
\text { Probabilidade de } \mathrm{H} 0=0.19 \%\end{array}$} & $\begin{array}{l}\text { Controle X } 4 \\
\text { semanas }\end{array}$ & $\begin{array}{l}\text { Controle X } 8 \\
\text { semanas }\end{array}$ & 4 sem $X 8$ sem \\
\hline & $0.1 \%$ & $0.1 \%$ & $0.1 \%$ \\
\hline \multicolumn{4}{|l|}{ Significante para $\alpha \leq 0.01$} \\
\hline \multicolumn{4}{|l|}{ DENSIDADE DE SUPERFÍCIE } \\
\hline \multirow{2}{*}{$\begin{array}{l}\text { Valor de } H=10.3307 \\
\text { Valor de } x^{2} p / 2^{\circ} \text { de liberdade }=10.33 \\
\text { Probabilidade de } H 0=0.57 \%\end{array}$} & $\begin{array}{c}\text { Controle X } 4 \\
\text { semanas }\end{array}$ & $\begin{array}{l}\text { Controle X } 8 \\
\text { semanas } \\
\text { NS }\end{array}$ & 4 sem $X 8$ sem \\
\hline & & & \\
\hline
\end{tabular}


TABELA 43 - Avaliação da espessura (em $\mu \mathrm{m}$ ) do epitélio da língua (região dorsal anterior) dos animais controle e tratados com inibidores de protease.

\begin{tabular}{|c|c|c|c|c|}
\hline Grupos & Camada basal & C.espinhosa & C. queratina & Epitélio total \\
\hline $\begin{array}{l}\text { Animais } \\
\text { Controle }\end{array}$ & $\begin{array}{c}6.49 \\
6.56 \\
6.65 \\
6.84 \\
\therefore=5 \\
\mathbf{6 . 6 1 \pm 0 . 7 4}\end{array}$ & 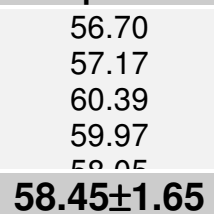 & $\begin{array}{c}58.20 \\
54.16 \\
59.33 \\
52.26 \\
\text { ᄃ } 1 \text { ᄃ } \\
\text { 55.70 } \pm 2.95\end{array}$ & $\begin{array}{r}121.39 \\
117.89 \\
126.37 \\
119.07 \\
11 n+1 \\
\mathbf{1 2 0 . 8 7 \pm 3 . 3 7}\end{array}$ \\
\hline \multirow[t]{2}{*}{$\begin{array}{l}\text { Inibidor de } \\
\text { protease } \\
\text { por } 4 \\
\text { semanas }\end{array}$} & 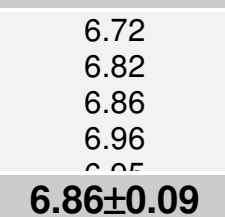 & $\begin{array}{c}39.56 \\
34.23 \\
37.27 \\
38.59 \\
\text { ก7 nn } \\
37.52 \pm 2.02\end{array}$ & $\begin{array}{c}55.99 \\
54.26 \\
53.40 \\
49.25 \\
\text { זᄃ } n n \\
\mathbf{5 3 . 7 6} \pm \mathbf{2 . 7 5}\end{array}$ & $\begin{array}{c}102.27 \\
095.31 \\
097.53 \\
094.80 \\
1 \text { nn nn } \\
98.14+23.31\end{array}$ \\
\hline & $\uparrow$ & $\downarrow$ & $\downarrow$ & $\downarrow$ \\
\hline \multirow[t]{3}{*}{$\begin{array}{l}\text { Inibidor de } \\
\text { protease } \\
\text { por } 8 \\
\text { semanas }\end{array}$} & $\begin{array}{l}7.31 \\
6.96 \\
6.89 \\
7.60 \\
0.07\end{array}$ & $\begin{array}{l}56.02 \\
55.53 \\
54.62 \\
54.52 \\
51\end{array}$ & $\begin{array}{l}67.03 \\
65.31 \\
67.75 \\
68.10 \\
n n-n\end{array}$ & $\begin{array}{l}130.36 \\
127.80 \\
129.26 \\
130.22\end{array}$ \\
\hline & $7.12 \pm 0.31$ & $54.50 \pm 1.62$ & 66.39 \pm 1.81 & $128.02 \pm 3.25$ \\
\hline & $\uparrow$ & $\downarrow$ & $\uparrow$ & $\uparrow$ \\
\hline
\end{tabular}


TABELA 44 - Avaliação da utilização de inibidor de protease sobre os parâmetros dos valores médios da espessura $(\mathrm{em} \mu \mathrm{m})$ no epitélio da língua (região dorsal anterior) dos animais controle e tratados. - Avaliação pelo teste Kruskal-Wallis

\section{ESPESSURA DA CAMADA BASAL}

Valor de $\mathrm{H}=9.5721$

Valor de $\mathrm{x}^{2} \mathrm{p} / 2^{\circ}$ de liberdade $=9.57$

Probabilidade de $\mathrm{HO}=0.83 \%$

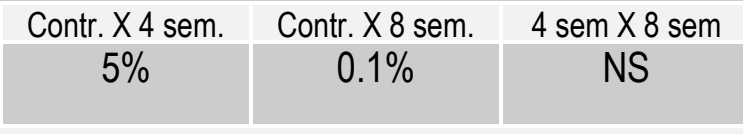

Significante para $\alpha \leq 0.01$

\section{ESPESSURA DA CAMADA ESPINHOSA}

Valor de $\mathrm{H}=12.5000$

Valor de $x^{2} p / 2^{\circ}$ de liberdade $=12.50$

Contr. X 4 sem. Contr. X 8 sem. 4 sem X 8 sem

Probabilidade de $\mathrm{H} 0=0.19 \%$

$0.1 \%$

$0.1 \%$

$0.1 \%$

Significante para $\alpha \leq 0.01$

\section{ESPESSURA DA CAMADA DE QUERATINA}

Valor de $\mathrm{H}=9.6200$

Valor de $\mathrm{x}^{2} \mathrm{p} / 2^{\circ}$ de liberdade $=9.62$

Probabilidade de $\mathrm{H} 0=0.81 \%$

Contr. X 4 sem. Cont. X 8 sem. 4 sem X 8 sem

Significante para $\alpha \leq 0.01$

NS

$1 \%$

$0.1 \%$

\section{ESPESSURA DO EPITÉLIO TOTAL}

Valor de $\mathrm{H}=12.0200$

Valor de $x^{2} p / 2^{\circ}$ de liberdade $=12.02$

Probabilidade de $\mathrm{HO}=0.25 \%$

Contr. X 4 sem. Contr. X 8 sem. 4 sem X 8 sem

Significante para $\alpha \leq 0.01$ 
TABELA 45 - Avaliação da Relação superfície externa/ Superfície basal do epitélio da língua (região dorsal anterior) dos animais controle e tratados com inibidor de protease.

\begin{tabular}{|c|c|c|}
\hline Animais Controle & $\begin{array}{c}\text { Inibidor de protease por } \\
\text { 4 semanas }\end{array}$ & $\begin{array}{c}\text { Inibidor de protease } \\
\text { por 8 semanas }\end{array}$ \\
\hline 0.9360 & 0.7910 & 1.1920 \\
0.7500 & 0.6560 & 1.1440 \\
0.8740 & 0.8670 & 1.1530 \\
0.0960 & 0.8590 & 1.1220 \\
0.7780 & 0.6600 & 1.1260 \\
\hline $\mathbf{0 . 6 8 6 8} \pm \mathbf{0 . 3 3}$ & $\mathbf{0 . 7 6 6 6 \pm 0 . 0 1}$ & $\mathbf{1 . 1 4 7 4 \pm \mathbf { 0 . 0 2 }}$ \\
\hline
\end{tabular}

TABELA 46 - Avaliação dos efeitos da utilização de inibidor de protease sobre os parâmetros dos valores médios da Relação superfície externa/ Superfície basal (em $\mu \mathrm{m})$ no epitélio da língua (região dorsal anterior) dos animais controle e tratados. - Avaliação pelo teste Kruskal-Wallis

\begin{tabular}{|c|c|c|c|}
\hline \multicolumn{4}{|c|}{ RELAÇÃO SUPERF. EXTERNA/SUPERF. BASAL DO EPITÉLIO DA PELE } \\
\hline Valor de $H=9.4200$ & Controle X 4 & Controle X 8 & 4 sem $X 8$ sem \\
\hline Valor de $x^{2} p / 2^{\circ}$ de liberdade & seman & semanas & \\
\hline $\mathrm{e} \mathrm{H} 0=0.90 \%$ & NS & $1 \%$ & $0.1 \%$ \\
\hline
\end{tabular}

Significante para $\alpha \leq 0.01$ 
TABELA 47 - Avaliação dos valores médios dos volumes celulares (em $\mu \mathrm{m}^{3}$ ) no epitélio da língua (região dorsal intermediária) dos animais controle e tratado com inibidor de protease.

\begin{tabular}{|c|c|c|c|c|c|c|}
\hline \multirow{2}{*}{$\begin{array}{l}\text { Estrutura } \\
\text { Estudada }\end{array}$} & \multicolumn{2}{|c|}{ Animais Controle } & \multicolumn{2}{|c|}{ Tratados - 4 semanas } & \multicolumn{2}{|c|}{ Tratados - 8 semanas } \\
\hline & C.Basal & C.Espinh. & C.basal & C.espinh. & C.basal & C.espinh. \\
\hline \multirow[t]{3}{*}{ Volume nuclear } & $\begin{array}{l}50.77 \\
62.04 \\
49.53 \\
52.99 \\
57.06\end{array}$ & $\begin{array}{l}59.36 \\
70.25 \\
57.08 \\
59.82 \\
65.32\end{array}$ & $\begin{array}{l}55.51 \\
65.33 \\
56.43 \\
62.37 \\
62.29\end{array}$ & $\begin{array}{l}63.69 \\
74.01 \\
74.18 \\
76.47 \\
65.65\end{array}$ & $\begin{array}{l}72.05 \\
65.62 \\
67.45 \\
68.81 \\
66.56\end{array}$ & $\begin{array}{l}77.15 \\
72.56 \\
67.56 \\
65.81 \\
68.11\end{array}$ \\
\hline & $54.47 \pm 5.10$ & $62.36 \pm 5.34$ & $60.38 \pm 4.22$ & $70.80 \pm 5.72$ & $68.09 \pm 2.50$ & $70.23 \pm 4.59$ \\
\hline & & & $\uparrow$ & $\uparrow$ & $\uparrow$ & $\uparrow$ \\
\hline \multirow[t]{3}{*}{ Volume celular } & $\begin{array}{l}64.54 \\
54.70 \\
62.09 \\
56.16 \\
59.20\end{array}$ & $\begin{array}{l}207.62 \\
194.57 \\
214.48 \\
205.38 \\
202.50\end{array}$ & $\begin{array}{l}58.34 \\
69.91 \\
69.85 \\
65.02 \\
65.14\end{array}$ & $\begin{array}{l}193.33 \\
217.07 \\
201.67 \\
217.12 \\
201.40\end{array}$ & $\begin{array}{l}73.40 \\
67.62 \\
70.58 \\
69.65 \\
67.97\end{array}$ & $\begin{array}{l}291.51 \\
269.53 \\
259.06 \\
282.31 \\
272.72\end{array}$ \\
\hline & $58.91 \pm 4.19$ & $204.91 \pm 7.27$ & $65.65 \pm 4.74$ & $206.11 \pm 10.56$ & $69.84 \pm 2.32$ & $275.02 \pm 12.40$ \\
\hline & & & $\uparrow$ & $\uparrow$ & $\uparrow$ & $\uparrow$ \\
\hline \multirow[t]{3}{*}{$\begin{array}{l}\text { Volume do } \\
\text { citoplasma }\end{array}$} & $\begin{array}{l}15.01 \\
01.71 \\
00.05 \\
05.39 \\
02.14\end{array}$ & $\begin{array}{l}142.39 \\
137.49 \\
144.23 \\
145.56 \\
143.14\end{array}$ & $\begin{array}{l}01.91 \\
04.58 \\
07.48 \\
02.73 \\
09.53\end{array}$ & $\begin{array}{l}119.15 \\
143.06 \\
125.20 \\
151.47 \\
137.71\end{array}$ & $\begin{array}{l}1.35 \\
2.00 \\
1.77 \\
2.20 \\
1.41\end{array}$ & $\begin{array}{l}214.36 \\
196.97 \\
193.25 \\
214.75 \\
204.61\end{array}$ \\
\hline & $4.86 \pm 5.99$ & $142.56 \pm 06.2$ & $5.32 \pm 3.19$ & $135.31 \pm 13.1$ & $1.74 \pm 0.36$ & $204.78 \pm 9.81$ \\
\hline & & & $\uparrow$ & $\downarrow$ & $\downarrow$ & $\uparrow$ \\
\hline \multirow[t]{3}{*}{$\begin{array}{c}\text { Relação Núcleo/ } \\
\text { citoplasma }\end{array}$} & $\begin{array}{l}0.4925 \\
0.4706 \\
0.4706 \\
0.4706 \\
0.4706\end{array}$ & $\begin{array}{l}0.1236 \\
0.1236 \\
0.1236 \\
0.1111 \\
0.1111\end{array}$ & $\begin{array}{l}0.4706 \\
0.5385 \\
0.4925 \\
0.4925 \\
0.6925\end{array}$ & $\begin{array}{l}0.1494 \\
0.1364 \\
0.1494 \\
0.1494 \\
0.1364\end{array}$ & $\begin{array}{l}0.5625 \\
0.5385 \\
0.5385 \\
0.5385 \\
0.5385\end{array}$ & $\begin{array}{l}0.1111 \\
0.1111 \\
0.0989 \\
0.0989 \\
0.0989\end{array}$ \\
\hline & $0.4750 \pm 0.00$ & $0.1186 \pm 0.00$ & $0.5373 \pm 0.09$ & $0.3442 \pm 0.44$ & $0.5433 \pm 0.01$ & $0.1038 \pm 0.00$ \\
\hline & & & $\uparrow$ & 个 & $\uparrow$ & $\downarrow$ \\
\hline \multirow[t]{2}{*}{$\begin{array}{l}\text { Densidade } \\
\text { numérica }\end{array}$} & $\begin{array}{l}15.50 \\
19.69 \\
16.11 \\
19.17 \\
16.89\end{array}$ & $\begin{array}{l}4.82 \\
4.93 \\
4.45 \\
4.87 \\
4.94\end{array}$ & $\begin{array}{l}17.14 \\
13.91 \\
14.30 \\
15.38 \\
15.35\end{array}$ & $\begin{array}{l}5.77 \\
4.61 \\
4.96 \\
4.61 \\
5.20\end{array}$ & $\begin{array}{l}13.62 \\
15.42 \\
14.17 \\
14.78 \\
15.16\end{array}$ & $\begin{array}{l}3.43 \\
3.71 \\
3.86 \\
3.54 \\
3.67\end{array}$ \\
\hline & $17.47 \pm 1.86$ & $4.80 \pm 0.20$ & $\begin{array}{c}15.21 \pm 1.25 \\
\Downarrow\end{array}$ & $\begin{array}{c}5.03 \pm 0.48 \\
\uparrow\end{array}$ & $\begin{array}{c}14.63 \pm 0.73 \\
\Downarrow\end{array}$ & $\begin{array}{c}3.64 \pm 0.16 \\
\Downarrow\end{array}$ \\
\hline \multirow[t]{2}{*}{$\begin{array}{l}\text { Densidade de } \\
\text { superfície }\end{array}$} & $\begin{array}{l}17.10 \\
16.19 \\
17.35 \\
18.16 \\
18.27\end{array}$ & $\begin{array}{l}1.62 \\
1.57 \\
1.56 \\
1.60 \\
1.64\end{array}$ & $\begin{array}{l}15.56 \\
15.99 \\
14.95 \\
16.17 \\
14.92\end{array}$ & $\begin{array}{l}1.44 \\
1.51 \\
1.47 \\
1.48 \\
1.47\end{array}$ & $\begin{array}{l}17.88 \\
17.71 \\
16.27 \\
17.98 \\
16.25\end{array}$ & $\begin{array}{l}1.49 \\
1.45 \\
1.47 \\
1.49 \\
1.53\end{array}$ \\
\hline & $17.41 \pm 0.85$ & $1.59 \pm 0.03$ & $15.51 \pm 0.57$ & $1.47 \pm 0.02$ & $17.21 \pm 0.87$ & $1.48 \pm 0.02$ \\
\hline
\end{tabular}

Obs: Estão expressos nesta tabela os dados relativos a: volume nuclear, citoplasmático e celular (em micrometros cúbicos $-\mu \mathrm{m}^{3}$ ), relação núcleo/citoplasma, densidade numérica (número de células em uma área definida) e de superfície (número de células em uma extensão definida de superfície epitelial). 
TABELA 48 - Avaliação dos efeitos da utilização de inibidor de protease sobre os parâmetros dos valores médios dos volumes celulares $\left(\mathrm{em} \mu \mathrm{m}^{3}\right)$ na camada basal do epitélio da língua (região dorsal intermediária) dos animais controle e tratados com inibidor de protease. - Avaliação pelo teste Kruskal-Wallis

\section{VOLUME NUCLEAR}

Valor de $\mathrm{H}=10.8200$

Valor de $x^{2} p / 2^{\circ}$ de liberdade $=10.82$

Probabilidade de $\mathrm{H} 0=0.45 \%$

Controle X 4

semanas

$5 \%$

Significante para $\alpha \leq 0.01$

\section{VOLUME CELULAR}

Valor de $\mathrm{H}=8.5400$

Valor de $\mathrm{x}^{2} \mathrm{p} / 2^{\circ}$ de liberdade $=8.54$

Probabilidade de $\mathrm{HO}=1.40 \%$

Significante para $\alpha \leq 0.01$

\section{VOLUME DO CITOPLASMA}

Valor de $\mathrm{H}=3.9200$

Valor de $x^{2} p / 2^{\circ}$ de liberdade $=3.92$

Probabilidade de $\mathrm{HO}=14.09 \%$

Significante para $\alpha \leq 0.05$
Controle X 4

semanas

$5 \%$
Controle X 8 semanas $0.1 \%$ $1 \%$

\section{RELAÇÃO NUCLEO/CITOPLASMA}

Valor de $\mathrm{H}=8.4000$

Valor de $\mathrm{x}^{2} \mathrm{p} / 2^{\circ}$ de liberdade $=8.40$

Probabilidade de $\mathrm{HO}=1.50 \%$

Significante para $\alpha \leq 0.01$

\section{DENSIDADE NUMÉRICA}

\section{Valor de $\mathrm{H}=7.7600$}

Valor de $x^{2} \mathrm{p} / 2^{\circ}$ de liberdade $=7.76$

Probabilidade de $\mathrm{H} 0=2.07 \%$

\section{Controle X 4 \\ semanas}

NS

\section{Controle X 8 semanas} $1 \%$
4 sem $X 8$ sem

NS
Significante para $\alpha \leq 0.05$

\section{DENSIDADE DE SUPERFÍCIE}

Valor de $\mathrm{H}=9.4200$

Valor de $x^{2} p / 2^{\circ}$ de liberdade $=9.42$

Probabilidade de $\mathrm{HO}=0.90 \%$

Significante para $\alpha \leq 0.01$

\begin{tabular}{|c|c|c|}
\hline $\begin{array}{c}\text { Controle X } 4 \\
\text { semanas } \\
5 \%\end{array}$ & $\begin{array}{c}\text { Controle X } 8 \\
\text { semanas } \\
1 \%\end{array}$ & 4 sem $\mathrm{X} 8$ sem \\
\hline $\begin{array}{c}\text { Controle X } 4 \\
\text { semanas } \\
5 \%\end{array}$ & $\begin{array}{c}\text { Controle X } 8 \\
\text { semanas } \\
1 \%\end{array}$ & 4 sem X 8 sem \\
\hline & NS \\
\hline
\end{tabular}

\section{Controle X 8} semanas

NS 
TABELA 49 - Avaliação dos efeitos da utilização de inibidor de protease sobre os parâmetros dos valores médios dos volumes celulares (em $\mu \mathrm{m}^{3}$ ) na camada espinhosa do epitélio da língua (região dorsal intermediária) dos animais controle e tratados com inibidor de protease. - Avaliação pelo teste Kruskal-Wallis

\section{VOLUME NUCLEAR}

Valor de $\mathrm{H}=5.4200$

Valor de $\mathrm{x}^{2} \mathrm{p} / 2^{\circ}$ de liberdade $=5.42$

Probabilidade de $\mathrm{HO}=6.65 \%$

Controle X 4

semanas

$5 \%$

Significante para $\alpha \leq 0.05$

\section{VOLUME CELULAR}

\section{Valor de $\mathrm{H}=9.3800$}

Valor de $x^{2} \mathrm{p} / 2^{\circ}$ de liberdade $=9.38$

Probabilidade de $\mathrm{HO}=0.92 \%$

Significante para $\alpha \leq 0.01$

\section{VOLUME DO CITOPLASMA}

Valor de $\mathrm{H}=9.7800$

Valor de $x^{2} p / 2^{\circ}$ de liberdade $=9.78$

Probabilidade de $\mathrm{HO}=0.75 \%$

Significante para $\alpha \leq 0.01$

\section{RELAÇÃO NUCLEO/CITOPLASMA}

Valor de $\mathrm{H}=12.0760$

Valor de $x^{2} p / 2^{\circ}$ de liberdade $=12.08$

Probabilidade de $\mathrm{HO}=0.24 \%$

Significante para $\alpha \leq 0.01$

\section{DENSIDADE NUMÉRICA}

\section{Valor de $\mathrm{H}=9.7975$}

Valor de $x^{2} p / 2^{\circ}$ de liberdade $=9.80$

Probabilidade de $\mathrm{H} 0=0.75 \%$

Controle X 4
semanas
NS

\begin{tabular}{c|c}
$\begin{array}{c}\text { Controle } X 8 \\
\text { semanas } \\
1 \%\end{array}$ & 4 sem $X 8$ sem \\
\hline$\%$ & $0.1 \%$
\end{tabular}

\begin{tabular}{|c|c|}
\hline Controle X 8 & 4 sem $X 8$ sem \\
\hline $5 \%$ & NS \\
\hline
\end{tabular}

Significante para $\alpha \leq 0.01$

\section{DENSIDADE DE SUPERFÍCIE}

Valor de $\mathrm{H}=9.7067$

Valor de $\mathrm{x}^{2} \mathrm{p} / 2^{\circ}$ de liberdade $=9.71$

Probabilidade de $\mathrm{HO}=0.78 \%$

Significante para $\alpha \leq 0.01$

\begin{tabular}{|c|c|c|}
\hline $\begin{array}{c}\text { Controle X } 4 \\
\text { semanas } \\
\text { NS }\end{array}$ & $\begin{array}{c}\text { Controle X } 8 \\
\text { semanas } \\
1 \%\end{array}$ & 4 sem $X 8$ sem \\
\hline $\begin{array}{c}\text { Controle X } 4 \\
\text { semanas }\end{array}$ & $\begin{array}{c}\text { Controle X } 8 \\
\text { semanas }\end{array}$ & 4 sem $X 8$ sem \\
\hline $0.1 \%$ & $1 \%$ & $0.1 \%$ \\
\hline $\begin{array}{c}\text { Controle X } 4 \\
\text { semanas } \\
\text { NS }\end{array}$ & $\begin{array}{c}\text { Controle X } 8 \\
\text { semanas } \\
1 \%\end{array}$ & 4 sem $X 8$ sem \\
\hline $\begin{array}{l}\text { Controle X } 4 \\
\text { semanas }\end{array}$ & $\begin{array}{c}\text { Controle X } 8 \\
\text { semanas }\end{array}$ & 4 sem $X 8$ sem \\
\hline $0.1 \%$ & $1 \%$ & NS \\
\hline
\end{tabular}


TABELA 50 - Avaliação da espessura (em $\mu \mathrm{m}$ ) do epitélio da língua (região dorsal intermediária) dos animais controle e tratados com inibidores de protease.

\begin{tabular}{|c|c|c|c|c|}
\hline $\begin{array}{l}\text { Grupos } \\
\text { estudados }\end{array}$ & C. basal & C. espinh. & C. queratina & $\begin{array}{c}\text { Epitélio } \\
\text { total }\end{array}$ \\
\hline \multirow[t]{5}{*}{ Animais Controle } & 5.42 & 31.37 & 23.71 & 60.50 \\
\hline & 5.47 & 33.45 & 28.93 & 67.85 \\
\hline & 5.29 & 31.48 & 29.73 & 66.50 \\
\hline & 5.02 & 31.75 & 22.86 & 59.63 \\
\hline & $\begin{array}{c}\approx \cap n \\
5.25 \pm 0.19\end{array}$ & $\begin{array}{c}n \cap \cap n \\
31.66 \pm 1.14\end{array}$ & $\begin{array}{c}n=1 n \\
26.13 \pm 3.07\end{array}$ & $63.05 \pm 3.81$ \\
\hline \multirow{6}{*}{$\begin{array}{l}\text { Inibidor de } \\
\text { protease por } 4 \\
\text { semanas }\end{array}$} & 5.98 & 43.12 & 28.38 & 77.48 \\
\hline & 5.92 & 40.06 & 28.46 & 74.44 \\
\hline & 5.84 & 41.51 & 29.92 & 77.27 \\
\hline & 5.77 & 40.49 & 27.61 & 73.87 \\
\hline & $5.90 \pm 0.09$ & $41.62 \pm 1.39$ & $28.55 \pm 0.84$ & $76.08 \pm 1.77$ \\
\hline & $\uparrow$ & $\uparrow$ & $\uparrow$ & $\uparrow$ \\
\hline \multirow{6}{*}{$\begin{array}{l}\text { Inibidor de } \\
\text { protease por } 8 \\
\text { semanas }\end{array}$} & 5.64 & 36.28 & 24.36 & 66.28 \\
\hline & 5.57 & 37.80 & 23.00 & 66.37 \\
\hline & 5.80 & 38.06 & 23.68 & 67.54 \\
\hline & 5.92 & 37.27 & 22.81 & 66.00 \\
\hline & $5.75 \pm 0.14$ & $37.24 \pm 0.72$ & $23.68 \pm 0.78$ & $66.68 \pm 0.65$ \\
\hline & $\uparrow$ & $\uparrow$ & $\uparrow$ & $\uparrow$ \\
\hline
\end{tabular}


TABELA 51- Efeitos da utilização de inibidor de protease sobre a espessura (em $\mu \mathrm{m})$ no epitélio da língua (região dorsal intermediária) dos animais controle e tratados. - teste Kruskal-Wallis

\section{ESPESSURA DA CAMADA BASAL}

Valor de $\mathrm{H}=10.3735$

Valor de $x^{2} \mathrm{p} / 2^{\circ}$ de liberdade $=10.37$

Probabilidade de $\mathrm{HO}=0.56 \%$

Contr. X 4 sem. Contr. X 8 sem. 4 sem X 8 sem

$0.1 \%$

$1 \%$

NS

Significante para $\alpha \leq 0.01$

\section{ESPESSURA DA CAMADA ESPINHOSA}

Valor de $\mathrm{H}=12.5000$

Valor de $x^{2} p / 2^{\circ}$ de liberdade $=12.50$

Probabilidade de $\mathrm{HO}=0.19 \%$

Contr. X 4 sem.

Contr. X 8 sem.

4 sem $X 8$ sem

Significante para $\alpha \leq 0.01$

\section{$0.1 \%$}

$0.1 \%$

$0.1 \%$

\section{ESPESSURA DA CAMADA DE QUERATINA}

Valor de $\mathrm{H}=6.5517$

Valor de $\mathrm{x}^{2} \mathrm{p} / 2^{\circ}$ de liberdade $=6.55$

Probabilidade de $\mathrm{HO}=3.78 \%$

Significante para $\alpha \leq 0.05$

\section{ESPESSURA DO EPITÉLIO TOTAL}

Valor de $\mathrm{H}=9.7800$

Valor de $x^{2} \mathrm{p} / 2^{\circ}$ de liberdade $=9.78$

Probabilidade de $\mathrm{HO}=0.75 \%$

Contr. X 4 sem

NS

Contr. X 8 sem.

NS

4 sem $X 8$ sem

Significante para $\alpha \leq 0.01$

\section{Contr. X 4 sem. Contr. X 8 sem.}

$0.1 \%$

NS
4 sem $X 8$ sem

$1 \%$ 
TABELA 52 - Avaliação da Relação superfície externa/ Superfície basal do epitélio da língua (região dorsal intermediária) dos animais controle e tratados com inibidor de protease.

\begin{tabular}{|c|c|c|}
\hline $\begin{array}{c}\text { Animais } \\
\text { Controle }\end{array}$ & $\begin{array}{c}\text { Inibidor de protease por } \\
\mathbf{4} \text { semanas }\end{array}$ & $\begin{array}{c}\text { Inibidor de protease por } \\
\mathbf{8} \text { semanas }\end{array}$ \\
\hline 0.8600 & 0.9560 & 1.1520 \\
1.1010 & 0.9720 & 1.2250 \\
1.1150 & 0.9260 & 1.2940 \\
1.1160 & 0.9600 & 1.1410 \\
0.8970 & 0.9500 & 1.2010 \\
\hline $\mathbf{1 . 0 1 7 8} \pm \mathbf{0 . 1 2}$ & $\mathbf{0 . 9 5 2 8} \pm \mathbf{0 . 0 1}$ & $\mathbf{1 . 2 0 2 6 \pm 0 . 0 6}$ \\
\hline
\end{tabular}

TABELA 53 - Avaliação dos efeitos da utilização de inibidor de protease sobre os parâmetros dos valores médios da Relação superfície externa/ Superfície basal (em $\mu \mathrm{m})$ no epitélio da língua (região dorsal intermediária) dos animais controle e tratados. - Avaliação pelo teste Kruskal-Wallis

RELAÇÃO SUPERF. EXTERNA/SUPERF. BASAL DO EPITÉLIO DA PELE

Valor de $\mathrm{H}=9.5000$

Valor de $x^{2} \mathrm{p} / 2^{\circ}$ de liberdade $=9.50$

Probabilidade de $\mathrm{H} 0=0.87 \%$

Significante para $\alpha \leq 0.01$
Controle X 4

semanas

NS
Controle X 8

semanas

$1 \%$
4 sem $X 8$ sem

$0.1 \%$ 
TABELA 54 - Avaliação dos valores médios dos volumes celulares (em $\mu \mathrm{m}^{3}$ ) no epitélio da língua (região dorsal posterior) dos animais controle e tratados com inibidor de protease.

\begin{tabular}{|c|c|c|c|c|c|c|}
\hline \multirow{2}{*}{$\begin{array}{l}\text { Estrutura } \\
\text { Estudada }\end{array}$} & \multicolumn{2}{|c|}{ Animais Controle } & \multicolumn{2}{|c|}{ Tratados - 4 semanas } & \multicolumn{2}{|c|}{ Tratados - 8 semanas } \\
\hline & C.Basal & C.Espinh. & C.basal & C.espinh. & C.basal & C.espinh. \\
\hline \multirow[t]{3}{*}{ Volume nuclear } & $\begin{array}{l}83.29 \\
83.49 \\
93.18 \\
92.15 \\
92.33\end{array}$ & $\begin{array}{l}095.66 \\
091.64 \\
103.70 \\
096.43 \\
098.16\end{array}$ & $\begin{array}{l}57.89 \\
58.35 \\
65.60 \\
64.86 \\
59.82\end{array}$ & $\begin{array}{l}123.49 \\
138.39 \\
110.08 \\
103.10 \\
105.61\end{array}$ & $\begin{array}{l}108.13 \\
102.87 \\
125.54 \\
101.29 \\
098.19\end{array}$ & $\begin{array}{l}134.73 \\
130.09 \\
146.98 \\
107.23 \\
119.44\end{array}$ \\
\hline & $88.88 \pm 5.03$ & $97.11 \pm 4.38$ & $61.30 \pm 3.66$ & $116.13 \pm 14.7$ & $127.69 \pm 15.1$ & $127.69 \pm 15.1$ \\
\hline & & & $v$ & $\uparrow$ & $\uparrow$ & 个 \\
\hline \multirow[t]{3}{*}{ Volume celular } & $\begin{array}{l}86.76 \\
95.01 \\
98.13 \\
84.59 \\
93.03\end{array}$ & $\begin{array}{l}345.69 \\
383.79 \\
382.53 \\
381.27 \\
372.11\end{array}$ & $\begin{array}{l}57.73 \\
58.07 \\
65.71 \\
65.70 \\
59.20\end{array}$ & $\begin{array}{l}452.61 \\
447.29 \\
412.51 \\
392.28 \\
398.55\end{array}$ & $\begin{array}{l}119.17 \\
110.14 \\
106.96 \\
124.71 \\
104.33\end{array}$ & $\begin{array}{l}676.96 \\
546.77 \\
535.46 \\
663.13 \\
553.79\end{array}$ \\
\hline & $91.50 \pm 5.67$ & $373.07 \pm 99.1$ & $61.28 \pm 4.07$ & $420.64 \pm 27.79$ & $113.06 \pm 8.58$ & $595.22 \pm 68.79$ \\
\hline & & & $\downarrow$ & $\uparrow$ & $\uparrow$ & $\uparrow$ \\
\hline \multirow[t]{3}{*}{$\begin{array}{l}\text { Volume do } \\
\text { citoplasma }\end{array}$} & $\begin{array}{l}3.27 \\
1.83 \\
5.80 \\
1.30 \\
0.88\end{array}$ & $\begin{array}{l}254.05 \\
280.09 \\
284.37 \\
285.61 \\
275.68\end{array}$ & $\begin{array}{l}2.17 \\
1.00 \\
0.85 \\
5.88 \\
1.31\end{array}$ & $\begin{array}{l}342.53 \\
308.90 \\
309.41 \\
286.67 \\
275.49\end{array}$ & $\begin{array}{l}11.04 \\
07.27 \\
05.67 \\
06.00 \\
06.14\end{array}$ & $\begin{array}{l}542.23 \\
416.68 \\
428.23 \\
516.15 \\
434.35\end{array}$ \\
\hline & $2.61 \pm 1.99$ & $275.96 \pm 12.85$ & $2.24 \pm 2.09$ & $304.60 \pm 25.73$ & $7.22 \pm 2.21$ & $467.52 \pm 57.39$ \\
\hline & & & $\downarrow$ & 个 & $\uparrow$ & 个 \\
\hline \multirow[t]{3}{*}{$\begin{array}{c}\text { Relação Núcleo/ } \\
\text { citoplasma }\end{array}$} & $\begin{array}{l}0.5385 \\
0.5873 \\
0.5385 \\
0.5625 \\
0.5873\end{array}$ & $\begin{array}{l}0.1111 \\
0.0989 \\
0.0989 \\
0.0989 \\
0.1111\end{array}$ & $\begin{array}{l}0.5152 \\
0.5152 \\
0.5385 \\
0.5385 \\
0.5385\end{array}$ & $\begin{array}{l}0.1111 \\
0.1236 \\
0.1111 \\
0.1111 \\
0.1111\end{array}$ & $\begin{array}{l}0.5625 \\
0.5625 \\
0.5385 \\
0.5873 \\
0.5625\end{array}$ & $\begin{array}{l}0.0870 \\
0.0989 \\
0.0870 \\
0.0989 \\
0.0870\end{array}$ \\
\hline & $0.5628 \pm 0.02$ & $0.1038 \pm 0.00$ & $0.5292 \pm 0.01$ & $0.1136 \pm 0.00$ & $0.5627 \pm 0.01$ & $00918 \pm 0.00$ \\
\hline & & & $\downarrow$ & $\uparrow$ & $\uparrow$ & $\downarrow$ \\
\hline \multirow[t]{3}{*}{ Densidade numérica } & $\begin{array}{l}11.53 \\
10.52 \\
10.19 \\
11.82 \\
10.75\end{array}$ & $\begin{array}{l}2.89 \\
2.31 \\
2.55 \\
2.62 \\
2.69\end{array}$ & $\begin{array}{l}17.32 \\
17.22 \\
15.22 \\
15.22 \\
16.89\end{array}$ & $\begin{array}{l}1.99 \\
2.01 \\
2.42 \\
2.55 \\
2.51\end{array}$ & $\begin{array}{l}8.39 \\
9.08 \\
9.35 \\
7.42 \\
9.59\end{array}$ & $\begin{array}{l}1.48 \\
1.83 \\
1.94 \\
1.51 \\
1.81\end{array}$ \\
\hline & $10.96 \pm 0.68$ & $2.61 \pm 0.21$ & $16.37 \pm 1.07$ & $2.29 \pm 0.27$ & $8.76 \pm 0.87$ & $1.71 \pm 020$ \\
\hline & & & $\uparrow$ & $v$ & 个 & $v$ \\
\hline \multirow[t]{3}{*}{$\begin{array}{l}\text { Densidade de } \\
\text { superfície }\end{array}$} & $\begin{array}{l}16.23 \\
14.67 \\
17.27 \\
14.96 \\
13.02\end{array}$ & $\begin{array}{l}3.58 \\
4.25 \\
3.65 \\
4.11 \\
4.37\end{array}$ & $\begin{array}{l}16.67 \\
15.29 \\
16.69 \\
14.98 \\
15.18\end{array}$ & $\begin{array}{l}3.47 \\
3.81 \\
3.62 \\
3.79 \\
3.87\end{array}$ & $\begin{array}{l}13.90 \\
12.83 \\
13.01 \\
13.66 \\
14.02\end{array}$ & $\begin{array}{l}2.41 \\
2.25 \\
2.32 \\
2.23 \\
2.33\end{array}$ \\
\hline & $15.23 \pm 1.61$ & $3.99 \pm 0.37$ & $15.76 \pm 0.84$ & $3.71 \pm 0.16$ & $13.48 \pm 0.51$ & $2.30 \pm 0.07$ \\
\hline & & & $\uparrow$ & $\downarrow$ & $\downarrow$ & $\downarrow$ \\
\hline
\end{tabular}

Obs: Estão expressos nesta tabela os dados relativos a: volume nuclear, citoplasmático e celular (em micrometros cúbicos $-\mu \mathrm{m}^{3}$ ), relação núcleo/citoplasma, densidade numérica (número de células em uma área definida) e de superfície (número de células em uma extensão definida de superfície epitelial). 
TABELA 55 - Avaliação dos efeitos da utilização de inibidor de protease sobre os parâmetros dos valores médios dos volumes celulares $\left(\mathrm{em} \mu \mathrm{m}^{3}\right)$ na camada basal do epitélio da língua (região dorsal posterior) dos animais controle e tratados com inibidor de protease. - Avaliação pelo teste Kruskal-Wallis

\section{VOLUME NUCLEAR}

Valor de $\mathrm{H}=12.5000$

Valor de $\mathrm{x}^{2} \mathrm{p} / 2^{\circ}$ de liberdade $=12.50$

Probabilidade de $\mathrm{H} 0=0.19 \%$

Controle X 4

semanas

$0.1 \%$
Controle X 8

semanas

$0.1 \%$

4 sem $X 8$ sem

$0.1 \%$

Significante para $\alpha \leq 0.01$

\section{VOLUME CELULAR}

Valor de $\mathrm{H}=12.5000$

Valor de $x^{2} \mathrm{p} / 2^{\circ}$ de liberdade $=12.50$

Probabilidade de $\mathrm{HO}=0.19 \%$

Significante para $\alpha \leq 0.01$

\begin{tabular}{c|c|c}
$\begin{array}{c}\text { Controle X } 4 \\
\text { semanas }\end{array}$ & $\begin{array}{c}\text { Controle } \mathrm{X} 8 \\
\text { semanas }\end{array}$ & 4 sem $\mathrm{X} 8 \mathrm{sem}$ \\
$0.1 \%$ & $0.1 \%$ & $0.1 \%$
\end{tabular}

\section{VOLUME DO CITOPLASMA}

Valor de $\mathrm{H}=7.9800$

Valor de $x^{2} p / 2^{\circ}$ de liberdade $=7.98$

Probabilidade de $\mathrm{HO}=1.85 \%$

\section{Controle X 4 \\ semanas \\ NS}
Controle X $8 \quad 4$ sem X 8 sem semanas $1 \%$ $1 \%$

Significante para $\alpha \leq 0.01$

\section{RELAÇÃO NUCLEO/CITOPLASMA}

Valor de $\mathrm{H}=6.9341$

Valor de $x^{2} \mathrm{p} / 2^{\circ}$ de liberdade $=6.93$

Probabilidade de $\mathrm{HO}=3.12 \%$

\section{Con}

Controle X 4

semanas

Controle X 8

4 sem $X 8$ sem

$5 \%$ semanas

Significante para $\alpha \leq 0.05$

\section{DENSIDADE NUMÉRICA}

Valor de $\mathrm{H}=12.5224$

Valor de $x^{2} \mathrm{p} / 2^{\circ}$ de liberdade $=12.52$

Probabilidade de $\mathrm{HO}=0.19 \%$

Controle X 4

semanas

Controle X 8

4 sem $X 8$ sem

$0.1 \%$

semanas

Significante para $\alpha \leq 0.01$

\section{DENSIDADE DE SUPERFÍCIE}

Valor de $\mathrm{H}=7.9800$

Valor de $\mathrm{x}^{2} \mathrm{p} / 2^{\circ}$ de liberdade $=7.98$

Probabilidade de $\mathrm{HO}=1.85 \%$
Controle X 4

semanas

NS
Controle X 8

4 sem $X 8$ sem semanas 
TABELA 56 - Avaliação dos efeitos da utilização de inibidor de protease sobre os parâmetros dos valores médios dos volumes celulares $\left(\mathrm{em} \mu \mathrm{m}^{3}\right)$ na camada espinhosa do epitélio da língua (região dorsal posterior) dos animais controle e tratados com inibidor de protease. - Avaliação pelo teste Kruskal-Wallis

\section{VOLUME NUCLEAR}

Valor de $\mathrm{H}=9.3600$
Valor de $\mathrm{x}^{2} \mathrm{p} / 2^{\circ}$ de liberdade $=9.36$

Probabilidade de $\mathrm{HO}=0.93 \%$

\begin{tabular}{|c|c|c|}
\hline $\begin{array}{c}\text { Controle X } 4 \\
\text { semanas }\end{array}$ & $\begin{array}{c}\text { Controle X } 8 \\
\text { semanas }\end{array}$ & 4 sem X 8 sem \\
\hline $1 \%$ & $0.1 \%$ & NS \\
\hline
\end{tabular}

Significante para $\alpha \leq 0.01$

\section{VOLUME CELULAR}

Valor de $H=12.5000$
Valor de $x^{2} p / 2^{\circ}$ de liberdade $=12.50$

Probabilidade de $\mathrm{HO}=0.19 \%$

\begin{tabular}{|c|c|c|}
\hline $\begin{array}{c}\text { Controle X } 4 \\
\text { semanas }\end{array}$ & $\begin{array}{c}\text { Controle X } 8 \\
\text { semanas }\end{array}$ & 4 sem $X 8$ sem \\
$0.1 \%$ & $0.1 \%$ & $0.1 \%$ \\
\hline
\end{tabular}

Significante para $\alpha \leq 0.01$

\section{VOLUME DO CITOPLASMA}

Valor de $\mathrm{H}=10.8200$

Valor de $\mathrm{x}^{2} \mathrm{p} / 2^{\circ}$ de liberdade $=10.82$

Probabilidade de $\mathrm{HO}=0.45 \%$

\begin{tabular}{c|c|c|}
\hline $\begin{array}{c}\text { Controle X } 4 \\
\text { semanas } \\
5 \%\end{array}$ & $\begin{array}{c}\text { Controle X 8 } \\
\text { semanas } \\
0.1 \%\end{array}$ & 4 sem X 8 sem \\
\hline
\end{tabular}

Significante para $\alpha \leq 0.01$

\section{RELAÇÃO NUCLEO/CITOPLASMA}

Valor de $\mathrm{H}=10.3505$

Valor de $x^{2} p / 2^{\circ}$ de liberdade $=10.35$

Probabilidade de $\mathrm{HO}=0.57 \%$

Significante para $\alpha \leq 0.01$

\section{DENSIDADE NUMÉRICA}

Valor de $H=11.0147$
Valor de $x^{2} p / 2^{\circ}$ de liberdade $=11.01$

Probabilidade de $\mathrm{HO}=0.41 \%$

\begin{tabular}{|c|}
\hline $\begin{array}{c}\text { Controle X } 4 \\
\text { semanas } \\
5 \%\end{array}$ \\
\hline $\begin{array}{c}\text { Controle X } 4 \\
\text { semanas } \\
\text { NS }\end{array}$ \\
\hline
\end{tabular}

Significante para $\alpha \leq 0.01$

Significante para $\alpha \leq 0.01$

\section{DENSIDADE DE SUPERFÍCIE}

Valor de $\mathrm{H}=9.9800$

Valor de $\mathrm{x}^{2} \mathrm{p} / 2^{\circ}$ de liberdade $=9.98$

Probabilidade de $\mathrm{H} 0=0.68 \%$

NS

\begin{tabular}{|c|c|c|}
\hline $\begin{array}{c}\text { Controle } \mathrm{X} 4 \\
\text { semanas } \\
5 \%\end{array}$ & $\begin{array}{c}\text { Controle } \mathrm{X} 8 \\
\text { semanas } \\
1 \%\end{array}$ & 4 sem $\mathrm{X} 8 \mathrm{sem}$ \\
\hline
\end{tabular}

Controle X 8

4 sem $X 8$ sem

semanas

$0.1 \%$

$1 \%$ 
TABELA 57 - Avaliação da espessura (em $\mu \mathrm{m}$ ) do epitélio da língua (região dorsal posterior) dos animais controle e tratados com inibidores de protease.

\begin{tabular}{|c|c|c|c|c|}
\hline Grupos estudados & Camada basal & C.espinh. & C. queratina & Epitélio total \\
\hline \multirow[t]{2}{*}{ Animais Controle } & $\begin{array}{l}6.01 \\
6.03 \\
5.94 \\
6.19 \\
n n\end{array}$ & $\begin{array}{l}22.54 \\
20.80 \\
23.44 \\
22.34 \\
n n \cap 1\end{array}$ & $\begin{array}{l}8.68 \\
8.07 \\
9.05 \\
8.13 \\
n n n\end{array}$ & $\begin{array}{l}37.23 \\
34.09 \\
38.43 \\
36.16 \\
\text { nᄃ n }\end{array}$ \\
\hline & $6.08 \pm 0.13$ & $22.01 \pm 1.12$ & $8.39 \pm 0.44$ & $36.23 \pm 1.70$ \\
\hline \multirow[t]{3}{*}{$\begin{array}{l}\text { Inibidor de protease } \\
\text { por } 4 \text { semanas }\end{array}$} & $\begin{array}{l}6.07 \\
6.47 \\
6.17 \\
6.53 \\
\therefore \leq n\end{array}$ & $\begin{array}{l}20.36 \\
21.06 \\
20.03 \\
21.30 \\
n n \cap 5\end{array}$ & $\begin{array}{l}8.75 \\
8.72 \\
9.42 \\
8.69 \\
n 11\end{array}$ & $\begin{array}{l}35.18 \\
36.25 \\
35.62 \\
36.52 \\
5571\end{array}$ \\
\hline & $6.36 \pm 0.23$ & $20.55 \pm 0.59$ & $8.93 \pm 0.31$ & $35.86 \pm 0.52$ \\
\hline & $\uparrow$ & $\downarrow$ & $\uparrow$ & $\downarrow$ \\
\hline \multirow[t]{3}{*}{$\begin{array}{l}\text { Inibidor de protease } \\
\text { por } 8 \text { semanas }\end{array}$} & $\begin{array}{l}6.89 \\
7.55 \\
7.38 \\
7.01 \\
557\end{array}$ & $\begin{array}{l}27.10 \\
34.61 \\
35.54 \\
26.74 \\
\end{array}$ & $\begin{array}{l}9.03 \\
8.71 \\
9.44 \\
9.26 \\
0 \triangle 5\end{array}$ & $\begin{array}{l}43.02 \\
50.87 \\
52.36 \\
43.01 \\
11.11\end{array}$ \\
\hline & $7.08 \pm 0.39$ & $30.60 \pm 4.18$ & $9.01 \pm 0.34$ & $46.70 \pm 4.54$ \\
\hline & $\uparrow$ & $\uparrow$ & $\uparrow$ & $\uparrow$ \\
\hline
\end{tabular}


TABELA 58 - Efeitos da utilização de inibidor de protease sobre a espessura (em $\mu \mathrm{m}$ ) no epitélio da língua (região dorsal posterior) dos animais controle e tratados. - Avaliação pelo teste Kruskal-Wallis

\section{ESPESSURA DA CAMADA BASAL}

Valor de $\mathrm{H}=10.2600$

Valor de $x^{2} \mathrm{p} / 2^{\circ}$ de liberdade $=10.26$

Probabilidade de $\mathrm{HO}=0.59 \%$

Contr. X 4 sem.

Contr. X 8 sem.

4 sem $X 8$ sem

Significante para $\alpha \leq 0.01$

\section{ESPESSURA DA CAMADA ESPINHOSA}

Valor de $\mathrm{H}=10.8394$

Valor de $x^{2} \mathrm{p} / 2^{\circ}$ de liberdade $=10.84$

Probabilidade de $\mathrm{HO}=0.44 \%$

$5 \%$

$0.1 \%$

$1 \%$

Significante para $\alpha \leq 0.01$

\section{ESPESSURA DA CAMADA DE QUERATINA}

Valor de $\mathrm{H}=4.8600$

Valor de $x^{2} \mathrm{p} / 2^{\circ}$ de liberdade $=4.86$

Probabilidade de $\mathrm{HO}=8.80 \%$

Contr. X 4 sem.

Contr. X 8 sem.

4 sem $X 8$ sem

Significante para $\alpha \leq 0.05$

$5 \%$

$5 \%$

NS

\section{ESPESSURA DO EPITÉLIO TOTAL}

Valor de $\mathrm{H}=9.4200$

Valor de $x^{2} \mathrm{p} / 2^{\circ}$ de liberdade $=9.42$

Probabilidade de $\mathrm{HO}=0.90 \%$

Contr. X 4 sem. Contr. X 8 sem. 4 sem X 8 sem

Significante para $\alpha \leq 0.01$

\begin{tabular}{c|c|c} 
NS & $1 \%$ & $0.1 \%$
\end{tabular}


TABELA 59 - Avaliação da Relação superfície externa/ Superfície basal do epitélio da língua (região dorsal posterior) dos animais controle e tratados com inibidor de protease.

\begin{tabular}{|c|c|c|}
\hline Animais Controle & $\begin{array}{c}\text { Inibidor de protease } \\
\text { por 4 semanas }\end{array}$ & $\begin{array}{c}\text { Inibidor de protease por } \\
\mathbf{8} \text { semanas }\end{array}$ \\
\hline 0.9190 & 0.6810 & 0.5520 \\
0.9930 & 0.6140 & 0.5440 \\
0.8440 & 0.7320 & 0.5960 \\
0.8110 & 0.6900 & 0.5120 \\
1.0810 & 0.6780 & 0.5330 \\
\hline $0.9296 \pm 0.1101$ & $0.6790 \pm 0.04$ & $0.5474 \pm 0.03$ \\
\hline & $\boldsymbol{\Downarrow}$ & $\boldsymbol{\Downarrow}$ \\
\hline
\end{tabular}

TABELA 60 - Avaliação dos efeitos da utilização de inibidor de protease sobre os parâmetros dos valores médios da Relação superfície externa/ Superfície basal (em $\mu \mathrm{m}$ ) no epitélio da língua (região dorsal posterior) dos animais controle e tratados. - Avaliação pelo teste Kruskal-Wallis

\begin{tabular}{|c|c|c|c|}
\hline \multicolumn{4}{|c|}{ RELAÇÃO SUPERF. EXTERNA/SUPERF. BASAL DO EPITÉLIO DA PELE } \\
\hline $\begin{array}{l}\text { Valor de } H=12.5000 \\
\text { Valor de } x^{2} p / 2^{\circ} \text { de liberdade }=12.50\end{array}$ & $\begin{array}{l}\text { Controle X } 4 \\
\text { semanas }\end{array}$ & $\begin{array}{c}\text { Controle X } 8 \\
\text { semanas }\end{array}$ & 4 sem $X 8$ sem \\
\hline Probabilidade de $\mathrm{H} 0=0.19 \%$ & $0.1 \%$ & $0.1 \%$ & $0.1 \%$ \\
\hline
\end{tabular}


TABELA 61 - Avaliação dos valores médios dos volumes celulares (em $\mu \mathrm{m}^{3}$ ) no epitélio da língua (região ventral) dos animais controle e tratados com inibidor de protease.

\begin{tabular}{|c|c|c|c|c|c|c|}
\hline \multirow{2}{*}{$\begin{array}{l}\text { Estrutura } \\
\text { Estudada }\end{array}$} & \multicolumn{2}{|c|}{ Animais Controle } & \multicolumn{2}{|c|}{ Tratados - 4 semanas } & \multicolumn{2}{|c|}{ Tratados - 8 semanas } \\
\hline & C.Basal & C.Espinh. & C.basal & C.espinh. & C.basal & C.espinh. \\
\hline \multirow[t]{3}{*}{ Volume nuclear } & $\begin{array}{l}69.11 \\
80.70 \\
67.81 \\
73.09 \\
62.17\end{array}$ & $\begin{array}{l}85.05 \\
86.67 \\
76.23 \\
77.01 \\
64.07\end{array}$ & $\begin{array}{l}87.21 \\
81.28 \\
85.69 \\
83.39 \\
75.18\end{array}$ & $\begin{array}{l}114.68 \\
129.92 \\
133.19 \\
110.67 \\
101.72\end{array}$ & $\begin{array}{l}95.29 \\
84.85 \\
87.23 \\
97.15 \\
90.67\end{array}$ & $\begin{array}{l}105.13 \\
093.38 \\
107.96 \\
094.65 \\
093.20\end{array}$ \\
\hline & $70.57 \pm 6.87$ & $77.80 \pm 8.98$ & $82.55 \pm 4.69$ & $\begin{array}{c}118.04 \pm 13 \\
2\end{array}$ & $91.03 \pm 5.20$ & $98.86 \pm 7.10$ \\
\hline & & & $\uparrow$ & $\uparrow$ & $\uparrow$ & $\uparrow$ \\
\hline \multirow[t]{3}{*}{ Volume celular } & $\begin{array}{l}83.21 \\
71.22 \\
70.58 \\
72.42 \\
74.78\end{array}$ & $\begin{array}{l}349.30 \\
317.11 \\
305.12 \\
360.17 \\
328.54\end{array}$ & $\begin{array}{l}92.69 \\
89.83 \\
89.87 \\
88.37 \\
80.48\end{array}$ & $\begin{array}{l}310.04 \\
345.66 \\
381.10 \\
311.02 \\
305.89\end{array}$ & $\begin{array}{l}96.29 \\
90.09 \\
99.70 \\
90.37 \\
93.46\end{array}$ & $\begin{array}{l}420.24 \\
374.82 \\
369.91 \\
416.83 \\
368.70\end{array}$ \\
\hline & $72.96 \pm 2.25$ & $332.04 \pm 22.63$ & $88.24 \pm 4.62$ & $330.74 \pm 32.37$ & $93.98 \pm 4.07$ & $390.10 \pm 26.08$ \\
\hline & & & $\uparrow$ & $\uparrow$ & $\uparrow$ & $\uparrow$ \\
\hline \multirow[t]{3}{*}{$\begin{array}{l}\text { Volume do } \\
\text { citoplasma }\end{array}$} & $\begin{array}{l}2.51 \\
3.41 \\
8.41 \\
3.31 \\
1.69\end{array}$ & $\begin{array}{l}262.63 \\
240.88 \\
241.05 \\
275.12 \\
251.53\end{array}$ & $\begin{array}{l}7.00 \\
6.44 \\
8.59 \\
1.16 \\
5.30\end{array}$ & $\begin{array}{l}176.85 \\
234.99 \\
253.18 \\
196.34 \\
204.17\end{array}$ & $\begin{array}{l}1.00 \\
5.24 \\
2.55 \\
3.14 \\
2.79\end{array}$ & $\begin{array}{l}315.11 \\
281.44 \\
275.26 \\
308.87 \\
275.50\end{array}$ \\
\hline & $3.86 \pm 2.63$ & $254.24 \pm 14.71$ & $5.69 \pm 2.83$ & $213.10 \pm 30.66$ & $2.94 \pm 1.42$ & $291.23 \pm 19.26$ \\
\hline & & & $\uparrow$ & $v$ & $v$ & $\uparrow$ \\
\hline \multirow[t]{3}{*}{$\begin{array}{l}\text { Relação Núcleo/ } \\
\text { citoplasma }\end{array}$} & $\begin{array}{l}0.5385 \\
0.5152 \\
0.5152 \\
0.5152 \\
0.5385\end{array}$ & $\begin{array}{l}0.0989 \\
0.0989 \\
0.0989 \\
0.0989 \\
0.0870\end{array}$ & $\begin{array}{l}0.5873 \\
0.5873 \\
0.6129 \\
0.5873 \\
0.5625\end{array}$ & $\begin{array}{l}0.1628 \\
0.1628 \\
0.1628 \\
0.1765 \\
0.1628\end{array}$ & $\begin{array}{l}0.5873 \\
0.5873 \\
0.5873 \\
0.5625 \\
0.5873\end{array}$ & $\begin{array}{l}0.1111 \\
0.0989 \\
0.1111 \\
0.1111 \\
0.1111\end{array}$ \\
\hline & $0.5231 \pm 0.01$ & $0.0965 \pm 0.00$ & $0.5875 \pm 0.01$ & $0.1655 \pm 0.00$ & $0.5823 \pm 0.01$ & $0.1087 \pm 0.00$ \\
\hline & & & $\uparrow$ & $\uparrow$ & $\uparrow$ & $\uparrow$ \\
\hline \multirow[t]{3}{*}{$\begin{array}{l}\text { Densidade } \\
\text { numérica }\end{array}$} & $\begin{array}{l}11.93 \\
14.04 \\
14.73 \\
13.81 \\
13.37\end{array}$ & $\begin{array}{l}2.86 \\
3.37 \\
3.60 \\
2.78 \\
3.04\end{array}$ & $\begin{array}{l}12.09 \\
10.89 \\
10.43 \\
11.32 \\
12.43\end{array}$ & $\begin{array}{l}3.23 \\
2.89 \\
2.62 \\
3.22 \\
3.62\end{array}$ & $\begin{array}{l}10.39 \\
11.58 \\
10.03 \\
11.09 \\
10.70\end{array}$ & $\begin{array}{l}2.34 \\
2.67 \\
2.70 \\
2.60 \\
2.71\end{array}$ \\
\hline & $13.68 \pm 1.04$ & $3.13 \pm 0.34$ & $11.43 \pm 0.82$ & $3.11 \pm 0.37$ & $10.75 \pm 0.60$ & $2.60 \pm 0.15$ \\
\hline & & & $\downarrow$ & $\downarrow$ & $\downarrow$ & $\downarrow$ \\
\hline \multirow[t]{2}{*}{$\begin{array}{l}\text { Densidade de } \\
\text { superfície }\end{array}$} & $\begin{array}{l}16.50 \\
15.53 \\
16.42 \\
15.47 \\
16.34\end{array}$ & $\begin{array}{l}3.22 \\
3.49 \\
3.67 \\
3.15 \\
3.43\end{array}$ & $\begin{array}{l}14.81 \\
15.65 \\
14.91 \\
14.95 \\
14.87\end{array}$ & $\begin{array}{l}3.57 \\
3.77 \\
3.87 \\
3.62 \\
3.60\end{array}$ & $\begin{array}{l}13.40 \\
12.82 \\
12.28 \\
11.66 \\
12.89\end{array}$ & $\begin{array}{l}2.95 \\
2.42 \\
2.60 \\
2.40 \\
2.65\end{array}$ \\
\hline & $16.05 \pm 0.50$ & $3.39 \pm 0.21$ & $15.03 \pm 0.34$ & $3.68 \pm 0.12$ & $12.61 \pm 0.66$ & $2.60 \pm 0.22$ \\
\hline
\end{tabular}

Obs: Estão expressos nesta tabela os dados relativos a: volume nuclear, citoplasmático e celular (em micrometros cúbicos $-\mu \mathrm{m}^{3}$ ), relação núcleo/citoplasma, densidade numérica (número de células em uma área definida) e de superfície (número de células em uma extensão definida de superfície epitelial). 
TABELA 62 - Avaliação dos efeitos da utilização de inibidor de protease sobre os parâmetros dos valores médios dos volumes celulares $\left(\mathrm{em} \mu \mathrm{m}^{3}\right)$ na camada basal do epitélio da língua (região ventral) dos animais controle e tratados com inibidor de protease. - Avaliação pelo teste Kruskal-Wallis

\section{VOLUME NUCLEAR}

Valor de $\mathrm{H}=11.0600$

Valor de $\mathrm{x}^{2} \mathrm{p} / 2^{\circ}$ de liberdade $=11.06$

Probabilidade de $\mathrm{H} 0=0.40 \%$

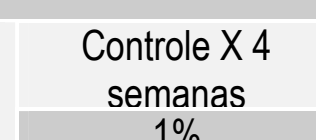

$1 \%$
Controle X 8 semanas $0.1 \%$

4 sem $X 8$ sem

Significante para $\alpha \leq 0.01$

\section{VOLUME CELULAR}

Valor de $\mathrm{H}=11.0600$

Valor de $x^{2} p / 2^{\circ}$ de liberdade $=11.06$

Probabilidade de $\mathrm{H} 0=0.40 \%$

Significante para $\alpha \leq 0.01$

\section{VOLUME DO CITOPLASMA}

\section{Valor de $\mathrm{H}=2.9400$}

Valor de $\mathrm{x}^{2} \mathrm{p} / 2^{\circ}$ de liberdade $=2.94$

Probabilidade de $\mathrm{HO}=22.99 \%$

Controle $X 4$
semanas
$1 \%$

\begin{tabular}{c|c}
$\begin{array}{c}\text { Controle } X 8 \\
\text { semanas } \\
0.1 \%\end{array}$ & 4 sem $X 8$ sem \\
\hline
\end{tabular}

Significante para $\alpha \leq 0.05$

\begin{tabular}{c|c|c|}
$\begin{array}{c}\text { Controle X 4 } \\
\text { semanas } \\
\text { NS }\end{array}$ & $\begin{array}{c}\text { Controle X 8 } \\
\text { semanas } \\
\text { NS }\end{array}$ & 4 sem X 8 sem \\
\hline
\end{tabular}

\section{RELAÇÃO NUCLEO/CITOPLASMA}

Valor de $\mathrm{H}=10.6321$

Valor de $x^{2} p / 2^{\circ}$ de liberdade $=10.63$

Probabilidade de $\mathrm{HO}=0.49 \%$

Significante para $\alpha \leq 0.01$

\section{DENSIDADE NUMÉRICA}

Valor de $\mathrm{H}=9.0600$

Valor de $x^{2} \mathrm{p} / 2^{\circ}$ de liberdade $=9.06$

Probabilidade de $\mathrm{HO}=1.08 \%$

Significante para $\alpha \leq 0.01$

\section{DENSIDADE DE SUPERFÍCIE}

Valor de $\mathrm{H}=11.5800$

Valor de $x^{2} p / 2^{\circ}$ de liberdade $=11.58$

Probabilidade de $\mathrm{HO}=0.31 \%$

Significante para $\alpha \leq 0.01$

\begin{tabular}{|c|c|c|}
\hline $\begin{array}{c}\text { Controle } X 4 \\
\text { semanas }\end{array}$ & $\begin{array}{c}\text { Controle } X 8 \\
\text { semanas }\end{array}$ & 4 sem $X 8$ sem \\
\hline
\end{tabular}

\begin{tabular}{l|l|l}
\hline $0.1 \%$ & $0.1 \%$ & NS \\
\hline
\end{tabular}


TABELA 63 - Avaliação dos efeitos da utilização de inibidor de protease sobre os parâmetros dos valores médios dos volumes celulares $\left(\mathrm{em} \mu \mathrm{m}^{3}\right)$ na camada espessura do epitélio da língua (região ventral) dos animais controle e tratados com inibidor de protease. - Avaliação pelo teste Kruskal-Wallis

\section{VOLUME NUCLEAR}

Valor de $\mathrm{H}=11.5800$

Valor de $\mathrm{x}^{2} \mathrm{p} / 2^{\circ}$ de liberdade $=11.58$

Probabilidade de $\mathrm{H} 0=0.31 \%$

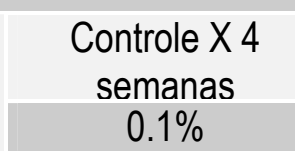

Controle X 8

4 sem $X 8$ sem

$0.1 \%$ semanas

$1 \%$

$1 \%$

Significante para $\alpha \leq 0.01$

\section{VOLUME CELULAR}

Valor de $\mathrm{H}=7.2600$

Valor de $x^{2} \mathrm{p} / 2^{\circ}$ de liberdade $=7.26$

Probabilidade de $\mathrm{HO}=2.65 \%$

Controle X 4
semanas
NS

\begin{tabular}{c|c}
$\begin{array}{c}\text { Controle X } 8 \\
\text { semanas } \\
1 \%\end{array}$ & 4 sem X 8 sem \\
\hline $1 \%$
\end{tabular}

Significante para $\alpha \leq 0.05$

\section{VOLUME DO CITOPLASMA}

Valor de $\mathrm{H}=11.1800$

Valor de $x^{2} p / 2^{\circ}$ de liberdade $=11.18$

Probabilidade de $\mathrm{HO}=0.37 \%$

\section{Controle X 4 \\ semanas \\ $5 \%$}
Controle X $8 \quad 4$ sem $X 8$ sem
semanas
$1 \%$
$0.1 \%$

Significante para $\alpha \leq 0.01$

\section{RELAÇÃO NUCLEO/CITOPLASMA}

Valor de $\mathrm{H}=12.4708$

Valor de $x^{2} \mathrm{p} / 2^{\circ}$ de liberdade $=12.47$

Probabilidade de $\mathrm{HO}=0.20 \%$

\begin{tabular}{c|c|c|}
$\begin{array}{c}\text { Controle } X 4 \\
\text { semanas }\end{array}$ & $\begin{array}{c}\text { Controle } X 8 \\
\text { semanas }\end{array}$ & 4 sem $X 8$ sem \\
\hline
\end{tabular}

Significante para $\alpha \leq 0.01$

\section{DENSIDADE NUMÉRICA}

Valor de $H=7.2800$
Valor de $x^{2} p / 2^{\circ}$ de liberdade $=7.28$
Probabilidade de $H 0=2.63 \%$

Significante para $\alpha \leq 0.05$

\section{DENSIDADE DE SUPERFÍCIE}

Valor de $\mathrm{H}=11.1800$

Valor de $x^{2} p / 2^{\circ}$ de liberdade $=11.18$

Probabilidade de $\mathrm{HO}=0.37 \%$

Significante para $\alpha \leq 0.01$

\begin{tabular}{|c|c|c|}
\hline $\begin{array}{c}\text { Controle X } 4 \\
\text { semanas } \\
\text { NS }\end{array}$ & $\begin{array}{c}\text { Controle X 8 } \\
\text { semanas } \\
1 \%\end{array}$ & 4 sem X 8 sem \\
\hline $\begin{array}{c}\text { Controle X 4 } \\
\text { semanas } \\
5 \%\end{array}$ & $\begin{array}{c}\text { Controle X 8 } \\
\text { semanas } \\
1 \%\end{array}$ & 4 sem X 8 sem \\
\hline & $0.1 \%$ \\
\hline
\end{tabular}


TABELA 64 - Avaliação da espessura (em $\mu \mathrm{m}$ ) do epitélio da língua (região ventral) dos animais controle e tratados com inibidores de protease.

\begin{tabular}{|c|c|c|c|c|}
\hline Grupos estudados & Camada basal & C.espinhosa & C. queratina & Epitélio total \\
\hline \multirow[t]{2}{*}{ Animais Controle } & $\begin{array}{l}5.17 \\
5.83 \\
5.66 \\
5.70 \\
5.6 ?\end{array}$ & $\begin{array}{l}26.45 \\
25.46 \\
24.44 \\
28.13 \\
25.51\end{array}$ & $\begin{array}{l}7.42 \\
7.34 \\
7.35 \\
7.94 \\
7.74\end{array}$ & $\begin{array}{l}39.04 \\
38.63 \\
37.45 \\
41.77 \\
38.87\end{array}$ \\
\hline & $5.59 \pm 0.25$ & $25.99 \pm 1.38$ & $7.55 \pm 0.26$ & $39.15 \pm 1.59$ \\
\hline \multirow[t]{3}{*}{$\begin{array}{l}\text { Inibidor de protease por } 4 \\
\text { semanas }\end{array}$} & $\begin{array}{l}6.49 \\
6.07 \\
6.45 \\
6.43 \\
6.49\end{array}$ & $\begin{array}{l}22.25 \\
20.87 \\
21.38 \\
20.99 \\
22.21\end{array}$ & $\begin{array}{l}7.40 \\
6.42 \\
6.76 \\
7.87 \\
7.27\end{array}$ & $\begin{array}{l}36.14 \\
33.36 \\
34.59 \\
35.29 \\
35.97\end{array}$ \\
\hline & $6.38 \pm 0.17$ & $21.54 \pm 0.65$ & $7.14 \pm 0.56$ & $35.07 \pm 1.13$ \\
\hline & $\uparrow$ & $\downarrow$ & $\downarrow$ & $\downarrow$ \\
\hline \multirow[t]{3}{*}{$\begin{array}{l}\text { Inibidor de protease por } 8 \\
\text { semanas }\end{array}$} & $\begin{array}{l}7.00 \\
7.32 \\
7.53 \\
7.84 \\
7.13\end{array}$ & $\begin{array}{l}26.51 \\
27.75 \\
31.56 \\
30.18 \\
27.98\end{array}$ & $\begin{array}{l}5.21 \\
5.75 \\
5.91 \\
5.87 \\
5.48\end{array}$ & $\begin{array}{l}38.72 \\
40.82 \\
45.00 \\
43.89 \\
40.59\end{array}$ \\
\hline & $7.36 \pm 0.33$ & $28.79 \pm 2.03$ & $5.64 \pm 0.29$ & $41.80 \pm 2.57$ \\
\hline & $\uparrow$ & $\uparrow$ & $\downarrow$ & $\uparrow$ \\
\hline
\end{tabular}


TABELA 65 - Efeitos da utilização de inibidor de protease sobre a espessura (em $\mu \mathrm{m}$ ) no epitélio da língua (região ventral) dos animais controle e tratados. Avaliação pelo teste Kruskal-Wallis

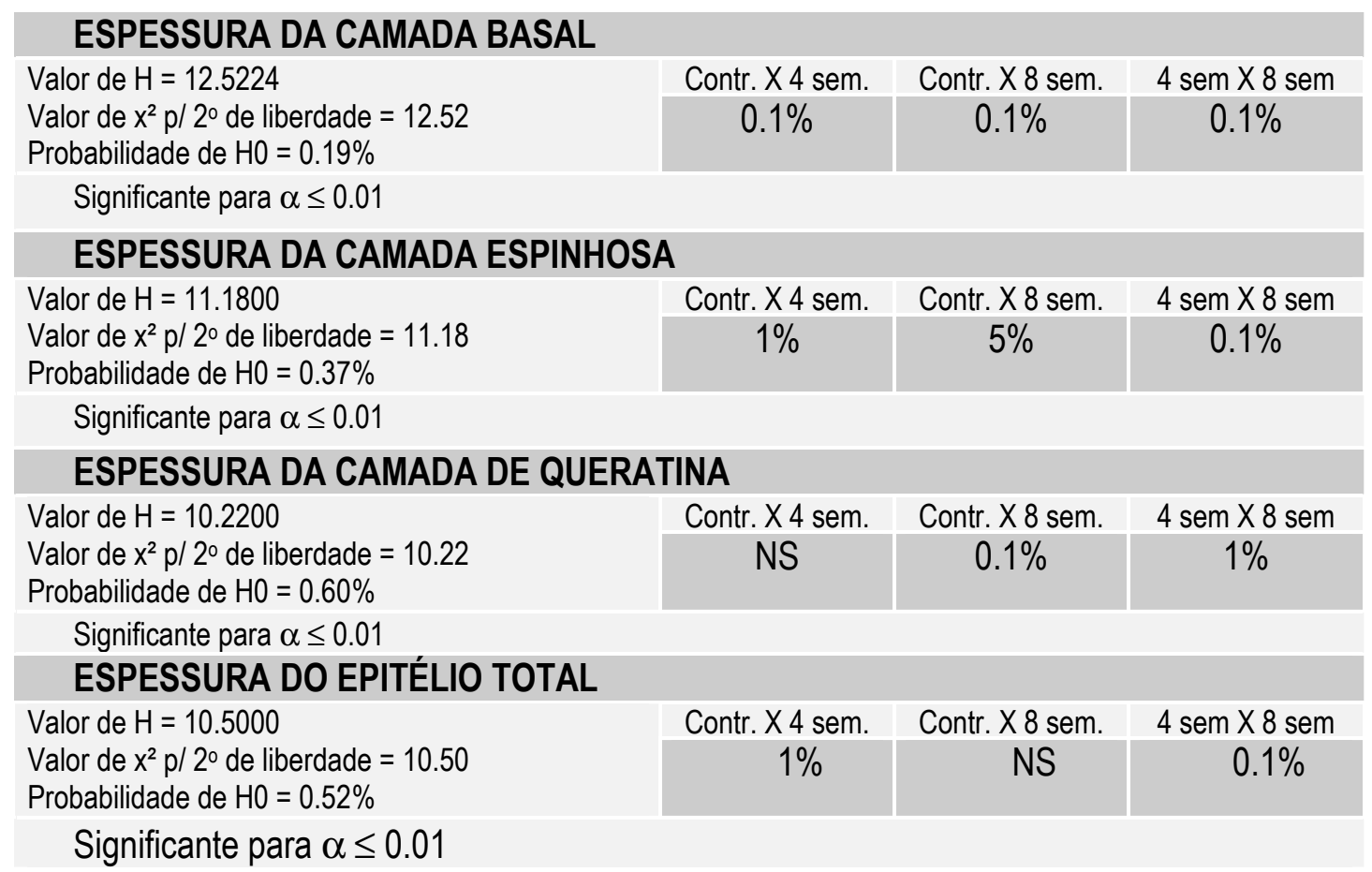


TABELA 66 - Avaliação da Relação superfície externa/ Superfície basal do epitélio da língua (região ventral) dos animais controle e tratados com inibidor de protease.

\begin{tabular}{|c|c|c|}
\hline Animais Controle & $\begin{array}{c}\text { Inibidor de protease por 4 } \\
\text { semanas }\end{array}$ & $\begin{array}{c}\text { Inibidor de protease por } \\
\mathbf{8} \text { semanas }\end{array}$ \\
\hline 0.7110 & 1.0630 & 0.5610 \\
0.7210 & 1.0540 & 0.5990 \\
0.7640 & 1.1110 & 0.5660 \\
0.6600 & 1.0630 & 0.6370 \\
0.8030 & 1.0730 & 0.5410 \\
\hline $\mathbf{0 . 7 3 1 8} \pm \mathbf{0 . 0 5}$ & $\mathbf{1 . 0 7 2 8} \pm \mathbf{0 . 0 2}$ & $\mathbf{0 . 5 8 0 8} \pm \mathbf{0 . 0 3}$ \\
\hline
\end{tabular}

TABELA 67 - Avaliação dos efeitos da utilização de inibidor de protease sobre os parâmetros dos valores médios da Relação superfície externa/ Superfície basal (em $\mu \mathrm{m})$ no epitélio da língua (região ventral) dos animais controle e tratados. - Avaliação pelo teste Kruskal-Wallis

\begin{tabular}{|c|c|c|c|}
\hline \multicolumn{4}{|c|}{ RELAÇÃO SUPERF. EXTERNA/SUPERF. BASAL DO EPITÉLIO DA PELE } \\
\hline $\begin{array}{l}\text { Valor de } H=12.5224 \\
\text { Valor de } x^{2} p / 2^{\circ} \text { de liberdade }=12.52\end{array}$ & $\begin{array}{l}\text { Controle X } 4 \\
\text { semanas }\end{array}$ & $\begin{array}{l}\text { Controle X } 8 \\
\text { semanas }\end{array}$ & $4 \mathrm{sem} X 8 \mathrm{sem}$ \\
\hline Probabilidade de $\mathrm{H} 0=0.19 \%$ & $0.1 \%$ & $0.1 \%$ & $0.1 \%$ \\
\hline
\end{tabular}

Significante para $\alpha \leq 0.01$ 
A análise dos valores obtidos pela avaliação estereológica do epitélio lingual de animais tratados com inibidor de protease e seus controles nos mostrou que:

1) os volumes celulares estão aumentados em todas as regiões da língua nos animais tratados, sendo que esse efeito tende a se iniciar nos primeiros períodos de uso do medicamento e se acentuar com o uso prolongado;

2) Existe uma tendência para o aumento da espessura do epitélio lingual, no entanto se observa que esse aumento não acontece na mesma proporção que o observado nos volumes celulares, o que pode ser verificado também ao se observar a diminuição na densidade numérica celular nas diferentes regiões da língua com o uso de inibidor de protease;

3) Na maiora das áreas estudadas, exceto na dorsal anterior, foi possível observar diminuição das pregas epiteliais;

4) Analisando-se, então, o conjunto dos dados obtidos, podemos considerar que existe uma aparente perda da capadidade de defesa como barreira, uma vez que o número de células está diminuído e as pregas epiteliais menos evidentes. Avaliações bioquímicas e imunológicas deverão ser realizadas para que se possa avaliar efeitos desse medicamento nas outras formas de defesa epiteliais. 


\subsection{Avaliação dos resultados de palatos e gengiva}

O tecido epitelial, caracterizado como barreirae importante, por essa característica, como uma defesa, embora apresente certa permeabilidade, protege o ambiente interno dos organismos vivos. É recoberto por epitélio do tipo escamoso estratificado, assim como outras áreas da mucosa bucal, e da mesma forma, apresenta grande variação anatômica na dependência das diferentes áreas. Os epitélios dos palatos duro, mole, e da região das gengivas apresentam diferentes graus de ceratinização. Também são diferentes as relações entre epitélio/tecido conjuntivo e a relação anatômica das camadas que formam o epitélio de revestimento (KALININ, et al., 2002).

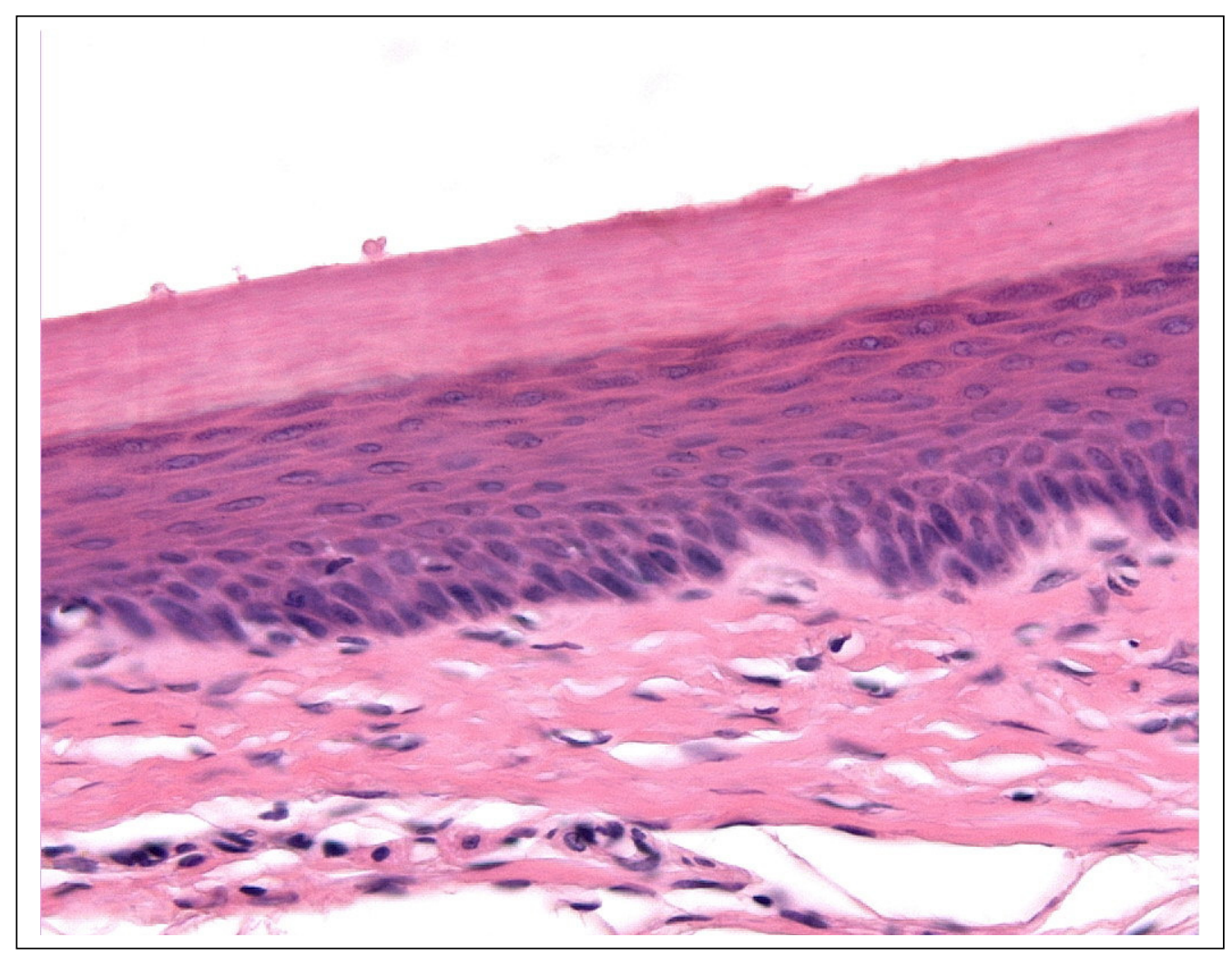

FIGURA 7- Histomorfologia da região do palato duro em animal controle. Observe a relação epitélio/conjuntivo. Aumento 20x 


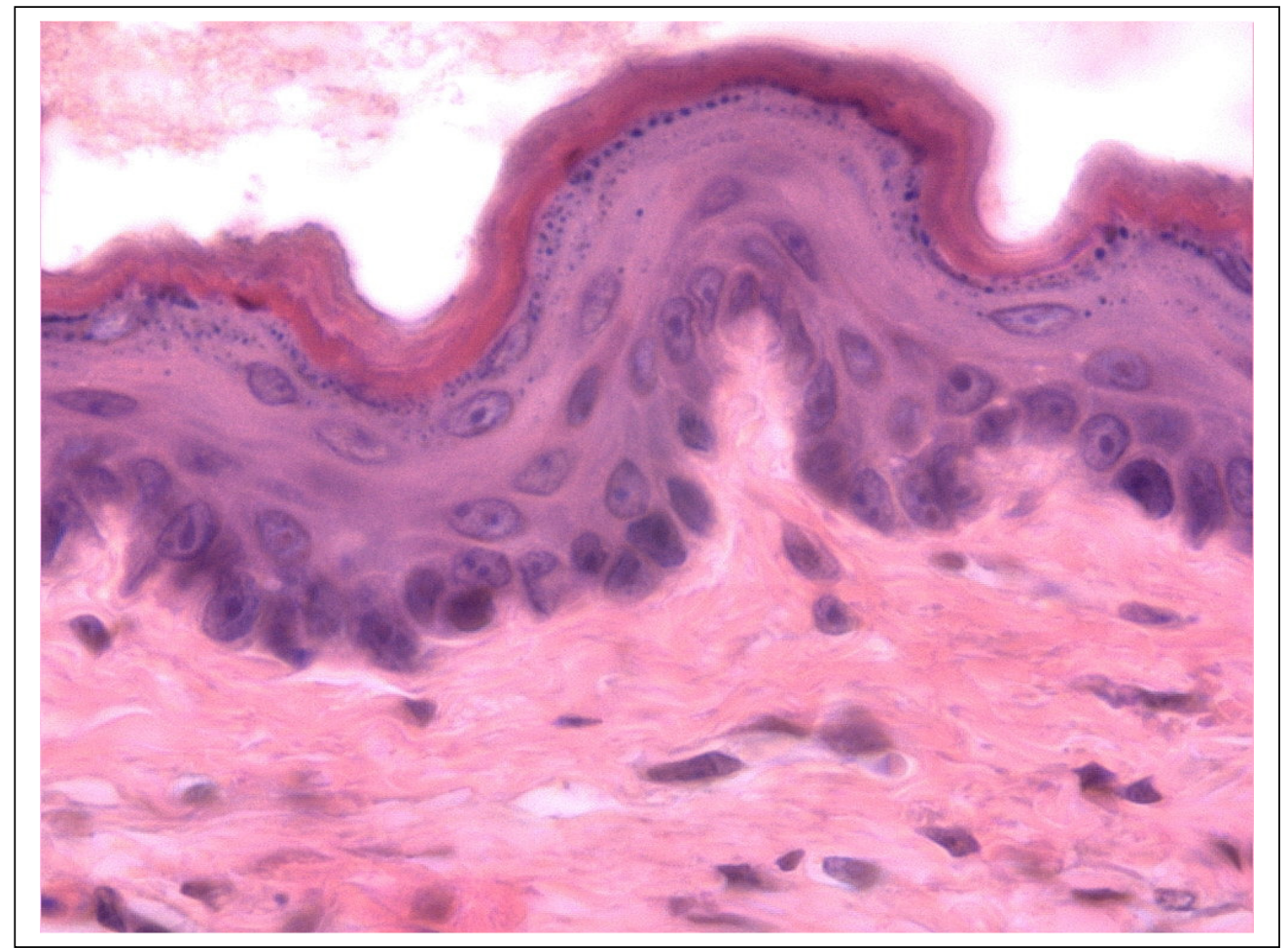

FIGURA 8 - Histomorfologia da região do palato mole em animal controle. Observe as camadas basal, espinhosa, granulosa e córnea, as glândulas em maior aumento, e a relação epitélio/conjuntivo. Aumento 40x

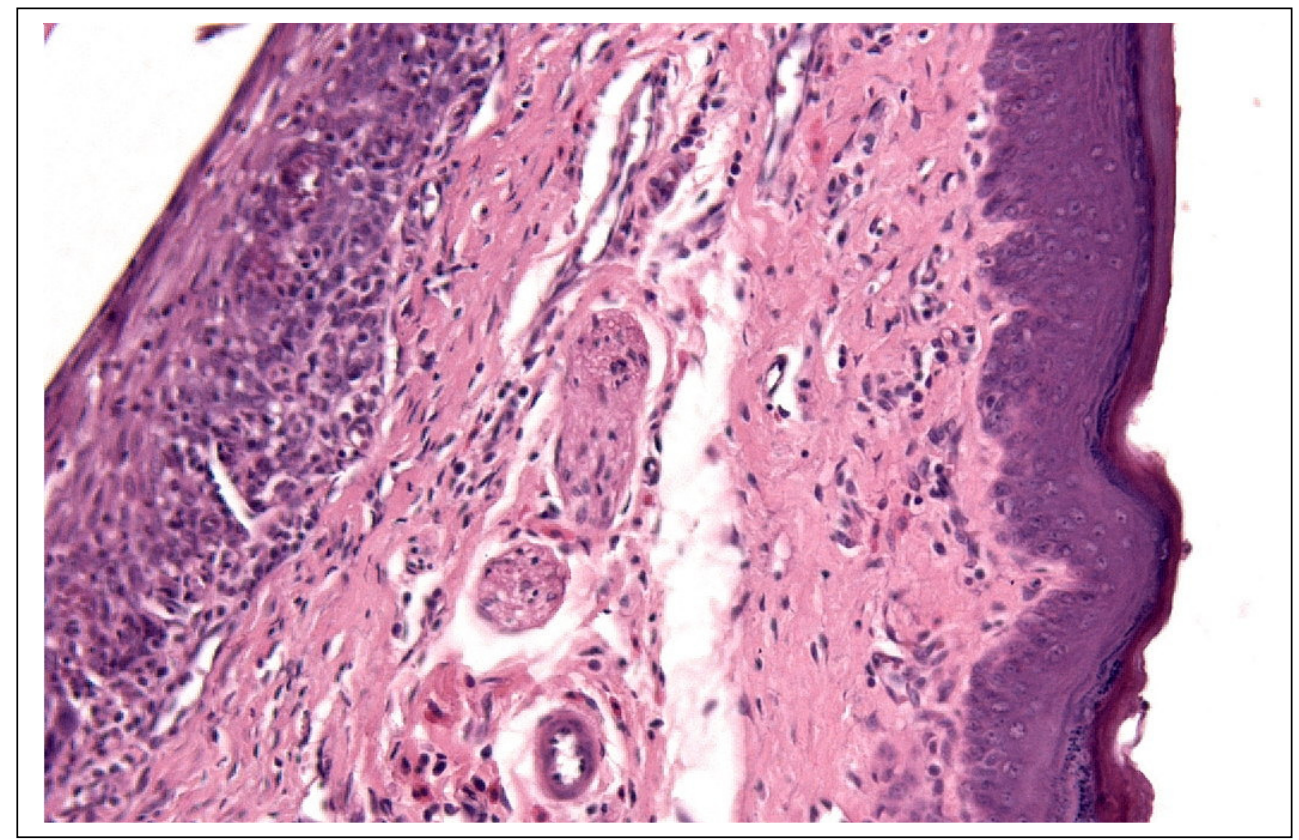

FIGURA 9 - Histomorfologia da região gengival em animal controle. Observe o epitélio gengival à direita da figura. Objetiva de aumento 10x 


\subsubsection{Cariometria dos palatos duro e mole e região gengival}

TABELA 68 - Avaliação do tamanho dos núcleos das células do epitélio do palato (região palato duro) dos animais controle e tratados com inibidor de protease.

\begin{tabular}{|c|c|c|c|c|c|c|}
\hline \multirow[t]{2}{*}{$\begin{array}{l}\text { Estrutura } \\
\text { Estudada }\end{array}$} & \multicolumn{2}{|c|}{ Animais Controle } & \multicolumn{2}{|c|}{$\begin{array}{c}\text { Tratados - } 4 \\
\text { semanas }\end{array}$} & \multicolumn{2}{|c|}{$\begin{array}{c}\text { Tratados - } 8 \\
\text { semanas }\end{array}$} \\
\hline & C.Basal & C.Espinh. & C.Basal & C.Espinh. & C.Basal & C.Espinh \\
\hline \multirow[t]{3}{*}{$\begin{array}{l}\text { Diâmetro } \\
\text { maior }\end{array}$} & $\begin{array}{l}7.46 \\
6.76 \\
7.72 \\
7.02 \\
6.56\end{array}$ & $\begin{array}{l}5.62 \\
5.74 \\
6.10 \\
6.12 \\
5.52\end{array}$ & $\begin{array}{l}5.98 \\
6.46 \\
6.26 \\
5.90 \\
6.54\end{array}$ & $\begin{array}{l}7.60 \\
6.64 \\
6.80 \\
6.40 \\
6.88\end{array}$ & $\begin{array}{l}6.72 \\
6.64 \\
7.06 \\
6.62 \\
6.80\end{array}$ & $\begin{array}{l}6.80 \\
6.64 \\
6.58 \\
6.60 \\
6.36\end{array}$ \\
\hline & $7.004 \pm 0.35$ & $5.82 \pm 0.27$ & $6.22 \pm 0.28$ & $6.86 \pm 0.45$ & $6.76 \pm 0.17$ & $6.59 \pm 0.15$ \\
\hline & & & $\downarrow$ & $\uparrow$ & $\downarrow$ & $\uparrow$ \\
\hline \multirow[t]{3}{*}{$\begin{array}{l}\text { Diâmetro } \\
\text { menor }\end{array}$} & $\begin{array}{l}4.42 \\
4.64 \\
4.64 \\
5.04 \\
4.60\end{array}$ & $\begin{array}{l}4.76 \\
4.84 \\
4.82 \\
4.48 \\
4.34\end{array}$ & $\begin{array}{l}4.08 \\
3.98 \\
3.78 \\
4.42 \\
4.00\end{array}$ & $\begin{array}{l}3.92 \\
4.58 \\
4.18 \\
4.40 \\
4.02\end{array}$ & $\begin{array}{l}3.98 \\
4.56 \\
4.22 \\
4.58 \\
4.12\end{array}$ & $\begin{array}{l}4.98 \\
5.14 \\
4.90 \\
4.88 \\
4.94\end{array}$ \\
\hline & $4.66 \pm 0.22$ & $4.64 \pm 0.22$ & $4.05 \pm 0.23$ & $4.22 \pm 0.27$ & $4.29 \pm 0.26$ & $4.96 \pm 0.10$ \\
\hline & & & $\downarrow$ & $\downarrow$ & $\downarrow$ & $\uparrow$ \\
\hline \multirow[t]{3}{*}{$\begin{array}{l}\text { Volume } \\
\text { nuclear }\end{array}$} & $\begin{array}{c}83.04 \\
97.23 \\
102.44 \\
105.44 \\
106.83\end{array}$ & $\begin{array}{l}77.64 \\
77.43 \\
84.00 \\
77.47 \\
63.05\end{array}$ & $\begin{array}{l}63.94 \\
68.91 \\
61.66 \\
70.26 \\
71.23\end{array}$ & $\begin{array}{l}85.85 \\
90.26 \\
82.17 \\
79.46 \\
77.54\end{array}$ & $\begin{array}{l}73.34 \\
88.73 \\
87.18 \\
88.90 \\
79.36\end{array}$ & $\begin{array}{l}104.52 \\
106.52 \\
097.65 \\
097.57 \\
093.88\end{array}$ \\
\hline & $99.08 \pm 9.68$ & $75.11 \pm 7.70$ & $67.20 \pm 4.17$ & $83.05 \pm 5.09$ & $83.50 \pm 6.89$ & $100.02 \pm 5.28$ \\
\hline & & & $\downarrow$ & $\uparrow$ & $\downarrow$ & $\uparrow$ \\
\hline \multirow[t]{3}{*}{ Área nuclear } & $\begin{array}{l}26.99 \\
26.73 \\
26.34 \\
25.45 \\
22.79\end{array}$ & $\begin{array}{l}21.06 \\
21.82 \\
23.03 \\
21.69 \\
18.51\end{array}$ & $\begin{array}{l}19.15 \\
20.15 \\
18.65 \\
20.44 \\
20.53\end{array}$ & $\begin{array}{l}23.36 \\
24.02 \\
22.46 \\
22.15 \\
21.77\end{array}$ & $\begin{array}{l}21.05 \\
23.83 \\
23.53 \\
23.86 \\
22.10\end{array}$ & $\begin{array}{l}26.63 \\
26.91 \\
25.38 \\
25.38 \\
24.71\end{array}$ \\
\hline & $25.66 \pm 1.70$ & $21.22 \pm 1.67$ & $19.78 \pm 0.83$ & $22.75 \pm 0.92$ & $22.87 \pm 1.24$ & $25.80 \pm 0.93$ \\
\hline & & & $v$ & $\uparrow$ & $\uparrow$ & $\uparrow$ \\
\hline \multirow[t]{3}{*}{$\begin{array}{l}\text { Perímetro } \\
\text { nuclear }\end{array}$} & $\begin{array}{l}17.45 \\
18.55 \\
18.88 \\
18.68 \\
19.25\end{array}$ & $\begin{array}{l}15.57 \\
16.77 \\
17.25 \\
16.68 \\
16.36\end{array}$ & $\begin{array}{l}15.98 \\
16.68 \\
16.05 \\
16.33 \\
16.85\end{array}$ & $\begin{array}{l}18.61 \\
17.81 \\
17.55 \\
17.14 \\
17.45\end{array}$ & $\begin{array}{l}17.11 \\
17.78 \\
18.02 \\
17.77 \\
17.44\end{array}$ & $\begin{array}{l}18.64 \\
18.61 \\
18.16 \\
18.16 \\
17.86\end{array}$ \\
\hline & $18.56 \pm 0.67$ & $16.52 \pm 0.62$ & $16.25 \pm 0.35$ & $17.71 \pm 0.55$ & $17.62 \pm 0.35$ & $18.28 \pm 0.33$ \\
\hline & & & $\downarrow$ & $\uparrow$ & $\downarrow$ & $\uparrow$ \\
\hline
\end{tabular}

Obs: Estão expressos nesta tabela os dados relativos a: Diâmetro maior em micrometros $(\mu \mathrm{m})$, diâmetro menor $(\mathrm{em} \mu \mathrm{m})$, perímetro do núcleo celular $(\mathrm{em} \mu \mathrm{m})$, área nuclear em micrometros quadrados $\left(\mu \mathrm{m}^{2}\right)$, e volume nuclear em micrometros cúbicos $\left(\mu \mathrm{m}^{3}\right)$. 
TABELA 69 - Avaliação dos efeitos da utilização de inibidor de protease sobre os parâmetros do tamanho dos núcleos das células da camada basal do palato (região palato duro) dos animais controles e tratados Avaliação pelo teste Kruskal-Wallis

\section{DIÂMETRO MAIOR}

Valor de $\mathrm{H}=9.7800$

Valor de $\mathrm{x}^{2} \mathrm{p} / 2^{\circ}$ de liberdade $=9.78$

Probabilidade de $\mathrm{H} 0=0.75 \%$

Significante para $\alpha \leq 0.01$

\begin{tabular}{c|c|c|}
\hline $\begin{array}{c}\text { Controle X } 4 \\
\text { semanas }\end{array}$ & $\begin{array}{c}\text { Controle X } 8 \\
\text { semanas }\end{array}$ & $\begin{array}{c}4 \text { sem } \times 8 \\
\text { sem }\end{array}$ \\
\hline $0.1 \%$ & NS & $1 \%$ \\
\hline
\end{tabular}

\section{DIÂMETRO MENOR}

Valor de $\mathrm{H}=8.8424$

Valor de $x^{2} p / 2^{\circ}$ de liberdade $=8.84$

Probabilidade de $\mathrm{HO}=1.20 \%$

\begin{tabular}{|c|c|c|}
\hline $\begin{array}{c}\text { Controle X } 4 \\
\text { semanas }\end{array}$ & $\begin{array}{c}\text { Controle X } 8 \\
\text { semanas }\end{array}$ & $\begin{array}{c}4 \text { sem } X 8 \\
\text { sem }\end{array}$ \\
\hline $0.1 \%$ & $5 \%$ & NS \\
\hline
\end{tabular}

Significante para $\alpha \leq 0.01$

\section{VOLUME NUCLEAR}

Valor de $H=11.1800$
Valor de $x^{2} p / 2^{\circ}$ de liberdade $=11.18$
Probabilidade de $H 0=0.37 \%$

\begin{tabular}{|c|c|c|}
\hline $\begin{array}{c}\text { Controle X 4 } \\
\text { semanas }\end{array}$ & $\begin{array}{c}\text { Controle X 8 } \\
\text { semanas }\end{array}$ & $\begin{array}{c}4 \text { sem X 8 } \\
\text { sem }\end{array}$ \\
\hline $0.1 \%$ & $5 \%$ & $1 \%$ \\
\hline
\end{tabular}

Significante para $\alpha \leq 0.01$

\begin{tabular}{|c|c|c|c|}
\hline \multicolumn{4}{|l|}{ ÁREA NUCLEAR } \\
\hline $\begin{array}{l}\text { Valor de } \mathrm{H}=11.1800 \\
\text { Valor de } \mathrm{x}^{2} \mathrm{p} / 2^{\circ} \text { de liberdade }=11.18 \\
\text { Probabilidade de } \mathrm{HO}=0.37 \%\end{array}$ & $\begin{array}{c}\text { Controle X } 4 \\
\text { semanas } \\
0.1 \%\end{array}$ & $\begin{array}{c}\text { Controle X } 8 \\
\text { semanas } \\
5 \%\end{array}$ & $\begin{array}{l}4 \operatorname{sem} X 8 \\
\text { sem } \\
1 \%\end{array}$ \\
\hline \multicolumn{4}{|l|}{ Significante para $\alpha \leq 0.01$} \\
\hline \multicolumn{4}{|l|}{ PERÍMETRO NUCLEAR } \\
\hline $\begin{array}{l}\text { Valor de } \mathrm{H}=11.1800 \\
\text { Valor de } \mathrm{x}^{2} \mathrm{p} / \mathrm{2}^{\circ} \text { de liberdade }=11.18 \\
\text { Probabilidade de } \mathrm{HO}=0.37 \%\end{array}$ & $\begin{array}{c}\text { Controle X } 4 \\
\text { semanas } \\
0.1 \%\end{array}$ & $\begin{array}{c}\text { Controle } X \varepsilon \\
\text { semanas } \\
5 \%\end{array}$ & $\begin{array}{c}4 \operatorname{sem} X \\
8 \text { sem } \\
1 \%\end{array}$ \\
\hline
\end{tabular}

Significante para $\alpha \leq 0.01$ 
TABELA 70 - Avaliação dos efeitos da utilização de inibidor de protease sobre os parâmetros do tamanho dos núcleos das células da camada espinhosa do palato (região palato duro) dos animais controles e tratados Avaliação pelo teste Kruskal-Wallis

\begin{tabular}{|c|c|c|c|}
\hline \multicolumn{4}{|l|}{ DIÂMETRO MAIOR } \\
\hline $\begin{array}{l}\text { Valor de } H=10.2566 \\
\text { Valor de } x^{2} p / 2^{\circ} \text { de liberdade }=10.26 \\
\text { Probabilidade de } H 0=0.59 \%\end{array}$ & $\begin{array}{l}\text { Controle X } 4 \\
\text { semanas } \\
0.1 \%\end{array}$ & $\begin{array}{c}\text { Controle X } 8 \\
\text { semanas } \\
1 \%\end{array}$ & $\begin{array}{l}4 \operatorname{sem} X 8 \\
\text { sem } \\
\text { NS }\end{array}$ \\
\hline \multicolumn{4}{|l|}{ Significante para $\alpha \leq 0.01$} \\
\hline \multicolumn{4}{|l|}{ DIÂMETRO MENOR } \\
\hline $\begin{array}{l}\text { Valor de } \mathrm{H}=11.1800 \\
\text { Valor de } \mathrm{x}^{2} \mathrm{p} / 2^{\circ} \text { de liberdade }=11.18 \\
\text { Probabilidade de } \mathrm{HO}=0.37 \%\end{array}$ & $\begin{array}{l}\text { Controle X } 4 \\
\text { semanas } \\
5 \%\end{array}$ & $\begin{array}{c}\text { Controle X } 8 \\
\text { semanas } \\
1 \%\end{array}$ & $\begin{array}{c}4 \text { sem } X 8 \\
\text { sem } \\
0.1 \%\end{array}$ \\
\hline \multicolumn{4}{|l|}{ Significante para $\alpha \leq 0.01$} \\
\hline \multicolumn{4}{|l|}{ VOLUME NUCLEAR } \\
\hline $\begin{array}{l}\text { Valor de } \mathrm{H}=10.8200 \\
\text { Valor de } \mathrm{x}^{2} \mathrm{p} / 2^{\circ} \text { de liberdade }=10.82 \\
\text { Probabilidade de } \mathrm{H} 0=0.45 \%\end{array}$ & $\begin{array}{l}\text { Controle X } 4 \\
\text { semanas } \\
5 \%\end{array}$ & $\begin{array}{c}\text { Controle } X 8 \\
\text { semanas } \\
0.1 \%\end{array}$ & $\begin{array}{l}4 \text { sem } X 8 \\
\text { sem } \\
1 \%\end{array}$ \\
\hline \multicolumn{4}{|l|}{$\begin{array}{l}\text { Significante para } \alpha \leq 0.01 \\
\text { ÁREA NUCLEAR }\end{array}$} \\
\hline $\begin{array}{l}\text { Valor de } H=10.8394 \\
\text { Valor de } x^{2} p / 2^{\circ} \text { de liberdade }=10.84 \\
\text { Probabilidade de } H 0=0.44 \%\end{array}$ & $\begin{array}{l}\text { Controle X } 4 \\
\text { semanas } \\
5 \%\end{array}$ & $\begin{array}{c}\text { Controle X } 8 \\
\text { semanas } \\
0.1 \%\end{array}$ & $\begin{array}{c}4 \operatorname{sem} X 8 \\
\text { sem } \\
1 \%\end{array}$ \\
\hline \multicolumn{4}{|l|}{ Significante para $\alpha \leq 0.01$} \\
\hline $\begin{array}{l}\text { Valor de } \mathrm{H}=10.4824 \\
\text { Valor de } \mathrm{x}^{2} \mathrm{p} / 2^{\circ} \text { de liberdade }=10.48 \\
\text { Probabilidade de } \mathrm{H} 0=0.53 \%\end{array}$ & $\begin{array}{c}\text { Controle X } 4 \\
\text { semanas } \\
1 \%\end{array}$ & $\begin{array}{c}\text { Controle X } 8 \\
\text { semanas } \\
0.1 \%\end{array}$ & $\begin{array}{l}4 \text { sem } X 8 \\
\text { sem } \\
5 \%\end{array}$ \\
\hline Significante para $\alpha \leq 0.01$ & & & \\
\hline
\end{tabular}


TABELA 71 - Avaliação dos parâmetros avaliação da forma dos núcleos das células epiteliais do palato (região palato duro) dos animais controles e tratados com inibidor de protease.

\begin{tabular}{|c|c|c|c|c|c|c|}
\hline \multirow[t]{2}{*}{$\begin{array}{l}\text { Estrutura } \\
\text { Estudada }\end{array}$} & \multicolumn{2}{|c|}{ Animais Controle } & \multicolumn{2}{|c|}{ Tratados - 4 semanas } & \multicolumn{2}{|c|}{$\begin{array}{c}\text { Tratados - } 8 \\
\text { semanas }\end{array}$} \\
\hline & C.Basal & C.Espinh. & C.Basal & C.Espinh. & C.Basal & C.Espinh. \\
\hline \multirow[t]{3}{*}{$\begin{array}{l}\text { Relação } \\
\text { DM/dm }\end{array}$} & $\begin{array}{l}1.66 \\
1.38 \\
1.58 \\
1.55 \\
1.52\end{array}$ & $\begin{array}{l}1.20 \\
1.20 \\
1.29 \\
1.38 \\
1.29\end{array}$ & $\begin{array}{l}1.51 \\
1.67 \\
1.70 \\
1.36 \\
1.70\end{array}$ & $\begin{array}{l}1.98 \\
1.49 \\
1.69 \\
1.48 \\
1.75\end{array}$ & $\begin{array}{l}1.70 \\
1.49 \\
1.69 \\
1.48 \\
1.67\end{array}$ & $\begin{array}{l}1.38 \\
1.31 \\
1.37 \\
1.37 \\
1.32\end{array}$ \\
\hline & $1.53 \pm 0.10$ & $1.27 \pm 0.07$ & $1.58 \pm 0.14$ & $1.67 \pm 0.20$ & $1.60 \pm 0.11$ & $1.35 \pm 0.03$ \\
\hline & & & $\uparrow$ & $\uparrow$ & $\uparrow$ & $\uparrow$ \\
\hline \multirow[t]{3}{*}{$\begin{array}{l}\text { Relação } \\
\text { Vol./Área }\end{array}$} & $\begin{array}{l}3.89 \\
3.87 \\
3.85 \\
3.79 \\
3.57\end{array}$ & $\begin{array}{l}3.44 \\
3.50 \\
3.60 \\
3.48 \\
3.25\end{array}$ & $\begin{array}{l}3.28 \\
3.36 \\
3.23 \\
3.39 \\
3.39\end{array}$ & $\begin{array}{l}3.62 \\
3.66 \\
3.53 \\
3.52 \\
3.49\end{array}$ & $\begin{array}{l}3.44 \\
3.65 \\
3.63 \\
3.66 \\
3.52\end{array}$ & $\begin{array}{l}3.87 \\
3.88 \\
3.77 \\
3.77 \\
3.72\end{array}$ \\
\hline & $3.79 \pm 0.13$ & $3.45 \pm 0.12$ & $3.33 \pm 0.07$ & $3.56 \pm 0.07$ & $3.58 \pm 0.09$ & $3.80 \pm 0.06$ \\
\hline & & & $\boldsymbol{v}$ & $\uparrow$ & $v$ & $\uparrow$ \\
\hline \multirow[t]{3}{*}{$\begin{array}{l}\text { Índice de } \\
\text { contorno }\end{array}$} & $\begin{array}{l}3.73 \\
3.63 \\
3.70 \\
3.69 \\
3.68\end{array}$ & $\begin{array}{l}3.60 \\
3.62 \\
3.61 \\
3.58 \\
3.58\end{array}$ & $\begin{array}{l}3.68 \\
3.73 \\
3.74 \\
3.63 \\
3.75\end{array}$ & $\begin{array}{l}3.87 \\
3.67 \\
3.75 \\
3.66 \\
3.77\end{array}$ & $\begin{array}{l}3.74 \\
3.66 \\
3.74 \\
3.66 \\
3.73\end{array}$ & $\begin{array}{l}3.63 \\
3.61 \\
3.62 \\
3.62 \\
3.61\end{array}$ \\
\hline & $3,68 \pm 0.03$ & $3.59 \pm 0.01$ & $3.70 \pm 0.05$ & $3.74 \pm 0.08$ & $3.70 \pm 0.04$ & $3.61 \pm 0.00$ \\
\hline & & & T & $\uparrow$ & $\uparrow$ & $\uparrow$ \\
\hline \multirow[t]{3}{*}{$\begin{array}{l}\text { Coeficiente De } \\
\text { forma }\end{array}$} & $\begin{array}{l}0.93 \\
0.93 \\
0.92 \\
0.95 \\
0.91\end{array}$ & $\begin{array}{l}0.97 \\
0.96 \\
0.97 \\
0.98 \\
0.98\end{array}$ & $\begin{array}{l}0.93 \\
0.90 \\
0.90 \\
0.96 \\
0.90\end{array}$ & $\begin{array}{l}0.84 \\
0.94 \\
0.90 \\
0.94 \\
0.89\end{array}$ & $\begin{array}{l}0.90 \\
0.94 \\
0.90 \\
0.94 \\
0.90\end{array}$ & $\begin{array}{l}0.96 \\
0.97 \\
0.96 \\
0.96 \\
0.96\end{array}$ \\
\hline & $0.92 \pm 0.01$ & $0.97 \pm 0.00$ & $0.91 \pm 0.02$ & $0.90 \pm 0.04$ & $0.91 \pm 0.02$ & $0.96 \pm 0.00$ \\
\hline & & & $\downarrow$ & $\downarrow$ & $\downarrow$ & $\downarrow$ \\
\hline \multirow[t]{3}{*}{$\begin{array}{l}\text { Excentrici- } \\
\text { dade }\end{array}$} & $\begin{array}{l}0.70 \\
0.70 \\
0.75 \\
0.59 \\
0.76\end{array}$ & $\begin{array}{l}0.40 \\
0.39 \\
0.48 \\
0.64 \\
0.50\end{array}$ & $\begin{array}{l}0.68 \\
0.76 \\
0.78 \\
0.56 \\
0.76\end{array}$ & $\begin{array}{l}0.84 \\
0.68 \\
0.76 \\
0.69 \\
0.80\end{array}$ & $\begin{array}{l}0.80 \\
0.69 \\
0.79 \\
0.68 \\
0.77\end{array}$ & $\begin{array}{l}0.62 \\
0.56 \\
0.59 \\
0.63 \\
0.52\end{array}$ \\
\hline & $0.70 \pm 0.06$ & $0.48 \pm 0.10$ & $0.70 \pm 0.09$ & $0.75 \pm 0.06$ & $0.74 \pm 0.05$ & $0.58 \pm 0.04$ \\
\hline & & & & $\uparrow$ & $\uparrow$ & $\uparrow$ \\
\hline
\end{tabular}

Obs: Estão expressos nesta tabela os dados relativos a: Relação Diâmetro maior/Diâmetro menor (DM/dm), Relação volume/área (Vol./Área), coeficiente de forma, índice de contorno, e excentricidade. 
TABELA 72 - Avaliação dos efeitos da utilização de inibidor de protease sobre os parâmetros da forma dos núcleos das células da camada basal do epitélio do palato (região palato duro) dos animais controles e tratados - Avaliação pelo teste Kruskal-Wallis

\section{DIÂMETRO MAIOR / DIÂMETRO MENOR}

Valor de $\mathrm{H}=0.9737$

Valor de $\mathrm{x}^{2} \mathrm{p} / 2^{\circ}$ de liberdade $=0.97$

Probabilidade de $\mathrm{H} 0=61.46 \%$

Significante para $\alpha \leq 0.05$

\section{VOLUME NUCLEAR / ÁREA NUCLEAR}

Valor de $\mathrm{H}=11.2000$

Valor de $x^{2} p / 2^{\circ}$ de liberdade $=11.20$

Probabilidade de $\mathrm{HO}=0.37 \%$

Significante para $\alpha \leq 0.01$

\section{ÍNDICE DE CONTORNO}

\section{Valor de $\mathrm{H}=0.9996$}

Valor de $\mathrm{x}^{2} \mathrm{p} / 2^{\circ}$ de liberdade $=1.00$

Probabilidade de $\mathrm{HO}=60.66 \%$

Significante para $\alpha \leq 0.05$

\section{COEFICIENTE DE FORMA}

\section{Valor de $\mathrm{H}=1.3085$}

Valor de $\mathrm{x}^{2} \mathrm{p} / 2^{\circ}$ de liberdade $=1.31$

Probabilidade de $\mathrm{HO}=51.98 \%$

\begin{tabular}{c}
$\begin{array}{c}\text { Controle X } 4 \\
\text { semanas } \\
\text { NS }\end{array}$ \\
\hline
\end{tabular}

Significante para $\alpha \leq 0.05$

\section{EXCENTRICIDADE}

Valor de $\mathrm{H}=1.4708$

Valor de $x^{2} \mathrm{p} / 2^{\circ}$ de liberdade $=1.47$

Probabilidade de $\mathrm{HO}=47.93 \%$

Controle X 4

semanas

NS
Controle X $8 \quad 4$ sem X 8 sem semanas

\begin{tabular}{l|l} 
NS & NS
\end{tabular}

Significante para $\alpha \leq 0.05$ 
TABELA 73 - Avaliação dos efeitos da utilização de inibidor de protease sobre os parâmetros da forma dos núcleos das células da camada espinhosa do epitélio do palato (região palato duro) dos animais controles e tratados - Avaliação pelo teste Kruskal-Wallis

\begin{tabular}{|c|c|c|c|}
\hline \multicolumn{4}{|c|}{ DIÂMETRO MAIOR / DIÂMETRO MENOR } \\
\hline $\begin{array}{l}\text { Valor de } H=10.7317 \\
\text { Valor de } x^{2} p / 2^{\circ} \text { de liberdade }=10.73 \\
\text { Probabilidade de } H 0=0.47 \%\end{array}$ & $\begin{array}{l}\text { Controle X } 4 \\
\text { semanas } \\
0.1 \%\end{array}$ & $\begin{array}{l}\text { Controle X } 8 \\
\text { semanas } \\
\text { NS }\end{array}$ & $\begin{array}{c}4 \text { sem } X 8 \text { sem } \\
1 \%\end{array}$ \\
\hline \multicolumn{4}{|l|}{$\begin{array}{l}\text { Significante para } \alpha \leq 0.01 \\
\text { VOLUME NUCLEAR / ÁREA NUCLEAR }\end{array}$} \\
\hline $\begin{array}{l}\text { Valor de } \mathrm{H}=10.8394 \\
\text { Valor de } \mathrm{x}^{2} \mathrm{p} / 2^{\circ} \text { de liberdade }=10.84 \\
\text { Probabilidade de } \mathrm{H} 0=0.44 \%\end{array}$ & $\begin{array}{l}\text { Controle X } 4 \\
\text { semanas } \\
5 \%\end{array}$ & $\begin{array}{l}\text { Controle X } 8 \\
\text { semanas } \\
0.1 \%\end{array}$ & $\begin{array}{c}4 \text { sem } X 8 \text { sem } \\
1 \%\end{array}$ \\
\hline \multicolumn{4}{|l|}{$\begin{array}{l}\text { Significante para } \alpha \leq 0.01 \\
\text { INDICE DE CONTORNO }\end{array}$} \\
\hline $\begin{array}{l}\text { Valor de } \mathrm{H}=10.9967 \\
\text { Valor de } \mathrm{x}^{2} \mathrm{p} / 2^{\circ} \text { de liberdade }=11.00 \\
\text { Probabilidade de } \mathrm{H} 0=0.41 \%\end{array}$ & $\begin{array}{l}\text { Controle X } 4 \\
\text { semanas } \\
0.1 \%\end{array}$ & $\begin{array}{l}\text { Controle X } 8 \\
\text { semanas } \\
5 \%\end{array}$ & $\begin{array}{c}4 \text { sem } X 8 \text { sem } \\
1 \%\end{array}$ \\
\hline \multicolumn{4}{|l|}{ Significante para $\alpha \leq 0.01$} \\
\hline $\begin{array}{l}\text { Valor de } H=11.3468 \\
\text { Valor de } x^{2} p / 2^{\circ} \text { de liberdade }=11.35 \\
\text { Probabilidade de } H 0=0.34 \%\end{array}$ & $\begin{array}{c}\text { Controle X } 4 \\
\text { semanas } \\
0.1 \%\end{array}$ & $\begin{array}{l}\text { Controle X } 8 \\
\text { semanas } \\
5 \%\end{array}$ & $\begin{array}{c}4 \mathrm{sem} X 8 \mathrm{sem} \\
0.1 \%\end{array}$ \\
\hline \multicolumn{4}{|l|}{ Significante para $\alpha \leq 0.01$} \\
\hline \multicolumn{4}{|l|}{ EXCENTRICIDADE } \\
\hline $\begin{array}{l}\text { Valor de } \mathrm{H}=10.5000 \\
\text { Valor de } \mathrm{x}^{2} \mathrm{p} / 2^{\circ} \text { de liberdade }=10.50 \\
\text { Probabilidade de } \mathrm{H} 0=0.52 \%\end{array}$ & $\begin{array}{l}\text { Controle X } 4 \\
\text { semanas } \\
0.1 \%\end{array}$ & $\begin{array}{l}\text { Controle X } 8 \\
\text { semanas } \\
\text { NS }\end{array}$ & $4 \mathrm{sem} X 8 \mathrm{sem}$ \\
\hline & & & \\
\hline
\end{tabular}


TABELA 74 - Avaliação do tamanho dos núcleos das células do epitélio do palato (região palato mole) dos animais controle e tratados com inibidor de protease.

\begin{tabular}{|c|c|c|c|c|c|c|}
\hline \multirow{2}{*}{$\begin{array}{l}\text { Estrutura } \\
\text { Estudada }\end{array}$} & \multicolumn{2}{|c|}{ Animais Controle } & \multicolumn{2}{|c|}{ Tratados - 4 semanas } & \multicolumn{2}{|c|}{ Tratados - 8 semanas } \\
\hline & C.Basal & C.Espinhosa & C.Basal & C.Espinhosa & C.Basal & C.Espinhosa \\
\hline \multirow[t]{3}{*}{$\begin{array}{l}\text { Diâmetro } \\
\text { maior }\end{array}$} & $\begin{array}{l}5.60 \\
5.76 \\
5.76 \\
5.80 \\
5.66\end{array}$ & $\begin{array}{l}5.74 \\
6.02 \\
6.14 \\
5.70 \\
5.84\end{array}$ & $\begin{array}{l}6.50 \\
6.32 \\
6.20 \\
6.22 \\
5.70\end{array}$ & $\begin{array}{l}6.18 \\
5.70 \\
6.48 \\
6.16 \\
5.92\end{array}$ & $\begin{array}{l}6.78 \\
7.10 \\
6.58 \\
6.82 \\
6.52\end{array}$ & $\begin{array}{l}6.62 \\
6.88 \\
6.50 \\
6.50 \\
6.62\end{array}$ \\
\hline & $5.71 \pm 0.08$ & $5.88 \pm 0.18$ & $6.18 \pm 0.129$ & $6.08 \pm 0.29$ & $6.76 \pm 0.22$ & $6.62 \pm 0.15$ \\
\hline & & & $\uparrow$ & $\uparrow$ & $\uparrow$ & $\uparrow$ \\
\hline \multirow[t]{3}{*}{$\begin{array}{l}\text { Diâmetro } \\
\text { menor }\end{array}$} & $\begin{array}{l}4.26 \\
4.44 \\
4.28 \\
4.26 \\
4.24\end{array}$ & $\begin{array}{l}4.48 \\
4.72 \\
4.54 \\
4.60 \\
4.44\end{array}$ & $\begin{array}{l}4.48 \\
4.38 \\
4.10 \\
4.94 \\
4.80\end{array}$ & $\begin{array}{l}4.20 \\
4.30 \\
4.04 \\
4.24 \\
4.10\end{array}$ & $\begin{array}{l}5.30 \\
5.42 \\
5.28 \\
4.78 \\
5.28\end{array}$ & $\begin{array}{l}5.28 \\
5.68 \\
5.24 \\
4.96 \\
5.24\end{array}$ \\
\hline & $4.29 \pm 0.08$ & $4.55 \pm 0.10$ & $4.54 \pm 0.33$ & $4.17 \pm 0.10$ & $5.21 \pm 0.24$ & $5.28 \pm 0.25$ \\
\hline & & & $\uparrow$ & $\downarrow$ & $\uparrow$ & $\uparrow$ \\
\hline \multirow[t]{3}{*}{$\begin{array}{l}\text { Volume } \\
\text { nuclear }\end{array}$} & $\begin{array}{l}62.04 \\
68.89 \\
66.42 \\
65.92 \\
63.54\end{array}$ & $\begin{array}{l}68.64 \\
80.52 \\
78.45 \\
71.93 \\
71.51\end{array}$ & $\begin{array}{l}73.47 \\
78.61 \\
78.40 \\
71.76 \\
76.33\end{array}$ & $\begin{array}{l}70.09 \\
64.76 \\
71.19 \\
71.93 \\
64.33\end{array}$ & $\begin{array}{c}114.11 \\
127.76 \\
109.69 \\
99.13 \\
109.03\end{array}$ & $\begin{array}{l}110.41 \\
132.07 \\
107.69 \\
099.20 \\
112.40\end{array}$ \\
\hline & $65.36 \pm 2.65$ & $74.71 \pm 5.03$ & $73.71 \pm 8.76$ & $68.46 \pm 3.63$ & $111.94 \pm 10.3$ & $112.35 \pm 12.1$ \\
\hline & & & $\uparrow$ & $\downarrow$ & $\uparrow$ & $\uparrow$ \\
\hline \multirow[t]{3}{*}{$\begin{array}{l}\text { Área } \\
\text { nuclear }\end{array}$} & $\begin{array}{l}18.98 \\
19.49 \\
19.54 \\
20.12 \\
18.77\end{array}$ & $\begin{array}{l}20.50 \\
20.69 \\
20.69 \\
22.34 \\
20.15\end{array}$ & $\begin{array}{l}22.87 \\
21.90 \\
20.01 \\
24.28 \\
21.54\end{array}$ & $\begin{array}{l}20.33 \\
19.31 \\
20.58 \\
20.64 \\
19.12\end{array}$ & $\begin{array}{l}28.24 \\
30.35 \\
27.43 \\
25.64 \\
27.25\end{array}$ & $\begin{array}{l}27.55 \\
30.98 \\
26.97 \\
25.51 \\
27.63\end{array}$ \\
\hline & $19.38 \pm 0.52$ & $20.87 \pm 0.84$ & $22.12 \pm 1.58$ & $19.99 \pm 0.72$ & $27.78 \pm 1.71$ & $27.72 \pm 2.00$ \\
\hline & & & $\uparrow$ & $\downarrow$ & $\uparrow$ & $\uparrow$ \\
\hline \multirow[t]{3}{*}{$\begin{array}{l}\text { Perímetro } \\
\text { nuclear }\end{array}$} & $\begin{array}{l}15.59 \\
16.12 \\
15.88 \\
15.93 \\
15.66\end{array}$ & $\begin{array}{l}16.12 \\
16.97 \\
16.90 \\
16.25 \\
16.26\end{array}$ & $\begin{array}{l}17.44 \\
16.97 \\
16.38 \\
17.62 \\
16.56\end{array}$ & $\begin{array}{l}16.51 \\
15.81 \\
16.79 \\
16.51 \\
15.92\end{array}$ & $\begin{array}{l}19.08 \\
19.79 \\
18.71 \\
18.40 \\
18.61\end{array}$ & $\begin{array}{l}18.78 \\
19.79 \\
18.52 \\
18.12 \\
18.71\end{array}$ \\
\hline & $15.83 \pm 0.21$ & $16.59 \pm 0.39$ & $16.99 \pm 0.53$ & $16.30 \pm 0.42$ & $18.91 \pm 0.54$ & $18.78 \pm 0.61$ \\
\hline & & & $\uparrow$ & $\downarrow$ & $\uparrow$ & $\uparrow$ \\
\hline
\end{tabular}

Obs: Estão expressos nesta tabela os dados relativos a: Diâmetro maior em micrometros $(\mu \mathrm{m})$, diâmetro menor $(\mathrm{em} \mu \mathrm{m})$, perímetro do núcleo celular $(\mathrm{em} \mu \mathrm{m})$, área nuclear em micrometros quadrados $\left(\mu \mathrm{m}^{2}\right)$, e volume nuclear em micrometros cúbicos $\left(\mu \mathrm{m}^{3}\right)$. 
TABELA 75 - Avaliação dos efeitos da utilização de inibidor de protease sobre os parâmetros do tamanho dos núcleos das células da camada basal do palato (região palato mole) dos animais controles e tratados Avaliação pelo teste Kruskal-Wallis

\section{DIÂMETRO MAIOR}

Valor de $\mathrm{H}=11.2000$

Valor de $x^{2} p / 2^{\circ}$ de liberdade $=11.20$

Probabilidade de $\mathrm{H} 0=0.37 \%$

Significante para $\alpha \leq 0.01$

\section{DIÂMETRO MENOR}

Valor de $\mathrm{H}=9.0925$

Valor de $x^{2} p / 2^{\circ}$ de liberdade $=9.09$

Probabilidade de $\mathrm{H} 0=1.06 \%$

Significante para $\alpha \leq 0.01$

\section{VOLUME NUCLEAR}

Valor de $\mathrm{H}=12.0200$

Valor de $x^{2} p / 2^{\circ}$ de liberdade $=12.02$

Probabilidade de $\mathrm{H} 0=0.25 \%$

\begin{tabular}{|c|c|}
\hline $\begin{array}{c}\text { Controle X } 4 \\
\text { semanas }\end{array}$ & $\begin{array}{c}\text { Controle X } 8 \\
\text { semanas }\end{array}$ \\
\hline $5 \%$ & $0.1 \%$ \\
\hline
\end{tabular}

4 sem $X 8$ sem

Significante para $\alpha \leq 0.01$

\section{ÁREA NUCLEAR}

Valor de $\mathrm{H}=12.0200$

Valor de $x^{2} p / 2^{\circ}$ de liberdade $=12.02$

Probabilidade de $\mathrm{H} 0=0.25 \%$

\begin{tabular}{c|c|c}
$\begin{array}{c}\text { Controle X } 4 \\
\text { semanas } \\
\text { NS }\end{array}$ & $\begin{array}{c}\text { Controle X 8 } \\
\text { semanas } \\
0.1 \%\end{array}$ & 4 sem X 8 sem \\
\hline
\end{tabular}

Significante para $\alpha \leq 0.01$

\section{PERÍMETRO NUCLEAR}

Valor de $\mathrm{H}=12.5000$

Valor de $x^{2} p / 2^{\circ}$ de liberdade $=12.50$

Probabilidade de $\mathrm{H} 0=0.19 \%$

Controle X 4 semanas

$0.1 \%$

Controle X 4

semanas

$1 \%$

Controle X 4

semanas

$1 \%$
Controle X $8 \quad 4$ sem X 8 sem semanas

$0.1 \%$

$0.1 \%$

Significante para $\alpha \leq 0.01$ 
TABELA 76 - Avaliação dos efeitos da utilização de inibidor de protease sobre os parâmetros do tamanho dos núcleos das células da camada espinhosa do palato (região palato mole) dos animais controles e tratados Avaliação pelo teste Kruskal-Wallis

\section{DIÂMETRO MAIOR}

Valor de $\mathrm{H}=10.1494$

Valor de $x^{2} p / 2^{\circ}$ de liberdade $=10.15$

Probabilidade de $\mathrm{H} 0=0.63 \%$

\begin{tabular}{|c|c|c|}
\hline $\begin{array}{c}\text { Controle X } 4 \\
\text { semanas } \\
\text { NS }\end{array}$ & $\begin{array}{c}\text { Controle X 8 } \\
\text { semanas }\end{array}$ & 4 sem X 8 sem \\
\hline $0.1 \%$ & $1 \%$ \\
\hline
\end{tabular}

Significante para $\alpha \leq 0.01$

\section{DIÂMETRO MENOR}

Valor de $\mathrm{H}=12.5224$

Valor de $x^{2} \mathrm{p} / 2^{\circ}$ de liberdade $=12.52$

Probabilidade de $\mathrm{H} 0=0.19 \%$

\begin{tabular}{c|c|c|}
$\begin{array}{c}\text { Controle } X 4 \\
\text { semanas } \\
0.1 \%\end{array}$ & $\begin{array}{c}\text { Controle } X 8 \\
\text { semanas } \\
0.1 \%\end{array}$ & 4 sem $X 8$ sem \\
\hline
\end{tabular}

Significante para $\alpha \leq 0.01$

\section{VOLUME NUCLEAR}

Valor de $\mathrm{H}=10.6741$

Valor de $x^{2} \mathrm{p} / 2^{\circ}$ de liberdade $=10.67$

Probabilidade de $\mathrm{H} 0=0.48 \%$

\begin{tabular}{c|c|c}
$\begin{array}{c}\text { Controle X } 4 \\
\text { semanas } \\
\text { NS }\end{array}$ & $\begin{array}{c}\text { Controle X } 8 \\
\text { semanas } \\
1 \%\end{array}$ & 4 sem $X 8$ sem \\
\hline
\end{tabular}

Significante para $\alpha \leq 0.01$

\section{ÁREA NUCLEAR}

Valor de $\mathrm{H}=10.5188$

Valor de $\mathrm{x}^{2} \mathrm{p} / 2^{\circ}$ de liberdade $=10.52$

Probabilidade de $\mathrm{H} 0=0.52 \%$

\begin{tabular}{c|c|c}
$\begin{array}{c}\text { Controle X } 4 \\
\text { semanas } \\
\text { NS }\end{array}$ & $\begin{array}{c}\text { Controle X 8 } \\
\text { semanas } \\
1 \%\end{array}$ & 4 sem X 8 sem \\
\hline
\end{tabular}

Significante para $\alpha \leq 0.01$

\section{PERÍMETRO NUCLEAR}

Valor de $\mathrm{H}=9.6372$

Valor de $x^{2} \mathrm{p} / 2^{\circ}$ de liberdade $=9.64$

Probabilidade de $\mathrm{H} 0=0.81 \%$

\begin{tabular}{c|c|c}
$\begin{array}{c}\text { Controle } \mathrm{X} 4 \\
\text { semanas } \\
\text { NS }\end{array}$ & $\begin{array}{c}\text { Controle } \mathrm{X} 8 \\
\text { semanas } \\
1 \%\end{array}$ & 4 sem $\mathrm{X} 8 \mathrm{sem}$ \\
\hline
\end{tabular}

Significante para $\alpha \leq 0.01$ 
TABELA 77 - Avaliação dos parâmetros avaliação da forma dos núcleos das células epiteliais do palato (região palato mole) dos animais controles e tratados com inibidor de protease.

\begin{tabular}{|c|c|c|c|c|c|c|}
\hline \multirow{2}{*}{$\begin{array}{l}\text { Estrutura } \\
\text { Estudada }\end{array}$} & \multicolumn{2}{|c|}{ Animais Controle } & \multicolumn{2}{|c|}{ Tratados - 4 semanas } & \multicolumn{2}{|c|}{ Tratados - 8 semanas } \\
\hline & C.Basal & C.Espinhosa & C.Basal & C.Espinhosa & C.Basal & C.Espinhosa \\
\hline \multirow[t]{3}{*}{$\begin{array}{l}\text { Relação } \\
\text { DM/dm }\end{array}$} & $\begin{array}{l}1.36 \\
1.40 \\
1.37 \\
1.32 \\
1.33\end{array}$ & $\begin{array}{l}1.30 \\
1.30 \\
1.37 \\
1.25 \\
1.35\end{array}$ & $\begin{array}{l}1.48 \\
1.47 \\
1.55 \\
1.29 \\
1.21\end{array}$ & $\begin{array}{l}1.52 \\
1.35 \\
1.64 \\
1.47 \\
1.49\end{array}$ & $\begin{array}{l}1.30 \\
1.33 \\
1.26 \\
1.46 \\
1.25\end{array}$ & $\begin{array}{l}1.27 \\
1.22 \\
1.26 \\
1.33 \\
1.28\end{array}$ \\
\hline & $1.35 \pm 0.03$ & $1.31 \pm 0.04$ & $1.40 \pm 0.14$ & $1.49 \pm 0.10$ & $1.32 \pm 0.08$ & $1.27 \pm 0.03$ \\
\hline & & & $\uparrow$ & $\uparrow$ & $\uparrow$ & $\downarrow$ \\
\hline \multirow[t]{3}{*}{$\begin{array}{l}\text { Relação } \\
\text { Vol./Área }\end{array}$} & $\begin{array}{l}3.25 \\
3.30 \\
3.30 \\
3.36 \\
3.24\end{array}$ & $\begin{array}{l}3.38 \\
3.40 \\
3.51 \\
3.54 \\
3.37\end{array}$ & $\begin{array}{l}3.58 \\
3.50 \\
3.35 \\
3.68 \\
3.47\end{array}$ & $\begin{array}{l}3.37 \\
3.29 \\
3.40 \\
3.39 \\
3.26\end{array}$ & $\begin{array}{l}3.98 \\
4.12 \\
3.92 \\
3.79 \\
3.90\end{array}$ & $\begin{array}{l}3.93 \\
4.16 \\
3.88 \\
3.77 \\
3.92\end{array}$ \\
\hline & $3.29 \pm 0.04$ & $3.44 \pm 0.07$ & $3.51 \pm 0.12$ & $3.34 \pm 0.06$ & $3.94 \pm 0.12$ & $3.93 \pm 0.14$ \\
\hline & & & $\uparrow$ & $\downarrow$ & $\uparrow$ & $\uparrow$ \\
\hline \multirow[t]{3}{*}{$\begin{array}{l}\text { Índice de } \\
\text { contorno }\end{array}$} & $\begin{array}{l}3.62 \\
3.63 \\
3.62 \\
3.61 \\
3.61\end{array}$ & $\begin{array}{l}3.62 \\
3.59 \\
3.62 \\
3.61 \\
3.61\end{array}$ & $\begin{array}{l}3.66 \\
3.65 \\
3.35 \\
3.60 \\
3.59\end{array}$ & $\begin{array}{l}3.69 \\
3.62 \\
3.72 \\
3.66 \\
3.67\end{array}$ & $\begin{array}{l}3.60 \\
3.61 \\
3.59 \\
3.66 \\
3.59\end{array}$ & $\begin{array}{l}3.60 \\
3.58 \\
3.59 \\
3.61 \\
3.59\end{array}$ \\
\hline & $3,61 \pm 0.00$ & $3.61 \pm 0.01$ & $3.57 \pm 0.12$ & $3.67 \pm 0.03$ & $3.61 \pm 0.02$ & $3.59 \pm 0.01$ \\
\hline & & & $\downarrow$ & $\uparrow$ & $\uparrow$ & $\uparrow$ \\
\hline \multirow[t]{3}{*}{$\begin{array}{l}\text { Coeficiente } \\
\text { De forma }\end{array}$} & $\begin{array}{l}0.96 \\
0.96 \\
0.96 \\
0.95 \\
0.96\end{array}$ & $\begin{array}{l}0.97 \\
0.97 \\
0.96 \\
0.98 \\
0.96\end{array}$ & $\begin{array}{l}0.94 \\
0.94 \\
0.93 \\
0.97 \\
0.98\end{array}$ & $\begin{array}{l}0.93 \\
0.96 \\
0.91 \\
0.94 \\
0.93\end{array}$ & $\begin{array}{l}0.97 \\
0.96 \\
0.98 \\
0.94 \\
0.98\end{array}$ & $\begin{array}{l}0.97 \\
0.98 \\
0.97 \\
0.96 \\
0.97\end{array}$ \\
\hline & $0.95 \pm 0.00$ & $0.96 \pm 0.00$ & $0.95 \pm 0.02$ & $0.93 \pm 0.01$ & $0.96 \pm 0.01$ & $0.97 \pm 0.00$ \\
\hline & & & & $\downarrow$ & $\downarrow$ & $\downarrow$ \\
\hline \multirow[t]{3}{*}{$\begin{array}{l}\text { Excentrici- } \\
\text { dade }\end{array}$} & $\begin{array}{l}0.56 \\
0.53 \\
0.62 \\
0.62 \\
0.58\end{array}$ & $\begin{array}{l}0.51 \\
0.50 \\
0.62 \\
0.48 \\
0.54\end{array}$ & $\begin{array}{l}0.66 \\
0.69 \\
0.71 \\
0.52 \\
0.38\end{array}$ & $\begin{array}{l}0.65 \\
0.59 \\
0.75 \\
0.67 \\
0.63\end{array}$ & $\begin{array}{l}0.54 \\
0.58 \\
0.52 \\
0.66 \\
0.52\end{array}$ & $\begin{array}{l}0.51 \\
0.50 \\
0.50 \\
0.56 \\
0.55\end{array}$ \\
\hline & $0.58 \pm 0.03$ & $0.53 \pm 0.05$ & $0.59 \pm 0.13$ & $0.65 \pm 0.05$ & $0.56 \pm 0.05$ & $0.52 \pm 0.02$ \\
\hline & & & $\uparrow$ & $\uparrow$ & $\uparrow$ & $\downarrow$ \\
\hline
\end{tabular}

Obs: Estão expressos nesta tabela os dados relativos a: Relação Diâmetro maior/Diâmetro menor (DM/dm), Relação volume/área (Vol./Área), coeficiente de forma, índice de contorno, e excentricidade. 
TABELA 78 - Avaliação dos efeitos da utilização de inibidor de protease sobre os parâmetros da forma dos núcleos das células da camada basal do epitélio do palato (região palato mole) dos animais controles e tratados - Avaliação pelo teste Kruskal-Wallis

\begin{tabular}{|c|c|c|c|}
\hline \multicolumn{4}{|c|}{ DIÂMETRO MAIOR / DIÂMETRO MENOR } \\
\hline \multirow{2}{*}{$\begin{array}{l}\text { Valor de } \mathrm{H}=1.7181 \\
\text { Valor de } \mathrm{x}^{2} \mathrm{p} / 2^{\circ} \text { de liberdade }=1.72 \\
\text { Probabilidade de } \mathrm{H} 0=42.36 \%\end{array}$} & $\begin{array}{c}\text { Controle X } 4 \\
\text { semanas }\end{array}$ & $\begin{array}{c}\text { Controle X } 8 \\
\text { semanas }\end{array}$ & 4 sem $X 8$ sem \\
\hline & NS & NS & NS \\
\hline \multicolumn{4}{|l|}{ Significante para $\alpha \leq 0.05$} \\
\hline \multicolumn{4}{|l|}{ VOLUME NUCLEAR / ÁREA NUCLEAR } \\
\hline \multirow{2}{*}{$\begin{array}{l}\text { Valor de } H=12.0415 \\
\text { Valor de } x^{2} p / 2^{\circ} \text { de liberdade }=12.04 \\
\text { Probabilidade de } H 0=0.24 \%\end{array}$} & $\begin{array}{c}\text { Controle X } 4 \\
\text { semanas }\end{array}$ & $\begin{array}{c}\text { Controle X } 8 \\
\text { semanas }\end{array}$ & 4 sem $X 8$ sem \\
\hline & $1 \%$ & $0.1 \%$ & $0.1 \%$ \\
\hline \multicolumn{4}{|l|}{ Significante para $\alpha \leq 0.01$} \\
\hline \multicolumn{4}{|l|}{ ÍNDICE DE CONTORNO } \\
\hline \multirow{2}{*}{$\begin{array}{l}\text { Valor de } \mathrm{H}=1.2852 \\
\text { Valor de } \mathrm{x}^{2} \mathrm{p} / 2^{\circ} \text { de liberdade }=1.29 \\
\text { Probabilidade de } \mathrm{H} 0=52.59 \%\end{array}$} & $\begin{array}{c}\text { Controle X } 4 \\
\text { semanas }\end{array}$ & $\begin{array}{c}\text { Controle X } 8 \\
\text { semanas }\end{array}$ & 4 sem $X 8$ sem \\
\hline & NS & NS & NS \\
\hline \multicolumn{4}{|l|}{ Significante para $\alpha \leq 0.05$} \\
\hline \multicolumn{4}{|l|}{ COEFICIENTE DE FORMA } \\
\hline \multirow{2}{*}{$\begin{array}{l}\text { Valor de } H=1.8508 \\
\text { Valor de } x^{2} p / 2^{\circ} \text { de liberdade }=1.85 \\
\text { Probabilidade de } H 0=37.64 \%\end{array}$} & $\begin{array}{c}\text { Controle X } 4 \\
\text { semanas }\end{array}$ & $\begin{array}{c}\text { Controle X } 8 \\
\text { semanas }\end{array}$ & 4 sem $X 8$ sem \\
\hline & NS & NS & NS \\
\hline \multicolumn{4}{|l|}{ Significante para $\alpha \leq 0.05$} \\
\hline \multicolumn{4}{|l|}{ EXCENTRICIDADE } \\
\hline \multirow{2}{*}{$\begin{array}{l}\text { Valor de } \mathrm{H}=0.8253 \\
\text { Valor de } \mathrm{x}^{2} \mathrm{p} / 2^{\circ} \text { de liberdade }=0.83 \\
\text { Probabilidade de } \mathrm{H} 0=66.19 \%\end{array}$} & $\begin{array}{c}\text { Controle X } 4 \\
\text { semanas }\end{array}$ & $\begin{array}{c}\text { Controle X } 8 \\
\text { semanas }\end{array}$ & 4 sem $X 8$ sem \\
\hline & & NS & NS \\
\hline
\end{tabular}


TABELA 79 - Avaliação dos efeitos da utilização de inibidor de protease sobre os parâmetros da forma dos núcleos das células da camada espinhosa do epitélio do palato (região palato mole) dos animais controles e tratados - Avaliação pelo teste Kruskal-Wallis

\begin{tabular}{|c|c|c|c|}
\hline \multicolumn{4}{|c|}{ DIÂMETRO MAIOR / DIÂMETRO MENOR } \\
\hline \multirow{2}{*}{$\begin{array}{l}\text { Valor de } \mathrm{H}=9.3685 \\
\text { Valor de } \mathrm{x}^{2} \mathrm{p} / 2^{\circ} \text { de liberdade }=9.37 \\
\text { Probabilidade de } \mathrm{H} 0=0.92 \%\end{array}$} & Controle X 4 & Controle X 8 & $4 \mathrm{sem} X 8 \mathrm{sem}$ \\
\hline & $\underset{1 \%}{\text { semanas }}$ & $\begin{array}{l}\text { semanas } \\
\text { NS }\end{array}$ & $0.1 \%$ \\
\hline \multicolumn{4}{|l|}{ Significante para $\alpha \leq 0.01$} \\
\hline \multicolumn{4}{|l|}{ VOLUME NUCLEAR / ÁREA NUCLEAR } \\
\hline \multirow{2}{*}{$\begin{array}{l}\text { Valor de } \mathrm{H}=10.5376 \\
\text { Valor de } \mathrm{x}^{2} \mathrm{p} / 2^{\circ} \text { de liberdade }=10.54 \\
\text { Probabilidade de } \mathrm{H} 0=0.51 \%\end{array}$} & Controle X 4 & Controle X 8 & 4 sem $X 8$ sem \\
\hline & $\begin{array}{l}\text { semanas } \\
\text { NS }\end{array}$ & $\begin{array}{l}\text { semanas } \\
1 \%\end{array}$ & $0.1 \%$ \\
\hline \multicolumn{4}{|l|}{ Significante para $\alpha \leq 0.01$} \\
\hline \multicolumn{4}{|l|}{ ÍNDICE DE CONTORNO } \\
\hline \multirow{2}{*}{$\begin{array}{l}\text { Valor de } \mathrm{H}=10.4847 \\
\text { Valor de } \mathrm{x}^{2} \mathrm{p} / 2^{\circ} \text { de liberdade }=10.48 \\
\text { Probabilidade de } \mathrm{H} 0=0.53 \%\end{array}$} & $\begin{array}{c}\text { Controle X } 4 \\
\text { semanas }\end{array}$ & $\begin{array}{c}\text { Controle X } 8 \\
\text { semanas }\end{array}$ & 4 sem $X 8$ sem \\
\hline & $1 \%$ & $5 \%$ & $0.1 \%$ \\
\hline \multicolumn{4}{|l|}{ Significante para $\alpha \leq 0.01$} \\
\hline \multicolumn{4}{|l|}{ COEFICIENTE DE FORMA } \\
\hline \multirow{2}{*}{$\begin{array}{l}\text { Valor de } \mathrm{H}=8.8932 \\
\text { Valor de } \mathrm{x}^{2} \mathrm{p} / 2^{\circ} \text { de liberdade }=8.89 \\
\text { Probabilidade de } \mathrm{H} 0=1.17 \%\end{array}$} & $\begin{array}{c}\text { Controle X } 4 \\
\text { semanas }\end{array}$ & $\begin{array}{c}\text { Controle X } 8 \\
\text { semanas }\end{array}$ & 4 sem $X 8$ sem \\
\hline & $1 \%$ & NS & $1 \%$ \\
\hline \multicolumn{4}{|l|}{ Significante para $\alpha \leq 0.01$} \\
\hline \multicolumn{4}{|l|}{ EXCENTRICIDADE } \\
\hline \multirow{2}{*}{$\begin{array}{l}\text { Valor de } \mathrm{H}=8.7229 \\
\text { Valor de } \mathrm{x}^{2} \mathrm{p} / 2^{\circ} \text { de liberdade }=8.72 \\
\text { Probabilidade de } \mathrm{H} 0=1.28 \%\end{array}$} & $\begin{array}{c}\text { Controle X } 4 \\
\text { semanas }\end{array}$ & $\begin{array}{c}\text { Controle X } 8 \\
\text { semanas }\end{array}$ & 4 sem $X 8$ sem \\
\hline & $1 \%$ & NS & $1 \%$ \\
\hline
\end{tabular}


TABELA 80 - Avaliação do tamanho dos núcleos das células do epitélio da região gengival dos animais controle e tratados com inibidor de protease.

\begin{tabular}{|c|c|c|c|c|c|c|}
\hline \multirow{2}{*}{$\begin{array}{l}\text { Estrutura } \\
\text { Estudada }\end{array}$} & \multicolumn{2}{|c|}{ Animais Controle } & \multicolumn{2}{|c|}{ Tratados - 4 semanas } & \multicolumn{2}{|c|}{ Tratados - 8 semanas } \\
\hline & C.Basal & C.Espinhosa & C.Basal & C.Espinhosa & C.Basal & C.Espinhosa \\
\hline \multirow[t]{2}{*}{$\begin{array}{l}\text { Diâmetro } \\
\text { maior }\end{array}$} & $\begin{array}{l}6.24 \\
6.34 \\
6.48 \\
6.42 \\
6.38\end{array}$ & $\begin{array}{l}6.34 \\
6.50 \\
6.94 \\
6.48 \\
6.54\end{array}$ & $\begin{array}{l}6.00 \\
5.68 \\
5.88 \\
6.62 \\
6.62\end{array}$ & $\begin{array}{l}5.88 \\
6.20 \\
5.78 \\
6.34 \\
6.70\end{array}$ & $\begin{array}{l}5.86 \\
5.58 \\
5.96 \\
5.96 \\
6.16\end{array}$ & $\begin{array}{l}6.16 \\
6.14 \\
6.26 \\
6.32 \\
6.84\end{array}$ \\
\hline & $6.37 \pm 0.09$ & $6.56 \pm 0.22$ & $\begin{array}{c}6.16 \pm 0.43 \\
\Downarrow\end{array}$ & $6.18 \pm 0.36$ & $\begin{array}{c}5.90 \pm 0.21 \\
\Downarrow\end{array}$ & $\begin{array}{c}6.34 \pm 0.28 \\
\Downarrow\end{array}$ \\
\hline \multirow[t]{2}{*}{$\begin{array}{l}\text { Diâmetro } \\
\text { menor }\end{array}$} & $\begin{array}{l}4.92 \\
4.90 \\
5.02 \\
4.82 \\
5.16\end{array}$ & $\begin{array}{l}5.52 \\
5.20 \\
5.24 \\
5.02 \\
5.04\end{array}$ & $\begin{array}{l}4.00 \\
4.18 \\
4.00 \\
3.70 \\
3.90\end{array}$ & $\begin{array}{l}4.58 \\
4.34 \\
4.36 \\
4.04 \\
4.66\end{array}$ & $\begin{array}{l}4.40 \\
4.32 \\
4.60 \\
4.26 \\
4.60\end{array}$ & $\begin{array}{l}4.64 \\
4.74 \\
4.62 \\
4.42 \\
4.66\end{array}$ \\
\hline & $4.96 \pm 0.13$ & $5.20 \pm 0.20$ & $3.95 \pm 0.17$ & $4.39 \pm 0.24$ & $4.43 \pm 0.15$ & $4.61 \pm 0.11$ \\
\hline \multirow[t]{2}{*}{$\begin{array}{l}\text { Volume } \\
\text { nuclear }\end{array}$} & $\begin{array}{l}94.62 \\
90.73 \\
88.80 \\
90.10 \\
90.32\end{array}$ & $\begin{array}{l}101.47 \\
101.08 \\
116.03 \\
105.61 \\
112.54\end{array}$ & $\begin{array}{l}62.14 \\
62.14 \\
60.75 \\
65.51 \\
69.89\end{array}$ & $\begin{array}{l}75.35 \\
73.91 \\
66.95 \\
68.98 \\
92.12\end{array}$ & $\begin{array}{l}69.94 \\
63.32 \\
65.97 \\
68.44 \\
70.76\end{array}$ & $\begin{array}{l}81.49 \\
83.84 \\
83.31 \\
78.47 \\
95.99\end{array}$ \\
\hline & $94.92 \pm 3.37$ & $107.34 \pm 6.6$ & $\begin{array}{c}63.88 \pm 3.30 \\
\Downarrow\end{array}$ & $\begin{array}{c}75.46 \pm 9.92 \\
\Downarrow\end{array}$ & $\begin{array}{c}67.68 \pm 6.78 \\
\Downarrow\end{array}$ & $\begin{array}{c}84.62 \pm 6.69 \\
\downarrow\end{array}$ \\
\hline \multirow[t]{3}{*}{ Área nuclear } & $\begin{array}{l}25.37 \\
24.06 \\
25.60 \\
24.72 \\
24.79\end{array}$ & $\begin{array}{l}27.79 \\
26.70 \\
28.56 \\
25.79 \\
26.00\end{array}$ & $\begin{array}{l}18.80 \\
18.71 \\
18.47 \\
19.35 \\
20.28\end{array}$ & $\begin{array}{l}21.27 \\
21.11 \\
19.78 \\
20.14 \\
24.44\end{array}$ & $\begin{array}{l}20.29 \\
19.01 \\
21.52 \\
20.00 \\
22.35\end{array}$ & $\begin{array}{l}22.51 \\
22.92 \\
22.79 \\
21.96 \\
25.10\end{array}$ \\
\hline & $24.90 \pm 0.60$ & $26.96 \pm 1.18$ & $19.12 \pm 0.72$ & $21.34 \pm 1.83$ & $20.63 \pm 1.31$ & $23.05 \pm 1.20$ \\
\hline & & & $\downarrow$ & $\downarrow$ & $\downarrow$ & $\downarrow$ \\
\hline \multirow[t]{2}{*}{$\begin{array}{l}\text { Perímetro } \\
\text { nuclear }\end{array}$} & $\begin{array}{l}17.86 \\
17.90 \\
18.17 \\
17.64 \\
17.97\end{array}$ & $\begin{array}{l}18.30 \\
18.17 \\
19.26 \\
18.46 \\
18.67\end{array}$ & $\begin{array}{l}15.91 \\
15.62 \\
15.71 \\
16.58 \\
16.85\end{array}$ & $\begin{array}{l}16.53 \\
16.73 \\
16.04 \\
16.54 \\
18.04\end{array}$ & $\begin{array}{l}16.23 \\
15.64 \\
16.69 \\
16.20 \\
17.02\end{array}$ & $\begin{array}{l}17.08 \\
17.19 \\
17.22 \\
17.04 \\
18.26\end{array}$ \\
\hline & $17.90 \pm 0.19$ & $18.57 \pm 0.42$ & $\begin{array}{c}16.13 \pm 0.54 \\
\Downarrow\end{array}$ & $16.77 \pm 0.75$ & $\begin{array}{c}16.35 \pm 0.52 \\
\Downarrow\end{array}$ & $\begin{array}{c}17.35 \pm 0.50 \\
\downarrow\end{array}$ \\
\hline
\end{tabular}

Obs: Estão expressos nesta tabela os dados relativos a: Diâmetro maior em micrometros $(\mu \mathrm{m})$, diâmetro menor $(\mathrm{em} \mu \mathrm{m})$, perímetro do núcleo celular (em $\mu \mathrm{m})$, área nuclear em micrometros quadrados $\left(\mu \mathrm{m}^{2}\right)$, e volume nuclear em micrometros cúbicos $\left(\mu \mathrm{m}^{3}\right)$. 
TABELA 81- Avaliação dos efeitos da utilização de inibidor de protease sobre os parâmetros do tamanho dos núcleos das células da camada basal da região gengival dos animais controles e tratados - Avaliação pelo teste Kruskal-Wallis

\section{DIÂMETRO MAIOR}

Valor de $\mathrm{H}=5.1986$

Valor de $x^{2} p / 2^{\circ}$ de liberdade $=5.20$

Probabilidade de $\mathrm{H} 0=7.43 \%$

\begin{tabular}{|c|c|c|}
\hline $\begin{array}{c}\text { Controle X } 4 \\
\text { semanas } \\
\text { NS }\end{array}$ & $\begin{array}{c}\text { Controle X } 8 \\
\text { semanas }\end{array}$ & 4 sem X 8 sem \\
\hline $5 \%$ & NS \\
\hline
\end{tabular}

Significante para $\alpha \leq 0.05$

\section{DIÂMETRO MENOR}

Valor de $\mathrm{H}=12.5448$

Valor de $x^{2} p / 2^{\circ}$ de liberdade $=12.54$

Probabilidade de $\mathrm{H} 0=0.19 \%$

\begin{tabular}{c|c|c|}
$\begin{array}{c}\text { Controle X } 4 \\
\text { semanas } \\
0.1 \%\end{array}$ & $\begin{array}{c}\text { Controle X } 8 \\
\text { semanas } \\
0.1 \%\end{array}$ & 4 sem X 8 sem \\
\hline & $0.1 \%$ \\
\hline
\end{tabular}

Significante para $\alpha \leq 0.01$

VOLUME NUCLEAR

Valor de $\mathrm{H}=11.2000$

Valor de $x^{2} p / 2^{\circ}$ de liberdade $=11.20$

Probabilidade de $\mathrm{H} 0=0.37 \%$

Controle X 4 semanas

Controle X $8 \quad 4$ sem X 8 sem $0.1 \%$ semanas

Significante para $\alpha \leq 0.01$

\section{ÁREA NUCLEAR}

Valor de $\mathrm{H}=11.1800$

Valor de $x^{2} p / 2^{\circ}$ de liberdade $=11.18$

Probabilidade de $\mathrm{H} 0=0.37 \%$

Controle X 4
semanas
$0.1 \%$

Significante para $\alpha \leq 0.01$

\section{PERÍMETRO NUCLEAR}

Valor de $\mathrm{H}=9.6200$

Valor de $x^{2} p / 2^{\circ}$ de liberdade $=9.62$

Probabilidade de $\mathrm{H} 0=0.81 \%$

Significante para $\alpha \leq 0.01$

\begin{tabular}{c|c|c|}
$\begin{array}{c}\text { Controle } \mathrm{X} 4 \\
\text { semanas } \\
0.1 \%\end{array}$ & $\begin{array}{c}\text { Controle } \mathrm{X} 8 \\
\text { semanas } \\
1 \%\end{array}$ & 4 sem $\mathrm{X} 8 \mathrm{sem}$ \\
\hline
\end{tabular}

Controle X $8 \quad 4$ sem X 8 sem manas

\begin{tabular}{l|l}
$1 \%$ & $5 \%$
\end{tabular}
$5 \%$ 
TABELA 82 - Avaliação dos efeitos da utilização de inibidor de protease sobre os parâmetros do tamanho dos núcleos das células da camada espinhosa da região gengival dos animais controles e tratados - Avaliação pelo teste Kruskal-Wallis

\section{DIÂMETRO MAIOR}

Valor de $\mathrm{H}=4.1925$

Valor de $x^{2} p / 2^{\circ}$ de liberdade $=4.19$

Probabilidade de $\mathrm{H} 0=12.29 \%$

\begin{tabular}{|c|c|c|}
\hline $\begin{array}{c}\text { Controle } X 4 \\
\text { semanas } \\
\text { NS }\end{array}$ & $\begin{array}{c}\text { Controle X } 8 \\
\text { semanas } \\
\text { NS }\end{array}$ & 4 sem X 8 sem \\
\hline
\end{tabular}

Significante para $\alpha \leq 0.05$

\section{DIÂMETRO MENOR}

Valor de $\mathrm{H}=10.6741$

Valor de $\mathrm{x}^{2} \mathrm{p} / 2^{\circ}$ de liberdade $=10.67$

Probabilidade de $\mathrm{H} 0=0.48 \%$

Controle X 4 Controle X 8 sem X 8 sem semanas

$0.1 \%$ semanas

$1 \% \quad$ NS

Significante para $\alpha \leq 0.01$

\section{VOLUME NUCLEAR}

Valor de $\mathrm{H}=10.8200$

Valor de $x^{2} p / 2^{\circ}$ de liberdade $=10.82$

Probabilidade de $\mathrm{H} 0=0.45 \%$

Controle X 4 semanas

$0.1 \%$

Significante para $\alpha \leq 0.01$

\section{ÁREA NUCLEAR}

Valor de $\mathrm{H}=10.8200$

Valor de $x^{2} \mathrm{p} / 2^{\circ}$ de liberdade $=10.82$

Probabilidade de $\mathrm{H} 0=0.45 \%$

Significante para $\alpha \leq 0.01$

\section{PERÍMETRO NUCLEAR}

Valor de $\mathrm{H}=10.2600$

Valor de $x^{2} p / 2^{\circ}$ de liberdade $=10.26$

Probabilidade de $\mathrm{H} 0=0.59 \%$

Significante para $\alpha \leq 0.01$

\begin{tabular}{c|c}
$\begin{array}{c}\text { Controle } X 8 \\
\text { semanas } \\
1 \%\end{array}$ & 4 sem $X 8$ sem \\
\hline
\end{tabular}

\begin{tabular}{c|c|c|}
$\begin{array}{c}\text { Controle X } 4 \\
\text { semanas } \\
0.1 \%\end{array}$ & $\begin{array}{c}\text { Controle X } 8 \\
\text { semanas } \\
1 \%\end{array}$ & 4 sem $\mathrm{X} 8$ sem \\
\hline
\end{tabular}

\begin{tabular}{c|c|c|}
$\begin{array}{c}\text { Controle X } 4 \\
\text { semanas } \\
0.1 \%\end{array}$ & $\begin{array}{c}\text { Controle X } 8 \\
\text { semanas } \\
1 \%\end{array}$ & 4 sem $\mathrm{X} 8$ sem \\
\hline
\end{tabular}


TABELA 83 - Avaliação dos parâmetros avaliação da forma dos núcleos das células epiteliais da região gengival dos animais controles e tratados com inibidor de protease.

\begin{tabular}{|c|c|c|c|c|c|c|}
\hline \multirow{2}{*}{$\begin{array}{l}\text { Estrutura } \\
\text { Estudada }\end{array}$} & \multicolumn{2}{|c|}{ Animais Controle } & \multicolumn{2}{|c|}{ Tratados - 4 semanas } & \multicolumn{2}{|c|}{ Tratados - 8 semanas } \\
\hline & C.Basal & C.Espinhosa & C.Basal & C.Espinhosa & C.Basal & C.Espinhosa \\
\hline $\begin{array}{l}\text { Relação } \\
\text { DM/dm }\end{array}$ & $\begin{array}{l}1.22 \\
1.34 \\
1.31 \\
1.33 \\
1.32\end{array}$ & $\begin{array}{l}1.15 \\
1.20 \\
1.34 \\
1.31 \\
1.32\end{array}$ & $\begin{array}{l}1.54 \\
1.40 \\
1.52 \\
1.84 \\
1.76\end{array}$ & $\begin{array}{l}1.31 \\
1.46 \\
1.35 \\
1.62 \\
1.50\end{array}$ & $\begin{array}{l}1.37 \\
1.32 \\
1.32 \\
1.43 \\
1.36\end{array}$ & $\begin{array}{l}1.35 \\
1.32 \\
1.38 \\
1.45 \\
1.49\end{array}$ \\
\hline & $1.30 \pm 0.04$ & $1.26 \pm 0.08$ & $1.61 \pm 0.18$ & $1.44 \pm 0.12$ & $1.36 \pm 0.04$ & $1.39 \pm 0.07$ \\
\hline & & & $\uparrow$ & $\uparrow$ & $\uparrow$ & $\uparrow$ \\
\hline $\begin{array}{l}\text { Relação } \\
\text { Vol./Área }\end{array}$ & $\begin{array}{l}3.77 \\
3.67 \\
3.79 \\
3.72 \\
3.72\end{array}$ & $\begin{array}{l}3.92 \\
3.87 \\
4.01 \\
3.79 \\
3.81\end{array}$ & $\begin{array}{l}3.25 \\
3.23 \\
3.21 \\
3.28 \\
3.37\end{array}$ & $\begin{array}{l}3.44 \\
3.44 \\
3.33 \\
3.36 \\
3.70\end{array}$ & $\begin{array}{l}3.37 \\
3.26 \\
3.48 \\
3.34 \\
3.54\end{array}$ & $\begin{array}{l}3.55 \\
3.58 \\
3.57 \\
3.51 \\
3.75\end{array}$ \\
\hline & $3.73 \pm 0.04$ & $3.88 \pm 0.08$ & $\begin{array}{c}3.26 \pm 0.06 \\
\downarrow\end{array}$ & $\begin{array}{c}3.45 \pm 0.14 \\
\downarrow\end{array}$ & $\begin{array}{c}3.39 \pm 0.11 \\
\downarrow\end{array}$ & $\begin{array}{c}3.59 \pm 0.09 \\
\downarrow\end{array}$ \\
\hline $\begin{array}{l}\text { Índice de } \\
\text { contorno }\end{array}$ & $\begin{array}{l}3.58 \\
3.61 \\
3.61 \\
3.62 \\
3.61\end{array}$ & $\begin{array}{l}3.61 \\
3.61 \\
3.62 \\
3.59 \\
3.57\end{array}$ & $\begin{array}{l}3.69 \\
3.64 \\
3.68 \\
3.80 \\
3.77\end{array}$ & $\begin{array}{l}3.61 \\
3.66 \\
3.62 \\
3.71 \\
3.70\end{array}$ & $\begin{array}{l}3.63 \\
3.61 \\
3.61 \\
3.65 \\
3.62\end{array}$ & $\begin{array}{l}3.62 \\
3.61 \\
3.63 \\
3.65 \\
3.66\end{array}$ \\
\hline & $3.60 \pm 0.01$ & $3.60 \pm 0.02$ & $3.71 \pm 0.06$ & $3.66 \pm 0.04$ & $3.62 \pm 0.01$ & $3.63 \pm 0.02$ \\
\hline & & & $\uparrow$ & $\uparrow$ & $\uparrow$ & $\uparrow$ \\
\hline $\begin{array}{l}\text { Coeficiente } \\
\text { De forma }\end{array}$ & $\begin{array}{l}0.97 \\
0.96 \\
0.97 \\
0.96 \\
0.98\end{array}$ & $\begin{array}{l}0.97 \\
0.97 \\
0.96 \\
0.97 \\
0.99\end{array}$ & $\begin{array}{l}0.93 \\
0.95 \\
0.93 \\
0.87 \\
0.89\end{array}$ & $\begin{array}{l}0.96 \\
0.94 \\
0.96 \\
0.92 \\
0.93\end{array}$ & $\begin{array}{l}0.96 \\
0.95 \\
0.96 \\
0.95 \\
0.96\end{array}$ & $\begin{array}{l}0.96 \\
0.96 \\
0.96 \\
0.94 \\
0.94\end{array}$ \\
\hline & $0.96 \pm 0.00$ & $0.97 \pm 0.00$ & $0.91 \pm 0.03$ & $0.94 \pm 0.01$ & $0.95 \pm 0.00$ & $0.95 \pm 0.01$ \\
\hline $\begin{array}{l}\text { Excentrici- } \\
\text { dade }\end{array}$ & $\begin{array}{l}0.54 \\
0.54 \\
0.53 \\
0.57 \\
0.46\end{array}$ & $\begin{array}{l}0.38 \\
0.51 \\
0.57 \\
0.54 \\
0.55\end{array}$ & $\begin{array}{l}0.69 \\
0.59 \\
0.67 \\
0.81 \\
0.79\end{array}$ & $\begin{array}{l}0.53 \\
0.66 \\
0.56 \\
0.75 \\
0.64\end{array}$ & $\begin{array}{l}0.58 \\
0.56 \\
0.53 \\
0.63 \\
0.60\end{array}$ & $\begin{array}{l}0.58 \\
0.53 \\
0.60 \\
0.65 \\
0.69\end{array}$ \\
\hline & $0.52 \pm 0.04$ & $0.51 \pm 0.07$ & $0.71 \pm 0.09$ & $0.62 \pm 0.08$ & $0.58 \pm 0.03$ & $0.61 \pm 0.06$ \\
\hline & & & $\uparrow$ & $\uparrow$ & $\uparrow$ & $\uparrow$ \\
\hline
\end{tabular}

Obs: Estão expressos nesta tabela os dados relativos a: Relação Diâmetro maior/Diâmetro menor (DM/dm), Relação volume/área (Vol./Área), coeficiente de forma, índice de contorno, e excentricidade. 
TABELA 84 - Avaliação dos efeitos da utilização de inibidor de protease sobre os parâmetros da forma dos núcleos das células da camada basal do epitélio da região gengival dos animais controles e tratados Avaliação pelo teste Kruskal-Wallis

\begin{tabular}{|c|c|c|c|}
\hline \multicolumn{4}{|c|}{ DIÂMETRO MAIOR / DIÂMETRO MENOR } \\
\hline \multirow{2}{*}{$\begin{array}{l}\text { Valor de } \mathrm{H}=9.9914 \\
\text { Valor de } \mathrm{x}^{2} \mathrm{p} / 2^{\circ} \text { de liberdade }=9.99 \\
\text { Probabilidade de } \mathrm{H} 0=0.68 \%\end{array}$} & $\begin{array}{c}\text { Controle X } 4 \\
\text { semanas }\end{array}$ & $\begin{array}{c}\text { Controle X } 8 \\
\text { semanas }\end{array}$ & 4 sem $X 8$ sem \\
\hline & $0.1 \%$ & NS & $1 \%$ \\
\hline \multicolumn{4}{|l|}{ Significante para $\alpha \leq 0.01$} \\
\hline \multicolumn{4}{|l|}{ VOLUME NUCLEAR / ÁREA NUCLEAR } \\
\hline \multirow{2}{*}{$\begin{array}{l}\text { Valor de } H=11.0344 \\
\text { Valor de } x^{2} p / 2^{\circ} \text { de liberdade }=11.03 \\
\text { Probabilidade de } \mathrm{H} 0=0.40 \%\end{array}$} & $\begin{array}{c}\text { Controle X } 4 \\
\text { semanas }\end{array}$ & $\begin{array}{c}\text { Controle X } 8 \\
\text { semanas }\end{array}$ & 4 sem $X 8$ sem \\
\hline & $0.1 \%$ & $1 \%$ & $5 \%$ \\
\hline \multicolumn{4}{|l|}{ Significante para $\alpha \leq 0.01$} \\
\hline \multicolumn{4}{|l|}{ ÍNDICE DE CONTORNO } \\
\hline \multirow{2}{*}{$\begin{array}{l}\text { Valor de } \mathrm{H}=10.1455 \\
\text { Valor de } \mathrm{x}^{2} \mathrm{p} / 2^{\circ} \text { de liberdade }=10.15 \\
\text { Probabilidade de } \mathrm{H} 0=0.63 \%\end{array}$} & $\begin{array}{c}\text { Controle X } 4 \\
\text { semanas }\end{array}$ & $\begin{array}{c}\text { Controle X } 8 \\
\text { semanas }\end{array}$ & 4 sem $X 8$ sem \\
\hline & $0.1 \%$ & NS & $1 \%$ \\
\hline \multicolumn{4}{|l|}{ Significante para $\alpha \leq 0.01$} \\
\hline \multicolumn{4}{|l|}{ COEFICIENTE DE FORMA } \\
\hline \multirow{2}{*}{$\begin{array}{l}\text { Valor de } H=11.1581 \\
\text { Valor de } x^{2} p / 2^{\circ} \text { de liberdade }=11.16 \\
\text { Probabilidade de } H 0=0.38 \%\end{array}$} & $\begin{array}{c}\text { Controle X } 4 \\
\text { semanas }\end{array}$ & $\begin{array}{c}\text { Controle X } 8 \\
\text { semanas }\end{array}$ & 4 sem $X 8$ sem \\
\hline & $0.1 \%$ & $5 \%$ & $1 \%$ \\
\hline \multicolumn{4}{|l|}{ Significante para $\alpha \leq 0.01$} \\
\hline \multicolumn{4}{|l|}{ EXCENTRICIDADE } \\
\hline \multirow{2}{*}{$\begin{array}{l}\text { Valor de } \mathrm{H}=9.5892 \\
\text { Valor de } \mathrm{x}^{2} \mathrm{p} / 2^{\circ} \text { de liberdade }=9.59 \\
\text { Probabilidade de } \mathrm{H} 0=0.83 \%\end{array}$} & $\begin{array}{c}\text { Controle X } 4 \\
\text { semanas }\end{array}$ & $\begin{array}{c}\text { Controle X } 8 \\
\text { semanas }\end{array}$ & 4 sem $X 8$ sem \\
\hline & $0.1 \%$ & NS & $5 \%$ \\
\hline
\end{tabular}


TABELA 85 - Avaliação dos efeitos da utilização de inibidor de protease sobre os parâmetros da forma dos núcleos das células da camada basal do epitélio da região gengival dos animais controles e tratados - Avaliação pelo teste Kruskal-Wallis

\begin{tabular}{|c|c|c|c|}
\hline \multicolumn{4}{|c|}{ DIÂMETRO MAIOR / DIÂMETRO MENOR } \\
\hline \multirow{2}{*}{$\begin{array}{l}\text { Valor de } \mathrm{H}=6.7763 \\
\text { Valor de } \mathrm{x}^{2} \mathrm{p} / 2^{\circ} \text { de liberdade }=6.78 \\
\text { Probabilidade de } \mathrm{H} 0=3.38 \%\end{array}$} & $\begin{array}{l}\text { Controle X } 4 \\
\text { semanas }\end{array}$ & $\begin{array}{l}\text { Controle X } 8 \\
\text { semanas }\end{array}$ & 4 sem $X 8$ sem \\
\hline & & $5 \%$ & NS \\
\hline \multicolumn{4}{|l|}{ Significante para $\alpha \leq 0.05$} \\
\hline \multicolumn{4}{|l|}{ VOLUME NUCLEAR / ÁREA NUCLEAR } \\
\hline \multirow{2}{*}{$\begin{array}{l}\text { Valor de } \mathrm{H}=10.8394 \\
\text { Valor de } \mathrm{x}^{2} \mathrm{p} / 2^{\circ} \text { de liberdade }=10.84 \\
\text { Probabilidade de } \mathrm{H} 0=0.44 \%\end{array}$} & $\begin{array}{l}\text { Controle X } 4 \\
\text { semanas }\end{array}$ & $\begin{array}{l}\text { Controle X } 8 \\
\text { semanas }\end{array}$ & 4 sem $X 8$ sem \\
\hline & $0.1 \%$ & $1 \%$ & $5 \%$ \\
\hline \multicolumn{4}{|l|}{$\begin{array}{l}\text { Significante para } \alpha \leq 0.01 \\
\text { iNDICE DE CONTORNO }\end{array}$} \\
\hline \multicolumn{4}{|l|}{ ÍNDICE DE CONTORNO } \\
\hline \multirow{2}{*}{$\begin{array}{l}\text { Valor de } \mathrm{H}=6.4939 \\
\text { Valor de } \mathrm{x}^{2} \mathrm{p} / 2^{\circ} \text { de liberdade }=6.49 \\
\text { Probabilidade de } \mathrm{H} 0=3.89 \%\end{array}$} & $\begin{array}{l}\text { Controle } X 4 \\
\text { semanas }\end{array}$ & $\begin{array}{l}\text { Controle X } 8 \\
\text { semanas }\end{array}$ & 4 sem $X 8$ sem \\
\hline & & $5 \%$ & NS \\
\hline \multicolumn{4}{|l|}{ Significante para $\alpha \leq 0.05$} \\
\hline \multicolumn{4}{|l|}{ COEFICIENTE DE FORMA } \\
\hline \multirow{2}{*}{$\begin{array}{l}\text { Valor de } \mathrm{H}=8.7141 \\
\text { Valor de } \mathrm{x}^{2} \mathrm{p} / 2^{\circ} \text { de liberdade }=8.71 \\
\text { Probabilidade de } \mathrm{H} 0=1.28 \%\end{array}$} & $\begin{array}{c}\text { Controle X } 4 \\
\text { semanas }\end{array}$ & $\begin{array}{c}\text { Controle X } 8 \\
\text { semanas }\end{array}$ & 4 sem $X 8$ sem \\
\hline & & $1 \%$ & NS \\
\hline \multicolumn{4}{|l|}{ Significante para $\alpha \leq 0.01$} \\
\hline \multicolumn{4}{|l|}{ EXCENTRICIDADE } \\
\hline \multirow{2}{*}{$\begin{array}{l}\text { Valor de } \mathrm{H}=4.8737 \\
\text { Valor de } \mathrm{x}^{2} \mathrm{p} / 2^{\circ} \text { de liberdade }=4.87 \\
\text { Probabilidade de } \mathrm{H} 0=8.74 \%\end{array}$} & $\begin{array}{l}\text { Controle X } 4 \\
\text { semanas }\end{array}$ & $\begin{array}{l}\text { Controle X } 8 \\
\text { semanas }\end{array}$ & $4 \mathrm{sem} X 8 \mathrm{sem}$ \\
\hline & & NS & NS \\
\hline
\end{tabular}


Analisando-se os valores obtidos pela avaliação cariométrica das células do epitélio dos palatos duro e mole e da região gengival, podemos observar que:

1) Nos palatos duro e mole existe uma tendência de aumento do volume dos núcleos das células epiteliais, principalmente com o uso prolongado do inibidor de protease;

2) Nâo existe grande variação da forma desses núcleos observada com o uso desse medicamento;

3) No epitélio gengival foi possível observar uma diminuição do volume nuclear nas diferentes camadas epiteliais, no entando esse efeito é principalmente observado nos primeiros períodos do uso do medicamento, tendendo a voltar a valores próximos dos observados para os controles com seu uso continuado;

4) Foi possível também observar alguma variação na forma dos núcleos das células do epitélio gengival, efeito esse que também tende a retornar a valores normais com o uso prolongado do medicamento 


\subsubsection{Estereologia dos palatos duro e mole e região gengival}

TABELA 86 - Avaliação dos valores médios dos volumes celulares (em $\mu \mathrm{m}^{3}$ ) no epitélio do palato (região palato duro) dos animais controle e tratados com inibidor de protease.

\begin{tabular}{|c|c|c|c|c|c|c|}
\hline \multirow{2}{*}{$\begin{array}{l}\text { Estrutura } \\
\text { Estudada }\end{array}$} & \multicolumn{2}{|c|}{ Animais Controle } & \multicolumn{2}{|c|}{ Tratados - 4 semanas } & \multicolumn{2}{|c|}{ Tratados - 8 semanas } \\
\hline & C.Basal & C.Espinhosa & C.Basal & C.Espinhosa & C.Basal & C.Espinhosa \\
\hline \multirow{7}{*}{$\begin{array}{l}\text { Volume } \\
\text { nuclear }\end{array}$} & 83.04 & 77.64 & 63.94 & 85.85 & 73.34 & 104.52 \\
\hline & 97.23 & 77.43 & 68.91 & 90.26 & 88.73 & 106.52 \\
\hline & 102.44 & 84.00 & 61.66 & 82.17 & 87.18 & 097.65 \\
\hline & 105.44 & 77.47 & 70.26 & 79.46 & 88.90 & 097.57 \\
\hline & 106.83 & 63.05 & 71.23 & 77.54 & 79.36 & 093.88 \\
\hline & $99.08 \pm 9.68$ & $75.11 \pm 7.70$ & $67.20 \pm 4.17$ & $83.05 \pm 5.09$ & $83.50 \pm 6.89$ & $100.02 \pm 5.28$ \\
\hline & & & $\downarrow$ & $\uparrow$ & $\downarrow$ & $\uparrow$ \\
\hline \multirow{7}{*}{$\begin{array}{l}\text { Volume } \\
\text { celular }\end{array}$} & 109.25 & 210.64 & 67.22 & 292.20 & 92.55 & 266.69 \\
\hline & 100.06 & 205.19 & 74.13 & 326.09 & 97.21 & 278.68 \\
\hline & 102.67 & 207.93 & 66.12 & 305.81 & 96.06 & 260.00 \\
\hline & 105.44 & 223.65 & 77.07 & 287.26 & 99.20 & 257.27 \\
\hline & 109.68 & 230.35 & 77.32 & 280.92 & 93.91 & 260.03 \\
\hline & $105.42 \pm 4.15$ & $215.55 \pm 10.88$ & $77.37 \pm 5.36$ & $298.45 \pm 17.95$ & $95.78 \pm 2.63$ & $264.53 \pm 8.63$ \\
\hline & & & $\downarrow$ & $\uparrow$ & $\downarrow$ & $\uparrow$ \\
\hline \multirow{7}{*}{$\begin{array}{l}\text { Volume do } \\
\text { citoplasma }\end{array}$} & 17.91 & 133.00 & 3.28 & 206.35 & 19.21 & 162.17 \\
\hline & 2.83 & 127.76 & 5.22 & 235.83 & 08.84 & 172.16 \\
\hline & 0.23 & 123.93 & 4.46 & 223.64 & 08.88 & 162.35 \\
\hline & 0.00 & 146.18 & 6.81 & 207.80 & 10.30 & 159.70 \\
\hline & 2.85 & 167.30 & 6.09 & 203.38 & 14.55 & 166.15 \\
\hline & $4.76 \pm 7.47$ & $139.63 \pm 17.60$ & $5.17 \pm 1.37$ & $215.40 \pm 13.86$ & $12.35 \pm 4.48$ & $164.50 \pm 4.86$ \\
\hline & & & $\uparrow$ & $\uparrow$ & $\uparrow$ & $\uparrow$ \\
\hline \multirow{7}{*}{$\begin{array}{c}\text { Relação } \\
\text { Núcleol } \\
\text { citoplasma }\end{array}$} & 0.6129 & 0.1494 & 0.4925 & 0.1236 & 0.4706 & 0.1765 \\
\hline & 0.5873 & 0.1364 & 0.4925 & 0.1236 & 0.5152 & 0.1765 \\
\hline & 0.5873 & 0.1494 & 0.4925 & 0.1236 & 0.4925 & 0.1765 \\
\hline & 0.5873 & 0.1494 & 0.4925 & 0.1111 & 0.4706 & 0.1905 \\
\hline & 0.5873 & 0.1364 & 0.4706 & 0.1111 & 0.4925 & 0.1628 \\
\hline & $0.5924 \pm 0.01$ & $0.1442 \pm 0.00$ & $0.4881 \pm 0.00$ & $0.1186 \pm 0.00$ & $0.4883 \pm 0.01$ & $0.1413 \pm 0.07$ \\
\hline & & & $\downarrow$ & $\downarrow$ & $\downarrow$ & $\downarrow$ \\
\hline \multirow{7}{*}{$\begin{array}{l}\text { Densidade } \\
\text { numérica }\end{array}$} & 9.15 & 4.75 & 14.88 & 3.42 & 12.11 & 3.75 \\
\hline & 9.99 & 4.94 & 13.49 & 2.89 & 10.29 & 3.59 \\
\hline & 9.74 & 4.81 & 15.13 & 3.27 & 10.41 & 4.17 \\
\hline & 9.48 & 4.47 & 12.98 & 3.74 & 10.09 & 4.21 \\
\hline & 9.12 & 4.34 & 12.93 & 3.83 & 11.51 & 4.08 \\
\hline & $9.49 \pm 0.37$ & $4.66 \pm 0.24$ & $13.88 \pm 1.05$ & $3.43 \pm 0.37$ & $10.88 \pm 0.88$ & $3.96 \pm 0.27$ \\
\hline & & & $\uparrow$ & $\downarrow$ & $\uparrow$ & $\downarrow$ \\
\hline \multirow{5}{*}{$\begin{array}{c}\text { Densidade } \\
\text { de superfície }\end{array}$} & 13.74 & 1.99 & 11.73 & 1.85 & 12.07 & 1.99 \\
\hline & 13.26 & 1.89 & 11.89 & 1.99 & 12.32 & 2.03 \\
\hline & 13.45 & 1.89 & 11.89 & 1.8 & 11.34 & 2.08 \\
\hline & $\begin{array}{l}13.13 \\
13.35\end{array}$ & $\begin{array}{l}1.80 \\
1.83\end{array}$ & 11.59 & 1.98 & 13.33 & 2.06 \\
\hline & $13.38 \pm 0.23$ & $1.88 \pm 0.07$ & $11.80 \pm 0.13$ & $1.92 \pm 0.07$ & $12.54 \pm 0.91$ & $2.07 \pm 0.07$ \\
\hline & & & $\downarrow$ & $\uparrow$ & $\uparrow$ & $\uparrow$ \\
\hline
\end{tabular}

Obs: Estão expressos nesta tabela os dados relativos a: volume nuclear, citoplasmático e celular (em micrometros cúbicos $-\mu \mathrm{m}^{3}$ ), relação núcleo/citoplasma, densidade numérica (número de células em uma área definida) e de superfície (número de células em uma extensão definida de superfície epitelial). 
TABELA 87 - Avaliação dos efeitos da utilização de inibidor de protease sobre os parâmetros dos valores médios dos volumes celulares $\left(\mathrm{em} \mu \mathrm{m}^{3}\right)$ na camada basal do epitélio do palato (região palato duro) dos animais controle e tratados com inibidor de protease. - Avaliação pelo teste Kruskal-Wallis

\begin{tabular}{|c|c|c|c|}
\hline \multicolumn{4}{|l|}{ VOLUME NUCLEAR } \\
\hline \multirow{2}{*}{$\begin{array}{l}\text { Valor de } \mathrm{H}=11.1800 \\
\text { Valor de } \mathrm{x}^{2} \mathrm{p} / 2^{\circ} \text { de liberdade }=11.18 \\
\text { Probabilidade de } \mathrm{H} 0=0.37 \%\end{array}$} & $\begin{array}{l}\text { Controle X } 4 \\
\text { semanas }\end{array}$ & $\begin{array}{l}\text { Controle X } 8 \\
\text { semanas }\end{array}$ & $\begin{array}{l}4 \operatorname{sem} X 8 \\
\text { sem }\end{array}$ \\
\hline & $0.1 \%$ & $5 \%$ & $1 \%$ \\
\hline \multicolumn{4}{|l|}{ Significante para $\alpha \leq 0.01$} \\
\hline \multicolumn{4}{|l|}{ VOLUME CELULAR } \\
\hline \multirow{2}{*}{$\begin{array}{l}\text { Valor de } H=12.5000 \\
\text { Valor de } x^{2} p / 2^{\circ} \text { de liberdade }=12.50 \\
\text { Probabilidade de } H 0=0.19 \%\end{array}$} & $\begin{array}{l}\text { Controle X } 4 \\
\text { semanas }\end{array}$ & $\begin{array}{l}\text { Controle X } 8 \\
\text { semanas }\end{array}$ & $\begin{array}{c}4 \text { sem } X 8 \\
\text { sem }\end{array}$ \\
\hline & $0.1 \%$ & $0.1 \%$ & $0.1 \%$ \\
\hline \multicolumn{4}{|l|}{ Significante para $\alpha \leq 0.01$} \\
\hline \multicolumn{4}{|l|}{ VOLUME DO CITOPLASMA } \\
\hline \multirow{2}{*}{$\begin{array}{l}\text { Valor de } \mathrm{H}=7.0013 \\
\text { Valor de } \mathrm{x}^{2} \mathrm{p} / 2^{\circ} \text { de liberdade }=7.00 \\
\text { Probabilidade de } \mathrm{HO}=3.02 \%\end{array}$} & $\begin{array}{l}\text { Controle X } 4 \\
\text { semanas }\end{array}$ & $\begin{array}{l}\text { Controle X } 8 \\
\text { semanas }\end{array}$ & $\begin{array}{c}4 \operatorname{sem} X 8 \\
\text { sem }\end{array}$ \\
\hline & NS & $1 \%$ & $5 \%$ \\
\hline \multicolumn{4}{|l|}{ Significante para $\alpha \leq 0.05$} \\
\hline \multicolumn{4}{|c|}{ RELAÇÃO NUCLEO/CITOPLASMA } \\
\hline $\begin{array}{l}\text { Valor de } H=10.2795 \\
\text { Valor de } x^{2} p / 2^{\circ} \text { de liberdade }=10.28 \\
\text { Probabilidade de } H 0=0.59 \%\end{array}$ & $\begin{array}{c}\text { Controle X } 4 \\
\text { semanas } \\
0.1 \%\end{array}$ & $\begin{array}{c}\text { Controle X } 8 \\
\text { semanas } \\
0.1 \%\end{array}$ & $\begin{array}{c}4 \operatorname{sem} \times 8 \\
\text { sem } \\
\text { NS }\end{array}$ \\
\hline \multicolumn{4}{|l|}{ Significante para $\alpha \leq 0.01$} \\
\hline \multicolumn{4}{|l|}{ DENSIDADE NUMÉRICA } \\
\hline $\begin{array}{l}\text { Valor de } H=12.5000 \\
\text { Valor de } x^{2} p / 2^{\circ} \text { de liberdade }=12.50 \\
\text { Probabilidade de } H 0=0.19 \%\end{array}$ & $\begin{array}{l}\text { Controle X } 4 \\
\text { semanas } \\
0.1 \%\end{array}$ & $\begin{array}{l}\text { Controle X } 8 \\
\text { semanas } \\
0.1 \%\end{array}$ & $\begin{array}{l}4 \operatorname{sem} \times 8 \\
\text { sem } \\
0.1 \%\end{array}$ \\
\hline \multicolumn{4}{|l|}{ Significante para $\alpha \leq 0.01$} \\
\hline \multicolumn{4}{|l|}{ DENSIDADE DE SUPERFÍCIE } \\
\hline $\begin{array}{l}\text { Valor de } \mathrm{H}=7.6336 \\
\text { Valor de } \mathrm{x}^{2} \mathrm{p} / 2^{\circ} \text { de liberdade }=7.63 \\
\text { Probabilidade de } \mathrm{HO}=2.20 \%\end{array}$ & $\begin{array}{l}\text { Controle X } 4 \\
\text { semanas } \\
1 \%\end{array}$ & $\begin{array}{l}\text { Controle X } 8 \\
\text { semanas } \\
\text { NS }\end{array}$ & $\begin{array}{l}4 \operatorname{sem} \times 8 \\
\text { sem } \\
\text { NS }\end{array}$ \\
\hline Significante para $\alpha \leq 0.05$ & & & \\
\hline
\end{tabular}


TABELA 88 - Avaliação dos efeitos da utilização de inibidor de protease sobre os parâmetros dos valores médios dos volumes celulares $\left(\mathrm{em} \mu \mathrm{m}^{3}\right)$ na camada espinhosa do epitélio do palato (região palato duro) dos animais controle e tratados com inibidor de protease. - Avaliação pelo teste Kruskal-Wallis

\begin{tabular}{|c|c|c|c|}
\hline \multicolumn{4}{|l|}{ VOLUME NUCLEAR } \\
\hline \multirow{2}{*}{$\begin{array}{l}\text { Valor de } \mathrm{H}=10.8200 \\
\text { Valor de } \mathrm{x}^{2} \mathrm{p} / 2^{\circ} \text { de liberdade }=10.82 \\
\text { Probabilidade de } \mathrm{HO}=0.45 \%\end{array}$} & Controle X 4 & $\begin{array}{l}\text { Controle X } \\
8 \text { semanas }\end{array}$ & $4 \operatorname{sem} \times 8$ \\
\hline & $5 \%$ & $0.1 \%$ & $1 \%$ \\
\hline \multicolumn{4}{|l|}{ Significante para $\alpha \leq 0.01$} \\
\hline \multicolumn{4}{|l|}{ VOLUME CELULAR } \\
\hline \multirow{3}{*}{$\begin{array}{l}\text { Valor de } \mathrm{H}=12.5000 \\
\text { Valor de } \mathrm{x}^{2} \mathrm{p} / 2^{\circ} \text { de liberdade }=12.50 \\
\text { Probabilidade de } \mathrm{H} 0=0.19 \%\end{array}$} & Controle X 4 & Controle X & $4 \operatorname{sem} \times 8$ \\
\hline & semanas & 8 semanas & sem \\
\hline & $0.1 \%$ & $0.1 \%$ & $0.1 \%$ \\
\hline \multicolumn{4}{|l|}{ Significante para $\alpha \leq 0.01$} \\
\hline \multicolumn{4}{|l|}{ VOLUME DO CITOPLASMA } \\
\hline \multirow{3}{*}{$\begin{array}{l}\text { Valor de } H=10.8200 \\
\text { Valor de } x^{2} p / 2^{\circ} \text { de liberdade }=10.82 \\
\text { Probabilidade de } H 0=0.45 \%\end{array}$} & Controle X 4 & Controle X & $4 \operatorname{sem} \times 8$ \\
\hline & semanas & 8 semanas & sem \\
\hline & $0.1 \%$ & & $1 \%$ \\
\hline \multicolumn{4}{|l|}{ Significante para $\alpha \leq 0.01$} \\
\hline \multicolumn{4}{|l|}{ RELAÇÃO NUCLEO/CITOPLASMA } \\
\hline \multirow{2}{*}{$\begin{array}{l}\text { Valor de } \mathrm{H}=12.8205 \\
\text { Valor de } \mathrm{x}^{2} \mathrm{p} / 2^{\circ} \text { de liberdade }=12.82 \\
\text { Probabilidade de } \mathrm{H} 0=0.16 \%\end{array}$} & Controle X 4 & Controle X & $4 \operatorname{sem} \times 8$ \\
\hline & semanas & $\begin{array}{c}8 \text { semanas } \\
0.1 \%\end{array}$ & sem \\
\hline \multicolumn{4}{|l|}{ Significante para $\alpha \leq 0.01$} \\
\hline \multicolumn{4}{|l|}{ DENSIDADE NUMÉRICA } \\
\hline \multirow{3}{*}{$\begin{array}{l}\text { Valor de } \mathrm{H}=11.1800 \\
\text { Valor de } \mathrm{x}^{2} \mathrm{p} / 2^{\circ} \text { de liberdade }=11.18 \\
\text { Probabilidade de } \mathrm{H} 0=0.37 \%\end{array}$} & Controle X 4 & Controle X & $4 \operatorname{sem} \times 8$ \\
\hline & semanas & 8 semanas & sem \\
\hline & $0.1 \%$ & $1 \%$ & $5 \%$ \\
\hline \multicolumn{4}{|l|}{ Significante para $\alpha \leq 0.01$} \\
\hline \multicolumn{4}{|l|}{ DENSIDADE DE SUPERFÍCIE } \\
\hline \multirow{3}{*}{$\begin{array}{l}\text { Valor de } \mathrm{H}=8.9812 \\
\text { Valor de } \mathrm{x}^{2} \mathrm{p} / 2^{\circ} \text { de liberdade }=8.98 \\
\text { Probabilidade de } \mathrm{HO}=1.12 \%\end{array}$} & Controle X 4 & Controle X & $4 \operatorname{sem} \times 8$ \\
\hline & semanas & 8 semanas & sem \\
\hline & NS & $0.1 \%$ & $1 \%$ \\
\hline Significante para $\alpha \leq 0.01$ & & & \\
\hline
\end{tabular}


TABELA 89 - Avaliação da espessura (em $\mu \mathrm{m}$ ) do epitélio do palato (região palato duro) dos animais controle e tratados com inibidores de protease.

\begin{tabular}{|c|c|c|c|c|}
\hline Grupos estudados & $\begin{array}{c}\text { Camada } \\
\text { Basal }\end{array}$ & C.Espinhosa & $\begin{array}{c}\text { C. de } \\
\text { queratina }\end{array}$ & $\begin{array}{c}\text { Epitélio } \\
\text { total }\end{array}$ \\
\hline \multirow[t]{2}{*}{ Animais Controle } & $\begin{array}{l}6.97 \\
7.14 \\
6.85 \\
7.23 \\
7.07\end{array}$ & $\begin{array}{l}50.17 \\
50.20 \\
50.64 \\
53.73 \\
51.61\end{array}$ & $\begin{array}{l}25.24 \\
25.76 \\
24.85 \\
27.04 \\
27.69\end{array}$ & $\begin{array}{l}82.38 \\
83.10 \\
82.34 \\
88.00 \\
86.37\end{array}$ \\
\hline & $7.05 \pm 0.14$ & $51.27 \pm 1.49$ & $26.11 \pm 1.20$ & $84.43 \pm 2.59$ \\
\hline \multirow[t]{3}{*}{$\begin{array}{l}\text { Inibidor de protease } \\
\text { por } 4 \text { semanas }\end{array}$} & $\begin{array}{l}8.45 \\
8.43 \\
8.51 \\
8.28 \\
8.40\end{array}$ & $\begin{array}{l}49.71 \\
45.24 \\
49.63 \\
49.99 \\
49.81\end{array}$ & $\begin{array}{l}32.88 \\
30.15 \\
32.00 \\
30.05 \\
31.12\end{array}$ & $\begin{array}{l}91.04 \\
83.82 \\
90.14 \\
88.32 \\
89.33\end{array}$ \\
\hline & $8.41 \pm 0.08$ & $48.87 \pm 2.03$ & $31.24 \pm 1.21$ & $88.53 \pm 2.81$ \\
\hline & $\uparrow$ & $\downarrow$ & $\uparrow$ & $\uparrow$ \\
\hline \multirow[t]{2}{*}{$\begin{array}{l}\text { Inibidor de protease } \\
\text { por } 8 \text { semanas }\end{array}$} & $\begin{array}{l}8.20 \\
8.00 \\
8.53 \\
7.75 \\
7.44\end{array}$ & $\begin{array}{l}49.76 \\
47.96 \\
48.21 \\
48.14 \\
44.61\end{array}$ & $\begin{array}{l}20.70 \\
23.40 \\
20.84 \\
21.61 \\
21.78\end{array}$ & $\begin{array}{l}78.66 \\
79.36 \\
77.58 \\
77.50 \\
73.83\end{array}$ \\
\hline & $\begin{array}{c}7.98 \pm 0.41 \\
\uparrow\end{array}$ & $47.73 \pm 1.89$ & $21.66 \pm 1.07$ & $77.38 \pm 2.13$ \\
\hline
\end{tabular}


TABELA 90 - Avaliação dos efeitos da utilização de inibidor de protease sobre os parâmetros dos valores médios da espessura (em $\mu \mathrm{m})$ no epitélio do palato (região palato duro) dos animais controle e tratados. Avaliação pelo teste Kruskal-Wallis

\begin{tabular}{|c|c|c|c|}
\hline \multicolumn{4}{|l|}{ ESPESSURA DA CAMADA BASAL } \\
\hline \multirow{3}{*}{$\begin{array}{l}\text { Valor de } \mathrm{H}=10.5000 \\
\text { Valor de } \mathrm{x}^{2} \mathrm{p} / 2^{\circ} \text { de liberdade }=10.50 \\
\text { Probabilidade de } \mathrm{H} 0=0.52 \%\end{array}$} & Controle X 4 & Controle X 8 & $4 \operatorname{sem} \times 8$ \\
\hline & semanas & semanas & sem \\
\hline & $0.1 \%$ & $1 \%$ & NS \\
\hline \multicolumn{4}{|l|}{ Significante para $\alpha \leq 0.01$} \\
\hline \multicolumn{4}{|l|}{ ESPESSURA DA CAMADA ESPINHOSA } \\
\hline \multirow{3}{*}{$\begin{array}{l}\text { Valor de } \mathrm{H}=10.2200 \\
\text { Valor de } \mathrm{x}^{2} \mathrm{p} / 2^{\circ} \text { de liberdade }=10.22 \\
\text { Probabilidade de } \mathrm{H} 0=0.60 \%\end{array}$} & Controle X 4 & Controle X 8 & $4 \operatorname{sem} \times 8$ \\
\hline & semanas & semanas & sem \\
\hline & $1 \%$ & $0.1 \%$ & NS \\
\hline \multicolumn{4}{|l|}{ Significante para $\alpha \leq 0.01$} \\
\hline \multicolumn{4}{|c|}{ ESPESSURA DA CAMADA DE QUERATINA } \\
\hline \multirow{3}{*}{$\begin{array}{l}\text { Valor de } H=12.5000 \\
\text { Valor de } x^{2} p / 2^{\circ} \text { de liberdade }=12.50 \\
\text { Probabilidade de } H 0=0.19 \%\end{array}$} & Controle X 4 & Controle X 8 & $4 \operatorname{sem} \times 8$ \\
\hline & semanas & semanas & sem \\
\hline & $0.1 \%$ & $0.1 \%$ & $0.1 \%$ \\
\hline \multicolumn{4}{|l|}{ Significante para $\alpha \leq 0.01$} \\
\hline \multicolumn{4}{|l|}{ ESPESSURA DO EPITÉLIO TOTAL } \\
\hline \multirow{3}{*}{$\begin{array}{l}\text { Valor de } \mathrm{H}=11.5800 \\
\text { Valor de } \mathrm{x}^{2} \mathrm{p} / 2^{\circ} \text { de liberdade }=11.58 \\
\text { Probabilidade de } \mathrm{HO}=0.31 \%\end{array}$} & Controle X 4 & Controle X 8 & $4 \operatorname{sem} \times 8$ \\
\hline & semanas & semanas & sem \\
\hline & $1 \%$ & $1 \%$ & $0.1 \%$ \\
\hline Significante para $\alpha \leq 0.01$ & & & \\
\hline
\end{tabular}


TABELA 91 - Avaliação da Relação superfície externa/ Superfície basal do epitélio do palato (região palato duro) dos animais controle e tratados com inibidor de protease.

\begin{tabular}{|c|c|c|}
\hline $\begin{array}{c}\text { Animais } \\
\text { Controle }\end{array}$ & $\begin{array}{c}\text { Inibidor de protease por } \mathbf{4} \\
\text { semanas }\end{array}$ & $\begin{array}{c}\text { Inibidor de protease por } \mathbf{8} \\
\text { semanas }\end{array}$ \\
\hline 0.8500 & 0.8450 & 1.0100 \\
0.9040 & 0.9100 & 0.9680 \\
0.9090 & 0.9080 & 1.0210 \\
0.9600 & 0.9490 & 0.9620 \\
\hline 0.8500 & 0.9470 & 0.9710 \\
\hline $\mathbf{0 . 8 9 4 6 \pm 0 . 0 4}$ & $\mathbf{0 . 9 1 1 8 \pm 0 . 0 4}$ & $\mathbf{0 . 9 8 6 4 \pm 0 . 0 2}$ \\
\hline
\end{tabular}

TABELA 92 - Avaliação dos efeitos da utilização de inibidor de protease sobre os parâmetros dos valores médios da Relação superfície externa/ Superfície basal (em $\mu \mathrm{m}$ ) no epitélio do palato (região palato duro) dos animais controle e tratados. - Avaliação pelo teste Kruskal-Wallis

\begin{tabular}{l|l|c|c|}
\hline \multicolumn{3}{|c|}{ RELAÇÃO SUPERFÍCIE EXTERNA/SUPERFÍCIE BASAL DO EPITÉLIO DO P. DURO } \\
\hline Valor de $\mathrm{H}=9.5170$ & Controle X 4 & Controle X 8 & 4 sem X 8 sem \\
\hline Valor de $\mathrm{x}^{2} \mathrm{p} / 2^{\circ}$ de liberdade $=9.52$ & semanas & semanas & \\
\hline Probabilidade de $\mathrm{H} 0=0.86 \%$ & NS & $0.1 \%$ & $1 \%$ \\
\hline Significante para $\alpha \leq 0.01$ & & &
\end{tabular}


TABELA 93 - Avaliação dos valores médios dos volumes celulares (em $\mu \mathrm{m}^{3}$ ) no epitélio do palato (região palato mole) dos animais controle e tratados com inibidor de protease.

\begin{tabular}{|c|c|c|c|c|c|c|}
\hline \multirow{2}{*}{$\begin{array}{l}\text { Estrutura } \\
\text { Estudada }\end{array}$} & \multicolumn{2}{|c|}{ Animais Controle } & \multicolumn{2}{|c|}{ Tratados - 4 semanas } & \multicolumn{2}{|c|}{ Tratados - 8 semanas } \\
\hline & C.Basal & C.Espinhosa & C.Basal & C.Espinhosa & C.Basal & C.Espinhosa \\
\hline \multirow[t]{3}{*}{$\begin{array}{l}\text { Volume } \\
\text { nuclear }\end{array}$} & $\begin{array}{l}62.04 \\
68.89 \\
66.42 \\
65.92 \\
63.54\end{array}$ & $\begin{array}{l}68.64 \\
80.52 \\
78.45 \\
71.93 \\
71.51\end{array}$ & $\begin{array}{l}73.47 \\
78.61 \\
78.40 \\
71.76 \\
76.33\end{array}$ & $\begin{array}{l}70.09 \\
64.76 \\
71.19 \\
71.93 \\
64.33\end{array}$ & $\begin{array}{l}114.11 \\
127.76 \\
109.69 \\
099.13 \\
109.03\end{array}$ & $\begin{array}{l}110.41 \\
132.07 \\
107.69 \\
099.20 \\
112.40\end{array}$ \\
\hline & $65.36 \pm 2.65$ & $74.71 \pm 5.03$ & $73.71 \pm 8.76$ & $68.46 \pm 3.63$ & $111.94 \pm 10.3$ & $112.35 \pm 12.1$ \\
\hline & & & 个 & $v$ & 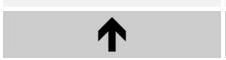 & $\uparrow$ \\
\hline \multirow[t]{3}{*}{$\begin{array}{l}\text { Volume } \\
\text { celular }\end{array}$} & $\begin{array}{l}67.83 \\
73.75 \\
68.63 \\
69.95 \\
67.84\end{array}$ & $\begin{array}{l}270.15 \\
268.13 \\
295.59 \\
281.10 \\
271.65\end{array}$ & $\begin{array}{l}81.70 \\
87.46 \\
89.45 \\
79.31 \\
82.73\end{array}$ & $\begin{array}{l}469.31 \\
467.40 \\
498.58 \\
474.18 \\
460.45\end{array}$ & $\begin{array}{l}127.88 \\
140.39 \\
125.17 \\
124.89 \\
126.66\end{array}$ & $\begin{array}{l}603.47 \\
644.28 \\
548.46 \\
590.51 \\
600.36\end{array}$ \\
\hline & $69.60 \pm 2.47$ & $277.32 \pm 11.35$ & $84.13 \pm 4.19$ & $473.98 \pm 14.60$ & $128.99 \pm 06.48$ & $604.61 \pm 23.44$ \\
\hline & & & 1 & 1 & $\uparrow$ & $\uparrow$ \\
\hline \multirow[t]{3}{*}{$\begin{array}{l}\text { Volume do } \\
\text { citoplasma }\end{array}$} & $\begin{array}{l}5.79 \\
4.86 \\
2.21 \\
4.03 \\
4.30\end{array}$ & $\begin{array}{l}201.51 \\
187.61 \\
217.14 \\
209.17 \\
200.14\end{array}$ & $\begin{array}{c}8.23 \\
8.85 \\
11.05 \\
7.55 \\
6.40\end{array}$ & $\begin{array}{l}399.22 \\
402.64 \\
427.39 \\
402.25 \\
396.12\end{array}$ & $\begin{array}{l}13.77 \\
12.63 \\
15.48 \\
25.76 \\
17.63\end{array}$ & $\begin{array}{l}493.06 \\
512.21 \\
440.77 \\
491.31 \\
487.96\end{array}$ \\
\hline & $4.23 \pm 1.31$ & $203.11 \pm 11.01$ & $8.41 \pm 13.81$ & $405.52 \pm 12.40$ & $17.05 \pm 5.21$ & $485.06 \pm 26.50$ \\
\hline & & & $\uparrow$ & $\uparrow$ & 1 & $\uparrow$ \\
\hline \multirow[t]{3}{*}{$\begin{array}{c}\text { Relação } \\
\text { Núcleo/ } \\
\text { citoplasma }\end{array}$} & $\begin{array}{l}0.4706 \\
0.4925 \\
0.4925 \\
0.4925 \\
0.4706\end{array}$ & $\begin{array}{l}0.0989 \\
0.1111 \\
0.1111 \\
0.0989 \\
0.0989\end{array}$ & $\begin{array}{l}0.5152 \\
0.5385 \\
0.5385 \\
0.5385 \\
0.5152\end{array}$ & $\begin{array}{l}0.0526 \\
0.0526 \\
0.0526 \\
0.0526 \\
0.0526\end{array}$ & $\begin{array}{l}0.5385 \\
0.5625 \\
0.5625 \\
0.5625 \\
0.3585\end{array}$ & $\begin{array}{l}0.0753 \\
0.0638 \\
0.0870 \\
0.0870 \\
0.0753\end{array}$ \\
\hline & $0.4837 \pm 0.01$ & $0.1038 \pm 0.00$ & $0.5292 \pm 0.01$ & $0.0526 \pm 0.00$ & $0.5169 \pm 0.08$ & $0.0777 \pm 0.00$ \\
\hline & & & $\uparrow$ & $\downarrow$ & $\uparrow$ & $\checkmark$ \\
\hline \multirow[t]{3}{*}{$\begin{array}{c}\text { Densidade } \\
\text { numérica }\end{array}$} & $\begin{array}{l}14.74 \\
13.56 \\
14.64 \\
14.30 \\
14.74\end{array}$ & $\begin{array}{l}3.70 \\
3.73 \\
3.38 \\
3.56 \\
3.68\end{array}$ & $\begin{array}{l}12.24 \\
11.43 \\
10.26 \\
12.61 \\
12.09\end{array}$ & $\begin{array}{l}2.13 \\
2.14 \\
2.01 \\
2.11 \\
2.22\end{array}$ & $\begin{array}{l}7.82 \\
7.12 \\
8.46 \\
8.94 \\
8.50\end{array}$ & $\begin{array}{l}1.66 \\
1.18 \\
1.98 \\
1.96 \\
1.67\end{array}$ \\
\hline & $14.39 \pm 0.50$ & $3.61 \pm 0.14$ & $11.72 \pm 0.92$ & $2.12 \pm 0.07$ & $8.16 \pm 0.70$ & $1.69 \pm 0.32$ \\
\hline & & & $v$ & $v$ & $v$ & $v$ \\
\hline \multirow[t]{3}{*}{$\begin{array}{c}\text { Densidade } \\
\text { de } \\
\text { superfície }\end{array}$} & $\begin{array}{l}16.11 \\
14.67 \\
13.97 \\
12.55 \\
12.28\end{array}$ & $\begin{array}{l}3.38 \\
3.29 \\
3.23 \\
3.02 \\
3.20\end{array}$ & $\begin{array}{l}12.95 \\
12.22 \\
12.80 \\
13.99 \\
13.64\end{array}$ & $\begin{array}{l}2.94 \\
2.50 \\
3.02 \\
2.44 \\
2.95\end{array}$ & $\begin{array}{l}14.08 \\
13.58 \\
14.01 \\
14.60 \\
15.03\end{array}$ & $\begin{array}{l}3.87 \\
3.51 \\
3.54 \\
3.64 \\
3.57\end{array}$ \\
\hline & $13.91 \pm 1.57$ & $3.22 \pm 0.13$ & $13.12 \pm 0.70$ & $2.77 \pm 0.27$ & $14.26 \pm 0.56$ & $3.62 \pm 0.14$ \\
\hline & & & $\downarrow$ & $\downarrow$ & $\uparrow$ & $\uparrow$ \\
\hline
\end{tabular}

Obs: Estão expressos nesta tabela os dados relativos a: volume nuclear, citoplasmático e celular (em micrometros cúbicos $-\mu \mathrm{m}^{3}$ ), relação núcleo/citoplasma, densidade numérica (número de células em uma área definida) e de superfície (número de células em uma extensão definida de superfície epitelial). 
TABELA 94 - Avaliação dos efeitos da utilização de inibidor de protease sobre os parâmetros dos valores médios dos volumes celulares (em $\mu \mathrm{m}^{3}$ ) na camada basal do epitélio do palato (região palato mole) dos animais controle e tratados com inibidor de protease. - Avaliação pelo teste Kruskal-Wallis

\section{VOLUME NUCLEAR}

Valor de $\mathrm{H}=12.0200$

Valor de $x^{2} p / 2^{\circ}$ de liberdade $=12.02$

Probabilidade de $\mathrm{HO}=0.25 \%$

Controle X 4

semanas

$1 \%$

Controle X 4

semanas

$0.1 \%$

Probabilidade de $\mathrm{HO}=0.19 \%$

Significante para $\alpha \leq 0.01$

\section{VOLUME DO CITOPLASMA}

Valor de $\mathrm{H}=10.8200$

Valor de $\mathrm{x}^{2} \mathrm{p} / 2^{\circ}$ de liberdade $=10.82$

Probabilidade de $\mathrm{HO}=0.45 \%$

Significante para $\alpha \leq 0.01$

\section{RELAÇÃO NUCLEO/CITOPLASMA}

Valor de $\mathrm{H}=6.4763$

Valor de $x^{2} \mathrm{p} / 2^{\circ}$ de liberdade $=6.48$

Probabilidade de $\mathrm{HO}=3.92 \%$

Significante para $\alpha \leq 0.05$

\begin{tabular}{|c|c|c|}
\hline $\begin{array}{c}\text { Controle X } 4 \\
\text { semanas } \\
0.1 \%\end{array}$ & $\begin{array}{c}\text { Controle X } 8 \\
\text { semanas } \\
5 \%\end{array}$ & $\begin{array}{c}4 \text { sem } X 8 \\
\text { sem } \\
1 \%\end{array}$ \\
\hline
\end{tabular}

\begin{tabular}{c|c}
$\begin{array}{c}\text { Controle X } 8 \\
\text { semanas }\end{array}$ & $\begin{array}{c}4 \text { sem } X 8 \\
\text { sem }\end{array}$ \\
$0.1 \%$ & $0.1 \%$
\end{tabular}

\begin{tabular}{|c|c|c|}
$\begin{array}{c}\text { Controle X } 4 \\
\text { semanas }\end{array}$ & $\begin{array}{c}\text { Controle } X 8 \\
\text { semanas }\end{array}$ & $\begin{array}{c}4 \text { sem } X 8 \\
\text { sem }\end{array}$ \\
\hline $5 \%$ & $5 \%$ & NS \\
\hline
\end{tabular}

\section{DENSIDADE NUMÉRICA}

Valor de $\mathrm{H}=12.5224$

Valor de $x^{2} p / 2^{\circ}$ de liberdade $=12.52$

Probabilidade de $\mathrm{HO}=0.19 \%$

Controle X 4

semanas

$0.1 \%$
Controle X 8
semanas

$0.1 \%$
$4 \operatorname{sem} X 8$

$0.1 \%$

Significante para $\alpha \leq 0.01$

\section{DENSIDADE DE SUPERFÍCIE}

Valor de $\mathrm{H}=3.6600$

Valor de $x^{2} p / 20$ de liberdade $=3.66$

Probabilidade de $\mathrm{HO}=16.04 \%$

Significante para $\alpha \leq 0.05$

\begin{tabular}{c|c|c|}
$\begin{array}{c}\text { Controle X 4 } \\
\text { semanas }\end{array}$ & $\begin{array}{c}\text { Controle X 8 } \\
\text { semanas }\end{array}$ & $\begin{array}{c}4 \text { sem X 8 } \\
\text { sem }\end{array}$ \\
\hline NS & NS & NS \\
\hline
\end{tabular}


TABELA 95 - Avaliação dos efeitos da utilização de inibidor de protease sobre os parâmetros dos valores médios dos volumes celulares $\left(\mathrm{em} \mu \mathrm{m}^{3}\right)$ na camada espinhosa do epitélio do palato (região palato mole) dos animais controle e tratados com inibidor de protease. - Avaliação pelo teste Kruskal-Wallis

\section{VOLUME NUCLEAR}

Valor de $\mathrm{H}=10.6741$

Valor de $x^{2} p / 2^{\circ}$ de liberdade $=10.67$

Probabilidade de $\mathrm{H} 0=0.48 \%$

Controle X 4

semanas

NS
Controle X 8 semanas $1 \%$

$4 \operatorname{sem} X 8$

sem

$0.1 \%$

Significante para $\alpha \leq 0.01$

\section{VOLUME CELULAR}

Valor de $\mathrm{H}=12.5000$

Valor de $x^{2} p / 2^{\circ}$ de liberdade $=12.50$

Probabilidade de $\mathrm{HO}=0.19 \%$

Controle X 4

semanas

$0.1 \%$
Controle X 8

semanas

$0.1 \%$

Significante para $\alpha \leq 0.01$

\section{VOLUME DO CITOPLASMA}

Valor de $\mathrm{H}=12.5000$

Valor de $x^{2} \mathrm{p} / 2^{\circ}$ de liberdade $=12.50$

Probabilidade de $\mathrm{HO}=0.19 \%$

Controle X 4

semanas

$0.1 \%$
Controle X 8

semanas

$0.1 \%$
$4 \operatorname{sem} X 8$

sem

$0.1 \%$

Significante para $\alpha \leq 0.01$

\section{RELAÇÃO NUCLEO/CITOPLASMA}

Valor de $\mathrm{H}=13.1332$

Valor de $x^{2} p / 2^{\circ}$ de liberdade $=13.13$

Probabilidade de $\mathrm{H} 0=0.14 \%$

Significante para $\alpha \leq 0.01$

Controle X 4

semanas

$0.1 \%$
Controle X 8 semanas

$0.1 \%$
$4 \operatorname{sem} X 8$

sem

\section{DENSIDADE NUMÉRICA}

Valor de $\mathrm{H}=12.5000$

Valor de $x^{2} p / 2^{\circ}$ de liberdade $=12.50$

Probabilidade de $\mathrm{HO}=0.19 \%$

Significante para $\alpha \leq 0.01$

\section{Controle X 4}

semanas

$0.1 \%$
Controle X 8

semanas

$0.1 \%$
$4 \operatorname{sem} \times 8$

sem

$0.1 \%$

\section{DENSIDADE DE SUPERFÍCIE}

Valor de $\mathrm{H}=12.2769$

Valor de $x^{2} p / 2^{\circ}$ de liberdade $=12.28$

Probabilidade de $\mathrm{HO}=0.22 \%$

Controle X 4

semanas

$0.1 \%$
Controle X 8

semanas

$0.1 \%$
4 sem $X 8$

sem

$0.1 \%$ 
TABELA 96 - Avaliação da espessura (em $\mu \mathrm{m}$ ) do epitélio do palato (região palato mole) dos animais controle e tratados com inibidores de protease.

\begin{tabular}{|c|c|c|c|c|}
\hline Grupos estudados & $\begin{array}{c}\text { Camada } \\
\text { Basal }\end{array}$ & $\begin{array}{c}\text { Cam. } \\
\text { Espinhosa }\end{array}$ & $\begin{array}{c}\text { C. de } \\
\text { queratina }\end{array}$ & $\begin{array}{c}\text { Epitélio } \\
\text { total }\end{array}$ \\
\hline \multirow[t]{2}{*}{ Animais Controle } & $\begin{array}{l}6.04 \\
6.67 \\
6.68 \\
7.08 \\
7.21\end{array}$ & $\begin{array}{l}26.81 \\
30.04 \\
29.35 \\
30.97 \\
29.25\end{array}$ & $\begin{array}{l}10.47 \\
10.21 \\
11.12 \\
10.72 \\
11.90\end{array}$ & $\begin{array}{l}43.32 \\
46.92 \\
47.15 \\
48.77 \\
48.36\end{array}$ \\
\hline & $6.73 \pm 0.45$ & $29.28 \pm 1.54$ & $10.88 \pm 0.65$ & $46.90 \pm 2.15$ \\
\hline \multirow{3}{*}{$\begin{array}{c}\text { Inibidor de protease por } \\
4 \text { semanas }\end{array}$} & $\begin{array}{l}7.61 \\
7.92 \\
7.69 \\
7.01 \\
7.19\end{array}$ & $\begin{array}{l}31.16 \\
36.41 \\
31.99 \\
36.98 \\
30.29\end{array}$ & $\begin{array}{l}14.49 \\
14.70 \\
14.90 \\
13.61 \\
14.98\end{array}$ & $\begin{array}{l}53.26 \\
59.03 \\
54.58 \\
57.60 \\
52.46\end{array}$ \\
\hline & $7.48 \pm 0.37$ & $33.36 \pm 3.10$ & $14.53 \pm 0.55$ & $55.38 \pm 2.82$ \\
\hline & $\uparrow$ & $\uparrow$ & $\uparrow$ & $\uparrow$ \\
\hline \multirow[t]{3}{*}{$\begin{array}{l}\text { Inibidor de protease por } \\
8 \text { semanas }\end{array}$} & $\begin{array}{l}6.74 \\
6.81 \\
6.74 \\
6.29 \\
6.26\end{array}$ & $\begin{array}{l}24.64 \\
27.65 \\
26.67 \\
26.07 \\
26.93\end{array}$ & $\begin{array}{l}16.66 \\
16.64 \\
17.23 \\
15.82 \\
16.15\end{array}$ & $\begin{array}{l}48.04 \\
51.10 \\
50.64 \\
48.18 \\
52.31\end{array}$ \\
\hline & $6.56 \pm 0.26$ & $26.39 \pm 1.13$ & $16.50 \pm 0.53$ & $50.05 \pm 1.87$ \\
\hline & $\downarrow$ & 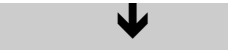 & $\uparrow$ & $\uparrow$ \\
\hline
\end{tabular}


TABELA 97 - Avaliação dos efeitos da utilização de inibidor de protease sobre os parâmetros dos valores médios da espessura (em $\mu \mathrm{m})$ no epitélio do palato (região palato mole) dos animais controle e tratados. Avaliação pelo teste Kruskal-Wallis

\section{ESPESSURA DA CAMADA BASAL}

Valor de $\mathrm{H}=7.4533$

Valor de $x^{2} \mathrm{p} / 2^{\circ}$ de liberdade $=7.45$

Probabilidade de $\mathrm{H} 0=2.41 \%$

Controle X 4

semanas

$5 \%$

Significante para $\alpha \leq 0.05$

\begin{tabular}{c|c} 
Controle X 8 & 4 sem X 8 \\
semanas & sem \\
NS & $1 \%$
\end{tabular}

\section{ESPESSURA DA CAMADA ESPINHOSA}

Valor de $\mathrm{H}=11.0600$

Valor de $x^{2} p / 2^{\circ}$ de liberdade $=11.06$

Probabilidade de $\mathrm{H} 0=0.40 \%$

Controle X 4

semanas

$1 \%$

\begin{tabular}{c|c} 
Controle $\mathrm{X} 8$ & 4 sem $\mathrm{X} 8$ \\
semanas & sem \\
$1 \%$ & $0.1 \%$
\end{tabular}

Significante para $\alpha \leq 0.01$

\section{ESPESSURA DA CAMADA DE QUERATINA}

Valor de $\mathrm{H}=12.5000$

Valor de $x^{2} p / 2^{\circ}$ de liberdade $=12.50$

Probabilidade de $\mathrm{H} 0=0.19 \%$

Significante para $\alpha \leq 0.01$
Controle X 4

semanas

$0.1 \%$

\section{Controle X 8} semanas $0.1 \%$
$4 \operatorname{sem} \times 8$

sem

$0.1 \%$

\section{ESPESSURA DO EPITÉLIO TOTAL}

Valor de $\mathrm{H}=10.8200$

Valor de $x^{2} p / 2^{\circ}$ de liberdade $=10.82$

Probabilidade de $\mathrm{H} 0=0.45 \%$

Controle X 4

semanas

$0.1 \%$
Controle X 8 semanas

$5 \%$
4 sem $X 8$

sem

$1 \%$

Significante para $\alpha \leq 0.01$ 
TABELA 98 - Avaliação da Relação superfície externa/ Superfície basal do epitélio do palato (região palato mole) dos animais controle e tratados com inibidor de protease.

\begin{tabular}{|c|c|c|}
\hline $\begin{array}{c}\text { Animais } \\
\text { Controle }\end{array}$ & $\begin{array}{c}\text { Inibidor de protease por } 4 \\
\text { semanas }\end{array}$ & $\begin{array}{c}\text { Inibidor de protease por } 8 \\
\text { semanas }\end{array}$ \\
\hline 1.0630 & 0.9190 & 0.9470 \\
0.9270 & 1.0000 & 0.9360 \\
0.8490 & 0.9130 & 0.9380 \\
1.0400 & 0.9810 & 0.9130 \\
0.9070 & 0.9420 & 0.9270 \\
\hline $0.9572 \square 0.09$ & $0.9510 \square 0.03$ & $0.9322 \square 0.01$ \\
\hline & $\Downarrow$ & $\Downarrow$ \\
\hline
\end{tabular}

TABELA 99 - Avaliação dos efeitos da utilização de inibidor de protease sobre os parâmetros dos valores médios da Relação superfície externa/ Superfície basal (em $\mu \mathrm{m})$ no epitélio do palato (região palato mole) dos animais controle e tratados. - Avaliação pelo teste Kruskal-Wallis

\section{RELAÇÃO SUPERFÍCIE EXTERNA/SUPERFÍCIE BASAL DO EPITÉLIO DO P. MOLE}

Valor de $\mathrm{H}=0.1857$

Valor de $\mathrm{x}^{2} \mathrm{p} / 2^{\circ}$ de liberdade $=0.19$

Probabilidade de $\mathrm{H} 0=91.13 \%$

Significante para $\alpha \leq 0.05$

\section{Controle X 4 \\ semanas}

NS

\author{
Controle X 8 \\ semanas
}

NS
4 sem $X 8$ sem

NS 
TABELA 100 - Avaliação dos valores médios dos volumes celulares $\left(e m \mu m^{3}\right)$ no epitélio da região gengival dos animais controle e tratados com inibidor de protease.

\begin{tabular}{|c|c|c|c|c|c|c|}
\hline \multirow{2}{*}{$\begin{array}{l}\text { Estrutura } \\
\text { Estudada }\end{array}$} & \multicolumn{2}{|c|}{ Animais Controle } & \multicolumn{2}{|c|}{ Tratados - 4 semanas } & \multicolumn{2}{|c|}{ Tratados - 8 semanas } \\
\hline & C.Basal & C.Espinhosa & C.Basal & C.Espinhosa & C.Basal & C.Espinhosa \\
\hline \multirow{7}{*}{$\begin{array}{l}\text { Volume } \\
\text { nuclear }\end{array}$} & 94.62 & 101.47 & 62.14 & 75.35 & 69.94 & 81.49 \\
\hline & 90.73 & 101.08 & 62.14 & 73.91 & 63.32 & 83.84 \\
\hline & 88.80 & 116.03 & 60.75 & 66.95 & 65.97 & 83.31 \\
\hline & 90.10 & 105.61 & 65.51 & 68.98 & 68.44 & 78.47 \\
\hline & 90.32 & 112.54 & 69.89 & 92.12 & 70.76 & 95.99 \\
\hline & $94.92 \pm 3.37$ & $107.34 \pm 6.6$ & $63.88 \pm 3.30$ & $75.46 \pm 9.92$ & $67.68 \pm 6.78$ & $84.62 \pm 6.69$ \\
\hline & & & $\downarrow$ & $\downarrow$ & $\downarrow$ & $\downarrow$ \\
\hline \multirow{7}{*}{$\begin{array}{l}\text { Volume } \\
\text { celular }\end{array}$} & 99.97 & 261.68 & 78.46 & 205.46 & 75.61 & 245.78 \\
\hline & 98.97 & 244.77 & 77.83 & 212.84 & 70.26 & \\
\hline & 99.93 & 229.57 & 73.33 & 196.91 & 75.00 & 238.86 \\
\hline & 99.99 & 277.58 & 74.25 & 198.95 & 74.49 & 241.59 \\
\hline & 98.35 & 238.22 & 79.10 & 214.95 & 76.97 & 264.13 \\
\hline & $96.24 \pm 3.42$ & $250.36 \pm 19.23$ & $76.59 \pm 2.61$ & $205.82 \pm 8.05$ & $72.26 \pm 2.12$ & $250.56 \pm 11.99$ \\
\hline & & & $\downarrow$ & $\downarrow$ & $\downarrow$ & $\uparrow$ \\
\hline \multirow{7}{*}{$\begin{array}{l}\text { Volume do } \\
\text { citoplasma }\end{array}$} & 5.35 & 160.21 & 16.32 & 130.11 & 5.67 & 164.29 \\
\hline & 8.24 & 143.69 & 15.69 & 138.93 & 6.94 & 178.84 \\
\hline & 11.13 & 113.54 & 12.58 & 129.96 & 9.03 & 155.55 \\
\hline & 9.89 & 171.97 & 8.74 & 129 & 6.05 & 163.12 \\
\hline & 8.03 & 125.68 & 9.21 & 122.83 & 6.21 & 168.14 \\
\hline & $8.42 \pm 56.95$ & $143.01 \pm 23.99$ & $12.50 \pm 3.52$ & $130.36 \pm 5.71$ & $6.80 \pm 1.68$ & $165.98 \pm 8.51$ \\
\hline & & & 个 & $\downarrow$ & $\downarrow$ & $\uparrow$ \\
\hline \multirow{7}{*}{$\begin{array}{l}\text { Relação } \\
\text { Núcleo/ } \\
\text { citoplasma }\end{array}$} & 0.5873 & 0.1905 & 0.5152 & 0.1494 & 0.5152 & 0.1364 \\
\hline & 0.6129 & 0.2048 & 0.5152 & 0.13 & 0.5 & 0.1364 \\
\hline & 0.6129 & 0.2195 & 0.4925 & 0.1364 & 0.5 & 0.1494 \\
\hline & 0.5873 & 0.1765 & 0.4925 & 0.13 & 0.5152 & 0.1494 \\
\hline & 0.6129 & 0.2048 & 0.5152 & 0.1384 & 0.5225 & 0.1364 \\
\hline & $0.6027 \pm 0.01$ & $0.1992 \pm 0.01$ & $0.5061 \pm 0.01$ & $0.1394 \pm 0.00$ & $0.5206 \pm 0.00$ & $0.1416 \pm 0.00$ \\
\hline & & & $\downarrow$ & $\downarrow$ & $\downarrow$ & $\downarrow$ \\
\hline \multirow{7}{*}{$\begin{array}{l}\text { Densidade } \\
\text { numérica }\end{array}$} & 10.00 & 3.82 & 12.75 & 4.87 & 13.97 & 4.07 \\
\hline & 10.64 & 4.45 & 12.85 & $4.7 c$ & 14.65 & 3.81 \\
\hline & 10.65 & 4.77 & 14.82 & 5.0 & 13.33 & 4.17 \\
\hline & 10.06 & 3.36 & 13.47 & 5.03 & 14.39 & 4.22 \\
\hline & 10.71 & 4.20 & 12.64 & 4.6 & 13.52 & $\begin{array}{l}4.26 \\
3.79\end{array}$ \\
\hline & $10.41 \pm 0.35$ & $4.12 \pm 0.54$ & $13.30 \pm 0.90$ & $4.86 \pm 0.19$ & $13.97 \pm 0.55$ & $4.01 \pm 0.20$ \\
\hline & & & $\uparrow$ & $\uparrow$ & $\uparrow$ & $\downarrow$ \\
\hline \multirow{7}{*}{$\begin{array}{l}\text { Densidade } \\
\text { de } \\
\text { superfície }\end{array}$} & 14.11 & 2.76 & 17.57 & 2.24 & 12.54 & 1.40 \\
\hline & 15.25 & 2.42 & 14.22 & 2.0 & 14.02 & 1.49 \\
\hline & 15.65 & 2.65 & 16.76 & 2.51 & 12.70 & 1.45 \\
\hline & 14.16 & 2.61 & 14.12 & 2.0 & 14.73 & 1.41 \\
\hline & 14.42 & 2.50 & 15.38 & 2.41 & 13.45 & 1.46 \\
\hline & $14.71 \pm 0.69$ & $2.58 \pm 0.13$ & $15.61 \pm 1.53$ & $2.25 \pm 0.20$ & $13.48 \pm 0.91$ & $1.44 \pm 0.03$ \\
\hline & & & $\uparrow$ & $\downarrow$ & $\downarrow$ & $\downarrow$ \\
\hline
\end{tabular}

Obs: Estão expressos nesta tabela os dados relativos a: volume nuclear, citoplasmático e celular (em micrometros cúbicos $-\mu \mathrm{m}^{3}$ ), relação núcleo/citoplasma, densidade numérica (número de células em uma área definida) e de superfície (número de células em uma extensão definida de superfície epitelial). 
TABELA 101 - Avaliação dos efeitos da utilização de inibidor de protease sobre os parâmetros dos valores médios dos volumes celulares $\left(\mathrm{em} \mu \mathrm{m}^{3}\right)$ na camada basal do epitélio da região gengival dos animais controle e tratados com inibidor de protease. - Avaliação pelo teste KruskalWallis

\section{VOLUME NUCLEAR}

Valor de $\mathrm{H}=11.2000$

Valor de $x^{2} p / 2^{\circ}$ de liberdade $=11.20$

Probabilidade de $\mathrm{H} 0=0.37 \%$

Controle X 4

semanas

$0.1 \%$

Significante para $\alpha \leq 0.01$

\section{VOLUME CELULAR}

Valor de $H=11.1800$

Valor de $x^{2} p / 2^{\circ}$ de liberdade $=11.18$

Probabilidade de $\mathrm{H} 0=0.37 \%$

Significante para $\alpha \leq 0.01$

\section{VOLUME DO CITOPLASMA}

Valor de $\mathrm{H}=10.8200$

Valor de $x^{2} p / 2^{\circ}$ de liberdade $=10.82$

Probabilidade de $\mathrm{H} 0=0.45 \%$

Significante para $\alpha \leq 0.01$

\section{RELAÇÃO NUCLEO/CITOPLASMA}

Valor de $\mathrm{H}=11.4967$

Valor de $x^{2} p / 2^{\circ}$ de liberdade $=11.50$

Probabilidade de $\mathrm{H} 0=0.32 \%$

Significante para $\alpha \leq 0.01$

\section{DENSIDADE NUMÉRICA}

Valor de $\mathrm{H}=10.2200$

Valor de $x^{2} p / 20$ de liberdade $=10.22$

Probabilidade de $\mathrm{H} 0=0.60 \%$

Significante para $\alpha \leq 0.01$

\section{DENSIDADE DE SUPERFÍCIE}

Valor de $\mathrm{H}=6.5000$

Valor de $\mathrm{x}^{2} \mathrm{p} / 2^{\circ}$ de liberdade $=6.50$

Probabilidade de $\mathrm{H} 0=3.88 \%$

Controle X 4

semanas

$0.1 \%$

\section{Controle X 4 \\ semanas \\ $1 \%$}

\begin{tabular}{c|c}
\hline Controle X 8 & 4 sem X8 \\
\hline semanas & sem \\
$0.1 \%$ & $5 \%$
\end{tabular}

\begin{tabular}{c|c|}
$\begin{array}{c}\text { Controle X } 8 \\
\text { semanas }\end{array}$ & 4 sem $X 8$ \\
\hline $1 \%$ & sem \\
\hline & $5 \%$
\end{tabular}

\begin{tabular}{c|c}
$\begin{array}{c}\text { Controle X } 8 \\
\text { semanas }\end{array}$ & 4 sem X 8 \\
\hline $5 \%$ & sem \\
\hline
\end{tabular}

\begin{tabular}{c|c|c|}
\hline $\begin{array}{c}\text { Controle X 4 } \\
\text { semanas }\end{array}$ & $\begin{array}{c}\text { Controle X 8 } \\
\text { semanas }\end{array}$ & 4 sem X 8 \\
\hline $0.1 \%$ & $0.1 \%$ & $5 \%$ \\
\hline
\end{tabular}

Significante para $\alpha \leq 0.05$

\author{
Controle X 4 \\ semanas \\ NS
}
Controle X 8
semanas
$0.1 \%$
4 sem $X 8$ sem NS


TABELA 102 - Avaliação dos efeitos da utilização de inibidor de protease sobre os parâmetros dos valores médios dos volumes celulares $\left(\mathrm{em} \mu \mathrm{m}^{3}\right)$ na camada espinhosa do epitélio da região gengival dos animais controle e tratados com inibidor de protease. - Avaliação pelo teste Kruskal-Wallis

\begin{tabular}{|c|c|c|c|}
\hline \multicolumn{4}{|l|}{ VOLUME NUCLEAR } \\
\hline $\begin{array}{l}\text { Valor de } \mathrm{H}=10.8200 \\
\text { Valor de } \mathrm{x}^{2} \mathrm{p} / 2^{\circ} \text { de liberdade }=10.82 \\
\text { Probabilidade de } \mathrm{H} 0=0.45 \%\end{array}$ & $\begin{array}{l}\text { Controle X } 4 \\
\text { semanas } \\
0.1 \%\end{array}$ & $\begin{array}{c}\text { Controle X } 8 \\
\text { semanas } \\
1 \%\end{array}$ & $\begin{array}{l}4 \operatorname{sem} \times 8 \\
\text { sem } \\
5 \%\end{array}$ \\
\hline \multicolumn{4}{|l|}{ Significante para $\alpha \leq 0.01$} \\
\hline \multicolumn{4}{|l|}{ VOLUME CELULAR } \\
\hline $\begin{array}{l}\text { Valor de } H=9.5000 \\
\text { Valor de } x^{2} p / 2^{\circ} \text { de liberdade }=9.50 \\
\text { Probabilidade de } H 0=0.87 \%\end{array}$ & $\begin{array}{l}\text { Controle X } 4 \\
\text { semanas } \\
1 \%\end{array}$ & $\begin{array}{l}\text { Controle X } 8 \\
\text { semanas } \\
\text { NS }\end{array}$ & $\begin{array}{l}4 \text { sem } X 8 \\
\text { sem } \\
0.1 \%\end{array}$ \\
\hline \multicolumn{4}{|l|}{ Significante para $\alpha \leq 0.01$} \\
\hline \multicolumn{4}{|l|}{ VOLUME DO CITOPLASMA } \\
\hline $\begin{array}{l}\text { Valor de } \mathrm{H}=6.7200 \\
\text { Valor de } \mathrm{x}^{2} \mathrm{p} / 2^{\circ} \text { de liberdade }=6.72 \\
\text { Probabilidade de } \mathrm{H} 0=3.47 \%\end{array}$ & $\begin{array}{l}\text { Controle X } 4 \\
\text { semanas } \\
\text { NS }\end{array}$ & $\begin{array}{l}\text { Controle X } 8 \\
\text { semanas } \\
\text { NS }\end{array}$ & $\begin{array}{l}4 \text { sem } X 8 \\
\text { sem } \\
1 \%\end{array}$ \\
\hline \multicolumn{4}{|l|}{$\begin{array}{l}\text { Significante para } \alpha \leq 0.05 \\
\text { RELAÇÃO NUCLEO/CITOPLASMA }\end{array}$} \\
\hline $\begin{array}{l}\text { Valor de } H=10.1177 \\
\text { Valor de } x^{2} p / 2^{\circ} \text { de liberdade }=10.12 \\
\text { Probabilidade de } \mathrm{H} 0=0.64 \%\end{array}$ & $\begin{array}{l}\text { Controle X } 4 \\
\text { semanas } \\
0.1 \%\end{array}$ & $\begin{array}{l}\text { Controle X } 8 \\
\text { semanas } \\
0.1 \%\end{array}$ & $\begin{array}{l}4 \text { sem } X 8 \\
\text { sem } \\
\text { NS }\end{array}$ \\
\hline \multicolumn{4}{|l|}{ Significante para $\alpha \leq 0.01$} \\
\hline \multicolumn{4}{|l|}{ DENSIDADE NUMÉRICA } \\
\hline $\begin{array}{l}\text { Valor de } \mathrm{H}=8.3400 \\
\text { Valor de } \mathrm{x}^{2} \mathrm{p} / 2^{\circ} \text { de liberdade }=8.34 \\
\text { Probabilidade de } \mathrm{H} 0=1.55 \%\end{array}$ & $\begin{array}{l}\text { Controle X } 4 \\
\text { semanas } \\
1 \%\end{array}$ & $\begin{array}{l}\text { Controle X } 8 \\
\text { semanas } \\
\text { NS }\end{array}$ & $\begin{array}{l}4 \text { sem } X 8 \\
\text { sem } \\
1 \%\end{array}$ \\
\hline \multicolumn{4}{|l|}{ Significante para $\alpha \leq 0.01$} \\
\hline \multicolumn{4}{|l|}{ DENSIDADE DE SUPERFÍCIE } \\
\hline $\begin{array}{l}\text { Valor de } \mathrm{H}=11.5800 \\
\text { Valor de } \mathrm{x}^{2} \mathrm{p} / 2^{\circ} \text { de liberdade }=11.58 \\
\text { Probabilidade de } \mathrm{H} 0=0.31 \%\end{array}$ & $\begin{array}{c}\text { Controle X } 4 \\
\text { semanas } \\
1 \%\end{array}$ & $\begin{array}{c}\text { Controle X } 8 \\
\text { semanas } \\
0.1 \%\end{array}$ & $\begin{array}{l}4 \text { sem } X 8 \\
\text { sem } \\
1 \%\end{array}$ \\
\hline Significante para $\alpha \leq 0.01$ & & & \\
\hline
\end{tabular}


TABELA 103 - Avaliação da espessura (em $\mu \mathrm{m})$ do epitélio da região gengival dos animais controle e tratados com inibidores de protease.

\begin{tabular}{|c|c|c|c|c|}
\hline Grupos estudados & $\begin{array}{c}\text { Camada } \\
\text { Basal }\end{array}$ & $\begin{array}{c}\text { Cam. } \\
\text { Espinhosa }\end{array}$ & $\begin{array}{c}\text { C. de } \\
\text { queratina }\end{array}$ & Epitélio total \\
\hline \multirow[t]{2}{*}{ Animais Controle } & $\begin{array}{l}6.74 \\
6.08 \\
6.42 \\
6.63 \\
6.60\end{array}$ & $\begin{array}{l}31.31 \\
33.58 \\
30.26 \\
33.52 \\
31.61\end{array}$ & $\begin{array}{l}9.69 \\
8.52 \\
8.48 \\
9.58 \\
9.95\end{array}$ & $\begin{array}{l}47.74 \\
48.18 \\
45.16 \\
49.73 \\
48.16\end{array}$ \\
\hline & $6.49 \pm 0.25$ & $32.05 \pm 1.45$ & $9.24 \pm 0.69$ & $47.79 \pm 1.65$ \\
\hline \multirow{3}{*}{$\begin{array}{l}\text { Inibidor de protease por } \\
4 \text { semanas }\end{array}$} & $\begin{array}{l}6.07 \\
6.68 \\
6.12 \\
6.70 \\
6.18\end{array}$ & $\begin{array}{l}39.54 \\
43.49 \\
37.00 \\
43.34 \\
38.43\end{array}$ & $\begin{array}{l}9.77 \\
9.80 \\
9.87 \\
9.97 \\
9.98\end{array}$ & $\begin{array}{l}55.38 \\
59.97 \\
52.99 \\
60.01 \\
54.59\end{array}$ \\
\hline & $6.35 \pm 0.31$ & $40.36 \pm 2.93$ & $9.87 \pm 0.09$ & $56.58 \pm 3.22$ \\
\hline & $\downarrow$ & $\uparrow$ & $\uparrow$ & $\uparrow$ \\
\hline \multirow[t]{3}{*}{$\begin{array}{l}\text { Inibidor de protease por } \\
8 \text { semanas }\end{array}$} & $\begin{array}{l}7.97 \\
7.29 \\
7.99 \\
7.04 \\
7.49\end{array}$ & $\begin{array}{l}67.68 \\
62.59 \\
65.54 \\
68.42 \\
65.48\end{array}$ & $\begin{array}{l}9.61 \\
8.14 \\
8.05 \\
9.28 \\
8.30\end{array}$ & $\begin{array}{l}85.26 \\
78.02 \\
81.58 \\
84.74 \\
81.27\end{array}$ \\
\hline & $7.55 \pm 0.41$ & $65.94 \pm 2.27$ & $8.65 \pm 0.73$ & $82.17 \pm 2.93$ \\
\hline & $\uparrow$ & $\uparrow$ & $\downarrow$ & $\uparrow$ \\
\hline
\end{tabular}


TABELA 104 - Avaliação dos efeitos da utilização de inibidor de protease sobre os parâmetros dos valores médios da espessura (em $\mu \mathrm{m})$ no epitélio da região gengival dos animais controle e tratados. - Avaliação pelo teste Kruskal-Wallis

\section{ESPESSURA DA CAMADA BASAL}

Valor de $\mathrm{H}=9.5000$

Valor de $\mathrm{x}^{2} \mathrm{p} / 2^{\circ}$ de liberdade $=9.50$

Probabilidade de $\mathrm{H} 0=0.87 \%$

Controle X 4

semanas

NS

Significante para $\alpha \leq 0.01$

\begin{tabular}{c|c}
$\begin{array}{c}\text { Controle X } 8 \\
\text { semanas }\end{array}$ & $\begin{array}{c}4 \text { sem } X 8 \\
\text { sem }\end{array}$ \\
$1 \%$ & $0.1 \%$
\end{tabular}

\section{ESPESSURA DA CAMADA ESPINHOSA}

Valor de $\mathrm{H}=12.5000$

Valor de $x^{2} \mathrm{p} / 2^{\circ}$ de liberdade $=12.50$

Probabilidade de $\mathrm{H} 0=0.19 \%$

Controle X 4

semanas

$0.1 \%$

\begin{tabular}{c|c}
$\begin{array}{c}\text { Controle } X 8 \\
\text { semanas }\end{array}$ & 4 sem $X 8$ \\
$0.1 \%$ & sem \\
\hline
\end{tabular}

Significante para $\alpha \leq 0.01$

\section{ESPESSURA DA CAMADA DE QUERATINA}

Valor de $\mathrm{H}=8.8800$

Valor de $x^{2} \mathrm{p} / 2^{\circ}$ de liberdade $=8.88$

Probabilidade de $\mathrm{H} 0=1.18 \%$

Significante para $\alpha \leq 0.01$

\section{ESPESSURA DO EPITÉLIO TOTAL}

Valor de $\mathrm{H}=12.5000$

Valor de $x^{2} p / 2^{\circ}$ de liberdade $=12.50$

Probabilidade de $\mathrm{H} 0=0.19 \%$

Significante para $\alpha \leq 0.01$
Controle X 4

semanas

$5 \%$

\begin{tabular}{c|c}
$\begin{array}{c}\text { Controle } X 8 \\
\text { semanas }\end{array}$ & $\begin{array}{c}4 \text { sem } X 8 \\
\text { NS }\end{array}$ \\
sem \\
& $0.1 \%$
\end{tabular}

Controle X 4

Controle X 8

$4 \operatorname{sem} \times 8$

semanas

semanas

$0.1 \%$

$0.1 \%$

sem

$0.1 \%$ 
TABELA 105 - Avaliação da Relação superfície externa/ Superfície basal do epitélio da região gengival dos animais controle e tratados com inibidor de protease.

\begin{tabular}{|c|c|c|}
\hline $\begin{array}{c}\text { Animais } \\
\text { Controle }\end{array}$ & $\begin{array}{c}\text { Inibidor de protease por } 4 \\
\text { semanas }\end{array}$ & $\begin{array}{c}\text { Inibidor de protease por } 8 \\
\text { semanas }\end{array}$ \\
\hline 0.7129 & 0.8820 & 1.0300 \\
0.6390 & 0.8550 & 1.0610 \\
0.8010 & 0.8620 & 1.0580 \\
0.8510 & 0.8240 & 1.0100 \\
\hline 0.6420 & 0.8210 & 1.0490 \\
\hline $0.7292 \pm 0.09$ & $0.8488 \pm 0.02$ & $1.0416 \pm 0.02$ \\
\hline
\end{tabular}

TABELA 106 - Avaliação dos efeitos da utilização de inibidor de protease sobre os parâmetros dos valores médios da Relação superfície externa/ Superfície basal (em $\mu \mathrm{m})$ no epitélio da região gengival dos animais controle e tratados. - Avaliação pelo teste Kruskal-Wallis

\section{RELAÇÃO SUPERFÍCIE EXTERNA/SUPERFÍCIE BASAL DO EPITÉLIO DA GENGIVA}

Valor de $\mathrm{H}=11.5800$

Valor de $x^{2} p / 2^{\circ}$ de liberdade $=11.58$

Probabilidade de $\mathrm{H} 0=0.31 \%$

Significante para $\alpha \leq 0.01$
Controle X 8

semanas

$4 \operatorname{sem} \times 8$

semanas

$0.1 \%$

$1 \%$

$1 \%$ . 
A análise estereológica aplicada aos epitélios dos palatos duro e mole e à região gengival nos animais estudados nos permitiu observar que:

1) o volume celular nas duas camadas do palato dura diminui nos períodos iniciais, mas aumenta com o uso continuado do medicamento;

2) apesar do volume celular aumentado, a espessura do epitélio na região do palato duro diminui, e isso se deve, principalmente, à diminuição expressiva da camada espinhosa;

3) é observado um pequeno aumento das pregas epiteliais no epitélio dessa região;

4) no palato mole, os volumes celulares aumentam de forma bastante marcante e progressiva com o uso continuado de inibidor de protease;

5) mas, embora num primeiro momento se observe ligeiro aumento da espessura epitelial, esse efeito tende a se reverter com o uso continuado do medicamento;

6) as pregas epiteliais nessa região - do palato mole - não apresentam grandes variações;

7) para a região gengival se observa pouca variação no volume celular na camada espinhosa, embora exista uma tendência de diminuição na camada basal;

8) apesar disso, o epitélio tende a se apresentar mais espesso, o que pode também ser observado pelo aumento da densidade numérica celular nessa área;

9) as pregas epiteliais da região gengival estão bem mais marcantes nos animais tratados com inibidor de protease, e esse efeito parece ser progressivo. 


\subsection{Avaliação da glândula salivar submandibular}

Histopatologicamente, a glândula submandibular do rato se encontra compactada por uma cápsula fibrosa que emite septos para seu interior, dividindo-a em lóbulos. Ela se constitui essencialmente de ácinos serosos e um sistema extenso de ductos intralobulares e interlobulares. Os ductos intralobulares dividem-se em uma porção anterior, ou túbulo contorcido granuloso, e uma porção distal, ou ducto estriado (Figuras 10 a 14).

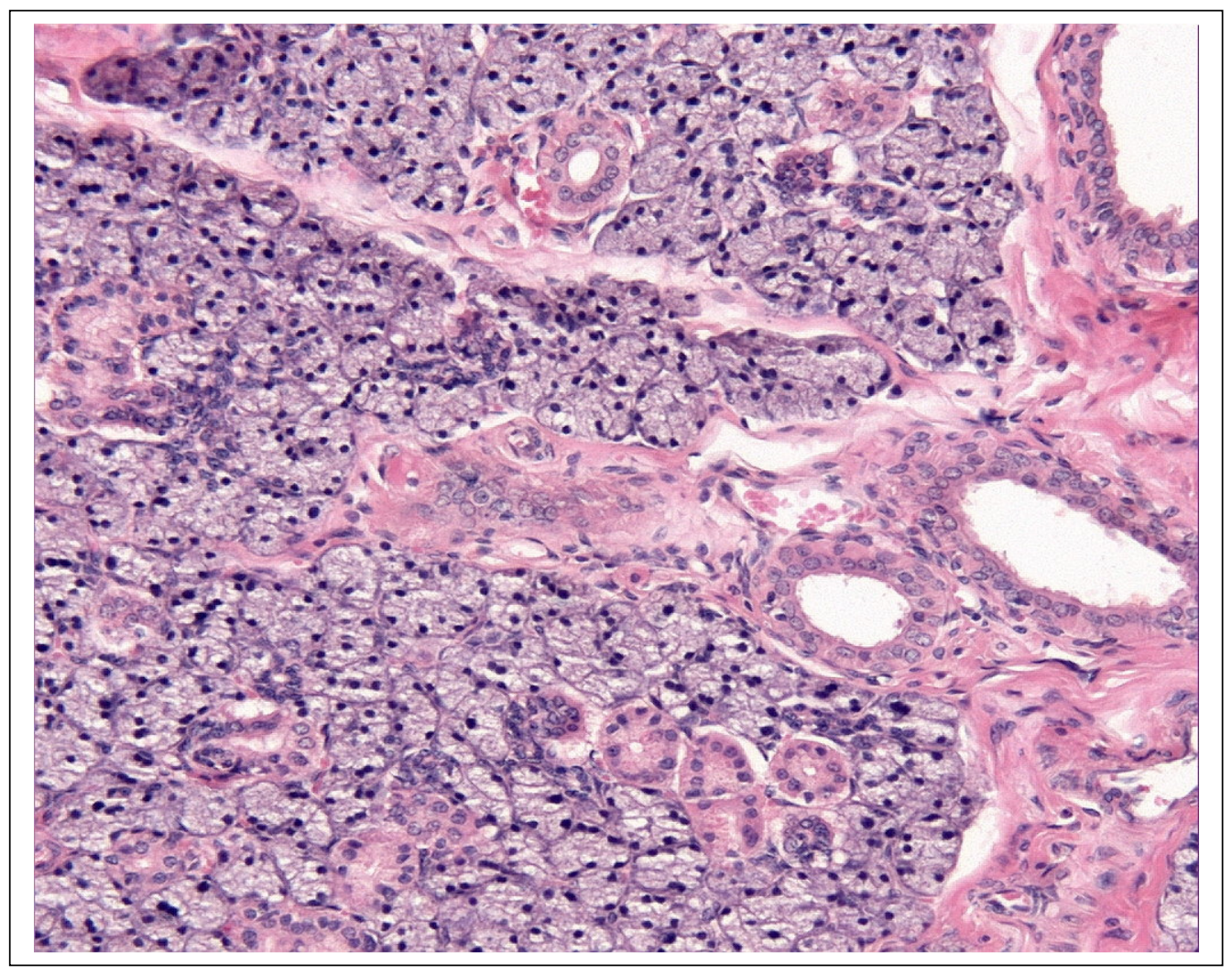

Figura 10 - Fotomicrografia da glândula salivar submandibular. HE. Obj.Aum.4x 


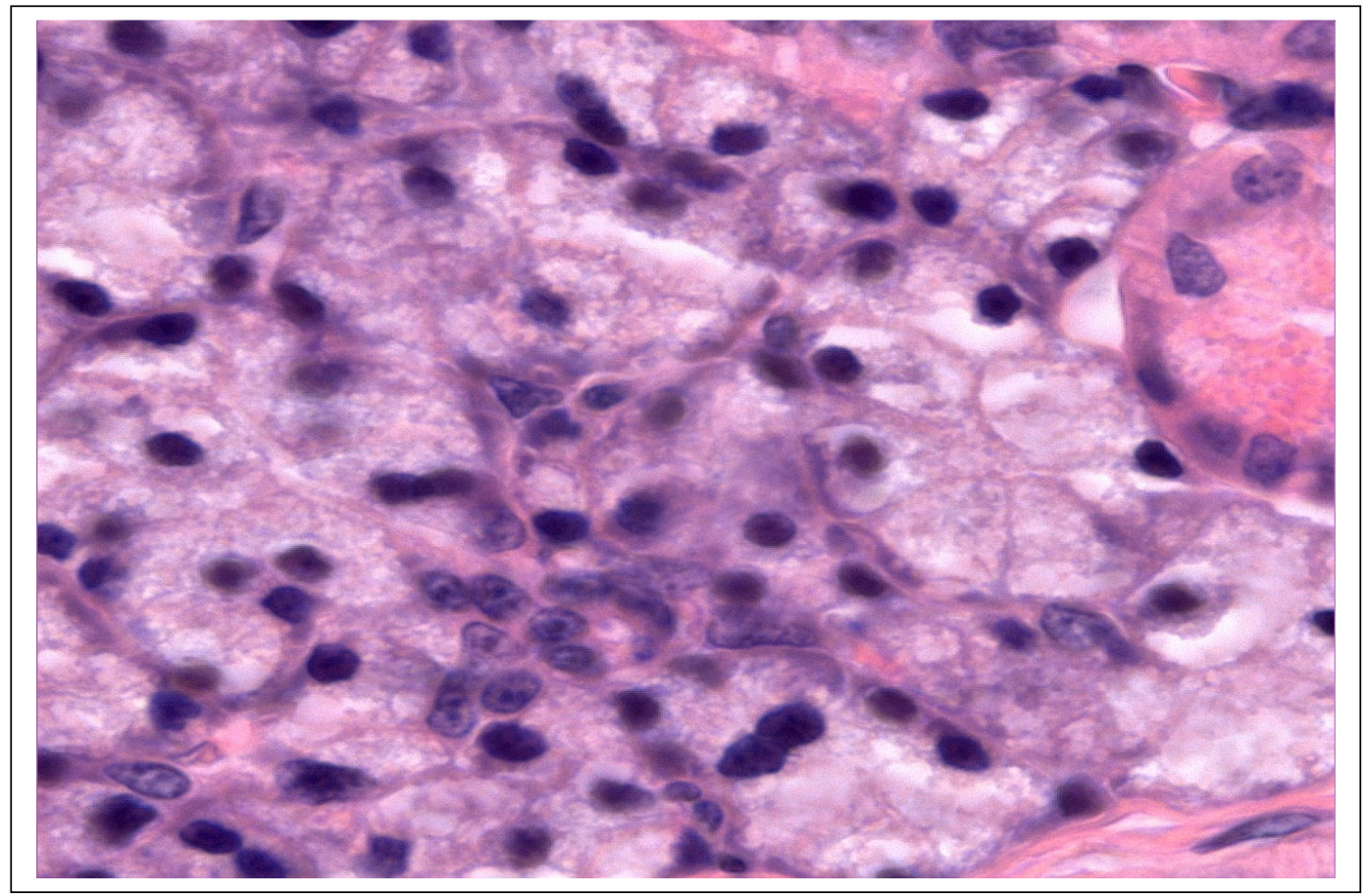

Figura 11 - Mesma glândula com objetiva de aumento 40x. Observe a relação entre ácinos e ductos H\&E.

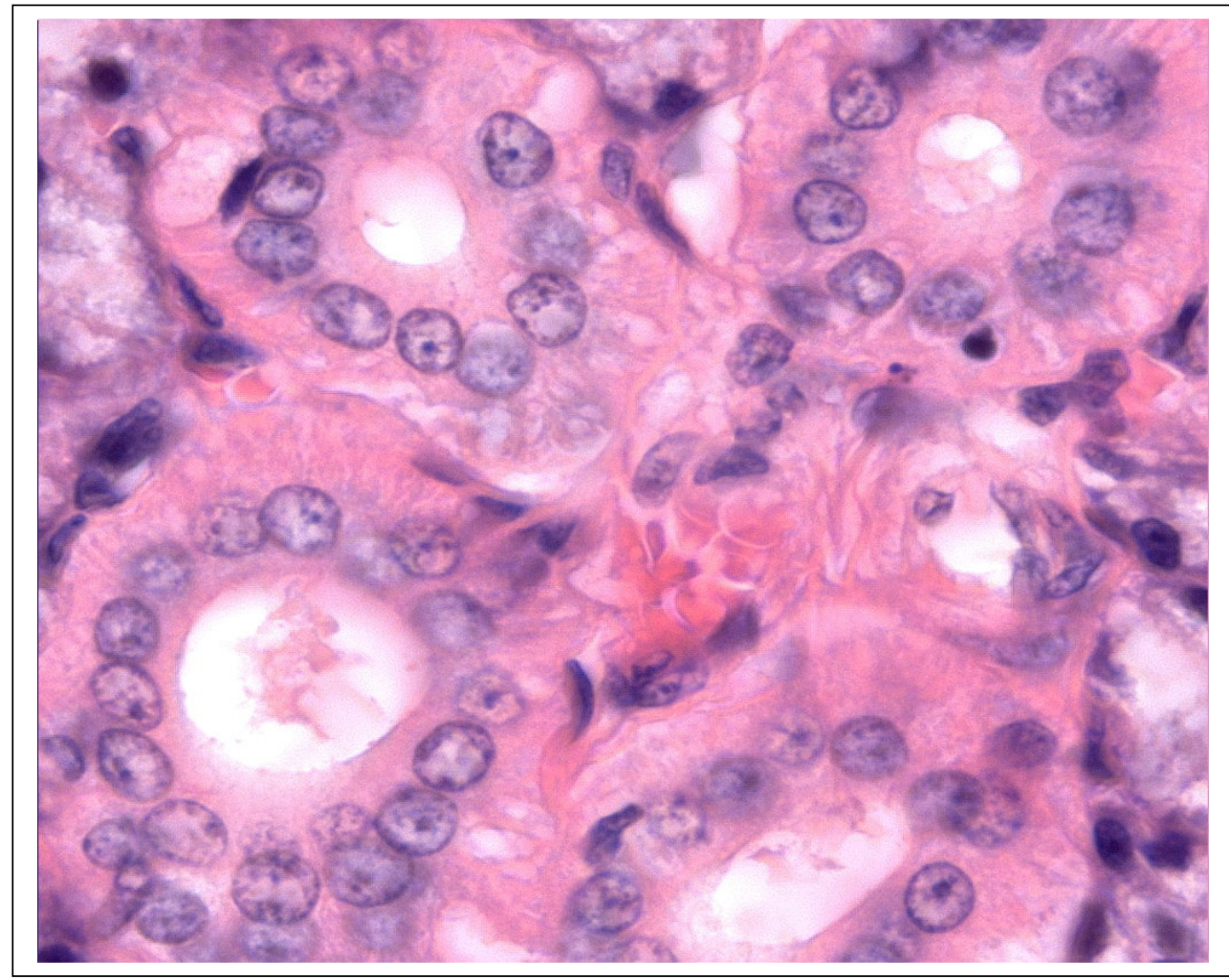

Figura 12 - Observe as características dos ductos estriados. H\&E. Objetiva de aumento $40 \mathrm{x}$. 


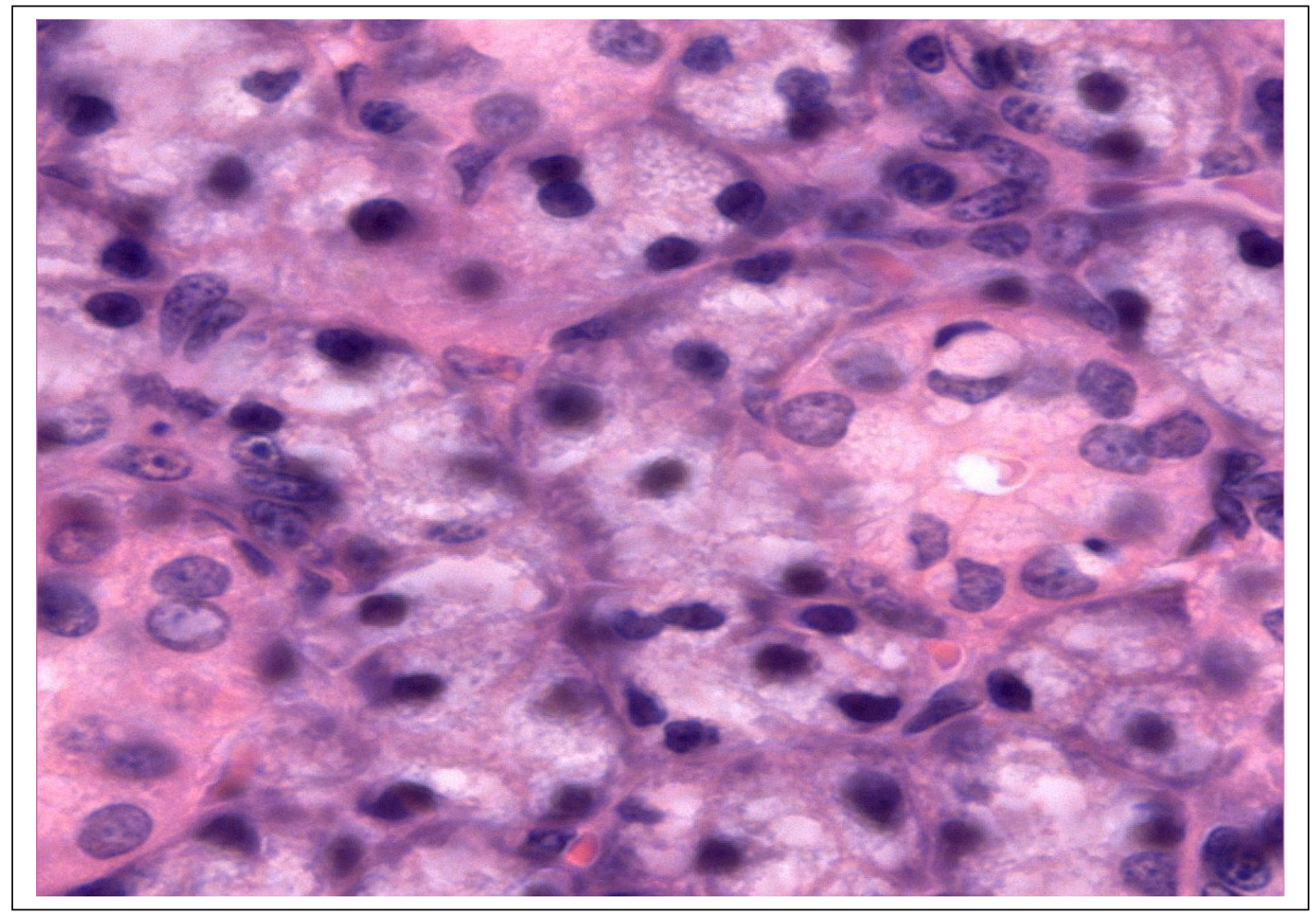

Figura 13 - Observe as características dos ductos estriados. H\&E. Objetiva de aumento 40x.

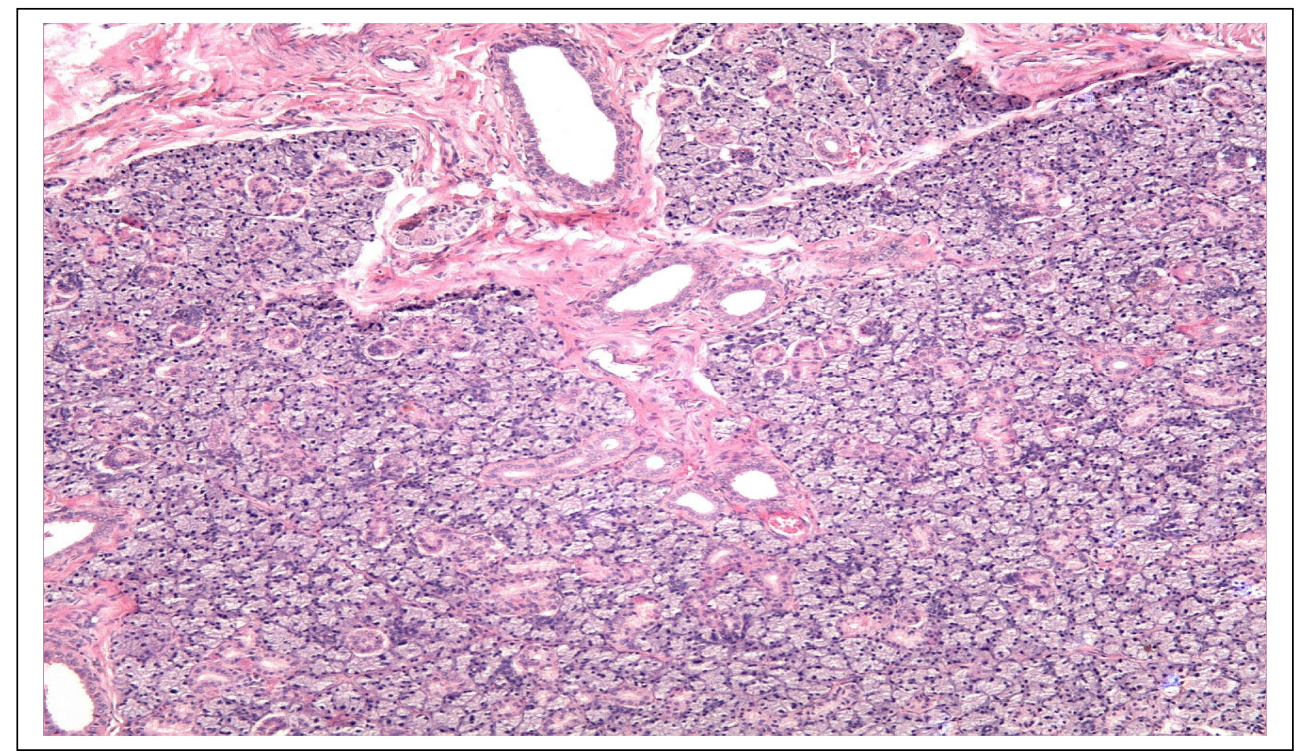

Figura 14 - Observe as características dos ductos excretores. H\&E. Objetiva de aumento 10x. 


\subsubsection{Cariometria das glândulas salivares submandibulares}

TABELA 107 - Avaliação do tamanho dos núcleos das células do epitélio da glândula submandibular (ácinos) dos animais controle e tratados com inibidor de protease.

\begin{tabular}{|c|c|c|c|}
\hline $\begin{array}{l}\text { Estrutura } \\
\text { Estudada }\end{array}$ & Animais Controle & $\begin{array}{c}\text { Tratados - } 4 \\
\text { semanas }\end{array}$ & $\begin{array}{c}\text { Tratados - } 8 \\
\text { semanas }\end{array}$ \\
\hline \multirow[t]{3}{*}{ Diâmetro maior } & $\begin{array}{l}4.54 \\
4.54 \\
4.44 \\
4.50 \\
4.52\end{array}$ & $\begin{array}{l}4.18 \\
4.56 \\
4.34 \\
4.54 \\
4.46\end{array}$ & $\begin{array}{l}5.36 \\
5.36 \\
5.30 \\
5.72 \\
5.48\end{array}$ \\
\hline & $4.50 \pm 0.04$ & $4.41 \pm 0.15$ & $5.44 \pm 0.16$ \\
\hline & & $\downarrow$ & $\uparrow$ \\
\hline \multirow[t]{3}{*}{ Diâmetro menor } & $\begin{array}{l}3.94 \\
3.90 \\
3.74 \\
3.86 \\
3.88\end{array}$ & $\begin{array}{l}3.50 \\
3.98 \\
3.60 \\
3.98 \\
3.60\end{array}$ & $\begin{array}{l}4.28 \\
4.24 \\
4.38 \\
4.50 \\
4.60\end{array}$ \\
\hline & $3.86 \pm 0.07$ & $3.73 \pm 0.23$ & $4.40 \pm 0.15$ \\
\hline & & $\downarrow$ & $\uparrow$ \\
\hline \multirow[t]{3}{*}{ Volume nuclear } & $\begin{array}{l}40.83 \\
40.11 \\
36.18 \\
39.42 \\
39.19\end{array}$ & $\begin{array}{l}30.40 \\
41.20 \\
33.51 \\
41.36 \\
43.96\end{array}$ & $\begin{array}{l}58.23 \\
57.69 \\
60.19 \\
69.53 \\
67.48\end{array}$ \\
\hline & $39.14 \pm 1.77$ & $38.08 \pm 5.80$ & $62.62 \pm 5.49$ \\
\hline & & $\downarrow$ & $\uparrow$ \\
\hline \multirow[t]{3}{*}{ Área nuclear } & $\begin{array}{l}14.15 \\
14.00 \\
13.10 \\
13.79 \\
13.82\end{array}$ & $\begin{array}{l}11.61 \\
14.26 \\
12.38 \\
14.29 \\
12.71\end{array}$ & $\begin{array}{l}18.03 \\
17.89 \\
18.35 \\
20.23 \\
19.87\end{array}$ \\
\hline & $13.77 \pm 0.40$ & $13.05 \pm 1.18$ & $18.87 \pm 1.09$ \\
\hline & & $\downarrow$ & $\uparrow$ \\
\hline \multirow[t]{2}{*}{ Perímetro nuclear } & $\begin{array}{l}13.55 \\
13.30 \\
12.89 \\
13.17 \\
13.23\end{array}$ & $\begin{array}{l}12.10 \\
13.45 \\
12.52 \\
13.41 \\
12.71\end{array}$ & $\begin{array}{l}15.21 \\
15.16 \\
15.26 \\
16.15 \\
15.88\end{array}$ \\
\hline & $13.22 \pm 0.23$ & $12.83 \pm 0.58$ & $15.53 \pm 0.45$ \\
\hline
\end{tabular}

Obs: Estão expressos nesta tabela os dados relativos a: Diâmetro maior em micrometros $(\mu \mathrm{m})$, diâmetro menor $(\mathrm{em} \mu \mathrm{m})$, perímetro do núcleo celular $(\mathrm{em} \mu \mathrm{m})$, área nuclear em micrometros quadrados $\left(\mu \mathrm{m}^{2}\right)$, e volume nuclear em micrometros cúbicos $\left(\mu \mathrm{m}^{3}\right)$. 
TABELA 108 - Avaliação dos efeitos da utilização de inibidor de protease sobre os parâmetros do tamanho dos núcleos das células da glândula submandibular (ácinos) dos animais controles e tratados - Avaliação pelo teste Kruskal-Wallis

\begin{tabular}{|c|c|c|c|}
\hline \multicolumn{4}{|l|}{ DIÂMETRO MAIOR } \\
\hline \multirow{2}{*}{$\begin{array}{l}\text { Valor de } H=10.8200 \\
\text { Valor de } x^{2} p / 2^{\circ} \text { de liberdade }=10.82 \\
\text { Probabilidade de } H 0=0.45 \%\end{array}$} & $\begin{array}{c}\text { Controle X } 4 \\
\text { semanas }\end{array}$ & $\begin{array}{c}\text { Controle X } 8 \\
\text { semanas }\end{array}$ & 4 sem $X 8$ sem \\
\hline & NS & $1 \%$ & $0.1 \%$ \\
\hline \multicolumn{4}{|l|}{ Significante para $\alpha \leq 0.01$} \\
\hline \multicolumn{4}{|l|}{ DIÂMETRO MENOR } \\
\hline \multirow{2}{*}{$\begin{array}{l}\text { Valor de } \mathrm{H}=9.9800 \\
\text { Valor de } \mathrm{x}^{2} \mathrm{p} / 2^{\circ} \text { de liberdade }=9.98 \\
\text { Probabilidade de } \mathrm{H} 0=0.68 \%\end{array}$} & Controle X 4 & Controle X 8 & 4 sem $X 8$ sem \\
\hline & $\begin{array}{c}\text { semanas } \\
\text { NS }\end{array}$ & semanas & $01 \%$ \\
\hline \multicolumn{4}{|l|}{ Significante para $\alpha \leq 0.01$} \\
\hline \multicolumn{4}{|l|}{ VOLUME NUCLEAR } \\
\hline \multirow{2}{*}{$\begin{array}{l}\text { Valor de } \mathrm{H}=10.2200 \\
\text { Valor de } \mathrm{x}^{2} \mathrm{p} / 2^{\circ} \text { de liberdade }=10.22 \\
\text { Probabilidade de } \mathrm{H} 0=0.60 \%\end{array}$} & $\begin{array}{c}\text { Controle X } 4 \\
\text { semanas }\end{array}$ & $\begin{array}{c}\text { Controle X } 8 \\
\text { semanas }\end{array}$ & 4 sem $X 8$ sem \\
\hline & NS & $0.1 \%$ & $1 \%$ \\
\hline \multirow{2}{*}{\multicolumn{4}{|c|}{$\begin{array}{l}\text { Significante para } \alpha \leq 0.01 \\
\text { ÁREA NUCLEAR }\end{array}$}} \\
\hline & & & \\
\hline \multirow{2}{*}{$\begin{array}{l}\text { Valor de } H=10.8200 \\
\text { Valor de } x^{2} p / 2^{\circ} \text { de liberdade }=10.82 \\
\text { Probabilidade de } \mathrm{H} 0=0.45 \%\end{array}$} & $\begin{array}{l}\text { Controle X } 4 \\
\text { semanas }\end{array}$ & $\begin{array}{l}\text { Controle X } 8 \\
\text { semanas }\end{array}$ & 4 sem $X 8$ sem \\
\hline & NS & $1 \%$ & $0.1 \%$ \\
\hline \multicolumn{4}{|l|}{ Significante para $\alpha \leq 0.01$} \\
\hline \multicolumn{4}{|l|}{ PERÍMETRO NUCLEAR } \\
\hline \multirow{2}{*}{$\begin{array}{l}\text { Valor de } \mathrm{H}=9.9800 \\
\text { Valor de } \mathrm{x}^{2} \mathrm{p} / 2^{\circ} \text { de liberdade }=9.98 \\
\text { Probabilidade de } \mathrm{H} 0=0.68 \%\end{array}$} & $\begin{array}{c}\text { Controle X } 4 \\
\text { semanas }\end{array}$ & $\begin{array}{c}\text { Controle X } 8 \\
\text { semanas }\end{array}$ & 4 sem $X 8$ sem \\
\hline & NS & $1 \%$ & $0.1 \%$ \\
\hline Significante para $\alpha \leq 0.01$ & & & \\
\hline
\end{tabular}


TABELA 109 - Avaliação dos parâmetros avaliação da forma dos núcleos das células epiteliais da glândula salivar submandibular (ácinos) dos animais controles e tratados com inibidor de protease.

\begin{tabular}{|c|c|c|c|}
\hline $\begin{array}{l}\text { Estrutura } \\
\text { Estudada }\end{array}$ & $\begin{array}{l}\text { Animais } \\
\text { Controle }\end{array}$ & $\begin{array}{c}\text { Tratados - } 4 \\
\text { semanas }\end{array}$ & $\begin{array}{l}\text { Tratados - } \\
8 \text { semanas }\end{array}$ \\
\hline \multirow[t]{3}{*}{$\begin{array}{l}\text { Diâmetro maior/ } \\
\text { Diâmetro menor }\end{array}$} & $\begin{array}{l}1.17 \\
1.18 \\
1.20 \\
1.18 \\
1.18\end{array}$ & $\begin{array}{l}1.21 \\
1.16 \\
1.22 \\
1.15 \\
1.26\end{array}$ & $\begin{array}{l}1.27 \\
1.29 \\
1.23 \\
1.30 \\
1.21\end{array}$ \\
\hline & $1.18 \pm 0.01$ & $1.20 \pm 0.04$ & $1.26 \pm 0.03$ \\
\hline & & 个 & $\uparrow$ \\
\hline \multirow[t]{2}{*}{$\begin{array}{c}\text { Relação } \\
\text { Volume/Área }\end{array}$} & $\begin{array}{l}2.81 \\
2.80 \\
2.71 \\
2.77 \\
2.78\end{array}$ & $\begin{array}{l}2.54 \\
2.83 \\
2.63 \\
2.83 \\
2.66\end{array}$ & $\begin{array}{l}3.18 \\
3.17 \\
3.20 \\
3.37 \\
3.34\end{array}$ \\
\hline & $2.77 \pm 0.03$ & $\begin{array}{c}2.69 \pm 0.12 \\
\downarrow\end{array}$ & $\begin{array}{c}3.25 \pm 0.09 \\
\uparrow\end{array}$ \\
\hline \multirow[t]{3}{*}{ Índice de Contorno } & $\begin{array}{l}3.57 \\
3.58 \\
3.58 \\
3.57 \\
3.58\end{array}$ & $\begin{array}{l}3.58 \\
3.57 \\
3.59 \\
3.57 \\
3.60\end{array}$ & $\begin{array}{l}3.60 \\
3.60 \\
3.58 \\
3.61 \\
3.58\end{array}$ \\
\hline & $3.57 \pm 0.00$ & $3.58 \pm 0.01$ & $3.59 \pm 0.01$ \\
\hline & & $\uparrow$ & $\uparrow$ \\
\hline \multirow[t]{2}{*}{$\begin{array}{l}\text { Coeficiente de } \\
\text { Forma }\end{array}$} & $\begin{array}{l}0.98 \\
0.98 \\
0.98 \\
0.98 \\
0.98\end{array}$ & $\begin{array}{l}0.98 \\
0.98 \\
0.98 \\
0.99 \\
0.97\end{array}$ & $\begin{array}{l}0.97 \\
0.97 \\
0.98 \\
0.97 \\
0.98\end{array}$ \\
\hline & $0.98 \pm 0.00$ & $0.98 \pm 0.00$ & $0.97 \pm 0.00$ \\
\hline \multirow[t]{3}{*}{ Excentricidade } & $\begin{array}{l}0.34 \\
0.36 \\
0.40 \\
0.38 \\
0.36\end{array}$ & $\begin{array}{l}0.42 \\
0.31 \\
0.40 \\
0.31 \\
0.43\end{array}$ & $\begin{array}{l}0.50 \\
0.52 \\
0.45 \\
0.47 \\
0.43\end{array}$ \\
\hline & $0.36 \pm 0.02$ & $0.37 \pm 0.05$ & $0.47 \pm 0.03$ \\
\hline & & 个 & $\uparrow$ \\
\hline
\end{tabular}

Obs: Estão expressos nesta tabela os dados relativos a: Relação Diâmetro maior/Diâmetro menor (DM/dm), Relação volume/área (Vol./Área), coeficiente de forma, índice de contorno, e excentricidade. 
TABELA 110 - Avaliação dos efeitos da utilização de inibidor de protease sobre os parâmetros da forma dos núcleos das células da glândula salivar submandibular (ácinos) dos animais controles e tratados Avaliação pelo teste Kruskal-Wallis

\begin{tabular}{|c|c|c|c|}
\hline \multicolumn{4}{|l|}{ DIÂMETRO MAIOR / DIÂMETRO MEN } \\
\hline \multirow{2}{*}{$\begin{array}{l}\text { Valor de } \mathrm{H}=10.2200 \\
\text { Valor de } \mathrm{x}^{2} \mathrm{p} / 2^{\circ} \text { de liberdade }=10.22 \\
\text { Probabilidade de } \mathrm{H} 0=0.60 \%\end{array}$} & \multirow{2}{*}{$\begin{array}{l}\text { Controle X } 4 \\
\text { semanas } \\
\text { NS }\end{array}$} & \multirow{2}{*}{$\begin{array}{l}\text { Controle X } 8 \\
\text { semanas } \\
1 \%\end{array}$} & \multirow{2}{*}{$\begin{array}{c}4 \mathrm{sem} X 8 \mathrm{sem} \\
5 \%\end{array}$} \\
\hline & & & \\
\hline \multicolumn{4}{|l|}{ Significante para $\alpha \leq 0.01$} \\
\hline \multicolumn{4}{|l|}{ VOLUME NUCLEAR / ÁREA NUCLEAR } \\
\hline \multirow{2}{*}{$\begin{array}{l}\text { Valor de } \mathrm{H}=10.8200 \\
\text { Valor de } \mathrm{x}^{2} \mathrm{p} / 2^{\circ} \text { de liberdade }=10.82 \\
\text { Probabilidade de } \mathrm{H} 0=0.45 \%\end{array}$} & \multirow{2}{*}{$\begin{array}{c}\text { Controle X } 4 \\
\text { semanas } \\
\text { NS }\end{array}$} & \multirow{2}{*}{$\begin{array}{c}\text { Controle X } 8 \\
\text { semanas } \\
1 \%\end{array}$} & 4 sem $X 8$ sem \\
\hline & & & $0.1 \%$ \\
\hline \multicolumn{4}{|l|}{ Significante para $\alpha \leq 0.01$} \\
\hline \multicolumn{4}{|l|}{ ÍNDICE DE CONTORNO } \\
\hline \multirow{2}{*}{$\begin{array}{l}\text { Valor de } \mathrm{H}=9.9800 \\
\text { Valor de } \mathrm{x}^{2} \mathrm{p} / 2^{\circ} \text { de liberdade }=9.98 \\
\text { Probabilidade de } \mathrm{H} 0=0.68 \%\end{array}$} & \multirow{2}{*}{$\begin{array}{l}\text { Controle X } 4 \\
\text { semanas } \\
\text { NS }\end{array}$} & \multirow{2}{*}{$\begin{array}{l}\text { Controle X } 8 \\
\text { semanas } \\
5 \%\end{array}$} & 4 sem $X 8$ sem \\
\hline & & & NS \\
\hline \multicolumn{4}{|l|}{ Significante para $\alpha \leq 0.01$} \\
\hline \multicolumn{4}{|l|}{ COEFICIENTE DE FORMA } \\
\hline \multirow{2}{*}{$\begin{array}{l}\text { Valor de } \mathrm{H}=10.2200 \\
\text { Valor de } \mathrm{x}^{2} \mathrm{p} / 2^{\circ} \text { de liberdade }=10.22 \\
\text { Probabilidade de } \mathrm{H} 0=0.60 \%\end{array}$} & \multirow{2}{*}{$\begin{array}{l}\text { Controle X4 } \\
\text { semanas } \\
\text { NS }\end{array}$} & \multirow{2}{*}{$\begin{array}{l}\text { Controle X } 8 \\
\text { semanas } \\
\text { NS }\end{array}$} & $4 \mathrm{sem} X 8 \mathrm{sem}$ \\
\hline & & & NS \\
\hline \multicolumn{4}{|l|}{ Significante para $\alpha \leq 0.01$} \\
\hline \multicolumn{4}{|l|}{ EXCENTRICIDADE } \\
\hline \multirow{2}{*}{$\begin{array}{l}\text { Valor de } H=10.2200 \\
\text { Valor de } x^{2} p / 2^{\circ} \text { de liberdade }=10.22 \\
\text { Probabilidade de } H 0=0.60 \%\end{array}$} & \multirow{2}{*}{$\begin{array}{l}\text { Controle X } 4 \\
\text { semanas } \\
\text { NS }\end{array}$} & \multirow{2}{*}{$\begin{array}{c}\text { Controle X } 8 \\
\text { semanas } \\
0.1 \%\end{array}$} & 4 sem $X 8$ sem \\
\hline & & & $1 \%$ \\
\hline
\end{tabular}


TABELA 111 - Avaliação do tamanho dos núcleos das células do epitélio da glândula salivar submandibular (ductos estriados) dos animais controle e tratados com inibidor de protease.

\begin{tabular}{|c|c|c|c|}
\hline $\begin{array}{l}\text { Estrutura } \\
\text { Estudada }\end{array}$ & $\begin{array}{l}\text { Animais } \\
\text { Controle }\end{array}$ & $\begin{array}{c}\text { Tratados - } 4 \\
\text { semanas }\end{array}$ & $\begin{array}{c}\text { Tratados }-8 \\
\text { semanas }\end{array}$ \\
\hline \multirow[t]{3}{*}{ Diâmetro maior } & $\begin{array}{l}5.76 \\
5.72 \\
5.96 \\
5.78 \\
5.38\end{array}$ & $\begin{array}{l}4.84 \\
4.76 \\
5.00 \\
4.92 \\
4.56\end{array}$ & $\begin{array}{l}6.70 \\
6.54 \\
6.72 \\
6.64 \\
6.84\end{array}$ \\
\hline & $5.72 \pm 0.21$ & $4.81 \pm 0.16$ & $6.68 \pm 0.11$ \\
\hline & & $\downarrow$ & $\uparrow$ \\
\hline \multirow[t]{3}{*}{ Diâmetro menor } & $\begin{array}{l}4.54 \\
4.74 \\
4.76 \\
4.56 \\
4.76\end{array}$ & $\begin{array}{l}3.44 \\
3.74 \\
3.56 \\
3.66 \\
3.64\end{array}$ & $\begin{array}{l}5.16 \\
5.22 \\
5.38 \\
5.36 \\
5.56\end{array}$ \\
\hline & $4.67 \pm 0.11$ & $3.60 \pm 0.11$ & $5.33 \pm 0.11$ \\
\hline & & $\downarrow$ & $\uparrow$ \\
\hline \multirow[t]{3}{*}{ Volume nuclear } & $\begin{array}{l}64.11 \\
75.92 \\
81.42 \\
71.18 \\
76.20\end{array}$ & $\begin{array}{l}36.39 \\
40.15 \\
40.85 \\
40.80 \\
37.66\end{array}$ & $\begin{array}{l}108.37 \\
106.74 \\
117.03 \\
114.16 \\
126.56\end{array}$ \\
\hline & $73.76 \pm 6.50$ & $39.17 \pm 2.02$ & $114.57 \pm 7.90$ \\
\hline & & $\downarrow$ & $\uparrow$ \\
\hline \multirow[t]{3}{*}{ Área nuclear } & $\begin{array}{l}21.57 \\
20.56 \\
22.43 \\
21.54 \\
19.23\end{array}$ & $\begin{array}{l}13.12 \\
14.03 \\
14.07 \\
14.17 \\
13.26\end{array}$ & $\begin{array}{l}27.24 \\
26.92 \\
28.57 \\
28.09 \\
30.10\end{array}$ \\
\hline & $21.06 \pm 1.22$ & $13.73 \pm 0.49$ & $28.18 \pm 1.25$ \\
\hline & & $\downarrow$ & $\uparrow$ \\
\hline \multirow[t]{3}{*}{ Perímetro nuclear } & $\begin{array}{l}15.63 \\
16.59 \\
16.92 \\
16.22 \\
16.59\end{array}$ & $\begin{array}{l}13.13 \\
13.43 \\
13.58 \\
13.58 \\
13.26\end{array}$ & $\begin{array}{l}18.74 \\
18.56 \\
19.10 \\
18.94 \\
19.56\end{array}$ \\
\hline & $16.39 \pm_{0.49}$ & $13.39 \pm 0.19$ & $18.98 \pm 0.38$ \\
\hline & & $\downarrow$ & $\uparrow$ \\
\hline
\end{tabular}

Obs: Estão expressos nesta tabela os dados relativos a: Diâmetro maior em micrometros $(\mu \mathrm{m})$, diâmetro menor $(\mathrm{em} \mu \mathrm{m})$, perímetro do núcleo celular (em $\mu \mathrm{m})$, área nuclear em micrometros quadrados $\left(\mu \mathrm{m}^{2}\right)$, e volume nuclear em micrometros cúbicos $\left(\mu \mathrm{m}^{3}\right)$. 
TABELA 112 - Avaliação dos efeitos da utilização de inibidor de protease sobre os parâmetros do tamanho dos núcleos das células da glândula salivar submandibular (ductos estriados) dos animais controles e tratados Avaliação pelo teste Kruskal-Wallis

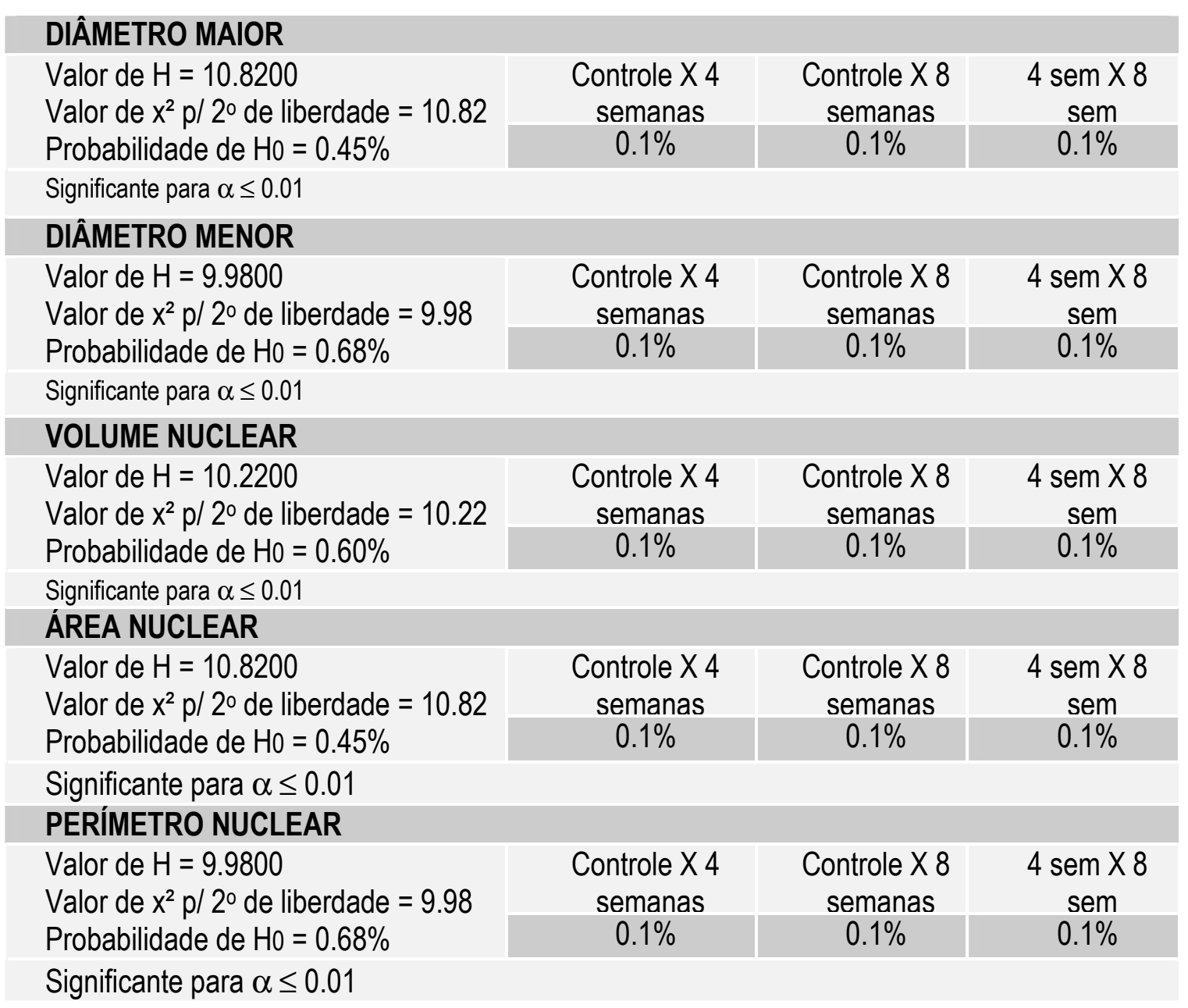


TABELA 113 - Avaliação dos parâmetros avaliação da forma dos núcleos das células epiteliais da glândula saslivar submandibular (ductos estriados) dos animais controles e tratados com inibidor de protease.

\begin{tabular}{|c|c|c|c|}
\hline $\begin{array}{l}\text { Estrutura } \\
\text { Estudada }\end{array}$ & Animais Controle & $\begin{array}{c}\text { Tratados - } 4 \\
\text { semanas }\end{array}$ & $\begin{array}{c}\text { Tratados - } 8 \\
\text { semanas }\end{array}$ \\
\hline \multirow[t]{3}{*}{$\begin{array}{c}\text { Diâmetro } \\
\text { maior/ } \\
\text { Diâmetro } \\
\text { menor }\end{array}$} & $\begin{array}{l}1.23 \\
1.27 \\
1.27 \\
1.23 \\
1.20\end{array}$ & $\begin{array}{l}1.44 \\
1.29 \\
1.44 \\
1.37 \\
1.27\end{array}$ & $\begin{array}{l}1.32 \\
1.27 \\
1.27 \\
1.27 \\
1.26\end{array}$ \\
\hline & $1.24 \pm 0.03$ & $1.36 \pm 0.08$ & $1.27 \pm 0.02$ \\
\hline & & $\uparrow$ & $\uparrow$ \\
\hline \multirow[t]{3}{*}{$\begin{array}{c}\text { Relação } \\
\text { Volume/Área }\end{array}$} & $\begin{array}{l}3.48 \\
3.39 \\
3.54 \\
3.48 \\
3.29\end{array}$ & $\begin{array}{l}2.71 \\
2.80 \\
2.80 \\
2.82 \\
2.71\end{array}$ & $\begin{array}{l}3.91 \\
3.88 \\
3.99 \\
3.96 \\
4.10\end{array}$ \\
\hline & $3.43 \pm 0.09$ & $2.76 \pm 0.05$ & $3.96 \pm 0.08$ \\
\hline & & $\downarrow$ & $\uparrow$ \\
\hline \multirow[t]{3}{*}{$\begin{array}{l}\text { Índice de } \\
\text { Contorno }\end{array}$} & $\begin{array}{l}3.59 \\
3.60 \\
3.60 \\
3.59 \\
3.58\end{array}$ & $\begin{array}{l}3.65 \\
3.61 \\
3.65 \\
3.63 \\
3.60\end{array}$ & $\begin{array}{l}3.61 \\
3.60 \\
3.60 \\
3.60 \\
3.59\end{array}$ \\
\hline & $3.59 \pm 0.00$ & $3.62 \pm 0.02$ & $3.60 \pm 0.00$ \\
\hline & & $\uparrow$ & $\uparrow$ \\
\hline \multirow[t]{3}{*}{$\begin{array}{l}\text { Coeficiente de } \\
\text { Forma }\end{array}$} & $\begin{array}{l}0.98 \\
0.98 \\
0.97 \\
0.97 \\
0.98\end{array}$ & $\begin{array}{l}0.95 \\
0.97 \\
0.94 \\
0.96 \\
0.97\end{array}$ & $\begin{array}{l}0.97 \\
0.97 \\
0.97 \\
0.97 \\
0.98\end{array}$ \\
\hline & $0.97 \pm 0.00$ & $0.95 \pm 0.01$ & $0.97 \pm 0.00$ \\
\hline & & $\downarrow$ & \\
\hline \multirow[t]{3}{*}{ Excentricidade } & $\begin{array}{l}0.42 \\
0.46 \\
0.52 \\
0.52 \\
0.45\end{array}$ & $\begin{array}{l}0.64 \\
0.50 \\
0.60 \\
0.57 \\
0.46\end{array}$ & $\begin{array}{l}0.58 \\
0.52 \\
0.51 \\
0.48 \\
0.50\end{array}$ \\
\hline & $0.47 \pm 0.04$ & $0.55 \pm 0.07$ & $0.51 \pm 0.03$ \\
\hline & & 个 & $\uparrow$ \\
\hline
\end{tabular}

Obs: Estão expressos nesta tabela os dados relativos a: Relação Diâmetro maior/Diâmetro menor (DM/dm), Relação volume/área (Vol./Área), coeficiente de forma, índice de contorno, e excentricidade. 
TABELA 114 - Avaliação dos efeitos da utilização de inibidor de protease sobre os parâmetros da forma dos núcleos das células da glândula salivar submandibular (ductos estriados) dos animais controles e tratados Avaliação pelo teste Kruskal-Wallis

\begin{tabular}{|c|c|c|c|}
\hline \multicolumn{4}{|l|}{ DIÂMETRO MAIOR } \\
\hline \multirow{3}{*}{$\begin{array}{l}\text { Valor de } \mathrm{H}=10.8200 \\
\text { Valor de } \mathrm{x}^{2} \mathrm{p} / 2^{\circ} \text { de liberdade }=10.82 \\
\text { Probabilidade de } \mathrm{H} 0=0.45 \%\end{array}$} & Controle X 4 & Controle X 8 & 4 sem $X 8$ sem \\
\hline & semanas & semanas & \\
\hline & $0.1 \%$ & $0.1 \%$ & $0.1 \%$ \\
\hline \multicolumn{4}{|l|}{ Significante para $\alpha \leq 0.01$} \\
\hline \multicolumn{4}{|l|}{ DIÂMETRO MENOR } \\
\hline \multirow{3}{*}{$\begin{array}{l}\text { Valor de } \mathrm{H}=9.9800 \\
\text { Valor de } \mathrm{x}^{2} \mathrm{p} / 2^{\circ} \text { de liberdade }=9.98 \\
\text { Probabilidade de } \mathrm{H} 0=0.68 \%\end{array}$} & Controle X 4 & Controle X 8 & 4 sem $X 8$ sem \\
\hline & semanas & semanas & \\
\hline & $0.1 \%$ & $0.1 \%$ & $0.1 \%$ \\
\hline \multicolumn{4}{|l|}{ Significante para $\alpha \leq 0.01$} \\
\hline \multicolumn{4}{|l|}{ VOLUME NUCLEAR } \\
\hline \multirow{3}{*}{$\begin{array}{l}\text { Valor de } H=10.2200 \\
\text { Valor de } x^{2} p / 2^{\circ} \text { de liberdade }=10.22 \\
\text { Probabilidade de } \mathrm{H} 0=0.60 \%\end{array}$} & Controle X 4 & Controle X 8 & 4 sem $X 8$ sem \\
\hline & semanas & semanas & \\
\hline & & $0.1 \%$ & $0.1 \%$ \\
\hline \multicolumn{4}{|l|}{ Significante para $\alpha \leq 0.01$} \\
\hline \multicolumn{4}{|l|}{ ÁREA NUCLEAR } \\
\hline \multirow{3}{*}{$\begin{array}{l}\text { Valor de } H=10.8200 \\
\text { Valor de } x^{2} p / 2^{\circ} \text { de liberdade }=10.82 \\
\text { Probabilidade de } H 0=0.45 \%\end{array}$} & Controle X 4 & Controle X 8 & 4 sem $X 8$ sem \\
\hline & semanas & semanas & \\
\hline & $0.1 \%$ & $0.1 \%$ & $0.1 \%$ \\
\hline \multicolumn{4}{|l|}{ Significante para $\alpha \leq 0.01$} \\
\hline \multicolumn{4}{|l|}{ PERÍMETRO NUCLEAR } \\
\hline \multirow{2}{*}{$\begin{array}{l}\text { Valor de } \mathrm{H}=9.9800 \\
\text { Valor de } \mathrm{x}^{2} \mathrm{p} / 2^{\circ} \text { de liberdade }=9.98 \\
\text { Probabilidade de } \mathrm{H} 0=0.68 \%\end{array}$} & Controle X 4 & Controle X 8 & 4 sem $X 8$ sem \\
\hline & $\begin{array}{l}\text { semanas } \\
0.1 \%\end{array}$ & $\begin{array}{l}\text { semanas } \\
0.1 \%\end{array}$ & $0.1 \%$ \\
\hline Significante para $\alpha \leq 0.01$ & & & \\
\hline
\end{tabular}


TABELA 115 - Avaliação do tamanho dos núcleos das células do epitélio da glândula submandibular (ductos granulosos) dos animais controle e tratados com inibidor de protease.

\begin{tabular}{|c|c|c|c|}
\hline $\begin{array}{l}\text { Estrutura } \\
\text { Estudada }\end{array}$ & Animais Controle & $\begin{array}{c}\text { Tratados - } 4 \\
\text { semanas }\end{array}$ & $\begin{array}{c}\text { Tratados - } 8 \\
\text { semanas }\end{array}$ \\
\hline \multirow[t]{2}{*}{ Diâmetro maior } & $\begin{array}{l}5.72 \\
5.78 \\
5.74 \\
5.82 \\
5.78\end{array}$ & $\begin{array}{l}4.36 \\
4.46 \\
4.14 \\
4.52 \\
4.34\end{array}$ & $\begin{array}{l}5.62 \\
5.98 \\
5.82 \\
5.58 \\
5.84\end{array}$ \\
\hline & $5.76 \pm 0.03$ & $\begin{array}{c}4.36 \pm 0.14 \\
\downarrow\end{array}$ & $5.76 \pm 0.16$ \\
\hline \multirow[t]{3}{*}{$\begin{array}{l}\text { Diâmetro } \\
\text { menor }\end{array}$} & $\begin{array}{l}4.54 \\
4.74 \\
4.72 \\
4.80 \\
4.61\end{array}$ & $\begin{array}{l}3.52 \\
3.86 \\
3.42 \\
3.86 \\
3.56\end{array}$ & $\begin{array}{l}4.58 \\
4.60 \\
4.62 \\
4.60 \\
4.96\end{array}$ \\
\hline & $4.68 \pm 0.10$ & $3.64 \pm 0.20$ & $4.67 \pm 0.16$ \\
\hline & & $\downarrow$ & $\downarrow$ \\
\hline \multirow[t]{3}{*}{ Volume nuclear } & $\begin{array}{l}71.17 \\
76.20 \\
63.12 \\
71.37 \\
70.11\end{array}$ & $\begin{array}{l}32.37 \\
38.77 \\
29.25 \\
38.55 \\
32.94\end{array}$ & $\begin{array}{l}70.13 \\
77.51 \\
74.20 \\
69.54 \\
83.09\end{array}$ \\
\hline & $70.39 \pm 4.69$ & $34.37 \pm 4.15$ & $74.89 \pm 5.60$ \\
\hline & & $\downarrow$ & $\uparrow$ \\
\hline \multirow[t]{3}{*}{ Área nuclear } & $\begin{array}{l}21.43 \\
20.23 \\
21.19 \\
22.71 \\
19.23\end{array}$ & $\begin{array}{l}12.11 \\
13.65 \\
11.26 \\
13.70 \\
12.64\end{array}$ & $\begin{array}{l}20.33 \\
21.71 \\
21.17 \\
20.26 \\
22.82\end{array}$ \\
\hline & $20.95 \pm 1.30$ & $12.67 \pm 1.03$ & $21.25 \pm 1.06$ \\
\hline & & $\downarrow$ & $\uparrow$ \\
\hline \multirow[t]{3}{*}{$\begin{array}{l}\text { Perímetro } \\
\text { nuclear }\end{array}$} & $\begin{array}{l}17.19 \\
16.59 \\
17.42 \\
17.78 \\
16.59\end{array}$ & $\begin{array}{l}12.44 \\
13.10 \\
11.92 \\
13.21 \\
12.46\end{array}$ & $\begin{array}{l}16.09 \\
16.72 \\
16.48 \\
16.04 \\
17.02\end{array}$ \\
\hline & $17.11 \pm 0.52$ & $12.62 \pm 0.53$ & $16.47 \pm 0.41$ \\
\hline & & $\downarrow$ & $\downarrow$ \\
\hline
\end{tabular}

Obs: Estão expressos nesta tabela os dados relativos a: Diâmetro maior em micrometros $(\mu \mathrm{m})$, diâmetro menor $(\mathrm{em} \mu \mathrm{m})$, perímetro do núcleo celular (em $\mu \mathrm{m})$, área nuclear em micrometros quadrados $\left(\mu \mathrm{m}^{2}\right)$, e volume nuclear em micrometros cúbicos $\left(\mu \mathrm{m}^{3}\right)$. 
TABELA 116 - Avaliação dos efeitos da utilização de inibidor de protease sobre os parâmetros do tamanho dos núcleos das células da glândula salivar submandibular (ductos granulosos) dos animais controles e tratados - Avaliação pelo teste Kruskal-Wallis

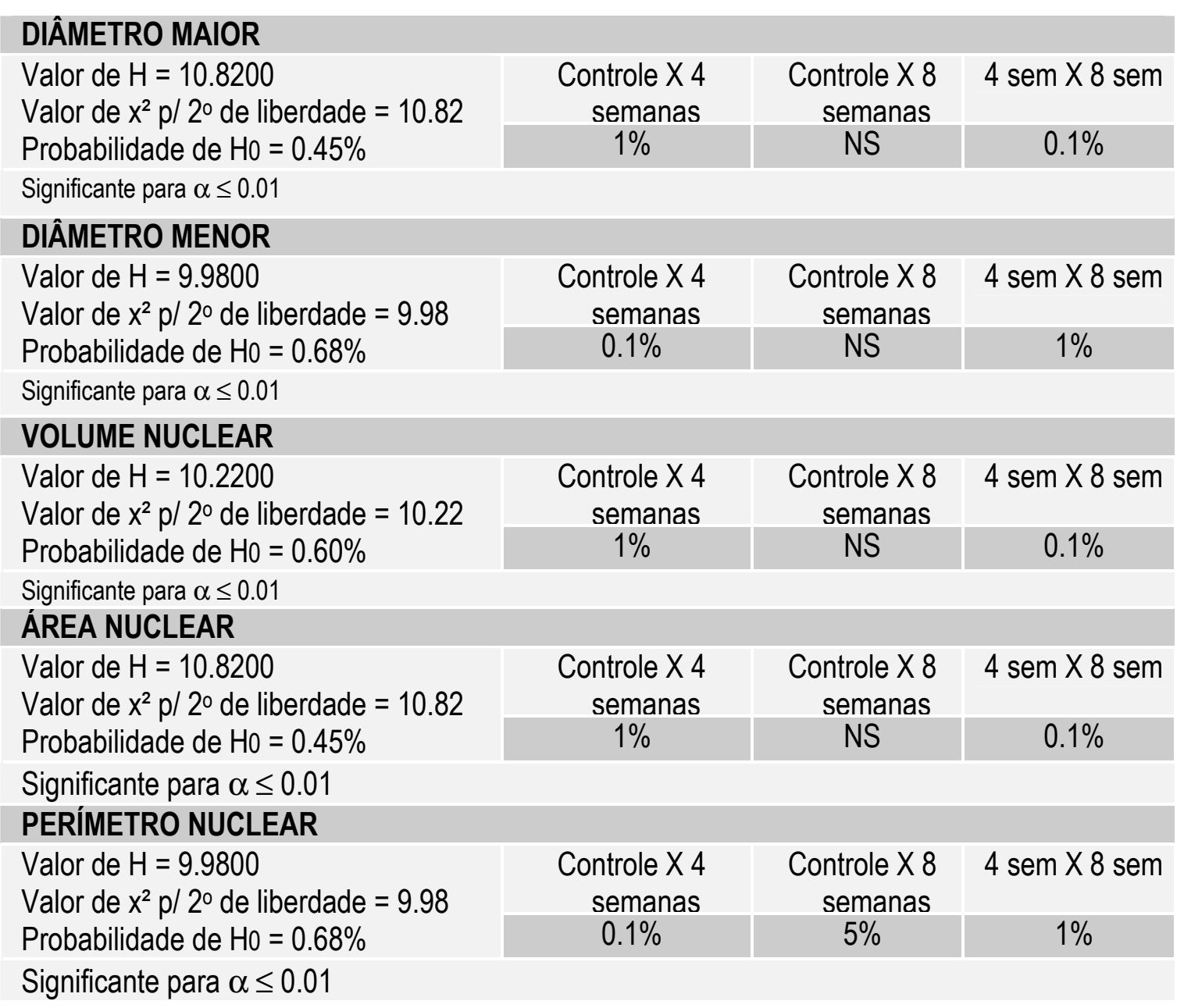


TABELA 117 - Avaliação dos parâmetros avaliação da forma dos núcleos das células epiteliais da glândula salivar submandibular (ductos granulosos) dos animais controles e tratados com inibidor de protease.

\begin{tabular}{|c|c|c|c|}
\hline $\begin{array}{l}\text { Estrutura } \\
\text { Estudada }\end{array}$ & Animais Controle & $\begin{array}{c}\text { Tratados - } 4 \\
\text { semanas }\end{array}$ & $\begin{array}{c}\text { Tratados - } 8 \\
\text { semanas }\end{array}$ \\
\hline \multirow[t]{2}{*}{$\begin{array}{l}\text { Diâmetro maior/ } \\
\text { Diâmetro menor }\end{array}$} & $\begin{array}{l}1.28 \\
1.27 \\
1.27 \\
1.29 \\
1.26\end{array}$ & $\begin{array}{l}1.27 \\
1.17 \\
1.23 \\
1.19 \\
1.24\end{array}$ & $\begin{array}{l}1.24 \\
1.33 \\
1.28 \\
1.22 \\
1.19\end{array}$ \\
\hline & $1.27 \pm 0.01$ & $\frac{1.22 \pm 0.04}{\Downarrow}$ & $\begin{array}{c}1.25 \pm 0.05 \\
\downarrow\end{array}$ \\
\hline \multirow[t]{2}{*}{$\begin{array}{c}\text { Relação } \\
\text { Volume/Área }\end{array}$} & $\begin{array}{l}3.58 \\
3.58 \\
3.39 \\
3.37 \\
3.48\end{array}$ & $\begin{array}{l}2.60 \\
2.76 \\
2.50 \\
2.77 \\
2.61\end{array}$ & $\begin{array}{l}3.37 \\
3.48 \\
3.45 \\
3.37 \\
3.58\end{array}$ \\
\hline & $3.48 \pm 0.10$ & $2.64 \pm 0.11$ & $3.45 \pm 0.08$ \\
\hline \multirow[t]{3}{*}{$\begin{array}{l}\text { Índice de } \\
\text { Contorno }\end{array}$} & $\begin{array}{l}3.60 \\
3.61 \\
3.59 \\
3.60 \\
3.60\end{array}$ & $\begin{array}{l}3.60 \\
3.57 \\
3.59 \\
3.58 \\
3.59\end{array}$ & $\begin{array}{l}3.59 \\
3.61 \\
3.60 \\
3.58 \\
3.58\end{array}$ \\
\hline & $3.60 \pm 0.00$ & $3.22 \pm 0.49$ & $3.59 \pm 0.01$ \\
\hline & & $\downarrow$ & $\downarrow$ \\
\hline \multirow[t]{2}{*}{$\begin{array}{l}\text { Coeficiente de } \\
\text { Forma }\end{array}$} & $\begin{array}{l}0.98 \\
0.97 \\
0.97 \\
0.97 \\
0.98\end{array}$ & $\begin{array}{l}0.97 \\
0.98 \\
0.98 \\
0.98 \\
0.98\end{array}$ & $\begin{array}{l}0.98 \\
0.96 \\
0.97 \\
0.98 \\
0.98\end{array}$ \\
\hline & $0.97 \pm 0.00$ & $0.97 \pm 0.00$ & $0.97 \pm 0.00$ \\
\hline \multirow[t]{2}{*}{ Excentricidade } & $\begin{array}{l}0.54 \\
0.59 \\
0.60 \\
0.61 \\
0.57\end{array}$ & $\begin{array}{l}0.45 \\
0.34 \\
0.42 \\
0.34 \\
0.43\end{array}$ & $\begin{array}{l}0.46 \\
0.56 \\
0.52 \\
0.48 \\
0.39\end{array}$ \\
\hline & $0.58 \pm 0.02$ & $\frac{0.39 \pm 0.05}{\downarrow}$ & $0.48 \pm 0.06$ \\
\hline
\end{tabular}

Obs: Estão expressos nesta tabela os dados relativos a: Relação Diâmetro maior/Diâmetro menor (DM/dm), Relação volume/área (Vol./Área), coeficiente de forma, índice de contorno, e excentricidade. 
TABELA 118 - Avaliação dos efeitos da utilização de inibidor de protease sobre os parâmetros da forma dos núcleos das células da glândula submandibular (ductos granulosos) dos animais controles e tratados - Avaliação pelo teste Kruskal-Wallis

\begin{tabular}{|c|c|c|c|}
\hline \multicolumn{4}{|c|}{ DIÂMETRO MAIOR / DIÂMETRO MENOR } \\
\hline \multirow{2}{*}{$\begin{array}{l}\text { Valor de } H=10.2200 \\
\text { Valor de } x^{2} p / 2^{\circ} \text { de liberdade }=10.22 \\
\text { Probabilidade de } H 0=0.60 \%\end{array}$} & $\begin{array}{c}\text { Controle X } 4 \\
\text { semanas }\end{array}$ & $\begin{array}{c}\text { Controle X } 8 \\
\text { semanas }\end{array}$ & 4 sem $X 8$ sem \\
\hline & $5 \%$ & & NS \\
\hline \multicolumn{4}{|l|}{ Significante para $\alpha \leq 0.01$} \\
\hline \multicolumn{4}{|l|}{ VOLUME NUCLEAR / ÁREA NUCLEAR } \\
\hline \multirow{2}{*}{$\begin{array}{l}\text { Valor de } \mathrm{H}=10.8200 \\
\text { Valor de } \mathrm{x}^{2} \mathrm{p} / 2^{\circ} \text { de liberdade }=10.82 \\
\text { Probabilidade de } \mathrm{H} 0=0.45 \%\end{array}$} & $\begin{array}{c}\text { Controle X } 4 \\
\text { semanas }\end{array}$ & $\begin{array}{c}\text { Controle X } 8 \\
\text { semanas }\end{array}$ & 4 sem $X 8$ sem \\
\hline & $0.1 \%$ & NS & $1 \%$ \\
\hline \multicolumn{4}{|l|}{ Significante para $\alpha \leq 0.01$} \\
\hline \multicolumn{4}{|l|}{ ÍNDICE DE CONTORNO } \\
\hline \multirow{2}{*}{$\begin{array}{l}\text { Valor de } \mathrm{H}=9.9800 \\
\text { Valor de } \mathrm{x}^{2} \mathrm{p} / 2^{\circ} \text { de liberdade }=9.98 \\
\text { Probabilidade de } \mathrm{H} 0=0.68 \%\end{array}$} & $\begin{array}{c}\text { Controle X } 4 \\
\text { semanas }\end{array}$ & $\begin{array}{c}\text { Controle X } 8 \\
\text { semanas }\end{array}$ & 4 sem $X 8$ sem \\
\hline & NS & NS & NS \\
\hline \multicolumn{4}{|l|}{ Significante para $\alpha \leq 0.01$} \\
\hline \multicolumn{4}{|l|}{ COEFICIENTE DE FORMA } \\
\hline \multirow{2}{*}{$\begin{array}{l}\text { Valor de } \mathrm{H}=10.2200 \\
\text { Valor de } \mathrm{x}^{2} \mathrm{p} / 2^{\circ} \text { de liberdade }=10.22 \\
\text { Probabilidade de } \mathrm{H} 0=0.60 \%\end{array}$} & $\begin{array}{c}\text { Controle X } 4 \\
\text { semanas }\end{array}$ & $\begin{array}{c}\text { Controle X } 8 \\
\text { semanas }\end{array}$ & 4 sem $X 8$ sem \\
\hline & & & NS \\
\hline \multicolumn{4}{|l|}{ Significante para $\alpha \leq 0.01$} \\
\hline \multicolumn{4}{|l|}{ EXCENTRICIDADE } \\
\hline \multirow{2}{*}{$\begin{array}{l}\text { Valor de } \mathrm{H}=10.2200 \\
\text { Valor de } \mathrm{x}^{2} \mathrm{p} / 2^{\circ} \text { de liberdade }=10.22 \\
\text { Probabilidade de } \mathrm{H} 0=0.60 \%\end{array}$} & $\begin{array}{c}\text { Controle X } 4 \\
\text { semanas }\end{array}$ & $\begin{array}{c}\text { Controle X } 8 \\
\text { semanas }\end{array}$ & 4 sem $X 8$ sem \\
\hline & $0.1 \%$ & $1 \%$ & $5 \%$ \\
\hline
\end{tabular}


TABELA 119 - Avaliação do tamanho dos núcleos das células do epitélio da glândula submandibular (ductos excretores) dos animais controle e tratados com inibidor de protease.

\begin{tabular}{|c|c|c|c|}
\hline $\begin{array}{l}\text { Estrutura } \\
\text { Estudada }\end{array}$ & Animais Controle & $\begin{array}{c}\text { Tratados - } 4 \\
\text { semanas }\end{array}$ & $\begin{array}{c}\text { Tratados - } 8 \\
\text { semanas }\end{array}$ \\
\hline \multirow[t]{3}{*}{ Diâmetro maior } & $\begin{array}{l}6.14 \\
6.14 \\
6.30 \\
6.18 \\
6.36\end{array}$ & $\begin{array}{l}4.96 \\
5.48 \\
5.72 \\
5.22 \\
5.32\end{array}$ & $\begin{array}{l}6.80 \\
6.18 \\
6.34 \\
6.46 \\
6.88\end{array}$ \\
\hline & $6.22 \pm 0.10$ & $5.34 \pm_{0.28}$ & $6.53 \pm_{0.29}$ \\
\hline & & $\downarrow$ & $\uparrow$ \\
\hline \multirow[t]{3}{*}{$\begin{array}{l}\text { Diâmetro } \\
\text { menor }\end{array}$} & $\begin{array}{l}4.80 \\
4.69 \\
4.70 \\
4.74 \\
4.58\end{array}$ & $\begin{array}{l}3.92 \\
4.28 \\
4.10 \\
4.34 \\
4.16\end{array}$ & $\begin{array}{l}5.38 \\
5.30 \\
5.12 \\
5.00 \\
5.10\end{array}$ \\
\hline & $4.70 \pm 0.08$ & $4.16 \pm 0.16$ & $5.18 \pm 0.15$ \\
\hline & & $v$ & $\uparrow$ \\
\hline \multirow[t]{3}{*}{$\begin{array}{l}\text { Volume } \\
\text { nuclear }\end{array}$} & $\begin{array}{l}89.27 \\
83.11 \\
85.22 \\
84.11 \\
78.97\end{array}$ & $\begin{array}{l}46.59 \\
60.89 \\
60.92 \\
58.13 \\
55.77\end{array}$ & $\begin{array}{c}118.94 \\
100.28 \\
99.31 \\
98.11 \\
110.45\end{array}$ \\
\hline & $84.13 \pm 3.71$ & $56.46 \pm 5.92$ & $105.41 \pm 9.01$ \\
\hline & & $\downarrow$ & $\uparrow$ \\
\hline \multirow[t]{3}{*}{ Área nuclear } & $\begin{array}{l}22.10 \\
22.95 \\
23.25 \\
22.81 \\
23.99\end{array}$ & $\begin{array}{l}15.43 \\
18.49 \\
18.52 \\
17.91 \\
17.45\end{array}$ & $\begin{array}{l}28.89 \\
25.84 \\
25.64 \\
25.45 \\
27.60\end{array}$ \\
\hline & $23.02 \pm 0.68$ & $17.56 \pm 1.27$ & $26.68 \pm 1.50$ \\
\hline & & $\downarrow$ & $\uparrow$ \\
\hline \multirow[t]{3}{*}{$\begin{array}{c}\text { Perímetro } \\
\text { nuclear }\end{array}$} & $\begin{array}{l}16.95 \\
17.19 \\
17.40 \\
17.16 \\
17.64\end{array}$ & $\begin{array}{l}14.02 \\
15.42 \\
15.55 \\
15.07 \\
14.97\end{array}$ & $\begin{array}{l}19.23 \\
18.08 \\
18.08 \\
18.11 \\
18.95\end{array}$ \\
\hline & $17.26 \pm_{0.26}$ & $15.00 \pm 0.60$ & $18.49 \pm 0.55$ \\
\hline & & $\downarrow$ & $\uparrow$ \\
\hline
\end{tabular}

Obs: Estão expressos nesta tabela os dados relativos a: Diâmetro maior em micrometros $(\mu \mathrm{m})$, diâmetro menor $(\mathrm{em} \mu \mathrm{m})$, perímetro do núcleo celular $(\mathrm{em} \mu \mathrm{m})$, área nuclear em micrometros quadrados $\left(\mu \mathrm{m}^{2}\right)$, e volume nuclear em micrometros cúbicos $\left(\mu \mathrm{m}^{3}\right)$. 
TABELA 120 - Avaliação dos efeitos da utilização de inibidor de protease sobre os parâmetros do tamanho dos núcleos das células da glândula submandibular (ductos excretores) dos animais controles e tratados - Avaliação pelo teste Kruskal-Wallis

\section{DIÂMETRO MAIOR}

Valor de $\mathrm{H}=10.8200$

Valor de $x^{2} p / 2^{\circ}$ de liberdade $=10.82$

Probabilidade de $\mathrm{H} 0=0.45 \%$

\begin{tabular}{|c|c|c|}
\hline $\begin{array}{c}\text { Controle } \mathrm{X} 4 \\
\text { semanas } \\
1 \%\end{array}$ & $\begin{array}{c}\text { Controle } \mathrm{X} 8 \\
\text { semanas }\end{array}$ & 4 sem $\mathrm{X} 8 \mathrm{sem}$ \\
\hline $5 \%$ & $0.1 \%$ \\
\hline
\end{tabular}

Significante para $\alpha \leq 0.01$

\section{DIÂMETRO MENOR}

Valor de $\mathrm{H}=9.9800$

Valor de $\mathrm{x}^{2} \mathrm{p} / 2^{\circ}$ de liberdade $=9.98$

Probabilidade de $\mathrm{H} 0=0.68 \%$

\begin{tabular}{|c|c|c|}
\hline $\begin{array}{c}\text { Controle } \mathrm{X} 4 \\
\text { semanas }\end{array}$ & $\begin{array}{c}\text { Controle } \mathrm{X} 8 \\
\text { semanas }\end{array}$ & 4 sem $\mathrm{X} 8 \mathrm{sem}$ \\
\hline $0.1 \%$ & $0.1 \%$ & $0.1 \%$ \\
\hline
\end{tabular}

Significante para $\alpha \leq 0.01$

\section{VOLUME NUCLEAR}

Valor de $\mathrm{H}=10.2200$

Valor de $x^{2} p / 20$ de liberdade $=10.22$

Probabilidade de $\mathrm{H} 0=0.60 \%$

Controle X 4 semanas $0.1 \%$
Controle X 8 semanas $0.1 \%$

4 sem $X 8$ sem

Significante para $\alpha \leq 0.01$

\section{ÁREA NUCLEAR}

Valor de $\mathrm{H}=10.8200$

Valor de $x^{2} p / 2^{\circ}$ de liberdade $=10.82$

Probabilidade de $\mathrm{H} 0=0.45 \%$

Controle X 4
semanas
$0.1 \%$

\begin{tabular}{c|c}
$\begin{array}{c}\text { Controle X 8 } \\
\text { semanas } \\
0.1 \%\end{array}$ & 4 sem $\mathrm{X} 8$ sem \\
\hline & $0.1 \%$ \\
\hline
\end{tabular}

Significante para $\alpha \leq 0.01$

\section{PERÍMETRO NUCLEAR}

Valor de $\mathrm{H}=9.9800$

Valor de $x^{2} p / 2^{\circ}$ de liberdade $=9.98$

Probabilidade de $\mathrm{H} 0=0.68 \%$

Controle X 4
semanas
$0.1 \%$

Controle X 8 semanas $0.1 \%$ 4 sem $X 8$ sem

Significante para $\alpha \leq 0.01$ 
TABELA 121 - Avaliação dos parâmetros avaliação da forma dos núcleos das células epiteliais da glândula submandibular (ductos excretores) dos animais controles e tratados com inibidor de protease.

\begin{tabular}{|c|c|c|c|}
\hline $\begin{array}{l}\text { Estrutura } \\
\text { Estudada }\end{array}$ & Animais Controle & $\begin{array}{c}\text { Tratados - } 4 \\
\text { semanas }\end{array}$ & Tratados - 8 semanas \\
\hline \multirow[t]{3}{*}{$\begin{array}{l}\text { Diâmetro maior/ } \\
\text { Diâmetro menor }\end{array}$} & $\begin{array}{l}1.36 \\
1.32 \\
1.37 \\
1.34 \\
1.35\end{array}$ & $\begin{array}{l}1.28 \\
1.30 \\
1.41 \\
1.22 \\
1.30\end{array}$ & $\begin{array}{l}1.29 \\
1.18 \\
1.26 \\
1.31 \\
1.37\end{array}$ \\
\hline & $1.34 \pm 0.01$ & $1.30 \pm 0.06$ & $1.28 \pm 0.06$ \\
\hline & & $v$ & $v$ \\
\hline \multirow[t]{3}{*}{$\begin{array}{c}\text { Relação } \\
\text { Volume/Área }\end{array}$} & $\begin{array}{l}3.52 \\
3.58 \\
3.61 \\
3.58 \\
3.67\end{array}$ & $\begin{array}{l}2.93 \\
3.22 \\
3.22 \\
3.16 \\
3.12\end{array}$ & $\begin{array}{l}4.02 \\
3.81 \\
3.79 \\
3.77 \\
3.94\end{array}$ \\
\hline & $3.59 \pm 0.05$ & $3.13 \pm 0.11$ & $3.86 \pm 0.10$ \\
\hline & & $\downarrow$ & $\uparrow$ \\
\hline \multirow[t]{3}{*}{$\begin{array}{l}\text { Índice de } \\
\text { Contorno }\end{array}$} & $\begin{array}{l}3.62 \\
3.61 \\
3.62 \\
3.61 \\
3.62\end{array}$ & $\begin{array}{l}3.60 \\
3.61 \\
3.63 \\
3.58 \\
3.61\end{array}$ & $\begin{array}{l}3.60 \\
3.58 \\
3.59 \\
3.61 \\
3.62\end{array}$ \\
\hline & $3.61 \pm 0.00$ & $3.60 \pm 0.01$ & $3.60 \pm 0.01$ \\
\hline & & $v$ & $v$ \\
\hline \multirow[t]{3}{*}{$\begin{array}{l}\text { Coeficiente de } \\
\text { Forma }\end{array}$} & $\begin{array}{l}0.96 \\
0.96 \\
0.96 \\
0.96 \\
0.96\end{array}$ & $\begin{array}{l}0.97 \\
0.97 \\
0.95 \\
0.98 \\
0.97\end{array}$ & $\begin{array}{l}0.97 \\
0.98 \\
0.97 \\
0.97 \\
0.96\end{array}$ \\
\hline & $0.96 \pm 0.00$ & $0.96 \pm 0.01$ & $0.97 \pm 0.00$ \\
\hline & & $v$ & $\uparrow$ \\
\hline \multirow[t]{3}{*}{ Excentricidade } & $\begin{array}{l}0.60 \\
0.54 \\
0.60 \\
0.62 \\
0.59\end{array}$ & $\begin{array}{l}0.52 \\
0.50 \\
0.65 \\
0.41 \\
0.52\end{array}$ & $\begin{array}{l}0.52 \\
0.39 \\
0.49 \\
0.53 \\
0.61\end{array}$ \\
\hline & $0.59 \pm_{0.03}$ & $0.52 \pm_{0.08}$ & $0.50 \pm 0.07$ \\
\hline & & $\downarrow$ & $\downarrow$ \\
\hline
\end{tabular}

Obs: Estão expressos nesta tabela os dados relativos a: Relação Diâmetro maior/Diâmetro menor (DM/dm), Relação volume/área (Vol./Área), coeficiente de forma, índice de contorno, e excentricidade. 
TABELA 122 - Avaliação dos efeitos da utilização de inibidor de protease sobre os parâmetros da forma dos núcleos das células da glândula submandibular (ductos excretores) dos animais controles e tratados - Avaliação pelo teste Kruskal-Wallis

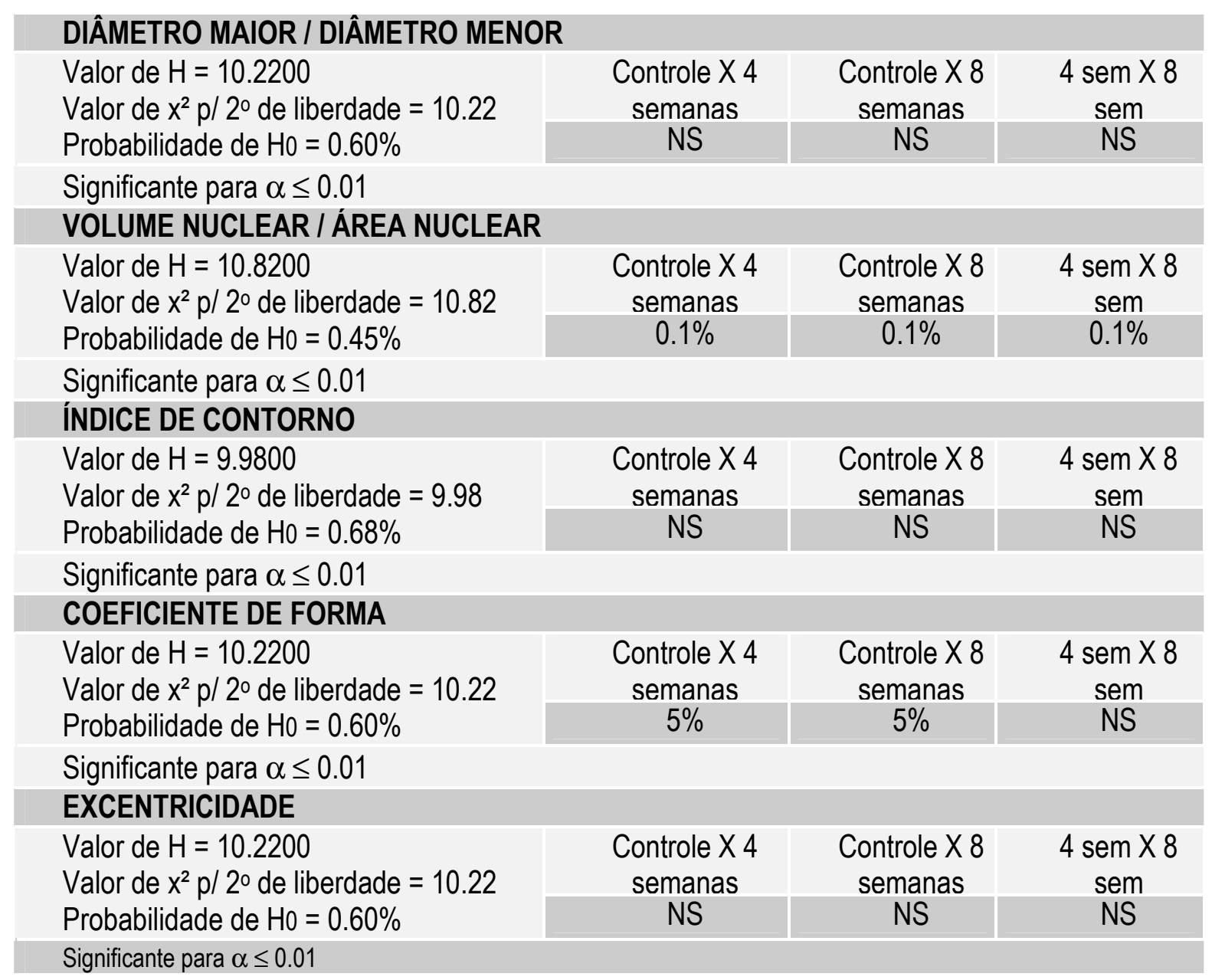




\subsubsection{Estereologia das glândulas salivares submandibulares}

TABELA 123 - Valores médios dos diâmetro médio e espessura da parede $(\mu \mathrm{m})$ dos ácinos, ductos granulosos, estriados e excretores da glândula submandibular dos animais controles e tratados com inibidor de protease (ritonavir).

\begin{tabular}{|c|c|c|c|c|c|c|}
\hline \multirow{2}{*}{$\begin{array}{l}\text { Estrutura } \\
\text { Estudada }\end{array}$} & \multicolumn{2}{|c|}{ Animais Controle } & \multicolumn{2}{|c|}{ Tratados - 4 semanas } & \multicolumn{2}{|c|}{ Tratados - 8 semanas } \\
\hline & $\begin{array}{l}\text { Diâmetro } \\
\text { médio }\end{array}$ & $\begin{array}{c}\text { Espessura da } \\
\text { parede }\end{array}$ & $\begin{array}{l}\text { Diâmetro } \\
\text { médio }\end{array}$ & $\begin{array}{c}\text { Espessura da } \\
\text { parede }\end{array}$ & $\begin{array}{l}\text { Diâmetro } \\
\text { médio }\end{array}$ & $\begin{array}{c}\text { Espessura da } \\
\text { parede }\end{array}$ \\
\hline \multirow[t]{3}{*}{ Ácinos } & $\begin{array}{l}27.1 \\
21.4 \\
25.0 \\
20.6 \\
23.4\end{array}$ & $\begin{array}{c}11.55 \\
8.91 \\
10.45 \\
8.68 \\
9.77\end{array}$ & $\begin{array}{l}27.3 \\
23.1 \\
23.2 \\
21.2 \\
26.4\end{array}$ & $\begin{array}{c}11.65 \\
9.71 \\
9.88 \\
8.92 \\
11.07\end{array}$ & $\begin{array}{l}23.4 \\
23.2 \\
21.4 \\
23.3 \\
25.6\end{array}$ & $\begin{array}{c}10.04 \\
9.16 \\
9.58 \\
9.90 \\
11.02\end{array}$ \\
\hline & $23.50 \pm 0.03$ & $9.872 \pm 0.03$ & $24.24 \pm 0.02$ & $10.24 \pm 1.09$ & $23.34 \pm 0.12$ & $10.22 . \pm 0.12$ \\
\hline & & & $\uparrow$ & $\uparrow$ & $\uparrow$ & $\uparrow$ \\
\hline \multirow[t]{2}{*}{$\begin{array}{l}\text { Ducto } \\
\text { granuloso }\end{array}$} & $\begin{array}{l}27.2 \\
22.0 \\
24.6 \\
23.5 \\
25.6\end{array}$ & $\begin{array}{l}11.03 \\
09.18 \\
08.79 \\
10.06 \\
10.98\end{array}$ & $\begin{array}{l}28.6 \\
29.6 \\
27.9 \\
26.4 \\
25.3\end{array}$ & $\begin{array}{l}10.76 \\
12.27 \\
12.12 \\
11.55 \\
10.97\end{array}$ & $\begin{array}{l}38.0 \\
25.5 \\
27.2 \\
29.9 \\
34.2\end{array}$ & $\begin{array}{l}17.10 \\
10.60 \\
11.95 \\
13.10 \\
15.02\end{array}$ \\
\hline & $24.58 \pm 0.23$ & $10.00 \pm 1.01$ & $\begin{array}{c}27.56 \pm 1.71 \\
\uparrow\end{array}$ & $\begin{array}{c}11.53 \pm 0.67 \\
\uparrow\end{array}$ & $\begin{array}{c}30.96 \pm 5.12 \\
\uparrow\end{array}$ & $\begin{array}{c}13.55 \pm 2.56 \\
\uparrow\end{array}$ \\
\hline \multirow[t]{3}{*}{$\begin{array}{l}\text { Ducto } \\
\text { estriado }\end{array}$} & $\begin{array}{l}25.7 \\
28.6 \\
24.1 \\
29.1 \\
23.6\end{array}$ & $\begin{array}{c}10.00 \\
11.55 \\
10.20 \\
11.79 \\
8.62\end{array}$ & $\begin{array}{l}35.9 \\
35.1 \\
34.0 \\
37.1 \\
32.9\end{array}$ & $\begin{array}{l}12.68 \\
11.97 \\
11.50 \\
14.08 \\
11.33\end{array}$ & $\begin{array}{l}36.6 \\
30.9 \\
32.3 \\
36.3 \\
34.6\end{array}$ & $\begin{array}{l}13.78 \\
10.36 \\
14.83 \\
14.32 \\
13.30\end{array}$ \\
\hline & $25.62 \pm 2.15$ & $10.43 \pm 1.28$ & $35.00 \pm 1.63$ & $12.31 \pm 1.11$ & $34.14 \pm 2.49$ & $13.31 \pm 1.75$ \\
\hline & & & $\uparrow$ & $\uparrow$ & $\uparrow$ & $\uparrow$ \\
\hline \multirow[t]{3}{*}{$\begin{array}{l}\text { Ducto } \\
\text { excretor }\end{array}$} & $\begin{array}{l}30.8 \\
37.3 \\
30.7 \\
29.7 \\
36.4\end{array}$ & $\begin{array}{l}11.10 \\
13.18 \\
12.26 \\
11.99 \\
11.96\end{array}$ & $\begin{array}{c}42.9 \\
36.8 \\
42.8 \\
38.8 \\
40.01\end{array}$ & $\begin{array}{l}15.34 \\
12.56 \\
12.00 \\
13.67 \\
13.93\end{array}$ & $\begin{array}{l}46.4 \\
37.0 \\
41.2 \\
38.3 \\
44.6\end{array}$ & $\begin{array}{c}12.6 \\
11.63 \\
11.00 \\
12.64 \\
15.32\end{array}$ \\
\hline & $32.98 \pm 3.57$ & $12.09 \pm 0.74$ & $40.26 \pm 2.62$ & $13.50 \pm 1.30$ & $41.50 \pm 4.00$ & $12.63 \pm 1.65$ \\
\hline & & & $\uparrow$ & $\uparrow$ & $\uparrow$ & $\uparrow$ \\
\hline
\end{tabular}


TABELA 124 - Avaliação dos efeitos da utilização de inibidor de protease sobre os diâmetros médios (DM) e as espessuras de parede (EP) dos ácinos e ductos da glândula submandibular (ductos excretores) dos animais controles e tratados - Avaliação pelo teste Kruskal-Wallis

\begin{tabular}{|c|c|c|c|c|c|c|}
\hline \multicolumn{7}{|c|}{ DIÂMETRO MÉDIO E ESPESSURA DA PAREDE DOS ÁCINOS } \\
\hline \multirow{3}{*}{$\begin{array}{l}\text { Valor de } \mathrm{H}=\mathrm{DM}=0.0352 ; \mathrm{EP}= \\
0.5000 \\
\text { Valor de } \mathrm{x}^{2} \mathrm{p} / 2^{\circ} \text { de liberdade }= \\
\mathrm{DM}=10.22 ; \mathrm{EP}=0.50 \\
\text { Probabilidade de } \mathrm{H} 0=\mathrm{DM}=0.60 \% \text {; EP } \\
=77,88 \%\end{array}$} & \multicolumn{2}{|c|}{$\begin{array}{l}\text { Controle X } 4 \\
\text { semanas }\end{array}$} & \multicolumn{2}{|c|}{$\begin{array}{l}\text { Controle X } 8 \\
\text { semanas }\end{array}$} & \multicolumn{2}{|c|}{$\begin{array}{l}4 \text { sem } X 8 \\
\text { sem }\end{array}$} \\
\hline & $\mathrm{DM}$ & EP & DM & $\mathrm{EP}$ & DM & EP \\
\hline & NS & NS & NS & NS & NS & NS \\
\hline \multicolumn{7}{|l|}{ SN = Não Significante } \\
\hline \multicolumn{7}{|l|}{ DUCTO GRANULOSO } \\
\hline \multirow{3}{*}{$\begin{array}{l}\text { Valor de } \mathrm{H}=\mathrm{DM}=6.3764 ; \mathrm{EP}=6.2600 \\
\text { Valor de } \mathrm{x}^{2} \mathrm{p} / 2^{\circ} \text { de liberdade }=\mathrm{DM}= \\
10.82 ; \mathrm{EP}=6.26 \\
\text { Probabilidade de } \mathrm{H} 0=\mathrm{DM}=0.45 \% ; \mathrm{EP} \\
=4.37 \%\end{array}$} & \multicolumn{2}{|c|}{$\begin{array}{l}\text { Controle X } 4 \\
\text { semanas }\end{array}$} & \multicolumn{2}{|c|}{$\begin{array}{l}\text { Controle X } 8 \\
\text { semanas }\end{array}$} & \multicolumn{2}{|c|}{$\begin{array}{l}4 \operatorname{sem} X 8 \\
\text { sem }\end{array}$} \\
\hline & DM & $E P$ & DM & EP & DM & EP \\
\hline & NS & NS & $1 \%$ & $1 \%$ & NS & NS \\
\hline \multirow{2}{*}{\multicolumn{7}{|c|}{$\begin{array}{l}\text { DM = Significante para } \alpha \leq 0.01 \text {; EP = Significante para } \alpha \leq 0.01 \\
\text { DUCTO ESTRIADO }\end{array}$}} \\
\hline & & & & & & \\
\hline \multirow{3}{*}{$\begin{array}{l}\text { Valor de } H=\mathrm{DM}=9.5000 ; \mathrm{EP}= \\
6.2000 \\
\text { Valor de } \mathrm{x}^{2} \mathrm{p} / \mathrm{2}^{\circ} \text { de liberdade = DM = } \\
9.50 ; \mathrm{EP}=6.20 \\
\text { Probabilidade de } \mathrm{H} 0=\mathrm{DM}=0.68 \% ; \mathrm{EP} \\
=4.37 \%\end{array}$} & \multicolumn{2}{|c|}{$\begin{array}{l}\text { Controle X } 4 \\
\text { semanas }\end{array}$} & \multicolumn{2}{|c|}{$\begin{array}{l}\text { Controle X } 8 \\
\text { semanas }\end{array}$} & \multicolumn{2}{|c|}{$\begin{array}{l}4 \operatorname{sem} X 8 \\
\text { sem }\end{array}$} \\
\hline & DM & EP & DM & EP & DM & EP \\
\hline & $0.1 \%$ & NS & $1 \%$ & $1 \%$ & NS & NS \\
\hline \multirow{2}{*}{\multicolumn{7}{|c|}{$\begin{array}{l}\text { DM = Significante para } \alpha \leq 0.01 \text {; EP = Significe } \\
\text { DUCTO EXCRETOR }\end{array}$}} \\
\hline & & & & & & \\
\hline \multirow{3}{*}{$\begin{array}{l}\text { Valor de } H=D M=8.0600 ; E P=3.2000 \\
\text { Valor de } x^{2} p / 20 \text { de liberdade }=D M= \\
8.06 ; E P=3.26 \\
\text { Probabilidade de } H 0=D M=1,78 \% ; E P \\
=19.50\end{array}$} & \multicolumn{2}{|c|}{$\begin{array}{l}\text { Controle X } 4 \\
\text { semanas }\end{array}$} & \multicolumn{2}{|c|}{$\begin{array}{l}\text { Controle X } 8 \\
\text { semanas }\end{array}$} & \multicolumn{2}{|c|}{$\begin{array}{l}4 \operatorname{sem} \times 8 \\
\text { sem }\end{array}$} \\
\hline & DM & $E P$ & DM & $E P$ & DM & EP \\
\hline & $1 \%$ & NS & $1 \%$ & NS & NS & NS \\
\hline
\end{tabular}


TABELA 125 - Valores médios da porcentagem relativa de pontos sobre as estruturas da glândula submandibular de animais controles e tratados com inibidor de protease - ritonavir.

\begin{tabular}{|c|c|c|c|c|c|}
\hline & Ácinos & $\begin{array}{l}\text { Ducto } \\
\text { granuloso }\end{array}$ & $\begin{array}{l}\text { Ducto } \\
\text { estriado }\end{array}$ & $\begin{array}{l}\text { Ducto } \\
\text { excretor }\end{array}$ & Conjuntivo \\
\hline \multirow[t]{7}{*}{ CONTROLE } & 603 & 16 & 092 & 004 & 285 \\
\hline & 682 & 96 & 066 & 000 & 156 \\
\hline & 610 & 97 & 012 & 039 & 242 \\
\hline & 604 & 73 & 034 & 134 & 155 \\
\hline & 434 & 59 & 122 & 032 & 353 \\
\hline & $586.60 \pm 91.52$ & $68.20 \pm 33.29$ & $65.20 \pm 44.01$ & $41.80 \pm 54.26$ & $238.20 \pm 85.23$ \\
\hline & $58.66 \%$ & $6.82 \%$ & $6.52 \%$ & $4.18 \%$ & $23.82 \%$ \\
\hline \multirow{8}{*}{$\begin{array}{c}4 \\
\text { SEMANAS }\end{array}$} & 588 & 61 & 27 & 23 & 301 \\
\hline & 433 & 71 & 56 & 43 & 397 \\
\hline & 443 & 44 & 43 & 49 & 421 \\
\hline & 514 & 42 & 28 & 40 & 376 \\
\hline & 550 & 46 & 58 & 83 & 263 \\
\hline & $505.60 \pm 67.12$ & $52.80 \pm 12.63$ & $42.40 \pm 14.77$ & $47.60 \pm 22.01$ & $351.60 \pm 66.86$ \\
\hline & $\downarrow$ & $\downarrow$ & $\downarrow$ & $\uparrow$ & $\uparrow$ \\
\hline & $50.56 \%$ & $5.28 \%$ & $4.24 \%$ & $4.76 \%$ & $35.16 \%$ \\
\hline \multirow{8}{*}{$\begin{array}{c}8 \\
\text { SEMANAS }\end{array}$} & 449 & 103 & 088 & 124 & 236 \\
\hline & 409 & 213 & 106 & 100 & 172 \\
\hline & 426 & 137 & 091 & 079 & 267 \\
\hline & 455 & 129 & 139 & 008 & 269 \\
\hline & 448 & 130 & 046 & 078 & 298 \\
\hline & $437.40 \pm 19.32$ & $142.40 \pm 41.53$ & $94.00 \pm 33.60$ & $77.80 \pm 43.30$ & $248.40 \pm 48.01$ \\
\hline & $\downarrow$ & $\uparrow$ & $\uparrow$ & $\uparrow$ & $\uparrow$ \\
\hline & $43.54 \% \%$ & $14.24 \%$ & $9.4 \%$ & $7.78 \%$ & $24.84 \%$ \\
\hline
\end{tabular}


TABELA 126 - Avaliação dos efeitos da utilização de inibidor de protease sobre a porcentagem relativa de ponstos contados sobre as estruturas glândula submandibular dos animais controles e tratados - Avaliação pelo teste Kruskal-Wallis

\begin{tabular}{|c|c|c|c|}
\hline \multicolumn{4}{|l|}{ ÁCINOS } \\
\hline \multirow{2}{*}{$\begin{array}{l}\text { Valor de } H=5.8400 \\
\text { Valor de } x^{2} p / 2^{\circ} \text { de liberdade }=5.84 \\
\text { Probabilidade de } H 0=5.39 \%\end{array}$} & $\begin{array}{c}\text { Controle X } 4 \\
\text { semanas }\end{array}$ & $\begin{array}{c}\text { Controle X } 8 \\
\text { semanas }\end{array}$ & $4 \underset{\text { sem }}{ } \times 8$ \\
\hline & NS & $5 \%$ & NS \\
\hline \multicolumn{4}{|l|}{ NS = Não Significante } \\
\hline \multicolumn{4}{|l|}{ DUCTO GRANULOSO } \\
\hline \multirow{2}{*}{$\begin{array}{l}\text { Valor de } H=9.9800 \\
\text { Valor de } x^{2} p / 2^{\circ} \text { de liberdade }=9.98 \\
\text { Probabilidade de } H 0=0.68 \%\end{array}$} & Controle X 4 & Controle X 8 & $4 \operatorname{sem} X 8$ \\
\hline & NS & $1 \%$ & $\begin{array}{l}\text { sem } \\
0.1 \%\end{array}$ \\
\hline \multicolumn{4}{|l|}{ Significante para $\alpha \leq 0.01$} \\
\hline \multicolumn{4}{|l|}{ DUCTO ESTRIADO } \\
\hline \multirow{2}{*}{$\begin{array}{l}\text { Valor de } \mathrm{H}=4.5000 \\
\text { Valor de } \mathrm{x}^{2} \mathrm{p} / 2^{\circ} \text { de liberdade }=4.50 \\
\text { Probabilidade de } \mathrm{H} 0=10.54 \%\end{array}$} & Controle X 4 & Controle X 8 & $4 \operatorname{sem} \times 8$ \\
\hline & $\begin{array}{l}\text { semanas } \\
\text { NS }\end{array}$ & $\begin{array}{l}\text { semanas } \\
\text { NS }\end{array}$ & $\begin{array}{l}\text { sem } \\
5 \%\end{array}$ \\
\hline \multicolumn{4}{|l|}{ NS = Não Significante } \\
\hline \multicolumn{4}{|l|}{ DUCTO EXCRETOR } \\
\hline \multirow{2}{*}{$\begin{array}{l}\text { Valor de } \mathrm{H}=2.4200 \\
\text { Valor de } \mathrm{x}^{2} \mathrm{p} / 2^{\circ} \text { de liberdade }=2.42 \\
\text { Probabilidade de } \mathrm{H} 0=29.82 \%\end{array}$} & Controle X 4 & Controle X 8 & $4 \operatorname{sem} \times 8$ \\
\hline & $\begin{array}{l}\text { semanas } \\
\text { NS }\end{array}$ & $\begin{array}{l}\text { semanas } \\
\text { NS }\end{array}$ & $\begin{array}{l}\text { sem } \\
\text { NS }\end{array}$ \\
\hline \multicolumn{4}{|l|}{ NS = Não Significante } \\
\hline \multicolumn{4}{|l|}{ TECIDO CONJUNTIVO } \\
\hline \multirow{3}{*}{$\begin{array}{l}\text { Valor de } \mathrm{H}=5.4600 \\
\text { Valor de } \mathrm{x}^{2} \mathrm{p} / 2^{\circ} \text { de liberdade }=5.46 \\
\text { Probabilidade de } \mathrm{H} 0=6.52 \%\end{array}$} & Controle X 4 & Controle X 8 & $4 \operatorname{sem} \times 8$ \\
\hline & semanas & semanas & sem \\
\hline & $5 \%$ & NS & $5 \%$ \\
\hline NS = Não Significante & & & \\
\hline
\end{tabular}


A avaliação cariométrica e a avaliação estereológica das glândulas salivares submandibulares dos animais utilizando inibidor de protease (ritonavir) e seus controles, mostraram que:

1) os volumes nucleares dos ácinos se apresentaram bastante aumentados com o uso prolongado do medicamento;

2) os núcleos também tendenram a se apresentar alongados;

3) os núcleos das células em ductos apresentaram uma grande diminuição inicial de volume, seguida de um aumento, que, em muitos casos, ultrapassava os valores observados nos animais controle (ver tabelas 111 e 115);

4) os diâmetros médios dos ductos tenderam a se apresentar aumentados, assim como a espessura de suas paredes, embora em menor grau, o que sugere um aumento da luz desses ductos;

5) foi observada também uma tendência de diminuição da contagem relativa de pontos contados sobre as estruturas acinares, sendo esse efeito aparentemente progressivo, assim como a tendência de aumento da contagem de pontos sobre os ductos, principalmente os ductos granulosos (ver tabela 125).

\section{DISCUSSÃO E CONCLUSÃO}

Inibidores de protesase aguam nos estágios vinais da replicação do HIV, ou seja, logo antes de as proteínas virais se agruparem de forma a produzir um novo vírus e deixar a célula do hospedeiro. Esse medicamento impede a clivagem das proteínas da forma correta para a produção de partículas virais infectantes (KUMAR, 2003).

Ritonavir é considerado o protótipo dos inibidores de protease, e uma vez que esses medicamentos são membros da família das enzimas conhecidas como "aspartil-proteases", seus efeitos colaterais incluem as alterações gastrintestinais, disfunções metabólicas e hepatotoxicidade. Os inibidores de protease em geral, e o ritonavir em particular tem o potencial de provocar interações com outros medicamentos por sua capacidade de inibir a enzina citocromo P450 (TEMPLE et al., 2003). 
A lipodistrofia, alteração na retenção e localização das gorduras corporais, acontece associada às disfunções metabólicas dos inibidores de protease, e é considerada como esperada em até $50 \%$ dos indivíduos que utilizam esse tipo de medicação (TEMPLE et al., 2003). Por esse motivo, uma das nossas preocupações foi analisar os efeitos do ritonavir nos níveis séricos de lipoproteínas, como os triglicérides, colesterol total, LDL, HDL e VLDL. Nossos resultados mostram que existe um aumento de lipoproteínas séricas, o que está em conformidade com grande parte dos trabalhos clínicos (em humanos) relacionados a esse efeito do ritonavir.

Estudos clínicos com inibidores de protease também demonstram significante redução dos níveis plasmáticos de RNA viral para o HIV-1, um aumento da contagem de células CD4+. No entanto também sugerem que os inibidores de protease atuam na diferenciação e viabilidade das células adiposas (HRUZ et al., 2001). Por outro lado, os inibidores de protease são hoje apontados como possíveis promessas de tratamento para inibição da proliferação de células neoplásicas (SRIRANGAM, et al., 2006; GILLS et al., 2007; BRUNNER et al., 2008, KUMAR et al., 2009). Nossos resultados mostram que os tecidos epeteliais parecem apresentar atrofia, o que estaria em conformidade com as informações sobre a ação desses medicamentos em células de rápida proliferação, no entanto, é preciso observar também que, se as células da camada basal mostram uma possível diminuição de atividade, caracterizada pela diminuição do volume nuclear, as células da camada espinhosa também mostra diminuição da maturação e diferenciação dessas células, o que poderia ser preocupante em se tratando de lesões malignas. Consideramos que a atuação dos inibidores de protease deve ser estudado em profundidade, para que as ações bioquímicas e moleculares sejam bem conhecidas.

O tecido epitelial é formado por células justapostas, existem basicamente dois tipos diferentes de tecido epitelial, o epitélio de revestimento e o epitélio glandular. Os epitélios podem ainda ainda ser descrito como barreira mecânica, ou como um órgão secretor ou absortivo. Essas características, dão ao tecido epitelial uma importância fundamental na defesa orgânica, e além dessas propriedades as células epiteliais podem emitir sinais quimiotáticos e produzir substâncias anti-microbianas (GANZ, 2002)

Estudos histomorfológicos nos permitem uma análise preliminar das 
possíveis alterações em tecidos e células. Nossas análises histomorfológicas se caracterizaram pela avaliação cariométrica (características dos núcleos celulares) e estereológicas (características das células e tecidos). A análise histomorfológica realizada se iniciou pela avaliação histopatológica das estruturas, considerando suas características morfológicas fundamentais, como mostrado nas figuras apresentadas de cada região estudada.

A cariometria, ou avaliação das características nucleares, foi realizada a partir da estimação dos diâmetros médios dos núcleos celulares das diferentes regiões epiteliais estudadas. A determinação desses eixos maior ( $D M=$ Diâmetro maior) e menor $(\mathrm{dm}=$ diâmetro menor) nos permitem chegar aos seguintes parâmetros nucleares: diâmetro nuclear médio (calculado pela fórmula: $M=\sqrt{ } D . d$ ); a relação entre os diâmetros maiores e menores (D/d); o perímetro nuclear $(P=\Pi / 2[3 / 2$. (D+d)$\mathrm{M}]$; a área nuclear $\left(\mathrm{A}=\Pi / 4 . \mathrm{M}^{2}\right)$; o volume nuclear $\left(\mathrm{V}=\Pi / 6 . \mathrm{M}^{3}\right)$; a relação entre volume e área $(\mathrm{V} / \mathrm{A})$; o coeficiente de forma $\left(\mathrm{F}=4\right.$. П. $\left.\left[\mathrm{A} / \mathrm{P}^{2}\right]\right)$; o índice de contorno (I $=P / \sqrt{ } A)$; e a excentricidade $(E=[\sqrt{ }(D+d) . \sqrt{ }(D-d)] / D)$.

A avaliação estereológica nos permitiu observar as células e o tecido, calculando, a partir da cariometria: os volumes celulares relativo e absoluto (sendo o volume relativo obtido pela contagem do número de pontos que incidiam sobre a estrutura estudada em relação ao número total de pontos da grade de Merz, e o volume absoluto pode então ser estimado, conhecendo-se o volume relativo e as dimensões das áreas analisadas); a relação entre a superfície externa e a superfície basal $(E / B=[P . \lambda] /[4 . I]$, onde $P=$ número de pontos que recaiam sobre o epitélio, $x=$ número de intersecções da linha teste com a interface considerada, e $\mathrm{I}=0$ comprimento da linha teste, determinada pela relação $\lambda=d$. $\rceil / 2$, onde $d=$ a distância entre dois pontos contíguos da linha teste). É bom lembrar que o fato de o volume epitelial observado ser constante para cada campo torna possível estabelecer uma relação direta entre essas duas interfaces.

A espessura média das camadas epiteliais, e das estruturas tubulares da glândula, foram estimadas pelo método de WEIBEL (1963), onde $E=[P . \lambda] / 2(I K+$ Ict), onde IK e Ict são os números das intersecções da linha-teste com a interface epitélio/ceratina e epitélio/conjuntivo, respectivamente.

Com a finalidade de se avaliar percentualmente as estruturas glandulares, foi 
utilizada uma variação do método de CHALKLEY (1943), utilizando-se, para isso os mesmos pontos-padrão da grade de Merz. Determinando-se quantas vezes as estruturas analisadas eram atingidas pelos pontos, e conhecido o número total de pontos, a porcentagem de pontos indicou a porcentagem relativa de cada componente estrutural.

A análise estatística foi feita utilizando o teste de Kruskall Wallis por serem amostras múltiplas e se tratar de dados considerados não-normais.

Estabelecidas as hipóteses Ho (nula) onde se admite serem as amostras provenientes de uma população semelhante, a hipótese alternativa $\mathrm{H}_{1}$ diz que as amostras são diferentes umas das outras. Para três amostras, de tamanho N1, N2 e N3 em número de 5 cada uma delas, o $U$ é calculado ordenando-se os dados das três amostras conjuntamente. Verificando-se e ordenando-se os valores de cada grupo se determinam os resultados estatísticos. A probabilidade permite avaliar 0 nível de significância. A hipótese $\mathrm{H}_{0}$ é rejeitada quando o nível de significância $(\alpha)$ for $\leq 0.05$.

Essas análises realizadas, nos permitiram recolher dados que possibilitaram fazer uma comparação entre os diferentes grupos estudados, animais tratados com inibidores de protease e seus controles.

Nossos resultados, então, nos permitiram observar que o uso de inibidores de protease levou a pequenas alterações em tecidos epiteliais, tanto glandulares como de revestimento, e que esses efeitos parecem ser progressivos, ou seja, se tormam mais expressivos com o uso continuado desse medicamento.

Essas alterações podem tornar esses tecidos mais suscetíveis a alterações bucais e alterar as reações teciduais frente a injúrias - possíveis de ocorrer durante um tratamento odontológico, principalmente cirúrgico, mas também em situações de reabilitação oral e tratamentos odontológicos de rotina.

Esses resultados são iniciais, e obtidos por análises histomorfológicas. Nossos próximos estudos serão análises histoquímicas e morfo-funcionais dos tecidos bucais, buscando compreender patogenia das alterações morfológicas observadas e a possibilidade de controle de suas conseqüências para o tratamento odontológico. 


\section{REFERÊNCIAS BIBLIOGRÁFICAS}

AHDIEH-GRANT, L.; LI, R.; LEVINE, A.M.; MASSAD, L.S.; STRICKLER, H.D.; MINKOFF, H.; MOXLEY, M.; PALEFSKY, J.; SACKS, H.; BURK, R.D.; GANGE, S.J. - Highly active antiretroviral therapy and cervical squamous intraepithelial lesions in human deficiency virus-positive women - Journal of the National Cancer Institute, vol. 96, n.14, pp. 1070-1076, July 21, 2004.

BARRY, M.; GIBBONS, S.; BACK, D.; MULCAHY, F. - Protease inhibitors in patients with HIV disease. Clinically important pharmacokinetic considerations. Clinical Pharmacokinetics, vol. 32, n.3, pp.194-209, Mar. 1997.

BARTLETT, J.G. - Protease inhibitors for HIV infection. Annals of Internal Medicine. Vol. 124, n.12, pp. 1086-1088, 15 June 1996.

BIGGAR, R.J. - AIDS related cancers in the era of highly active antiretroviral therepy. Oncology, vol. 15, pp. 439-448, 2001.

BOSHOFF, C. and WEISS, R. - AIDS-related malignancies. National Review of Cancer, vol. 2, pp. 373-382, 2002.

BRUNNER, T.B.; GEIGER, M.; GRABENBAUER, G.G.; LANG-WELZENBACH, M.; MANTONI. T.S.; CAVALLARO, A., SAUER, R.; HOHENBERGER, W.; McKENNA, W.G. - Phase I trial of the Human Immunodeficiency Virus protease inhibitor nelfinavir and chemoradiation for locally advanced pancreatic cancer. Journal of Clinical Oncoloty, vol. 26, n.16, pp. 2699-2706, June 1, 2008.

CHALKLEY, H.W. - Method for the quantitative morpuologic analysis of tissues Journal of the National Cancer Institute, Bethesda, vol.4, pp.47-53, Aug. 1943.

GANZ, T. - Epithelia: not just physical barriers. Proceedings of the New York Academy of Sciences, vol. 99, n.6, pp. 3357-3358, March 19, 2002. 
GATES, A.E. \& KAPLAN, L.D. - AIDS malignancies in the era of highly active antiretroviral therapy, Oncology, vol. 15, n.5, pp. 657-665, May 2002.

GILLS, J.J.; LOPICCOLO, J.; TSURUTAMI, J.; SHOEMAKER, R.H.; BEST, C.J.; ABU-ASAB, M.S.; BOROJERDI, J.; WARFEL, N.A.; GARDNER, E.R.; DANISH, M.; HOLLANDER, M.C.; KAWABATA, S.; TSOKOS, N.; FIGG, W.D.; STEEG, P.S.; DENNIS, P.A. - Nelfinavir, a lead HIV protease inhibitor, is a broad-spectrum, anticancer agent that induces sendoplasmatic reticulum stress, autophagy, and apoptosis in vitro and in vivo. Clinical Cancer Research, vol. 13, n.17, pp. 51835194, Sept.1, 2002.

HSU, A.; GRANNEMAN, G.R.; BERTZ, R.J. - Ritonavir. Clinical pharmacokinetics and interactions wity other anti-HIV agents. Clinical Pharmacokinetics, vol. 35, n.4, pp. 275-291, Oct. 1998.

HRUZ, P.W.; MURATA, H.; MUECKLER, M. - Adverse metabolic consequences of HIV protease inhibitor therapy: the search for a central mechanism. Amefican Journal of Physiology, Endocrinology and Metabolism, vol. 280, n.4, pp. E549E553, April, 2001.

IKEZOE, T.; SAITO, T.; BANDOBASHI, K.; YANG, Y.; KOEFFLER, H.P.; TAGUSHI, H. - HIV-1 protease inhibitor induces growth arrest and apoptosis of human multiple myeloma cells via inactivation of signal transducer and activator of transcription 3 and extracellular signal-regulated kinase 1/2. Molecular Cancer Therapy, vol. 3, pp. 473-479, 2004.

KALININ, A.E.; KAJAVA, A.V.; STEINERT, P.M. - Epithelial berrier function: assembly and structural features of the cornivied cell envelope. Bioessays, vol. 24, n.9, pp. 789-800, 2002

KING, J.R.; WYNN, H.; BRUDAGE, R.; ACOSTA, E.P. - Pharmacokinetic enhancement of protease inhibitor therapy. Clinical Pharmacokinetic, vol. 43, n. 5, pp. 291-311, 2004. 
KOMESU, M. C., CAVEHAGHI, F. M., SALA, M. A., LOPES, R. A. - Efeito da desnutrição Pós-natal sobre os núcleos celulares do epitélio do rato. In: 10. Encontro de Iniciação Científica e 10. Encontro de Professores Pesquisadores, 1998, Franca SP. Anais - 10. Encontro de Iniciação Científica e 10. Encontro de Professores Pesquisadores, p.47-51, 1998.

KOMESU, M. C., CAVENAGHI, F. M., SALA, M. A., LOPES, R. A. - Long-term effects of undernutrition on the rat epithelial cells. In: 78th General Session \& Exibition of the IADR 2000, Washington. Journal of Dental Research, v.79. p.588, 2000.

KOMESU, M.C.,CAVENAGHI, F.M.,SALA, M.A., DEKKER, N.P., MORAES, E.A.S. Long-term effect of early protein/calorie malnutrition on bFGF availability in rat skin. Nutrition Research. Estados Unidos: , v.23, n.11, p.1555 - 1567, 2003.

KUMAR, S.; KWEI, G.Y.; POON, G.K.; ILIFF, S.A.; WANG, Y.; CHEN, Q.; FRANKLIN, R.B.; DIDOLKAR, V.; WANG, R.W.; YAMAZAKI, M.; CHIU, S-H. L.; LIN, J.H.; PEARSON, P.G.; VAILLIE, T.A. - Pharmacokinetics and interactions of a novel antagonist of chemokine receptor 5 (CCR5) with ritonavir in rats and monkeys: role of CYP3A and P-glycoprotein. The Journal of Pharmacology and Experimental Therapeutics Fast Forward, vol. 304, n.3, pp. 1161-1171, March 2003.

LENHARD, J.M.; CROOM, D.K.; WEIEL, J.E.; WINEGAR, D.A. - HIV protease inhibitors situmulate hepatic triglyceride synthesis. Aterosclerosis, Thrombosis, and Vascular Biology, vol. 20, pp. 2625-2614, 2000.

MAGGIORELLA, L.; WEN, B.; GRASCOGNA, V.; OPOLON, P.; BOURHIS, J.; DEUTSH, E. - Combined ratiation sensitizing and anti-angiogenic effects of ionizing radiation and the protease inhibitor ritonavir in a head and neck carcinoma model. Anticancer Research, vol. 25, pp. 4357-4362, 2005.

meionorte.com, 2009 - Qual a diferença entre colesterol e triglicérides? Disponível em http://www.meionorte.com/joaoadala,qual-a-diferenca-entre-colesterol-etriglicerides,56279.html, acessado em 20 de julho de 2009. 
MERZ, W. $\square$. Die Streckenmessung un Gerichteten Strukturen im Mikroskop und ihre Anwendung zur Bestimmung von Oberflächen-volumen relationen im knockengewebe - Mikroskopie, Wien, vol.22, n.5-6, pp.132-142, Feb. 1968.

MOTTA, A. C. F., KOMESU, M. C., SALA, M. A., LOPES, R. A. - Effects of post-natal undernutrition and diabete on gum epithelium In: 17th. Annual Meeting of Brazilian Society for Dental Research, 2000, Águas de Lindóia: American Association for Dental Research, Alexandria, Journal of Dental Research, v.80, p.1089, 2001

PATICK, A.K. \& POTTS, K.E. - Protease inhibitors as antiviral agents. Clinical and Microbiological Reviews, vol. 11, n.4, pp. 614-627, Oct. 11, 1998.

RABKIN, C.S. - AIDS and cancer in the era of highly antive antiretroviral therapy (HAART). European Journal of Cancer, vol. 37, n.10, pp. 1316-1319, July 2001.

RATHBUN, R.C. and ROSSI, D.R. - Low-dose ritonavir for protease inhbitor pharcacokinetic enhancement. Annals of Pharmacotherapy, vol. 36, pp. 702-706, 2002.

RIDDLE, T.M.; SCHILDMEYER, N.M.; PHAN, C.; FICHTENBAUM, C.J.; HUI, D.Y. The HIV protease inhibitor ritonavir increasess lipoprotein poduction and has no effect on lipoprotein clearance in mice. Journal of Lipid Research. Vol. 43, pp. 1458-1463, Sept. 2002.

SINGH, B.; SABIN, S.; ROFIN, O.; SHAHA, A.; HAL-ER, G.; LUCENTE, F.E. Alterations in head and neck cancer occurring in HIV-infected patients, Result of a pilot, longitudinal, prospective study. Acta Odontológica, vol. 38, n.8, pp. 10471050, 1999.

SRIRANGAM, A.; MITRA, R.; WANG, M.; GORSKI, J.C.; BADVE, S.; BALDRIDGE, L.A.; HAMILTON, J.; KISHIMOTO, H.; HAWES, J.; LI, L.; ORSCHELL, M.; SROUR, E.F.; BLUM, J.S.; DONNER, D.; SLEDGE, G.W.; HAKSHATRI, H.; POTTER, D.A. - 
Effects of HIV protease inhibitor ritonavir on Adt-regulated cell proliferation in breast cancer. Clinical Cancer Research, vol. 12, n. 6, pp. 1883-1896, March 15, 1006.

TANGA, M. B., BUTTROS, K. R., Nakao, C., KOMESU, M. C. - Progressive effects of diabetes mellitus on the skin epithelium of the rat. International Journal of Morphology. Chile: , v.21, n.2, p.143 - 148, 2003

TEMPLE, M.E.; KORANYI, K.I.; NAHATA, M.C. - Lipodystrophy in HIV-infected pediatric patients receiving protease inhibitors. The Annals of Pharmacotherapy. Vol. 37, n.9, pp. 1214-1218, 2003.

XU, A.; YIN, S.; WONG, L.C.; CHAN, K.W.; LAM, K.S.L. - Adiponectin ameliarates dyslipidemia induced by the human imunodeficiency virus protease inhibitor ritonavir in mice. Endocrinology, vol. 145, n.2, pp. 487-494, 2004.

WEIBEL, E.R. - Principles and Methods for the morphometric study of the lung and other organs - Laboratory Investigation, vol.12, n.2, pp. 131-155, 1963.

WINSTON, A. and BOFFITO, M. - The management of HIV-1 protease inhibitor pharmacokinetic interactions. Journal of Antimicrobial Chemotherapy, vol. 56, n.1, pp. 1-5, doi:10.1093/jac/dki184, 2005.

WYNN, G.H.; ZAPOR, M.J.; SMITH, B.H.; WORTMANN, G.; OESTERHELD, J.R.; ARMSTRONG, S.C.; COZZA, K.L. - Antiretrovirals: Part I: Overview, History, and focus on Protease Inhibitors, Psychosomatics, vol.45, pp. 262-270, June 2004.

YANG, Y.; IKEZOE, T.; TAKEUCHI, T., ADACHI, Y.; OHTSURI, Y.; TAKEUCHI, W.; KOEFLER, H.P.; TAGUCHI, H. - HIV-1 protease inhibitor induces growth arrest and apoptosis of human prostate cancer LNCaP cells in vitro and in vivo in conjunction with blockade of androgen receptor STAT3 and AKT signalin. Cancer Sciences, vol. 96, pp. 425-433, 2005. 